University of San Diego

Digital USD

1987

\title{
The Heart and Spirit of Transformational Leadership A Qualitative Case Study of Herb Kelleher's Passion for Southwest Airlines
}

Kevin L. Freiberg EdD

University of San Diego

Follow this and additional works at: https://digital.sandiego.edu/dissertations

Part of the Leadership Studies Commons

\section{Digital USD Citation}

Freiberg, Kevin L. EdD, "The Heart and Spirit of Transformational Leadership A Qualitative Case Study of Herb Kelleher's Passion for Southwest Airlines" (1987). Dissertations. 496.

https://digital.sandiego.edu/dissertations/496

This Dissertation: Open Access is brought to you for free and open access by the Theses and Dissertations at Digital USD. It has been accepted for inclusion in Dissertations by an authorized administrator of Digital USD. For more information, please contact digital@sandiego.edu. 
THE HEART AND SPIRIT OF TRANSFORMATIONAL LEADERSHIP:

A QUALITATIVE CASE STUDY OF HERB KELLEHER'S

PASSION FOR SOUTHWEST AIRLINES

A dissertation submitted in partial fulfillment

of the requirements for the degree of

Doctor of Education

\author{
by \\ Kevin L. Freiberg \\ University of San Diego \\ 1987
}

Dissertation Committee

Joseph Rost, Ph.D., Director

William Foster, Ed.D.

Larry Williamson, Ph.D. 
Copyright 1987

by

Kevin L. Freiberg

All Rights Reserved 


\section{ABSTRACT}

THE HEART AND SPIRIT OF TRANSFORMATIONAL LEADERSHIP:

A QUALITATIVE CASE STUDY OF' HERB KELLEHER'S

PASSION FOR SOUTHWEST AIRLINES

FREIBERG, KEVIN I., Ed.D. University of San Diego, 1987

$432 \mathrm{pp}$.

Director: Joseph C. Rost, Ph.D.

The notion of transformational leadership as developed by James MacGregor Burns has contributed significantly to a new consensus ${ }^{-\infty}$ in the literature regarding the nature of leadership. Burns introduced the concept of transformational leadership, suggesting that leaders are individuals who transform their institutions by embracing competition and conflict, meeting the mutual goals of both leader: and followers, successfully articulating their values to followers and drawing them into a common purpose and a shared vision, using power resources and politics to satisfy their followers' needs and wants, and raising the moral aspirations of both leaders and led. While the contemporary literature on leadership has done much to further our understanding about the nature of transformational leadership, very few works provide us with case study examples of transformational leaders. Missing is an understanding of what leaders actually co in the process of leading followers and transforming organizations. 
The present study sought to provide a descriptive analysis of how one leader in charge of a major American corporation has shaped and transformed his institution. Through open-ended interviews and direct observation, this study examined Herbert $D$. Kelleher, the Chairman of the Board, President, and Chief Executive officer of Southwest Airlines, a Dallas, Texas-based corporation that has a 15year history, approximately 5,000 employees, and one billion dollars in assets. Key informant interviews were held with Kelleher and Southwest Airlines employees from different levels and a variety of positions within the corporation to determine the degree to which Kelleher personifies transformational leadership.

This case study presents Herb Kelleher as an individual who has affected significant institutional change at Soutinwest Airlines by satisfying the wants and needs of his followers and by raising them to higher levels of motivation and morality. It was determined that Kelleher's ability to successfully change his organization and meet the needs of his people is because he clearly demonstrates the qualities of transformational leadership. 


\section{DEDICATION}

To the people of Southwest Airlines who dared to make a difference by courageously fighting to champion the cause of the customer. 


\section{ACKNOWLEDGEMENTS}

No price tag can adequately reflect the value of the relationships that are built during the course of one's graduate experience. This project was an especially exciting undertaking for me largely because of those who believed in the concept of transformational leadership and shared in the vision of promoting it. I am extremely grateful to Mary Lou Nagle who is an outstanding typist and editor. Mary Lou is a very talented individual whose patience, concern, and understanding for me were a source of undaunted support throughout my graduate career. I would especially like to thank Pat Mason who typed this manuscript and saw it through several rough drafts. With a work of this magnitude there are those unsung heroes and heroines whose efforts go unnoticed--Pat is one of those individuals. She is the real champion behind this project and without her, this goal would never have been accompIished.

There are two people who became partners in this project and encouraged me from start to finish. First, I would like to thank my mother for the long hours she spent editing the manuscript. She is a brilliant writer and her suggestions were always on target. Her command of the ii 
English language and passion for writing have been a tremendous source of inspiration for me. Second, many thanks to my dad for his generosity and "can do" attitude. He essentially made it possible for the manuscript to be typed by freeing up Pat's time in what was already a very busy law practice. I am extremely proud that my mom and dad thought this project was worthy of their time and effort.

Among my academic colleagues, special recognition is due to Bill Foster and Larry Williamson. Bill is a tremendous thinker and a very gifted scholar. The ideas brought forth in his graduate seminars contributed to shaping many of the core ideas that pervade this manuscript. He is an extremely insightful individual and $h .$, influence helped to sharpen my arguments. Larry is another very dedicated scholar whose intellectual prowess and acuity challenged my thinking and encouraged me to make this a better product. I am grateful for his friendship as he has been a source of unparalleled support during my tenure at the University of San Diego. I would also like to thank Al Weitzel for his counsel on some of the critical communication issues in the manuscript, and steve Williams for applying his analytical mastery to my arguments and pointing out their flaws--AI and Steve were wonderful sources of support when it came time to defend what I had written. 
I have been privileged to work with another extraordinarily dedicated professional. Through his guidance and the revising of sections in the manuscript that defied comprehension, Joe Rost helped to make the final product much more readable. His contributions to this work and to my graduate career have been invaluable--he had a remarkable way of helping me to develop confidence in my ideas and encourage me to pursue them without compromise. Joe has been a major force behind a graduate program that is making dramatic advancements in the field of leadership. He has played a significant role in building a culture within the School of Education where both graduate students and faculty are challenged to think critically and moved to higher levels of motivation and morality. I am thankful and very proud to have shared in this special community.

Without question this project was made possible because of the special men and women at Southwest Airlines who willingly shared their experiences and poured out their stories so that the rest of us might learn. I am indebted to Colleen Barrett who graciously agreed to participating in the project from the beginning. Colleen made herself available throughout the investigation and went above and beyond the call of duty to provide me with everything from corporate documents to video tapes that enabled me to obtain additional data. In the process she not only became a co-researcher, but also a good friend. I am especially 
$v i$

grateful to Herb Kelleher for his generosity and for his wonderful ability to make people feel significant. Herb has influenced my life profoundly by showing me the value of compassion and concern for others through vivid personal example.

Lastly and most importantly there came moments when encouragement from two devoted friends who believed in this project from the beginning provided me with the inspiration and perseverance needed to continue. To Tony Smith who shared my struggle throughout the entire journey of graduate school. Tony has been my collaborator in every phase of this journey and has contributed more good ideas to this work than space will allow me to tell. Conceptually and pragmatically he is a brilliant thinker and I am grateful that he has allowed me to tap his wisdom over the years. While the responsibility for the final manuscript is mine, he shared in its creation. To Jacquelyn Portle who is a woman with a host of exceptional qualities and a source of extreme joy in my life. Her interest in this work, warm heart, and wonderfully sunny spirit helped me to make progress even when I felt disheartened. In spite of my inconsistencies and obsession with the task of writing, Jacquelyn's support never wavered. In the end she has given me reason for hope and cause for celebration. 
Page

DEDICATION . . . . . . . . . . . . . . ii

ACKNOWLEDGEMENTS .............. . .

TABLE OF CONTENTS . . . . . . . . . . . . . vii

LIST OF FIGURES . . . . . . . . . . . . . . $\mathrm{x}$

CONTENTS OF APPENDICIES ............. . $\mathrm{xV}$

STATEMENT OF THE ISSUE ............. 1

Introduction . . . . . . . . . . . 1

The Issue .............. . . 6

Purpose of the study . . . . . . . . . 7

Relevance of the Issue to Leadership . . . . . 9

Definition of Terms .......... 10

Dissertation Organization ......... 11

REVIEW OF LITERATURE . . . . . . . . . . . 13

Transformational Leadership Literature . . . . 13

Competition and Conflict ........ 15

Accomplishing the Goals of Both Leader and Led 21

Vision and Alignment ........ . . 26

Shaping Values and Educating by Example . . 37

power and Politics ......... . . 45

Generativity: The Development of Followers . . 58

Symbolic Leadership . . . . . . . . 74

organizational Symbolism . . . . . . 78

Metaphors ........... 86

MYths ............. 88

vii 
viii

Rituals and Ceremony . . . . . . . 89

Stories . . . . . . . . . . . . 91

Synthesis and Integration of Research . . . . . 94

RESEARCH DESIGN AND METHODOLOGY . . . . . . . . . 101

Phenomenological Approach . . . . . . . . 103

Phenomenological Research Procedures . . . 103

The Ethnographical Approach . . . . . . . 104

Ethnographic Research Procedures . . . . 105

Participants . . . . . . . . . . . . 106

National Leader . . . . . . . . . 106

Followers . . . . . . . . . . . 107

Number of Participants . . . . . . . . 108

Site Selection ............. 109

On-site Observation . . . . . . . . . 109

Interviewing the Participants . . . . . . 111

The Intervilewing Process . . . . . . . . 113

Additional Data Gathering Procedures . . . . 115

Organizational Documents . . . . . . . 115

Organizational Outputs . . . . . . . 116

Data Analysis . . . . . . . . . . . . 117

Transcription . . . . . . . . . . . 117

Descriptive Analysis . . . . . . . . . . 118

AN INDOMITABLE SPIRIT OF PERSEVERANCE: THE

HISTORY OF SOUTHWEST AIRLINES . . . . . . . . 120

HERB KELLEHER'S PASSION FOR SOUTHWEST AIRLINES • • • 145

Competition and conflict . . . . . . . . . 147 
Accomplishing the Mutual Goals of Leader and Led . 163

Vision and Alignment. . . . . . . . . . . 183

Shaping Values and Educating by Example . . . 193

That Loving Spirit . . . . . . . . . . 197

Pride and Confidence . . . . . . . . . 217

Work is Fun . . . . . . . . . . . 221

Service to the Customer . . . . . . . . 235

Lean Bureaucracy . . . . . . . . . . . 240

Power and Politics . . . . . . . . . . . 248

Generativity: The Development of Followers . . 268

Organizational Symbolism . . . . . . . . 305

SUMMARY, CONCLUSIONS, AND DISCUSSION • • • • • • • 352

Summary and Conclusions . . . . . . . . . 352

Discussion of Implications for Future Research • • 374

strengths . . . . . . . . . . . . . 374

Weaknesses . . . . . . . . . . 377

Future Research . . . . . . . . . . 379

Concluding Remarks . . . . . . . . . . 381

REFERENCES . . . . . . . . . . . . . 383

APPENDIX . . . . . . . . . . . . . . . . 399 


\section{IIST OF FIGURES}

Eigure

Page

1. Herb D. Kelleher . . . . . . . . . . 122

2. Profile Characterizing Herb Kelleher . . . . 123

3. The tri-city route Rollin King sketched on a napkin . . . . . . . . . . . . 126

4. Southwest Airlines' mission statement . . . 195

5. Herb Kelleher's mission statement . . . . . 196

6. Southwest's heart-shaped logo . . . . . . 200

7. Additional versions of Southwest's logo . . . 201

8. Kelleher's concluding remarks from quarterly reports . . . . . . . . . . . . 214

9. Excerpt from article about Kelleher's special appearing in company newsletter . . . . . 216

10. Herb Kelleher, Colleen Barrett and other members of the Southwest family sporting California jams . . . . . . . . . . 225

11. Herb Kelleher and Don Valentine playing around with the official company beach ball in Kelleher's office . . . . . . . 226

12. Herb Kelleher aressed up as the MASH character Klinger . . . . . . . . . . 228 
13. Herb Kelleher leading Southwest employees in Chicago during the st. Patrick's Day parade . . . . . . . . . . . . . 232

14. Southwest employees on the company float during Chicago's st. Patrick's Day Parade .

15. Article appearing in the september/October issue of the company's newsletter . . . . . 241

16. Poem appearing in the December, 1986 issue of the company's newsletter . . . . . . . 242

17. Results of Southwest's customer service performance .. . . . . . . . . . 243

18. Herb Kelleher sharing a laugh with Iieutenant Governor Bill Hobby . . . . . . . . . 258

19. San Antonio Mayor Henry Cisneros chatting with Herb Kelleher aboard a San Antonio trolley . . . . . . . . . . . . . 264

20. Article about Larry Brennan appearing in the company's newsletter . . . . . . . 286

21. Shea Runnels featured in an article in Southwest's "Spirit" Magazine . . . . . . 293

22. Herb Kelleher with Shea Runnels, Shea Runnels, and Shea with Tonda Montague . . . 294

23. Herb Kelleher ready to make a game-winning pass, Herb Kelleher hauled off the court . .

24. Herb Kelleher with some of the Southwest cheerleading squad . . . . . . . . . 
25. Remarks from staff members of the

Ronald McDonald Houses . . . . . . . 300

26. Remarks from ticket agent Peg Herrington

that appeared in the Ronald McDonald

House advertisements in Southwest's

Spirit Magazine . . . . . . . . . . . 301

27. Remarks from first officer Ricci Rowe . . . 302

28. Remarks from flight attendant Pamela Landa . . 303

29. Herb Kelleher's Christmas message to

Southwest employees . . . . . . . . 306

30. Southwest's Boeing 737-300 aircraft . . . . 311

31. Southwest Airline's corporate logo . . . . . 312

32. Graphic display of the title of Southwest's corporate newsletter . . . . . . 315

33. Southwest's love theme exemplified

in its advertising . . . . . . . . . . 316

34. Southwest's love theme exemplifying

the company's benefits . . . . . . . 317

35. "It's Your Day" appears monthly in the company's newsletter and highlights the accomplishments of Southwest employees . . 320

36. "All In A Day's Work" also appears monthly in the company's newsletter to highlight Southwest employees . . . . . . . . . . 321

37. Southwest advertisements promoting the company's spirit . . . . . . . . . . . 
38. Southwest advertisement promoting company spirit . . . . . . . . . . . . . 325

39. Southwest flight attendants promoting military fares . . . . . . . . . . .

40. Southwest employees promoting The Company Plane theme . . . . . . . . . . 328

41. Another version of the Company Plane promotion using a member of Southwest Airlines . . . . . . . . . . . .

42. Herb Kelleher appears in a company advertisement promoting automatic ticket machines . . . . . . . . . . .

43. Herb Kelleher appears in a company advertisement promoting the convenience of open seating . . . . . . . . . . .

44. Herb Kelleher appears in small space advertisements . . . . . . . . . . .

45. The cover of a card sent to southwest employees at Thanksgiving . . . . . . 336

46. The inside of the Thanksgiving Day card sent to southwest employees . . . . . . 337

47. Verses appearing on a Christmas card sent to southwest employees . . . . . . . . 338

48. Verses appearing on a Valentine Day card sent to Southwest employees . . . . . . 
xiv

49. Children of Southwest employees appear on

a holiday card sent to members of Southwest Airlines . . . . . . . . . . 340

50. Herb Kelleher presenting awards to Southwest employees at the annual awards banguet. 342

51. "The spirit of Kitty Hawk," and Brigadier

General Charles "Chuck" Yeager joins

Captains Earl Tomlin and Paul Carter in

the cockpit of the new aircraft . . . . . . 345

52. Bob Hope escorted by two Southwest

flight attendants. Kelleher presents

Hope with a model of the company plane . . . 346

53. "Help Herb" brochure that is distributed

throughout the company soliciting

employees' suggestions . . . . . . . . 348

54. Logo promoting Southwest's customer

service orientation . . . . . . . . 349

55. Memo from Herb Kelleher exemplifying his

commitment to leadership development . . . 351

56. Greg Roessner's letter nominating Herb

Kelleher for the "Great Boss's Award" of

the Dallas Times Herald . . . . . . . 355 
CONTENTS OF APPENDICES

$\begin{array}{cll}\text { Appendix } & & \text { Page } \\ \text { A. } & \text { Letters from Southwest Customers . . . . } 399 \\ \text { B. } & \text { Herb Kelleher's Senior Management Team . } 403 \\ \text { C. } & \text { Resume for Herb Kelleher . . . . . . . } 407 \\ \text { D. } & \text { Kelleher Cultivating His Relationship } \\ & \text { With The City of Chicago . . . . . . } 409 \\ \text { E. } & \text { Southwest's Love Theme . . . . . . . } 410 \\ \text { F. } & \text { Winning Spirit Article . . . . . . } 416 \\ \text { G. } & \text { Luv Lines Anniversary Issue . . . . . . } 419 \\ \text { H. } & \text { Southwest Star of the Month . . . . . } 436\end{array}$


CHAPTER I

STATEMENT OF THE ISSUE

\section{Introduction}

All over America and the world today, we are faced with problems that appear to be insurmountable. The national deficit, bankrupt nations, economic dislocation in our cities, security and defense problems, and the threat of nuclear destruction are overwhelming. Never before have we seen a group of young people as confused, demoralized, and consequently apathetic as the contemporary youth generation. Moral standards are eroding as evidenced by the climbing divorce rate, and poverty runs rampant inside our borders and throughout the world. In the midst of these devastating circumstances, our nation is confronted with a problem that is perhaps even more critical: a crisis in leadership.

Ruch and Goodman (1983) described how the effects of our confusion about leadership are manifested in the corporate structures of our nation:

America's corporate leadership is facing the test of its life. In the face of a tremendous storehouse of rich natural resources, brainpower, and human talent that has been the envy of the world since the 
production miracles of World War II, our industrial leaders now stand bewildered. (p. 3)

In concert with the criticism levied by Peters and Waterman (1982), Ruch and Goodman (1983) cited irrelevant leadership and management research, schools of business, education, and public administration that have been unresponsive to business needs, changing male/female roles, and the rise of unionization as being among the many roots reaching to the core of the crisis in American corporate leadership. Moreover, these researchers have pointed out that a new generation of business leaders are climbing into chief executive officer positions with no experience in dealing with the downside economy. They have been mentored in an economic environment where the weaknesses of leadership were glossed over by blossoming earnings and a "bottom line" that bulged at the seams. Now, in a highly turbulent and radically changing economic environment, these executives have very few role models to study.

The crisis of leadership is not only exhibited within the corridors of our corporate structures, it extends into the broader domain of our political system. Burns (1984) argued that "the American political system faces a pervasive crisis of self-confidence that only the rarest kind of laadership can overcome. The symptoms of the crisis take the long-observed form of political aisarray, institutionalized stalemate, and governmental ineptitude and 
impotence" (p. 11). Burns has suggested that many leaders strike out against the political system because it makes leadership so difficult. Candidates rebel against scrounging for money, reckoning with pressures from special interest groups, and meeting the demands of television and other media.

Suggesting that we have created a system that focuses on the trivial aspects of leadership, Burns (1984) explained that:

our life and death engagement with leadership has given way to the cult of personality, to a "gee whiz" approach to celebrities. We peer into the private lives of leaders, as though their sleeping habits, eating preferences, and sexual practices, " dogs, and hobbies carry messages of profound significance. ( $p$. 1)

If Burns is correct in assuming that this has been the focal point of our attention, it should not come as a shock to recognize that our confusion about the issue of leadership has hindered our ability to cultivate leaders in our political system as well as our organizations.

If, as the preceding discussion suggests, there is a leadership crisis facing our nation and the world today, it is crucial that we as scholars, practitioners, and potential leaders confront the problems associated with the old models of leadership and develop a new understanding about 
the nature of this critical concept. Fortunately, a new consensus is emerging in the literature regarding the nature of leadership. The catalytic agent behind this new intellectual movement has been James MacGregor Burns, whose ideas appear in a comprehensive volume entitled Leadership (Burns, 1978).

Burns (1978) introduced the concept of transformational leadership, suggesting that leaders are individuals who transform their institutions by meeting the mutual goals of both leaders and followers, successfully articulating their values to followers and drawing them into a common purpose, and raising the moral aspirations of both leader and led. The notion of transformational leadership is evidenced in the popular literature on organizational culture (Bass, 1985; Deal \& Kenneày, 1982; Lorsch \& Donaldson, 1983; Miller, 1984; Morgan, 1986; Pondy, 1983; Schein, 1985), excellence (Hickman \& Silva, 1984; Naisbitt, 1982; Naisbitt \& Aburdene, 1985; Peters \& Austin, 1985; Peters \& Waterman, 1982), and leadership (Bennis \& Nanus, 1985; Bolman \& Deal, 1984; Burns, 1984; Henderson, 1979; Levinson \& Rosenthal, 1984; Tichy \& Devanna, 1986).

In contrast to transformational leadership, Burns (1978) presented the notion of transactional leadership. Central to the concept of transactional leadership is the idea that leaders engage in an exchange process with followers and other leaders that may be economic, 
political, or psychological in nature. For example, this type of leadership may take the form of a transaction where pay incentives are provided to followers who meet the written and unwritten standards outlined by the leader, where jobs are exchanged for votes, or where particular subsidies are traded for campaign contributions. In this sense, transactional leadership is fundamentally different from transformational leadership in that the relationship between leader and led is solely based upon the exchange or transaction and has no enduring or higher purpose to hold the parties together. Once the exchange process has been completed, both leaders and followers will eventually go their separate ways. Conversely, transformational leadership occurs when the long range purposes of both leaders and led are fused, power bases are drawn together as mutual support for a more enduring relationship, where real, intended change occurs, and leaders and followers are elevated to higher levels of human conduct.

As Bass (1985) has accurately pointed out, the concepts of leadership advanced by Burns (1978) have contributed to a new and emerging paradigm that not only demonstrates the importance of leadership to the success of organizations, but the new framework has also created a significant change in the way we theorize about, and practice leading and organizing change. 
The Issue

While the contemporary literature on organizational culture and leadership has done much to further our understanding about the nature of transformational leadership, very few works provide us with case study examples of transformational leaders. Scholars contributing to this new consensus on leadership have described the processual nature of transformational leadership conceptually and theoretically. However, these studies do little to show us the application of a given theory or concept through actual living examples. This is a very serious void in the literature on leadership because without case study examples it is difficult to distinguish what determines an individual who is a transformational leader from one who does not exemplify the concept. Moreover, the minimal use of in depth studies in the literature makes it difficult for scholars and practitioners to determine how leaders affect significant institutional change. Missing is an understanding of what leaders actually do in the process of leading followers and transforming organizations. In essence, the literature does not address the very means by which leaders accomplish their ends.

While there is some research (Bennis \& Nanus, 1985; Levinson \& Rosenthal, 1984) that examines the leadership abilities of high-level executives through the method of 
case study, only a few of the examples in these studies illustrate aspects of transformational leadership in its purest sense. This is also a serious problem because in attempting to gain access to executives in high-level positions, researchers often investigate entrepreneurs or managers who are not transformational leaders. Therefore, it is important that scholars seeking to better understand the notion of transformational leadership use in-depth examples of those who are truly responsible for building and transforming institutions.

Purpose of the study

It is the position of this researcher that if we are going to learn about transformational leadership from leaders, we must examine specific leaders in particular contexts. Hence, this study seeks to address the problems outlined above by providing an in-depth description of how one leader in charge of a major American corporation has shaped and transformed his institution. specifically, this study examined the chief executive officer of a Dallas, Texas-based corporation that has a 15 year history, approximately five thousand employees, and one billion dollars in assets.

Six aspects of transformational leadership are examined to: (1) determine the degree to which this individual exemplifies the model offered by Burns (1978), and (2) determine how he operationalizes each of the 
primary components of transformational leadership. The primary components of transformational leadership are:

1. The leader's ability to win followers and mobilize their commitment in an environment of competition and conflict;

2. The accomplishment of the mutual goals of both leaders and followers;

3. The leader's ability to communicate his or her vision and align individual development with organizational purpose;

4. The leader's ability to shape individual and organizational values and educate by example.

5. The leader's ability to use power effectively and engage in sophisticated political behavior in order to accomplish the mutual goals of both leaders and followers;

6. The generative processes whereby leaders engage in developmental relationships with followers so as to develop Euture leaders.

In an effort to accomplish the objectives of this study, the investigator examined four aspects of transformational leadership:

1. The mechanisms (e.g., symbols, language, stories, rituals, etc.) by which the leader articulates his values to followers and embeds them in the organization; 
2. The operational methods the leader uses to elicit the commitment of his followers to a common organizational mission, purpose, or vision;

3. The processes by which the leader mobilizes resources to further his mission; meet the needs of followers, and affect organizational change; and

4. The approaches (e.g., coaching, mentoring, sponsoring processes) used by the leader in the development of followers and the generation of future transformational leaders.

Relevance of the Issue to Leadership

An examination of this kind contributes significantly to the new literature on leadership by providing scholars and practitioners with detailed, descriptive information about how the concept of transformational leadership is operationalized. It seems reasonable that this information can be particularly useful for those who are interested in increasing their effectiveness as leaders as well as those who want to enhance organizational effectiveness. The information gained from this study can also provide us with insight about the "interplay between the person as a leader and the interactive organization that follows" (Levinson \& Rosenthal, 1984, p. 6). 
Definition of Terms

The following terms are referred to and used throughout the course of this research.

Ceremonial: A system of several rites connected with a single occasion or event (adapted from Trice, 1984).

Language: A particular form or manner in which members of a group use vocal sounds and written signs to convey meanings to each other (adapted from Trice, 1984).

Myth: A dramatic narrative of imagined events, usually used to explain origins or transformations of something. Also, an unquestioned belief about the practical benefits of certain techniques and behaviors that may not be supported by demonstrated fact (adapted from Trice, $1984)$.

Organizational symbolism: "Those aspects of an organization that its members use to reveal or make comprehendible the unconscious feelings, images, and values that are inherent in that organization" (Dandridge, Mitroff, \& Joyce, 1980, p. 77).

Rites and Rituals: Relatively elaborate, dramatic, planned sets of activities that consolidate various forms of cultural expressions into one event, which are carried out through social interactions, usually for the benefit of an audience (adapted from Trice, 1984). 
Story: A narrative based on real events but often told using a combination of truth and fiction (adapted from Trice, 1984).

Symbol: Any object, act, event, quality, or relation that serves as a vehicle for convering meaning ladapted from Trice, 1984).

Transformational Leadership: "When one or more persons engage with others in such a way that leaders and followers raise one another to higher levels of motivation and morality. Transforming leadership ultimately becomes moral in that it raises the level of human conduct and ethical aspiration of both leader and led, and thus has a transforming effect on both." (Burns, 1978, p. 20)

\section{Dissertation Organization}

In describing how the concept of transformational leadership is operationalized by one individual, the second chapter of this investigation presents a review of literature surrounding the major components of the concept. The research design and methodology for this study is outlined in Chapter Three. That chapter also includes a more detailed description of the leader involved in this study, his followers, and the organization. Chapter Four describes the history of Southwest Airlines. This chapter provides the background of the organization which is necessary for understanding the growth and development of its leader. Chapter Five presents the responses gained 
from interviews that were conducted with the leader and his followers. The researcher's observations and interpretations of the data collected are also included in this chapter. Additionally, Chapter Five presents an array of Figures that compliment the data gathered in the interviews and through observation. Finally, Chapter Six presents a summary of the study and the researcher's conclusions regarding the degree to which the subject of this investigation personifies transformational leadership. The summary and conclusion in this chapter are followed by a discussion of the strengths and weaknesses of the study and the researcher's concluding remarks. 
CHAPTER II

REVIEW OF LITERATURE

\section{Transformational Leadership Literature}

In his explanation of leadership, Burns (1978) was very explicit about the potential for transforming leadership to achieve broad human purposes. He advocated that the dynamic of transforming leadership is identifying expressed and unexpressed wants among followers, bringing them to higher levels of consciousness regarding their needs, and transforming their needs into hopes and expectations. Burns (1978) concluded that

The essence of leadership in any polity is the recognition of real need, the uncovering and exploiting of contradictions among values and between values and practice, the realigning of values, the reorganization of institutions where necessary, and the governance of change. The leader's fundamental act is to induce people to be aware or conscious of what they feel--to feel their true needs so strongly, to define their values so meaningfully, that they can be moved to purposeful action. (pp. 43-44) 
Transforming leadership is a developmental process in which a leader seeks to raise the moral aspirations of followers by capitalizing on competition and conflicts, accomplishing the mutual goals of both leader and led, articulating a vision that moves followers to purposeful action, shaping values and educating by example, using power resources and political behavior to meet the needs of leaders and followers, establishing the types of empathic relationships with followers that will ultimately make them leaders, and by building strong organizational cultures that embed within the organization the foregoing elements of leadership. Transforming leadership, then, is dynamic leadership in that it often elevates followers to be actively involved as leaders themselves. As followers become involved, as their own levels of aspiration are raised to that of the leader, they become more selfdirected and actualized, and ultimately play a significant role in the process of transformation. In this sense, leaders and followers become fused into a mutually bonded relationship where both "continuously transform each other and the organization to higher levels of motivation and performance based on higher standards of moral and ethical conduct" (Rost, 1985, p. 5). The ultimate test of this type of leadership is "its capacity to transcend the claims of the multiplicity of everyday wants and needs and expectations, to respond to higher levels of moral 
development, and to relate leader-ship behavior--its roles, choices, style, commitments--to a set of reasoned, relatively explicit, conscious values" (Burns, 1978, p. 46).

\section{Competition and Conflict}

Naisbitt (1982) has pointed out that in the new information society there is stiff competition for raw and human resources. He noted that we are moving into a global economy where competition for products, markets and technology has forced the United states to become more dependent on other nations. In the midst of our shift to a global economy, Naisbitt and Aburdene (1985) proposed that the contemporary work force will be transformed from a buyer's market to a seller's market. Due to a significant decline in the growth of the work force, those organizations that were able to choose from a wide variety of well-qualified, highly-competent job applicants are now in fierce competition for the best people. This means that potential employees are now confronted with more alternatives, opportunities, and choices regarding the types of organizations with which they will associate. This also means the followers will have more choices concerning the leaders to whom they will become committed. Moreover, these individuals will make scrupulous decisions about the corporations they work for based on the nature of the leadership within those organizations. Naisbitt and Aburdene concluded that 
Corporations will aggressively compete for fewer first-rate employees. The most talented people will be attracted to those corporations that succeed in reinventing themselves into companies that are great places to work for because the people in them grow personally while contributing to the company. (p. 18)

one of the predominant distinguishing factors of transformational leadership is that individuals become followers by choice. Burns (1978) argued that followers can define their true needs only when they have had the opportunity to evaluate the "competing diagnoses, claims, and values" of those who desire to become leaders. Through their exposure to competing alternatives, followers are able to make intelligent choices about leaders. Thus, "the moral legitimacy of transformational leadership . . . is grounded in conscious choice among real alternatives" ( $p$. 36, the emphasis was Burns'). The point of distinction here is that leaders compete for followers by providing followers with alternatives that take into account their real needs, alternatives that aim to address their values and accomplish their goals. Burns (1978) indicated that "leadership over human beings is exercised when persons with certain motives and purposes mobilize, in competition and conflict with others, institutional, political, psychological, and other resources so as to arouse, engage, and satisfy the motives of followers" (p. 18). Thus, 
according to Burns, competition and conflict are necessary conditions in order for transformational leadership to be exercised.

Allison (1984) determined that leadership extends beyond the realm of mere office holding and decision making power and authority. That is, positions of power such as chief executive officer, general, or chief of staff do not necessarily constitute leadership because in each of these situations subordinates are required to follow superiors, with positional or legitimate power by virtue of their contractual agreements. Under these conditions Burns' (1978) notion of choice among alternatives is often denied by the authoritative nature of the relationship. Accordingly, Kellerman (1984) identified the difference between headship and leadership, suggesting that the former is determined by position while the latter is based on the relationship between leaders and followers. Headship can be linked to the "rights and duties of an office or status in a hierarchical structure, whether a formal organization or an informally stratified collectivity" (Edinger, 1975, p. 255). Kellerman held that headship is maintained through organizational structure. She affirmed that the focus of leadership "is not on role or person, but on the special nature of the relationship between leader and followers." (p. 71). Thus, leaders, in contrast to heads, 
are given power and influence purposefully by group members who, in turn, follow because they want to follow.

Ohmann (1975) recognized that where true leadership exists, followers voluntarily delegate rights of selfdirection to leaders in the interest of satisfying mutual goals. Leaders therefore understand that their influence "must be exercised with due regard for the attendant obligations to [followers]. - who have temporarily and voluntarily yielded their rights in the interest of this common undertaking" (p. 710). Consequently, leaders use this "delegated authority" to enhance the shared values and promote the common good of both leaders and followers. Ohmann, in accordance with Burns (1978) and Kellerman (1984), understood that leadership is a function of individuals making conscious decisions based on their freedom to choose and their capacities for making value judgments. Thus, these authors would suggest that commitment on the part of followers is a consequence of competition and conflict and an inherent component of transformational leadership, while compliance is the result of authority based on hierarchial position and an essential part of headship.

In consort with transformational leadership is Iindblom's (1968) notion of reconstructive leadership which also emphasizes competition or conflict as central to the relationship between leaders and followers. Lindblom 
suggested that reconstructive leaders shape policies that are designed to meet the preferences of followers; however, he points out that leaders also use their influence to transform the preferences of some followers so that they are aligned with the preferences of the leader. In this sense, both leaders and followers are involved in a mutual influence process where leaders compete for followers by creating policies designed to meet their needs.

In his discussion of the political aspects of changing organizations, Baldridge (1983) indicated that conflict is not necessarily a symptom of malignant forces within the organization, but rather a catalyst in advancing healthy organizational change. He pointed out that conflict is a natural and normal part of dynamic social systems. This coincides with Burns' (1978) position that the potential for conflict pervades human relationships, and transformational leaders understand that potential as both constructive and destructive. The issue for Burns, however, is not the irrepressible nature of conflict but the role of transformational leadership in "expressing, sharing, and curbing it." Noticing that conflict has the capacity to motivate, energize, and jar people into action, he contended that the function of leadership is to incite and trigger the transformation of conflicting goals, values, wants, and needs into constructive behaviors. In this sense, leaders mobilize followers by capitalizing on the 
conflict that energizes in an environment of diverse psychological, social, and political interests.

Ackerman (1984) demonstrated how leaders are open to conflict. She likened leadership to the martial arts where individuals are trained to "embrace the enemy" in order to develop a larger, more complete perspective from which to make judgments. This proactive stance enables the leader to use the conflicting situation to his or her advantage as a leverage point in responding to the wants and needs of followers. Concurrent with Ackerman's point of view, Burns (1978) concluded that

Leaders . . do not shun conflict; they confront it, exploit it, ultimately embody it. standing at the points of contact among latent conflict groups, they . - shape as well as express and mediate conflict. They do this largely by influencing the intensity and scope of conflict. Within limits they can soften or sharpen the claims and demands of their followers, as they calculate their own political resources in dealing with competing leaders within their own constituencies and outside. Similarly, they can narrow or broaden the scope of conflict as they seek to limit or multiply the number of entrants into a specific political arena. (p. 39)

In a more recent work, Burns (1984) strengthened the preceding argument by showing how the nature of 
transformational leadership has affected the reshaping of our political system. He pointed out that the genius of the framers of the Constitution was to divide judicial power into three federal branches of government where the "officials within were made to be chosen by, accountable to, and in some cases dismissable by, diverse, conflicting, and overlapping sets of voters, so that conflict would be permanently built into government" (p. 107).

In support of the positions offered by Ackerman (1984) and Burns (1978), Kiefer and Senge (1984) affirmed that leaders in metanoic organizations are motivated by the risks and rewards of competition and therefore confront it with zest and enthusiasm. In these organizations leaders embrace competition as a strategy for furthering the common vision; as a result, competition becomes a means rather than an end in itself. Thus, it must be understood that competition and conflict are not only an inherent part of the nature of transformational leadership, they are also the very tools used by leaders in the process of learning.

Accomplishing the Goals of Both Leader and Led

That transformational leadership recognizes that "the organization finds its greatest expression in the consciousness of a common social responsibility" (Bennis and Nanus, 1985, p. 217). These authors argued that leaders create a symbiotic relationship with followers in which the subtle interplay between the wants and needs of followers, 
and the leader's capacity to understand these collective aspirations, unites followers into a responsible community that takes ownership and responsibility for the success of the organization and its long-term survival. Zaleznik (1983) explained that with an imaginative capacity and the ability to communicate, leaders who are driven by a human and social purpose, can reform the individual goals and desires of followers into a broader world view. Illustrating this point, Gardner (1965) maintained that:

Leaders have a significant role in creating the state of mind that is the society . . . They can conceive and articulate goals that lift people out of their petty preoccupations, cärry them above the conflicts that tear a society apart, and unite them in the pursuit of objectives worthy of their best efforts. (p. 12)

Transformational leadership involves "the accomplishment of a goal through the direction of human assistants" (Prentice, 1983, p. 140). Therefore, leaders raise the level of commitment in those who follow by merging their own goals as leaders and the goals of their followers into an integrated force. Buckley and Perkins (1984) have called this process the integrational stage of organizational transformation. In their view, an organization reaches an integration stage when leaders and followers establish a sense of trust, cooperation, and openness. The 
result is that the organization reaches a stage of balanced wholeness in which leaders and followers develop shared commitment by working together as one.

Harrison (1984) described the oneness between leaders and followers as attunement, the "resonance or harmony among the parts of the system, and between the parts and the whole. Attunement . . binds us to one another . . by opening us to one another's needs and to our own sense of what is fitting and right" (pp. 101-102). Attunement, then, stands at the center of the transformational leader's effort to meet the human goals of leaders and followers. It implies that both leaders and followers participate in the pursuit of a common purpose.

According to Ackerman (1984), leaders attempt to establish a common purpose. This unifies both leaders and followers by creating in each a sense of organizational security and identity. "The security comes from two major sources: shared acceptance of the purpose and future goals of the organization and the sense of togetherness or community that is created by the collective effort" ( $p$. 129). Nelson and Burns (1984) reaffirmed that the formulation of future goals must be a collective effort. These researchers have argued that when organizational goals are developed in isolation and simply passed on to followers, the process of organizational transformation is severely hindered. They explained that in order to build a bond of 
mutual trust, both leaders and followers must participate in the goal-setting process. It is through this process then, that leaders and followers become committed to a common purpose.

In his discussion of leadership, Sergiovanni (1984) noted that leaders have a unique ability to create a mesh between organizational objectives and the goals, desires, and objectives of followers. He indicated that leaders and followers bargain and negotiate to reach a set of common agreements in which the needs of each are met. These agreements ultimately result in a set of common beliefs about how the mutual goals of leader and led can be accomplished in congress with fulfilling the mission and purpose of the organization. In his seminal work, Barnard (1938) also recognized the relationship between mutual goal attainment and leadership. He concluded that "the inculcation of belief in the real existence of a common purpose is an essential executive function " (p. 87).

The process of mutual goal attainment becomes a reality because transformational leaders possess a perceptiveness that makes them keenly aware of their followers' needs. This sensitivity also enables them to understand the goals and desires of followers. "The leader's unique achievement is a human and social one which stems from understanding fellow workers and the relationship of their individual goals to the group goal that must be carried 
out" (Prentice, 1983, p. 141). These leaders have both the desire and ability to create an environment where the wants and needs of followers can be satisfied. They are particularly adept at using their skills and insight to establish a balance between cooperative common action (Long, 1963) and the fulfillment of individual goals. In this sense, transformational leadership is not merely the leader's fulfillment of his or her own selfish motives at the expense of followers. Rather, transformational leadership seeks to advance the common good of both leaders and followers (Ohmann, 1983). This notion of a balance between individual goals and mutual objectives is clearly articulated in Collier's (1983) statement that "the first task of business leaders . . . is to create an environment in which there can flourish not only individual genius but, more important, the collective capacities of other people in the organization" (p. 172).

Follett (1941) also understood the important role leaders have in satisfying the motives of followers. She pointed out that by addressing the mutually held purpose of leaders and followers, the effective leader is able to develop consonance with followers that empowers both to deeper levels of organizational commitment. She pointed out that the successful leader causes followers to see that it is not his or her mission that is to be accomplished, 
but a collective mission, fed by the needs and desires of the group.

In addressing the mutual goals of both leader and led, transformational leaders establish a sense of trust with their followers. Bennis and Nanus (1985) noted that "trust is the emotional glue that binds followers and leaders together [and] - . the lubrication that maintains the organization" (p. 153). This relationship of trust, in turn, establishes an environment where the collaborative efforts of both leaders and led affect significant organizational change and propel the institution forward. Miller (1984) has suggested that "the genius of leadership is the mobilization of human energy in pursuit of goals held by the followers, and this may be accomplished only under a condition of trust between leader and followers " (p. 122). Consequently, leaders hold on to their followers because they understand how the implications of their own actions affect the needs of followers (Levinson \& Rosenthal, 1984). Once this bond of trust has been established, followers are more willing to adopt and promote the leader's vision for the organization.

\section{Vision and Alignment}

Kiefer and Senge (1984) have used the term "metanoic" to describe organizations that are very proactive with regard to influencing their destinies and the environments around them. These researchers pointed out that 
"metanoic," from the Greek word "metanoa," meaning "a fundamental shift of mind,"was used by early Christians to describe the reawakening of intuition and vision. (p. 70) Metanoic organizations can be identified by at least two common characteristics. First, they have a well-defined, clearly-articulated vision of the future. And second, they are abie to create a sense of alignment around that vision. According to Naisbitt and Aburdene (1985), "Vision is the line between dream and action" (p. 21), the "organizing principle," and the "catalytic force" underlying everything that individuals do in the organization. This means that leaders and followers alike relate everything that happens in the organization to their idealized view of what the organization should be. As Follett (1941) pointed out so long ago, "The most successful leader of all is one who sees another picture not yet actualized. He sees the things which telong in his present picture but which are not yet there" (p. 143). Thus, the successful organizations of the future will be driven by a powerful vision, by their sense of where they are going, how they will get there, and what they will look like once they have arrived. At the helm of this driving force stands the transformational leader, who is the source of the vision and who possesses the conceptual foresight and practical skills necessary to realize it. Kanter (1983) demonstrated that transformational leaders have the ability to create vision 
and engage followers' imaginations in pursuit of it. over three decades ago selznick (1957) recognized that as an advocate of institutional purpose, the leader is the source of a vision and that any discussion of transformational leadership must emphasize the "leader's responsibility to define the mission of the enterprise" (p. 26). Transformational leaders do this by gradually and persistently embedding their own assumptions in the mission and purpose of their organizations. Whether these basic assumptions are synonymized as guiding beliefs, theories-in-use, basic principles, or the guiding visions upon which the organization is founded, it is quite clear that they are the fundamental rudiments that clearly express what the organization represents (Argyris, 1976; Bennis, 1983; Davis, 1984; Donaldson \& Lorsch, 1983; Dyer, 1983; Pettigrew, 1979; Schein, 1983).

In communicating a valued vision of the future, transformational leaders create an organizational environment where commitment is highly valued and followers have a standard by which they can measure the success of their own behaviors. Bennis and Nanus (1985) explained that the leader's vision provides followers with a foundation or guideline for making daily decisions about what is good and what is bad for the organization. This is because, as Tichy and Devanna (1986) pointed out, the leader's vision establishes a "conceptual framework or paradigm" within 
which followers will develop a better understanding about the mission and purpose of the organization. deBivort (1984) also showed how the leader's vision is a standard for organizational members to judge their own actions. The strong, well-conceived, and highly attractive vision of what the organization is seeking to become is the cornerstone of a fast-tracking transformative effort. The vision becomes the single "master template" through which all participants in the transformative process can, singly and collectively, assess their undertakings; it provides coordination and synchronization. (p. 246)

To be compelling and elicit the commitment of followers, transformational leaders "project ideas into images that excite people" (Zaleznik, 1983, p. 129). Based on their intuition about the future and their ability to articulate a well-defined vision, leaders provide direction for the present that inspires followers and moves both followers and leaders to purposeful action in a unique and special way. The image created by a transformational leader appeals to his or her followers' higher values and aspirations (heroism, challenge, dignity, and significance). The excitement and enthusiasm generated from the image builds within followers a spirit of confidence that exalts them to transcend their fears and preoccupations with the present, allowing them to embrace a valued vision 
of what they could become, where they could go, and what they could accomplish (Berlew, 1974).

Peters (1983) concluded that leaders communicate their vision by living it before it is a reality to anyone but themselves. They respond to the higher levels of moral development in followers by relating immediate goals to their long-range and more enduring goals. Leaders transform the hopes of followers into expectations by communicating a purpose that creates excitement and instills energy. They do this by articulating a set of values in order to fashion institutions and structures that will not only inspire the pursuit of heroism, but also establish a framework in which paths for heroic deeds will be created. For example, Burns (1984) indicated that the structuring of American government, the "supreme act of transforming leadership," emerged because a small band of men heroically committed to a particular set of values were able to transcend their immediate interests for a valued vision of the future.

President John F. Kennedy's impact on the managers at Honeywell and the members of the National Aeronautics and Space Administration (NASA) illustrates the power in establishing a vivid, compelling vision of the future. Kennedy provided individuals in both organizations with a strategic vision that stretched their concepts of what could be and encouraged them to bridge the gap between 
ideal reality and what presently seemed possible (Ackoff, 1981). As Naisbitt (1982) explained, "A strategic vision is a clear image of what you want to achieve, which then organizes and instructs every step toward that goal. The extraordinarily successful strategic vision for NASA was 'put a man on the moon by the end of the decade.' That strategic vision gave magnetic direction to the entire organization. Nobody had to be told or reminded of where the organization was going" (p. 94).

As with the members of NASA, Kennedy's vision had a significant impact on the people at Honeywell. Miller (1984) was particularly impressed with the commitment, sacrifice, and heroism evidenced by these individuals:

I remember listening to managers at Honeywell's Aerospace and Defense Group talk about the time when they were working on the Apollo program. They worked insanely long hours and with total dedication. They worked as if they were at war. They felt that they were responsible for landing $a$ man on the moon and that this nation's pride and prestige was in their hands. They made personal sacrifices that no manager could ask or demand. They were not motivated by the financial aspects of their project. They were not responding to management techniques or evident selfinterest. They were rasponding to what they felt was 
a noble purpose, and through sacrificing to that purpose they achieved self esteem. (p. 43)

Leaders are able to facilitate organizational transformation not only because the excitement of their vision appeals to the aspirations of followers, but also because they are very passionate and persistent (Bennis, 1984) in the diffusion of their vision. The natural consequences of this persistence and passion is that leaders never miss an opportunity to communicate their vision (Naisbitt and Aburdene, 1985). Harrison (1984) noted that leaders articulate their vision daily to others through their behaviors, and through the decisions that they make. It is their consistency in sharing this vision that transforms the dream into reality. This consistency is also what helps the leader penetrate the whole organization with his or her vision. As Buckley and Perkins (1984) pointed out, "Effective packaging of the vision generates excitement and unifies the organization. As a stone dropped in a pond sends ripples to a farthest shore, so does an articulated new direction ripple out to affect the health and vitality of the organism" (p. 62).

As we have seen, one of the priorities of transformational leadership is the installation of vision which commits followers and leaders to a common purpose. Whether it is labeled as the central theme, ideology, focus, cause, mission, philosophy, or vision, most contemporary scholars 
contributing to the new consensus on the nature of leadership (Adams, 1984, 1986; Bennis, 1984; Bolman \& Deal, 1984; Burns, 1984; Deal \& Kennedy, 1982; Frost, Moore, Louis, Lundberg, \& Martin, 1985; Greenfield, 1984; Hickman \& Silva, 1984; Lawrence, 1984; Meyer, 1984; Naisbitt \& Aburdene, 1985; Peters \& Waterman, 1982; Peters \& Austin, 1985; Sergiovanni, 1984; Tichy \& Devanna, 1986; Vaill, 1984) agree that a primary ingredient in leading people is the articulation of a compelling vision. This vision, then, is what enables transformational leaders to draw followers into alignment where both leaders and followers are committed to the same mission.

Alignment is the critical process in which a leader attracts people who can play a significant role in realizing the vision by taking ownership of it and sharing the responsibility and recognition for achieving it (Naisbitt \& Aburdene, 1985). Perhaps the foremost experts writing on the subject at present, Kiefer and senge (1984) have explained that alignment is catalyzed by the leader's ability to foster a compelling vision. Alignment is a mesh between organizational objectives and individual development where leaders and followers perform as an "integrated whole." That is, there is a very evident sense of interconnectedness among individuals that are committed to the same vision. Kiefer \& Senge (1984) liken alignment to the intense, awe-inspiring level of teamwork that is manifested 
in outstanding athletic teams and symphony orchestras. In each of their examples, the group's performance extends beyond the realm of what seems possible.

Every so often we hear of a group of people who . . transcend their personal limitations and realize a collective synergy with results that far surpass expectations based on past performance. Anyone hearing a fine symphonic or jazz group hopes for one of those 'special' concerts that uplift both the audience and the performers . . . In sports, the 1980 U.S. Olympic hockey team stunned the world by winning the gold medal against the vastly more talented and experienced Russian and Finnish teams. (As cited in Naisbitt \& Aburdene, 1985, p. 4)

Alignment, then is a condition facilitated by the leader wherein members of an organization have developed a tremendous sense of significance because they recognize and understand that their individual contributions are important to the overall mission of the organization. As this happens, each individual begins to align his or her own purpose with the purpose of the organization until there is a oneness between the individual's purpose and that of the organization. Harrison (1984) explained that "alignment occurs when organizational members act as parts of an integrated whole, each finding the opportunity to express his or her true purpose through the organization's purpose" 
(p. 100). According to kiefer and senge (1984), organizations that are highly aligned can have a significant impact on an individual's relationship to the organization and sense of identity. Maslow (1965) indicated that individuals who are committed to a team or organization with a high degree of alignment define themselves according to the organization's purpose and the contributions they make to it. In this sense, individuals do not distinguish between themselves and the tasks they perform or the organizational roles they play. According to Maslow, these individuals identify with their tasks so intensely that it is difficult for them to define themselves without reference to those tasks.

Alignment then, takes place when leaders transform their own vision into a shared organizational vision with which the followers identify. Through the process of identification followers develop a oneness with the leader and define themselves in relationship to the leader's vision. As followers begin to identify with the vision articulated by the leader, they also begin to identify with one another because they are fundamentally committed to a common purpose. The result is that both leader and led are drawn into an integrated whole that creates for each a general sense of humanness, a higher level of selfactualization, and a production capacity that transcends individual capabilities. 
Supporting the notion of oneness, Kiefer and stroh (1984) affirmed that:

Alignment is a special condition wherein people operate freely and fully as part of a larger whole. It is created when people see their organization's purpose as an extension of their personal purposes. People who are aligned identify with the organization and consciously assume responsibility for its success. They normally support each other out of a recognition that, "we are a part of the same whole." (p. 175) Miller's (1984) treatment of ownership is closely akin to the concept of alignment. Ownership produces a condition of interdependency in which an individual's well-being is limited to the productive organization. Consequently, the individual feels responsible for the success of the organization because he or she identifies so closely with it. This is why Miller argued that "the conditions that lead to personal fulfillment are becoming the same conditions that lead to corporate productivity" (p. 183).

Buckley and Perkins (1984) contended that a resonance field develops in highly aligned organizations. Resonance, exists when various parts and processes are brought together through a common vision to produce a whole where the actual effect is much greater than the parts. Resonance or alignment, then, is the outcome of the leader's ability to integrate an individual's job with a higher 
transcendent purpose. According to Ohmann (1975), this integrative function is an essential mandate for every leader.

Thus, transforming leaders understand that when followers identify with their organization's purpose, when they develop ownership in a shared vision, they will perceive themselves as doing their life's work instaad of just putting in time (Naisbitt \& Aburdene, 1985). It is important to note here that as followers identify with the organization's purpose, they are, in essence, identifying with the leader's purpose. This is because the mission and purpose of the organization is established by the result of the leader's vision.

\section{Sharing Values and Educating by Example}

As Beyer (1981) has accurately stated, the values and ideology that are embedded in an organization originate with its leaders. Thus, transformational leaders are value shapers. They shape values "through persistently embodying them in how they deal with the myriad, ad hoc, isolated events of everyday. Because it is practically impossible for leaders to accomplish their ends directly, it is their capacities to shape values and educate by example that ultimately move the organization" (Collins, 1983, p. 120, paraphrasing Peters, 1983, pp. 202-213). Burns (1978) maintained that one of the most crucial aspects of leadership is to bring followers to higher levels of conscious- 
ness regarding their own values. He has suggested that leaders awaken the substantive values in followers that ultimately become the basis for purposeful action. Langer (as cited in Simpson, 1971) argued that "values exist only when there is consciousness . . .where nothing is felt; nothing matters" (p. 73). The leader's fundamental concern then, is true consciousness, raising it among followers so that they will identify those values that express their most deeply-held needs. Burns described these values as end values (freedom and dignity, justice and peace, and liberty and equality) and contrasted them with modal values (due process, individual liberties, and fair play).

The distinction Burns (1978) made between end values and modal values can be likened to the contrast Bennis and Nanus (1985) made between doing things right and doing the right thing. Bennis and Nanus have argued that management is a function of doing things right (modal values), while leadership is a result of doing the right thing (end values). Thus, because of their long-range focus and preoccupation for seeing their followers do the right thing, transformational leaders are more concerned with shaping end values.

Greenfield (1984) believes that "organizations are built on the unification of people around values" (p. 166). The powerful, but essential business of leadership is to be an entrepreneur for ultimate values. One of the common 
denominators in every excellent company that Peters and Waterman (1982) studied was that the leaders of those corporations took the process of value-shaping seriously. The concluded that the great organizations are characterized by a unified sense of mission founded upon new and enduring values fashioned by leaders. In his discussion of chief executive officers, Henderson (1979) added that strong leadership provides direction and motivation to the corporation by establishing a remarkably clear value system. Garfield (1986) proposed that the individuals and organizations with outstanding performances all possess a strong commitment to values. He indicated that values are what constitute an organization's character and provide direction to its mission.

Similarly, Deal and Kennedy (1982) held that "shared values define this fundamental character of [an] organization" and Tichy and Devanna (1986) noted that an organization's character (its political system, power structure, and human resources) is mobilized around a set of values. These values are what drive the corporation's business stracegy.

Understanding values as the underlying principles upon which organizations operate, Rost (1985) advocated that: Transforming leaders shape the values that influence how people behave in the organization, how people think about the organization and its products and 
services, how people interact with each other in the organization, and how the organization interacts with the society in which it operates and the world in a global sense. (p. 7)

Foster (1985) also recognized the relationship of values to the organization by suggesting that leaders create systems of shared values that provide followers with an understanding of what is right and what is wrong, guidelines for coping with the natural world, and ways for ordering personal relationships. Selznick (1957) stated that the infusion of values within an organization will affect personal agendas, the perception and dispositions of employees, the distribution of power, and relations with outside institutions. In an extensive volume devoted solely to the managemeint of values, McCoy (1985) wrote:

For a corporation to be infused with value means, first, that it has a high level of integration in its total operation. Throughout its various divisions and layers of management, there are common understandings that provide a sense of community and relationship. It means, second, that there is a sense of corporate identity . . . Everyone possesses a firm knowledge that they are part of the same organization and contributing in different ways to shared goals. Because a corporation is distinguished by its value commitments . . the central problem of leadership 
has to do with control of the core of value commitments and the continual care of them. (pp. 182, 186) Shaping and enhancing values are of primary importance to leaders wrote Deal and Kennedy (1982). They argue that the essence of an organization's philosophy is the value system that influences the daily behaviors of everyone in the organization and provides guidelines for the standards they are to uphold. This is why Burns (1978) determined that the leader has a tremendous potential for influence in the organization through value shaping. "Mobilized and shaped by gifted leadership, sharpened and strengthened by conflict, values can be the source of vital change" ( $p$. 41). Peters (1978) acknowledged that the most important processes within an organization are centered around the interpretation of contemporary and historical events and the transformation and maintenance of the dominating values within the organization.

Miller (1984) concluded that significant institutional change is the result of leaders promoting and marketing new values. He explained that their success in shaping values is determined by their abilities to appeal to the more enduring values and long-term potential of followers. Accordingly, Ohmann (1975) reported that an effective leader "interprets or crystallizes values for followers by defining them in a larger, more meaningful context." The integrative function of the successful leader is to relate 
immediate values to the overriding and more eternal values of followers. The leader's "long-term values naturally express themselves in well-defined policies, and it is against this frame of reference that the decisions of this moment easily fall into proper perspective" (p. 712). Ohmann recognized that an individual's closely-held values significantly impact everything he or she does; hence, organizational transformation comes as a result of the leader's ability to promote new, and over arching values. Bennis and Nanus (1985) also pointed out the leaders role in affecting change through shaping values. These researchers affirmed that "the effective leader needs to articulate new values - . in order to transform, support, and institutionalize new meanings and directions" (p. 139). In his discussion of managers and leaders, Zaleznik (1983) indicated that leaders need to be proactive instead of reactive. That is, leaders must shape values rather than react to them, they create images, transform hopes into expectations, establish ideals, and define objectives that influence the direction an organization takes. "The net result of this influence, zaleznik explained, "is to change the way people think about what is desireable, possible, and necessary" (p. 127). Therefore, values must be understood as an integral part of the change process, and the role of value shaping must be understood as a necessary 
dimension of transformation leadership (McCoy, 1985; O'Toole, 1981).

Deal and Kennedy (1982) found that an organization that has been deeply imbued with a strong and shared value system manifests that value system in its structure. That is, the activities that pervade the organization are predicated upon the dominant values embedded in the organization. Selznick (1957) discussed the fundamental role of leaders in the process of shaping values and establishing institutional purpose:

The formation of an institution is marked by the making of value commitments, that is, choices which fix the assumptions of policy makers as to the nature of the enterprise, its distinctive aims, methods, and roles... The institutional leader is primarily an expert in the promotion and protection of values. Institutional survival, properly understood, is a matter of maintaining values and distinctive identity. (pp. 28, 152-153)

In his seminal work on leadership and organizational culture, schein (1985) outlined the mechanisms by which leaders promote and protect values. He explained that leaders design and structure their organizations so as to reflect their deeply held assumptions (values) about people, the very nature of their business, the means to accomplish their objectives, and the types of relationships 
they see necessary for achieving the mutually held goals of both leader and led. Leaders communicate their own values, assumptions, and priorities, he wrote, "by consistently linking rewards and punishments to the behavior they are concerned with" (p. 234). Leaders provide individuals with recognition and create status systems that are consistent with their deeply-rooted assumptions. Schein noted that one of the most effective ways that leaders shape values is by selecting and recruiting organizational members that fit the particular assumptions and values the leader wishes to embed in the organization. In recruiting an individual who holds very strongly to a particular set of assumptions, the leader has made a statement to the organization about the way he or she "wants it to be."

Leaders also articulate their deeply-held beliefs by whom they promote, whom they socialize into the "inner circle," to whom they offer early retirement, and whom they excommunicate from the fold. In each case an implicit message is sent to other organizational members about the goals, priorities, and values of the leader (Schein, 1985). Burns (1978) indicated that much of what can be identified as leadership behavior is made up of the day-today interactions which leaders have with followers. Transformational leaders are keenly aware of the influence that their daily activities have upon followers. As Peters (1983) has stated, it is difficult for leaders to affect 
change directly. Therefore, in their daily efforts they must focus on sending the proper signals, knowing that followers constantly interpret their behaviors. Schein (1985) noted that "the most powerful signal that [followers] respond to is what catches a leader's attention consistently, particularly what arouses him emotionally" (p. 319). Thus, leaders shape values and educate by vivid, living, personal example in the mundane events of every day. Through their daily activities and personal behavior, leaders teach, coach, and enable followers; they deliberately become role models, mentors who exemplify the very assumptions and values to which they want followers to adhere. In order to do this, leaders make themselves known and become highly visible throughout the organization.

As educators, transformational leaders shape values by living them in everything that they do. As Rost (1985) has suggested, "they articulate their values in memos, speeches, conferences with followers, meetings, retreats, and ceremonial occasions" (p. 7). Collectively, these activities enable the leader to "intervene purposefully and effectively in what one philosopher called 'the brute flow of random detail that adds up to everyday experience'" (Peters, 1983, p. 212).

\section{Power and Politics}

As a result of competition and conflict, transformational leaders focus their attention upon organizations as 
individuals and groups caught in a state of tension between conflicting goals, competing values, and self-serving interests. Moreover, organizations are looked upon as arenas of scarce resources where power and influence, coalition formation, bargaining, coercion, and compromise among individuals or interest groups affect the allocation of these resources. This assumes that organizations are highly politicized environments where leaders must be politically sophisticated in their efforts to mobilize real or symbolic resources. Consequently, transformational leaders perceive power and political dynamics as a very inherent and complex part of the change process.

As pointed out earlier, Burns (1978) observed that leadership is exercised in an environment of competition and conflict where leaders appeal to the motives of potential followers. He argued that transformational leaders are power holders of a special kind; they are political actors who use power to achieve the purposes of both leaders and followers. The crucial distinction between power wielding and leadership is mutuality of purpose. Unlike power wielding wherein the person uses power to achieve his/her purposes only, Burns defined leadership as "leaders inducing followers to act for certain goals that represent the values and the motivations--the wants and needs, the aspirations and expectations--of both leaders and followers" (p. 19). 
Absolute power "objectifies its victims; it literally turns them into objects," Burns said (p. 21). He concluded that power wielders are people who become objectified and dehumanized themselves because they have a thing-like view of other people. Criticizing the oppressiveness of power wielding, Mcclelland (1975) showed that by empowering followers, leaders can increase their own power and influence. He noted that power wielding

does not often lead to effective social leadership for the reason that such a person [follower] tends to be passive and useless to the leader who gets his satisfaction from dominating them. Slaves are the most inefficient form of labor ever devised by man. If a leader wants to have far-reaching influence, he must make his followers feel powerful and able to accomplish things on their own. (p. 263)

McClelland and Burnham (1983) described effective leaders as those who have developed a "measure of maturity" which enables them to use power to further the common good of organizational members rather than for their own interests. Showing how leaders exercise power on behalf of followers, the authors noted that a leader's pursuit and use of power are oriented toward serving the institution rather than self-aggrandizement. Collins (1983) also indicated that effective leaders have attained a particular level of personal maturity in using power. She explained 
that those leaders who use power to realize the joint purposes of leaders and followers are not reliant upon the approval of other organizational members to enhance their own self-esteem. In fact, these leaders share power with followers because they understand that the leader-follower relation is both the motive and the means for accomplishing their ends. Again, McClelland (1975) determined that "even the most dictatorial leader [sic] does not succeed if he has not instilled in at least some of his followers a sense of power and the strength to pursue the goals he has set" (p. 263)

Recognizing that the complexity of change is a function of the diverse distribution of power within organizations, transformational leaders do not assume that power rests solely in positions of authority (Tichy and Devanna, 1986). While they acknowledge the existence and importance of authority, they understand that it is only one among many forms of control (Bolman and Deal, 1984). As a result, leaders are particularly astute at broadening their bases of power.

Leaders' power sources consist of having the ability to mobilize the resources needed by their respective institutions, being "in the know"--establishing formal and informal sources of information, and cultivating support for their positions through networking with sponsors (Kanter, 1983). More importantly, she argued that leaders 
expand their power bases by sharing power with other members of the organization.

The productive capacity of nations, like organizations, grows if the skill base is upgraded. People with the tools, information, and support to make more informed decisions and act more quickly can often accomplish more. By empowering others, a leader does not decrease personal power; instead the leader may increase it--especially if the whole organization performs better. (p. 26)

Zaleznik (1983) added that in developing individuals and organizations, the leader's mandate is to promote talented people who will facilitate the "legitimate uses of power" to influence positions. In his study of six leaders, Maccoby (1981) also found that these individuals increased their power resources because they were willing to share them with others. He indicated that the "new style leader" empowers of followers by involving them in the process of planning and policy making.

Kotter (1983) accurately stated that leaders, in order to perform effectively, must understand the dynamics of power relationships and know how to acquire and use power resources to influence others. Leaders establish power relationships by enhancing others' perceptions of their competence and expertise, by creating within followers an "unconscious identification" with the values and ideals 
they stand for, and by appealing to followers' beliefs in the leader as a protector of those common values and ideals. He noted that leaders are very intuitive about what types of power resources are most effective in mobilizing various types of people under differing circumstances. Moreover, Kotter suggested that true leaders are aware of the obligations and risks involved in the exercise of power, yet understand it is necessary for enhancing organizational effectiveness and fulfilling the goals and aspirations of both leaders and led.

Given that organizations are characterized by a diverse distribution of power and a scarcity of resources, transformational leaders view them as highly-charged political environments wherein individuals struggle to reconcile differing views and bargain among themselves in order to advance their own agendas. While these leaders have tremendous vision and long-range perspectives, they also possess the ability to look beyond organizational ideas and insist upon a realistic appraisal of the political dynamics that affect the change process.

The perspective held by transformational leaders, then, is that change is always political and any vision of organizational transformation must take into account political realities. While leaders recognize that those who initiate change may camouflage their efforts in a variety of ethical and technical appearances, they also 
understand that the real intent of organizational members is to transform the organization so that it serves their own interests. Farrar, DeSantis and Cohen (1983) have set forth a most useful analogy for understanding the political dynamics of an institution. They have suggested that the political activity within an organization can be likened to a large lawn party. The party is a temporary convergence of guests (political actors from outside the organization and within the organization) that have

larger and more lasting concerns awaiting them at home. Moreover, these guests do not attend for the same reasons. Some have come for the food, some to hear the music, some to talk with friends, some from a sense of obligation; and some aren't sure why they've come. And they have different ideas about what they want the party to be and what they hope to gain by attending it. For some, the party is an escape from dull routine, for others a chance to cultivate business prospects, and many guests have never consciously identified their wants. Nor does each guest recognize what the other guests want. Each is relatively free to make the party whatever seems most appropriate. (p. 118)

The descriptive power of the analogy offered by Farrar et al. presents us with a very realistic portrayal of 
organizations by capturing the political dynamics of organizational life.

Morgan (1986) has suggested that members of any organization possess a complex set of predispositions that involve their goals, expectations, aspirations, values, and interests. When there is a divergence in predispositions among various individuals or groups, the emerging results is what Lortie (1975) and Weick (1976) have labeled a loosely coupled system. These researchers have suggested that subsystems within organizations do not always function in a highly coordinated fashion. As a result of this disjuncture, people are lodged in a competitive environment of power and politics.

Levinson (1981) clearly illustrated the antecedents that encourage political activities in and around organizations:

Leadership transcends and subsumes management. Leaders these days deal with conflicting forces within the organization. Organizations cannot readily adapt without internal conflicting forces, since these enable people to examine the multifaceted nature of problems and their possible solutions. Organizations without loyal opposition become stultified bureaucracies; without external opposition they are unable to realize their contributions to society as a whole. (p. 333) 
Levinson's description provides us with a basis for understanding the politics of leadership and thus the political processes that pervade organizations. One of the main functions of the transformational leader, then, is to ensure that these processes advance organizational goals (Tichy and Devanna, 1986) and engage followers in purposeful action. This is why Rost (1982) emphatically concluded that "leadership is in essence political, and that any model that leaves the politics out of leadership is invalid and unacceptable" (p. 20).

Sergiovanni (1984) affirmed that political dynamics are inherent in the process of leading. He explained that, in its simplest form, leadership is a mutual influence process wherein leaders and followers influence each other so as to accomplish the objectives both have. Recognizing that organizations are "characterized by multiple interest groups, unclear and competing goals, diffuse sources of power, and ambiguous lines of authority," Sergiovanni advocated that "sensitivity to politics and political behavior [are] key ingredients in successful leadership" (p. 109). Accordingly, Bennis (1984) held that organizations are taking a much more active role in shaping public opinion, influencing federal, state, and local legislative bodies, and mobilizing key constituencies. As a result, leaders must become politically sophisticated in dealing 
with influential actors inside and outside their institutions.

One of the methods by which leaders demonstrate their political sophistication is through the cultivation of stakeholding audiences. Kotter and Lawrence (1974) found that successful leaders may spend over a year taking the temperature and analyzing the positions of important stakeholders. These researchers pointed out that rallying key figures around new ideas and future directions is a significant part of the value shaping process. Recognizing that the environment in which corporations operate is constantly shifting and changing, siu (1980) shows how important it is for leaders to maintain positive, healthy relationships with various stakeholding groups and constituents. By staying actively involved with key stakeholders, leaders broaden their range of alternatives in the process of making strategic decisions.

Describing the sensitivity leaders have in dealing with constituents, Bennis and Nanus (1985) reported that Iacocca transformed the internal political structure at Chrysler when he took over as chief executive officer. They indicated that

One of Iacocca's first acts was to redefine Chrysler's links to various external stakeholders, not only to the Government, which has lobbied successfully to guarantee substantial loans, but to the UAW as well, 
by inviting UAW President Douglas Fraser to join the Chrysler Board. (p. 145)

This illustration is particularly important to our understanding of transformational leaders, not only because it shows the genius of Iacocca in wooing key stakeholders, but also because it reminds us of the political dynamics inherent in the transformation that took place at Chrysler. Another essential factor involved in the political dynamics of transformational leadership is the leader's ability to build and maintain coalitions. In a very thorough description of the politics of policy making, Allison (1971) explained that leaders skillfully use power resources and action channels to activate and mobilize players in various positions. Through their enlistment of key players, leaders build coalitions to further their goals and interests. Allison pointed out that in the shaping of policy, the actions taken by leaders are political in nature and the outcome of these actions must necessarily be seen as political resultants.

Baldridge (1983) contrasted the role of the autocrat who wields power with contemporary leaders who must adopt political roles. Suggesting that it is the leader's senior staff or closest advisors who make most of the strategic decisions, Baldridge argued that "expertise becomes more important than ever, and leadership increasingly amounts to the ability to assemble, persuade, and facilitate the 
activities of knowledgeable experts" (p. 58). In consort with Baldridge, Peters (1983) confirmed that leadership involves a shrewd blend of timing, strategic foresight, and the "political acumen necessary to build stable, workable coalitions" (p. 211).

In another work, Baldridge (1983b) indicated that leaders build viable political coalitions by enlisting support from external constituencies and using committees effectively. He noted that effective leaders cultivate external constituents because they understand that major decision makers are often tied to these outside groups and will respond to pressure from them. Additionally, Baldridge suggested that major decisions are made by committees of specialists in organizations; therefore, to know key members of a committee or to be a member of a powerful committee or board of directors is to have influence over critical decisions. Thus, transformational leaders jockey between external constituencies and important committees to build coalitions and establish courses of action that will facilitate desired changes.

An understanding of transformational leadership, then, is not complete without including the functions of power and politics. Paige (1977) suggested that "the concept of political leadership directs attention to the potentially creative behavior of salient persons in interaction with significant others of similar potential as they engage in 
initiatives of pervasive societal relevance" (p. 99). Paige, in concert with Burns (1978, 1984) and others (Allison, 1971; Cohen \& March, 1974; Edelman, 1964; Rost, 1982) would agree that transformational leadership necessarily encompasses the concepts of power and politics. However, power and politics must be viewed as positive forces used by leaders to establish contexts in which both leaders and followers can develop joint solutions.

It is also important to understand transformational leaders as individuals with broad sociopolitical perspectives (Levinson \& Rosenthal, 1984) who use their political savvy to reach out and activate particular groups. Burns (1978) suggested that,

Exceptional leadership may also make a difference in transforming dormant into active followers . . . into a new kind of political participation. Heroic, transcending, transforming leadership excites the previously bored and apathetic; it creates a political connection with the alienated; it reaches even to the wants and needs of the anomic and shapes their motivation. (p. 137)

From this perspective Drucker (1971) argued that politics is an honorable and creative endeavor, advocating that it is "at once a responsibility of man [and] the chief moral duty in human life" (p. 181). He exhorted leaders to realize the full opportunity that politics provides. 
The ultimate end of this political behavior, then, is to enhance the process of moral development and facilitate the actualization of human potential among leaders and followers.

Transformational leaders embrace politics as an "intensely personal and human enterprise" (McCoy, 1985, p. 137 ) and understand that no solution will be developed, no goal will be accomplished, and no purpose will be realized without the recognition of this fact. Ultimately, transformational leadership involves the process of politicking and the use of power resources to preserve the dignity and humanity of both leaders and led. In this sense, power and political relationships are not to be viewed as negative and dehumanizing, but rather as a means by which resources are mobilized to meet the mutual goals of leaders and followers, and move each to higher levels of motivation and morality.

\section{Generativity: The Development of Followers}

Has the leader a right to mold and shape? of what use is motivation, experience and wisdom if not to be instructive for those who are younger? Leaders not only have the right--they have the obligation. (Levinson, 1981, p. 153)

Transformational leadership embodies the notion of generativity (Erickson, 1963), or the development of future generations. This points to the processual nature of 
leadership in that transforming leaders engage in developmental relationships with followers to create a world that reflects progress and growth, a world that transcends the one in which leaders and followers now live. Leaders do this by appealing to the needs in followers to pursue a higher purpose and contribute to something larger than themselves (Collins, 1983).

Bennis and Nanus (1985) indicated that by showing followers how their work contributes to the overall mission of the enterprise, great leaders can move them to higher levels of motivation and morality. one of the most fundamental human needs we have is to become devoted to something bigger than ourselves that instills meaning and direction in our lives. Zaleznik (1983) added that when followers feel a sense of contribution to the well-being of society or a larger whole, they have fulfilled a mission in life and feel significant for making a difference. He pointed out that this sense of significance stems from the fundamental desire to identify with institutions that have social vision.

In their research on the excellent companies, Peters and Waterman (1982) found that one of the common characteristics in the leaders they studied is that they have a special knack for helping followers to find transcendent meaning in work. By cultivating a recognition of and responsibility for the larger social environment within 
which the organization functions, these leaders have profound effects on their followers (Kiefel and senge, 1984). They freely appeal to their followers' desires to respond to a higher organizational call. In his discussion of spirituality in erganizations, Mcknight (1984) pointed out that individuals desire to make a connection between work and a higher, more noble purpose in which the human spirit is inspired and the utilization of mind and soul is enhanced. "Increasingly, I find that business executives long for a work experience which reinforces their connectedness to a larger whole and which cultivates within them a set of aspirations which transcend narrow personal concerns ( $\mathrm{p} .149$ ).

Transforming leaders attempt to educate and mobilize followers in ways that accomplish a personal and social mission for all involved. They understand their followers want to accomplish purposes through which their work takes on meaning and significance, and fits holistically and harmoniously with other priorities such as family, health, and spirituality. They recognize that "having a clear sense of transcendent purpose--one that goes beyond oneself - . is a catalyst for our conduct. A life purpose gives meaning to our lives and allows us to take comfort when we are faced with misfortunes" (Mcknight, 1984, p. 143). Transformational leaders help followers integrate life and work by turning things into a cause (Naisbitt \& Aburdene, 
1985) - Moreover, by drawing followers into a social purpose, leaders contribute to shaping social structures that are more humane for future generations. Manning (1981) defined the moral "as that sphere embracing the obligations, responsibilities, and rights which correspond to the personal and social imperative of humanization" ( $p$. 5). Through the process of generativity then, transformational leaders create social systems that encourage the moral aspirations of followers and, in turn, raise the collective morality of society.

Chester Barnard (1938) understood the importance of integrating personal and organizational goals with a deeper purpose for living. The often-quoted Barnard was concerned with the dignity of the individual and establishing $a$ balance wherein individual development contributes to the general welfare of society. "He saw the purpose of individuals to be contributing to the society as a whole within a framework of individual freedom and responsibility" (Wolf, 1974, p. 49). Perhaps a brief glance at excerpts from some of Barnard's speeches will illustrate his thinking and help us to then understand the generative end toward which transformational leaders aspire.

In an unpublished commencement address titled "What Other Purpose?" given at the Polytechnic Institute of Brooklyn, June 17, 1936, Barnard articulated his ideas regarding the individual's ultimate purpose: 
One thing only would I distill from the thoughts of men concerning the act of life. This is that the use of all our facilities in proper balance . . . and the subordination of immediate self-interest to the larger purpose of aid to others is the road leading to the great accomplishment. This achievement involves perpetual struggle in the manifold nature of our being. There are many ends and purposes between which we must secure a harmony and balance. It is this perpetual conflict of the well-being that gives us our great duties and opportunities . . . to struggle upward toward the light of the ideal and the spirit-these as one harmonious whole should be the ends of our ambition. The never ending achievement of each day's work yet never attainable, the only course which promises enduring satisfaction. (cited in Wolf, 1974, p. 47)

Barnard's remarks exemplify, in part, the process of generativity and reveal the struggle in which leaders and followers engage to create a world that reflects progressively higher standards of human and moral development. Again, his philosophy that a person must be guided by a purpose that is beyond self is found in an unpublished speech made on June 14,1932 . Upon receiving the "Distinguished Service Medallion" for his work in the city of Newark, he told the Newark Exchange Club that, 
Though the power that popularity sometimes gives must not be depreciated because it must be applied usefully to the highest purposes, the abiding esteem, the high respect, the enduring influence that make for true progress can come, it seems to me, only from a personal service--a service which expresses a worthy ambition, which reveals an ability given by devotion to a high cause. (cited in Wolf, 1974, p. 48)

Inherent in the construct of generativity is the leader's ability to discern what it means to become human. This means that transformational leaders have an accurate understanding of the fundamental needs that lie within the heart of human existence. They look beyond organizational objectives to those things that will provide followers with opportunities for reaching the fullness of their humanity. Leaders enhance the humanness of followers by providing them with a purpose that transcends the mundane events of their everyday existence. Closely related to the concept of transcendent purpose is the notion of transcendent heroics advanced by Becker (1973). An understanding or leaders and followers as heroic beings may be an important contribution to this philosophy of generative leadership. By providing followers with an opportunity to be heroic, and in recognizing their own desires for heroism, transformational leaders can establish a framework wherein both leaders and led satisfy their needs for significance. 
James (1958) pointed out that "mankind's common instinct for reality . - has always held the world to be essentially a theatre for heroism" (p. 281). According to Becker (1973), nothing stretches further into human nature than the notion of the heroic. This is a vital truth that transformational leaders are quick to recognize. Becker held that narcissism (one of the principal concepts for understanding our urge to heroism) is our natural tendency to be absorbed with ourselves. In humans there is a natural level of narcissism that is inseparable from selfworth, and this sense of worth is something about which we need to feel secure. "When you combine natural narcissism with the basic need for self-esteem, you create a creature who has to feel himself an object of primary value: first in the universe, representing in himself all of life" (Becker, 1973, p. 3).

Sibling rivalry, according to Becker (1973), is a plight that is characterized by the fact that a child cannot allow himself or herself to be second best or devalued. Hence, sibling rivalry is a manifestation of the basic human condition; human beings must justify themselves as creatures of primary value who stand out heroically and make contributions to life that are bigger and better than anything or anyone else. Picking up on the theme advanced by James (1958), Becker suggested that society is a symbolic system of interrelated actions, customs, and 
ritual practices designed to serve as an instrument for earthly heroism,

Each culture has a different hero system: what the anthropologists call cultural relativity is thus really the relativity of hero systems the world over. But each cultural system is a dramatization of earthly heroics; each system cuts out roles for performances, of various degrees of heroism - . . It doesn't matter whether the cultural hero-system is frankly magical, religious, and primitive or secular, scientific, and civilized. It is still a mythical herosystem in which people serve in order to earn a feeling of primary value, of cosmic specialness, of ultimate usefulness to creation, of unshakable meaning. They earn this feeling by carving out a place in nature, by building an edifice that reflects human value. (Becker, 1973, p. 5)

Becker understood that we are impelled by a necessary dualism; we seek transcendence, we need at one in the same time to stand out heroically and yet be conforming members of society. Becker argued that we transcends death by finding meaning for our lives in the rituals and symbols that feed our cherished narcissism. In another work, Becker (1975) added that in his "burning desire to count. - what man really fears is not so much extinction, but extinction with insignificance" (p. 4). 
By drawing our attention to the dualistic nature of human beings, Becker makes a tremendous contribution to our understanding of leadership and the process of generativity. Whether they are intellectually cognizant of it or not, transformational leaders recognize that followers are suspended in the absolute tension of their own dualism. Based on this understanding, leaders seek to build a world where followers can meet their needs for stability and security without sacrificing their sense of significance, integrity, and individuality. Thus, transformational leaders endeavor to create a world where the plan for action is to authenticate human relationships and establish the kind of social systems that provide followers with opportunities to achieve heroic transcendence. As Burns (1978) pointed out, only the rarest kind of leadership will rise to accomplish such tasks. Perhaps this is because only the rarest kind of leadership will recognize that "the urge to heroism is natural, and to admit it, honest" (Becker, 1973, p. 4).

Rost (1984) has suggested that, "generativity is a synthesis of the successful resolution of the conflicts of previous life stages as well as the successful transition from one state to another" (p. 1). Generative leadership then, takes place when a leader synthesizes his or her successful development through previous life stages and seeks to impact the knowledge, experience, and maturity 
gained from this synthesis to future leaders. Generative leaders are individuals who have developed a true integration of self in which they are able to go beyond their own narcissistic nature and commit themselves to followers in caring relationships where they too will begin to develop personal integration. Thus, transformational leadership is dynamic and generative in that it often elevates followers to become actively involved as leaders themselves. This is done when leaders establish enduring, collaborative relationships with followers in which they are seen as enablers, coaches, educators, mentors and sponsors (Peters \& Austin, 1985).

According to Naisbitt and Aburdene (1985) leaders in re-invented corporations are committed to the personal growth of followers and see their growth as a prerequisite to the growth of the organization. They indicated that the new role of the leader is a "developer and cultivator of human potential" (p. 53). Citing the success of several leaders, these authors noted that leaders are coaches, team builders, and even servants who create nurturing environments where followers are supported, understood, and loved. They see the role of the leader as that of a teacher who paves the way for individuals to create, accomplish, grow and expand. In this sense, transformational leaders develop working relationships that enable followers to achieve higher levels of maturity where their potentials 
are maximized, their skills are developed, and they can increase the richness of their experiences (Ohmann, 1975). Zaleznik (1983) suggested that leaders help followers to grow and develop by establishing one-to-one relationships with them. They become mentors who intuitively bet on the commitment, talent, and creative capabilities of followers. Leaders as mentors take risks with followers by investing in them emotionally. The willingness to take such risks is imperative in developing future leaders. Miller (1984) gave an account of the way top executives. described those mentors who had the greatest influence on their own development as leaders. These role models were characterized as individuals who took the time to develop their followers because they were genuinely interested in them. These individuals were dedicated to their work and devoted to their people, they were trustworthy and demonstrated a tremendous ability to educate by example.

In their examination of six executive officers, Levinson and Rosenthal (1984) explained that each of the leaders under investigation were intimately involved in the process of generativity. These leaders were "talent scouts and people-growers [who] loved to mentor and to develop others" (p. 288). They were constantly developing their people and facilitating a commitment and devotion from their people to themselves and their organizations. 
A central issue for all of these leaders, and one inadequately discussed in the literature of leadership, was their involvement in succession. All of our leaders were intimately involved in the long-range planning for succession. They spent a great deal of time on selection, screening, development, and succession, and they were particularly preoccupied with it at those levels closest to them . . . Five out of six saw themselves as teachers of younger managers. Teaching seemed to be an important personal function for them. (p. 277)

Through their roles as teachers, mentors, and nurturers, leaders engage followers in the kind of relationships that advance moral development and, in turn, facilitate the process of generativity. Kohlberg and Kramer (1969) posited that individuals progress through six stages of moral evolution in which maturation ultimately results in the enhancement of their humanity. The final stage of evolution is characterized by an adoption of values and beliefs that serve as authentic expressions of the self. At this stage, an individual develops a sense of oneness with other people and relates to them as persons with dignity and worth. This description of Kohlberg and Kramer's sixth stage is characteristic of the relationships transformational leaders develop with followers. In the nurturing process, leaders and followers are moved to 
higher levels of personal integration where each attains a synthesis of life as previously defined by Rost (1984). This synthesis dramatically affects the relationships that leaders have with followers; it enables leaders and led to relate to each other on a higher moral plane where both enhance their dignity and humanness. These relationships have been best described by Buber $(1937 / 1970)$ in his classic work $I$ and Thou.

Buber (1937/1970) argued that all encounters could be classified as I-it relationships or I-thou relationships. In I-it relationships individuals are objectified, they become nothing more than things, objects, or "its" that we label and categorize. Buber contrasted I-it relationships with "I-thou" relationships where one person relates to another as a "sacred thou." An I-thou relationship exists when "I" enter into an empathic relationship with "thou" that is not ordinary or mundane. Such relationships are characterized by a sense of oneness in which leaders and followers experience the joys of full humanness because of their reverence for one another. It is in the I-thou encounter that alienation is abolished and humanness is enhanced. Thus, it is also in the I-thou encounter that the process of moral development can be facilitated.

Although she does not refer to Buber's work, Gilligan (1982) has advocated a framework for moral aevelopment that appears to sustain I-thou relationships. Criticizing 
previous models of moral development (Kohlberg and Kramer, 1969; Levinson, 1978; Vaillant, 1977) for having a male bias and subordinating intimate, caring relationships, Gilligan argued that these models fail to describe the progression of relationships toward a maturity of interdependence. She suggested that we live in a male-oriented society that rewards separation and independence and hinders the development of oneness or interdependence in relationships. Calling for a model of moral development that embodies the fusion of identity, intimacy, nurturance, responsibility, and care, Gilligan posited that "Women replace the bias of men towards separation with a representation of the interdependence of self and other, both in love and work" (p. 170). Gilligan's description sounds very much like Buber's I-thou relationship. Buber explained that

The basic word I-thou can be spoken only with one's whole being. The concentration and fusion into a whole being can never be accomplished by me, can never be accomplished without me. I require a thou to become; becoming I, I say thou. All actual life is encounter. (p. 62)

Gilligan and Buber have both pointed out that the emergence of relationships charactexized by emotional oneness creates and sustains one's humanity and, thus, enhances the process of moral development. According to 
Gilligan, "The experience of relationship brings an end to isolation, which otherwise hardens into indifference, an absence of active concern for others, though perhaps a willingness to respect their rights... . Relationships of care - . depict ongoing attachments as the path that leads to maturity" (pp. 163, 170).

The relationships that leaders develop with followers exemplify Buber's (1937/1970) notion of the I-thou encounter. As nurturers and developers of human potential, transformational leaders foster an emotional oneness with followers in which they are treated as sacred thous with feelings, goals, and motives that need to be harnessed. Moreover, leaders understand that intimacy and interdependence (Giliigan, 1982) are inherent in the development of I-thou relationships. Hence, transformational leadership embraces Gilligan's concept of interdependence and Buber's treatment of I-thou relationships as essential to the process of moral development.

In cultivating I-thou relationships with followers, leaders understand that it is nearly impossible to develop a synthesis of life and personal integration (Rost, 1984) without developing the whole person. As teachers and mentors, they relate to followers as whole persons, as individuals with dignity that bring every aspect of their personhood into the organization (Barnard, 1938). Thus, in the mentoring process, transformational leaders do not 
differentiate an individual from his or her organizationally prescribed role.

Bartholome (1983) pointed out the shallowness of identifying people according to the roles they play. He recognized the very thing that Buber described, that in relating to the executive and not the man, we create an Iit relationship in which we depersonalize the individual. According to Bartholome (1983),

This false dichotomy, executive/man, is the basis for many mistakes. When we do not directly address the man we fail; and everything that we provide the executive so he can manage better is a gimmick and will not last. (p. 55)

Transformational leadership embodies the notion of generativity in that leaders transform followers and the world around them by facilitating the process of moral development. Leaders transform the hopes of followers into expectations (Burns, 1978) by drawing them into purposes that provide meaning and direction, purposes that transcend their immediate needs and have enduring value. By building a society in which opportunities for heroic deeds will be established, transformational leaders not only inspire the pursuit of heroism, they also seek to satisfy the eternal quests for significance that emanate from followers caught in the tension of their own dualistic natures. Finally, transformational leaders engage in teaching and mentoring 
relationships that enhance the dignity and humanity of followers, and transform followers into future leaders. Generativity, then, involves the leader's awareness of and sensitivity to the potential impact he or she has on the development of future generations.

\section{Symbolic Leadership}

The preceding section of this literature review outlined the nature of transformational leadership. It was pointed out that real, intended transformation is brought about in an environment of competition and conflict when leaders meet the mutual goals of both leader and led, clearly articulate their visions and draw followers into a common purpose (alignment), shape values and educate by example, use power and politics to achieve the purposes of both leaders and followers, and develop followers through the process of generativity. Peters (1978) indicated that the symbolic behaviors of leaders impact more often on such transformations than do formally constructed change tools.

It is reasonable to propose . . that an effective set of change tools is actually embedded in senior management's daily message sending and receiving activities, and that these tools can be managed in such a way as to energize and redirect massive lumbering business and government institutions. The tools will be characterized as symbols (the raw material), patterns (the systematic use of raw 
material), and settings (the showcase for the systematic use. (pp.1 3-4)

Leaders must understand the symbolic importance of their actions. They must recognize that their daily actions and activities communicate what involvement is important to them and what they want other members of the organization to value.

Ginzberg and Reilley (1957) pointed out that followers are constantly in tune with the daily actions of leaders. While followers pay particular attention to what leaders say, they are much more influenced by what they do. Accordingly, Schein (1985) explained that leaders send powerful messages to followers simply by what they consistently pay attention to. This is because followers understand that leaders focus on and pay attention to those things they care about most. Thus, Peters (1983) affirmed that "top management is at the apex of the symbolic signaling system" (p. 211). Effective leaders view their daily activities as symbolic opportunities to guide and direct followers. Moreover, because they understand that followers will interpret and attach meaning to their every action, leaders try very hard to maintain a high level of consistency in their behaviors.

March (1984) reasoned that the interpretations we make and the meanings we give to the situations and circumstances around us affect the way we live. When our 
deeply-rooted beliefs and assumptions change, our lives are transformed. (Schein, 1985) argued that leadership is essentially affecting change by symbolically influencing the beliefs and assumptions that surround organizational Iife. Bennis (1984) added that "the extent to which leadership is truly effective is based on the extent to which individuals place symbolic value on the intentions. - [of leaders]" (p. 70). Transformational leaders affect change by what Burns (1978) has called "the symbolic solution of internal and external conflict." That is, transformational leaders identify the cognitions and themes that are important to followers so as to interact with them symbolically in ways that will significantly transform their established assumptions and beliefs (Eoyang, 1983, p. 244).

Transformational leadership may serve to reconcile psychological contrr ictions between various cognitions and experiens by providing a coherent symbolic context which incorporates the disparate elements into a meaningful and consistent gestalt. Thus, transforming leadership may provide an external symbolic framework which permits the psychological resolution of confused or ill understood cognitions and experiences. ( $p .115)$

Eoyang's point is significant to our understanding of how leaders affect transformational change. If, as he has 
argued, symbols remain consistent and compatible with established beliefs, values, and deeply-rooted assumptions, then leaders change these things through the process of symbolic interaction with followers. For example, new symbols "may affect the value and importance attributed to established beliefs by introducing new ideas which take on comparable if not superior importance relative to previous notions" (Eoyang, 1983, p. 118). Thus, transformational leaders change institutions and bring followers to higher levels of moral aspiration by embedding within their organizations a new set of symbols. Eoyang calls these "transformational symbols" because they have the power to transform the established belief system held by others.

Burns (1978) explained that "the most lasting and pervasive leadership of all is intangible and noninstitutional" (p. 454), suggesting that, in part, leadership is a symbolic process emanating from the ideas embraced in social movements. In this sense, symbols must be understood as the primary tools by which leaders affect change and symbolic expression must be viewed as in inherent part of transformational leadership. Hence, an investigation of how symbolic leadership is put into practice would necessarily examine the symbols used by leaders in the process of organizational transformation. 
Organizational symbolism

Foster (1985) stated, "the search for meaning is a fundamental reality in our lives, including our organizational lives" (p. 3). Organizational reality is not something beyond human consciousness waiting to be discovered introspectively; rather it is continually being recreated intersubjectively. The expression of this creation is manifested in the process of symbolic interaction. Thus, the transformation of organizational reality is a result of revising the symbolic structures we use to describe that reality. As organizational actors we create and use paradigms through which our experiences acquire significance (Brown, 1978), we design and construct symbols in our efforts to concretize and give meaning to the very nature of organizational life. By changing the symbol or the paradigm we use to talk about those experiences, we are altering the descriptive elements of them. Hence, in changing the descriptive elements of our experiences we are, in essence, transforming organizational reality.

At this point it is crucial to understand what is meant when using the term organization. Organization in this sense refers to "the system of relations that draw the parts of an entity into a whole that is conceptually much more than the mere aggregation of its parts" (Smith, 1982, p. 334). If there were no system of relations to bring the parts together as a whole, there would be no organization, 
just disconnected parts. This definition emphasizes the notion of relationships, relations among parts and relations among relations. Smith argued that these relations do not exist in any verifiable form.

If we view the essence of the organizing phenomenon to be relationships, we immediately encounter an epistemological problem, for we cannot actually see relationships; we can only infer them. When we look at the behaviors of two parts, such as two people interrelating, the interactors' behaviors are visible; the interactions themselves are not. Just as the trees express the existence of the invisible wind, so the behaviors of the parts carry in their actions the invisible relationships between them. (pp. 327-328)

Smith's concept of organization is significant because it emphasizes the importance of symbolic expression. If the concept of organization, like the notion of love, is not a physically verifiable concept, then the only way we can begin to understand it is by talking about it metaphorically. How we think and talk about relations among parts and relations among relations will be determined by the characteristics of the metaphors we use and by the relationships among those metaphors. This is why transformational leadership is inherently symbolic; it involves the use of language to help followers identify and describe these intangible relationships and come to a 
common understanding of what the organization is all about. From this perspective, metaphors, specialized language, and other forms of symbolic expression (Pondy, 1978; Smircish \& Morgan, 1982) become the means by which leaders and followers objectify their intersubjective realities. Organization and language are significantly entwined and we cannot think of one ass separate from the other. "Because all behavior is language, how we talk (behave) shapes our relations (organizing), and our relating (organizing) is our language (behavior)" (Smith, 1982, p. 328).

Dandridge, Mitroff, and Joyce (1980) described organizational symbolism as those "aspects of an organization that its members use to reveal or make comprehendible the unconscious feelings, images, and values, inherent in the organization" (p. 77). Cohen (1976) choose to use the term symbol as opposed to the word culture in describing organizations. He argued that culture is a cognition that exists in the minds of people and that the only way we can understand that cognition is through the symbols that represent it. "Symbols are objects, acts, concepts, or linguistic formations that stand ambiguously for a multiplicity of disparate meanings" (p. 23). Cohen's view of organizational symbolism is very similar to that of Dandridge et al (1981) and Smircich (1985), all of whom believe that organizational symbols are what enable 
individuals to observe and verify subjectively constituted worlds.

Organizational symbolism, then, enables leaders and followers to open up aspects of organizational reality that are otherwise closed for them. That is, through the use of symbols, leaders and followers are able to encounter a level of organizational reality that could not be reached in any other way. This level has been labeled by Deetz and Kersten (1983) as the deep structure of organizational reality and represents the unexamined values, beliefs, and assumptions that govern manifest action. Geertz (1973) maintained that symbols function to express or represent dimensions or reality that would otherwise be unconscionable. Geertz defined a symbol as "any object, act, event, quality, or relation which serves as a vehicle for conception--the conception is the symbol's meaning" ( $p$. 62). The perspective offered by Geertz and others (Cohen, 1976; Dandridge et a1., 1980; Smircich, 1985) suggests that organizations are symbolic forms in which reality is a symbolic construction. Thus, recognizing that organizations are symbolic constructions of reality, transformational leaders are particularly aware of the symbolic implications of their actions and how those actions contribute to the construction of organizational reality. While the topic of symbolism has pervaded a number of academic disciplines concerned with human behavior such as 
anthropology, arts, linguistics, political science, psychology, and sociology, (Barthes, 1964; Blumer, 1969; Duncan, 1953; Edelman, 1967; Goffman, 1959; Jung, 1964; Langer, 1957; Meltzer, Petras, \& Reynolds, 1975; Serber, 1975), it is the field of organizational communication that has recently provided researchers with rich sources of data for developing the area of organizational symbolism (Bormann, 1983; Burke, 1972; Conrad, 1983; Pacanowsky, 1983; Pacanowsky \& O'Donnell-Trujillo, 1982; Pacanowsky \& O'Donnell-Trujillo, 1983; Putnam, 1982; Redding, 1979; Smircich, 1983b; Tompkins \& Cheney, 1983; Tompkins \& Cheney, 1985; Trujillo, 1983). These works outline the major concepts embodied within the concept of organizational symbolism.

Bormann (1983) indicated that when organizational members agree on a subjective meaning or come to share a common consciousness, the result is symbolic convergence. People make implementations about the signs and objects around them, they attempt to assign symbolic meaning through rituals, myths, metaphors, and stories to the events and behaviors of others in their environment. Thus, symbolic convergence refers to the way people make sense out of their common experiences and develop a shared understanding about the nature of organizational reality. "The power of symbolic convergence theory to explain the way organizational members make sense of their social and 
material realities stems from the human tendency to want to understand events in terms of people enacting purposive scenarios" (Borman, 1983, p. 104)

Symbolic convergence theory resembles, although differs in form, from what Burke (1969), and later, Tompkins and Cheney (1983), labeled as identification. In his explanation of identification, Burke reasoned that "A is not identical with his colleague, B. But insofar as their interests are joined, $A$ is identified with $B "$ ( $p$. 20). In another work, Burke (1967) held that "identification at its simplest is also a deliberate device, as when the politician seeks to identify himself with his audience - . but identification can also be an end, as when people earnestly yearn to identify themselves with some group [e.g. organization]" (p. 63). The relationship between symbolic convergence and identification can be seen, in part by the way that people engage in the process of identification when their symbolic worlds overlap (Cheney, 1983). If through symbolic convergence, followers come to a common consciousness or shared understanding with a leader about the nature of organizational reality, they are, in essence, identifying with his or her symbolic interpretation of the objects, events, and behaviors that constitute the organization. From this perspective, then, transformational leaders encourage followers to identify 
with the organization and its mission through the process of symbolic convergence.

Goffman's (1959) dramaturgical analysis is also a basis for the study of organizational symbolism. The dramaturgical perspective suggests that the actions of leaders and followers should be seen as performances that involve the use of symbols to dramatize the ritual and routine of organizational life. Smircich (1985) recognized that "symbolic forms and symbolic action are essentially dramatic. They involve the totality of the person including cognitions, feelings, and sensations" (p. 68). The notion of performance as popularized by Goffman implies theatricality and play acting. Goffman's perspective would encourage us to look at organizations as social theatres, stages upon which dramas are enacted (Baldridge \& Deal, 1983) by organizational actors playing a variety of different roles.

Pacanowsky and O'Donnell-Trujillo (1983) pointed out that efforts to affect change within an organization could be seen as carefully scripted performances. Organizational performances can vary for the same actor or actress as he or she plays in different scenes to different audiences. Goffman (1959) distinguished between "on-stage" performances and "back stage" performances indicating that performances are intentionally symbolic. Illustrating Goffman's theme, Pacanowsky and O'Donnell-Trujillo (1983) 
noted that "the boss and the secretary may treat the auditor politely but differently while even the boss's performance of 'politeness' will vary depending on who the performance is for--his boss, the auditor, or the secretary" (p. 130)

Proponents of the dramaturgical perspective (Baldridge \& Deal, 1983; Dandridge, Mitroff, \& Joyce, 1980; Pettigrew, 1979; Smircich, 1985; Turner, 1980) have concluded that organizational reality is not analogous to a drama but rather is a drama. They maintain that dramatic performances are those symbolic expressions through which the drama of life is enacted. In this sense, organizational members can be seen as actors involved in the social construction of reality through the symbols they create and use (Burke, 1972).

Dramaturgically, then, organizations should be seen not as preexisting instrumental entities (Brown, 1978) but rather as processes of organizing enacted (performed) by organizational members. When actors become involved in the processes of organizing, they are, in essence, metaphorically creating their own reality through carefully scripted performances. With this in mind, the process of organizational transformation can be seen as a "social construction [of reality] continualiy reconstructed" (Pacanowsky \& O'Donnell-Trujillo, 1983, p. 128) by the symbolic language transformational leaders use. 
The dramaturgical perspective shows us that organizational transformation is a function of the performances of both leaders and followers. The fact that these performances are intentionally symbolic suggests that they are purposefully enacted through the metaphors, myths, rituals and ceremony, and stories created by the actors. As the fundamental concepts underlying the notion of organizational symbolism, these constructs will serve as the categorical basis upon which the final section of this literature review will be organized.

Metaphors. Metaphors play a critical role in the production, understanding, and transformation of human thought and action (Smith \& Eisenberg, 1985). Metaphors influence the ways in which we interpret our world (Lakoff and Johnson, 1980), create knowledge (Kuhn, 1970), learn (Ortony, 1979), and behave as social actors (Berg, 1985; Deetz \& Mumby, 1984; Koch \& Deetz, 1981; Weick, 1979). Moreover, metaphors should not be seen as value-free representations of reality, but rather as symbolic concepts in which particular ideologies and world-views are manifested (Eoyang, 1983; Deetz \& Mumby, 1984).

organizational researchers have focused on the symbolic impact of the metaphor, suggesting that metaphors play a critical role in helping organizational members reduce uncertainty by assigning meaning to particular events (Brown, 1984; Eisenberg, 1984; Pondy, 1983; Smith, 
1985; Smith \& Simmons, 1983). Increasing attention has been devoted to how metaphors are used by leaders in the construction of organizational realities (Pacanowsky \& O'Donnell-Trujillo, 1983). Krefting and Frost (1985) argued that metaphors enable us to express ourselves in those areas for which we have no specific language. Metaphors provide organizational members with a wide array of alternatives for "accessing meaning." Bates (1984) pointed out that metaphors help us to explore and interpret our experiences and create meaning out of our actions. Organizational members "use metaphors continually to represent relationships and to define the power structures which organize behavior" (Bates, 1984, p. 265). Peters and Waterman (1982) demonstrated the utility of metaphors in giving meaning to organizational experience. Smircich (1983b) showed how metaphorical language allowed leaders to explain unknown organizational characteristics in an insurance company and Eisenberg (1984) viewed the metaphor as one mechanism leaders use in facilitating change.

The metaphor is a powerful means by which a synergistic effect is created in the expression of an intended meaning. Bednar and Hineline (1982) indicated that "what is communicated through metaphor goes beyond mere observational reporting and acquires an intangible quality that reveals more of the intended meaning than literal translation can convey" (p. 6). According to Brown (1976), such 
"meaningfulness" is manifested in the "suggestive power and connotative richness of the metaphor" (p. 181). Thus, metaphors help individuals characterize, label, and make sense of their organizations by figuratively capturing meaning.

Myths. In every organization, myths exist to make sense of the environment. Bolman and Deal (1984) pointed out that myths function to "explain, express, maintain solidarity and cohesion, legitimize, communicate unconscious wishes and conflicts, mediate contradictions, and provide narrative to anchor the present in the past" ( $p$. 153). Myths are the stories that identify and describe the social fabric of an organization, according to owen (1984). Whether the stories are true or not is irrelevant; however what is significant is that they reflect the organization's past and present and project its future. Myths emerge out of the historical events of the institution and function to express its central values (Durkheim, 1961).

Mitroff and Kilmann (1975) pointed out that corporate traditions are established and perpetuated through myths. This is similar to Conrad's (1981) view that myths are the channels through which individuals express their collective thoughts. Schorer (1960) and Carbaugh (1985) maintained that myths are symbolic tools, instruments by which we simplify the complex, struggle to make our actions and experiences intelligible, and ultimately make sense out of 
Iife. Thus, myths act as the conduit through which the attitudes, values, beliefs, and expectations of the organization are expressed (Dewine \& Wagner, 1981). They are the focal point for the symbolic activity of an organization (Conrad, 1981) and the means by which an organization presents its public face (Brown, MaMillan, \& Blackman, 1981). As such, myths serve as a primary method used by leaders to foster commitment to the perception of a unique organizational character (Smircich, 1981) and the legitimacy of its purpose and mission (Pettigrew, 1979).

Rituals and Ceremony. Owen (1984) suggested that myths are acted out through rituals. "Ritual is nothing more nor less than the dramatic reenactment of the myths. It is the re-presentation of the myth in present time" ( $p$. 219). Rituals are those commonplace activities that have been elevated to higher levels of significance because they possess special meaning for the organization. In their justification, explanation, and illustration of myths, rituals enhance our understanding of the belief structures of an institution. They regulate organizational activity surrounding the organization's central purpose (Carbaugh, 1985). From this perspective, rituals can function to reduce uncertainty and anxiety among organizational members and "convey messages to external constituencies" (Bowman \& Deal, 1984; p. 159). 
Trice and Beyer (1984) defined rituals and ceremonials as "deliberately planned, carefully managed, often rehearsed social dramas with well-defined roles for people to perform" (p. 655). Rituals and ceremony also play a significant role in organizational symbolism. Rituals have a cementing influence on the organization in that they unify individuals. "The consolidation and interdependence of cultural forms is particularly evident in rites and ceremonials" (p. 654). Rituals exist to preserve and maintain ongoing social life and elicit consensus over organizational values and ideologies. Owen (1984) pointed out that this is clearly exemplified in the Catholic celebration of the Mass. The Lord's supper has been elevated in the Mass to a ritual that allows Catholics to participate in the life, death and resurrection of Christ. Through the rituals and ceremony of the Mass, the Catholic Church has preserved and perpetuated its values and ideologies. Hence, while it has not been immune from forces seeking to divide it, the Catholic Church has remained a unified institutior. throughout the centuries.

Finally, Deal and Kennedy (1982) defined rites and rituals as "the systematic and programmed routines of dayto-day life" in an organization. Showing the important role these symbolic elements play in the creation and maintenance of organizational cultures, these writers maintained that in their mundane manifestations--which we 
call rituals--they show employees the kind of behavior that is expected of them. In their extravaganzas--which we call ceremonies--they provide visible and potent examples of what the company stands for. (p. 15)

Stories. While anthropologists have recognized the importance and utility of stories in understanding human behavior for years (Georges, 1969), organizational researchers are just recently beginning to understand the value in looking at stories. Mitroff and Kilmann (1975) argued that "if accounting and finance are the backbone of organizations, then the stories which permeate all organizations of any size are their lifeblood" (p. 18). Martin (1982) suggested that stories are a memorable and credible way for organizational members to learn about the values and beliefs of a particular organization. Like myths and rituals, stories serve to unify organizational members because they embody an image of the organization's mission and purpose (Clark, 1970) and show how the leader's vision is translated into reality.

closely related to the dramaturgical perspective is Wilkins' (1978) view that stories are scripts that guide and direct the performances of organizational members. That is, stories are often historic accounts of the organization's way of doing things told in a heroic fashion. 
Organizational stories that have become scripts provide the same kind of cognitive "satisficing" device that a standard operation procedures does. - - The decision maker has only to place an incoming problem into the framework of a wellknown story about how such a problem was handled to decide what should be done. (Wilkins, 1983, p. 84)

By symbolizing abstract values and deeply-held assumptions, stories serve to implicitly control and instruct actors in their organizational performances (Perron, 1979). Thus, transformational leaders communicate their vision of the organization's overriding purpose, its values and beliefs, in the stories that they tell and the stories that are told about them. When these values and beliefs are housed in a story that appeals to a wide range of followers and becomes socially integrated into the organization, it energizes people and draws them together in a unified effort to achieve the leader's vision. McCoy (1985) affirmed that a vivid, compelling story will attract people and involve them in what it symbolizes. Well-told stories are remembered by organizational members and passed along to others. As a result, they generate belief and encourage commitment to a "particular perspective," an approach to problem solving, implied causal relationships and deep-seated values" (Wilkins, 1983; p. 90). 
Pacanowky and O'Donnell-Trujillo (1982) maintained that stories are used to "substantiate organizational knowledge or pass on the unrecorded traditions or customs of organizational life" (p. 126). Organizational members share their experiences through the stories they tell. This seems to be consistent with Brown's (1984) treatment of stories. "Stories appear to have the power to take an incident, frame and freeze it, and transmit the incident to organizational members in a memorable, recognizable package with implications for the present, past, and future life within that organization" (p. 14).

Schein (1985) explained that while stories institutionalize a leader's behavior, he or she may not always be in control of those stories and what is communicated through them. Therefore, effective leaders are particularly adept at reinforcing existing stories and creating and promoting new stories that symbolize their values and beliefs. Stories, then, are yet another means by which transformational leaders perpetuate their values, vision, and organizational philosophy throughout the institutions they serve. Through the perpetuation of vivid, descriptive, and detailed stories, leaders also help followers establish logical frameworks in which their performances may be organized (Faules, 1982). 
Synthesis and Integration of Research

Transformational leadership as advocated by Burns (1978) is a broad, overreaching and highly philosophical construct; yet, as the literature suggests, it is not without practical value. It is philosophical in that it seeks to enhance the humanness of followers by raising them to higher levels of motivation and morality. Leadership is practical in that leaders affect significant institutional change by addressing the real wants and needs of followers. The literature also shows that transformational leadership transcends individual disciplines. Illustrating this point, Burns (1984) recognized that "the problem is that no field of study calls for a more difficult and daring crossing of disciplinary borders than does the study of leadership, and no field suffers more from narrow specialization" (p. 6). Thus, by its eclectic and multidisciplinary nature the construct of transformational leadership embodies anthropology, communication, linguistics, organizational development, organizational theory, philosophy, political science, psychology, sociology, and theology. Collectively, these fields provide us with an unadulterated approach to the study of leaders, and they present us with an enormous variety of perspectives from which to understand leadership. Also, by focusing on the similarities and differences in leaders across disciplines, this multidisciplinary approach 
accounts for the vastness and complexity of leadership. Thus, inherent within transformational leadership is a universal quality that not only confirms the theoretical validity of the construct, but also lays the praxilogical foundations for transformation in the real world.

This literature review outlines some of the major concepts encompassed within the construct of transformational leadership. The literature shows that leadership exists in a context of competition and conflict (Allison, 1984; Burns, 1978; Kiefel and Senge, 1984).

The most basic understanding of leadership is that of a relationship between leader and follower; that is, leadership cannot exist in isolation from followers (Brown 1978, 1984). Bennis \& Nanus, 1985; Buckley \& Perkins, 1984; Harrison, 1984; Levinson \& Rosenthal, 1984; Miller, 1984; Prentice, 1983; Zaleznik, 1983; and others) have all pointed out that transformational leadership involves the mutual goal attainment of both leaders and followers. Leaders seek to address the needs of followers by integrating their goals with the goals of the organization or vice versa. Consequently, leaders and followers are bound together in a shared commitment to each other.

The literature clearly indicates that leaders energize followers by articulating a vision that provides them with excitement and enthusiasm for the present (Ackoff, 1981; Bennis \& Nanus, 1985; Burns, 1978, Deal \& Kennedy, 1982; 
Tichy \& Devanna, 1986). Organizations in which leaders communicate a compelling vision have been characterized as metanoic by Keifer and Senge (1984). Metanoic organizations are described as having a high degree of alignment (Harrison, 1984; Naisbitt \& Aburdene, 1985) while followers take ownership in the leader's vision and share the responsibility for realizing it. Thus, vision and alignment draw organizational members together in an integrated whole that functions as a highly cohesive team.

As we have seen, transformational leaders are intensely committed to bringing followers to higher levels of consciousness regarding their own values. They recognize that values guide and direct the actions of followers and are therefore the underlying principles upon which organizations operate (Burns, 1978, Deal \& Kennedy, 1982; Foster, 1985; Greenfield, 1984; Henderson, 1979; McCoy, 1985; Peters \& Waterman, 1982; Schein, 1985; Selznick, 1957). Leaders are necessarily value shapers who instill within followers a set of values by exemplifying them in their daily actions (Peters, 1983). Leaders educate by example, they communicate values by what they do, what they pay attention to (Peters \& Austin, 1985), whom they recruit, reward, and punish, and whom they treat preferentially (schein, 1985). Because it is practically impossible for them to influence everyone in the organization directly, they are very consistent role models who 
educate followers through vivid, living, personal example (Collins, 1983; Peters, 1983).

Given that transformational leadership exists in an environment of competition and conflict over scarce resources, effective leaders possess a high degree of political sophistication. They are particularly astute at using power resources to mobilize followers in a particular direction or purpose (Burns, 1978; Bolman \& Deal, 1984; Kotter, 1983; McClelland, 1975; McClelland \& Burnham 1983). Leadership, then, involves the legitimate acquisition and ethical use of power resources (Zaleznik, 1983). In mobilizing scarce resources, leaders cultivate stakeholding audiences (Kotter \& Lawrence, 1974), shape public opinion (Bennis, 1984), build and maintain coalitions (Peters, 1983), and activate strategic action channels (Allison, 1971). These activities suggest that political dynanics are an inherent part of transformational leadership (Cohen \& March, 1974; Farrar, DeSanctis \& Cohen, 1983; Levinson, 1981; Paige, 1977; Rost, 1982; Sergiovanni, 1984).

Transformational leaders are deeply committed to the development and care of future generations (Levinson, 1981). In providing followers with a sense of transcendent purpose (Barnard, 1938; Mcknight, 1984; Sheey, 1981), leaders satisfy their desires for heroism (Becker, 1973, 1975) and help them rise to higher levels of moral development (Burns, 1978; Gilligan, 1982; Levinson, 1978; Manning, 
1981). Through the process of generativity (Erikson, 1963; Kohlberg, 1969) leaders establish collaborative, empathic relationships (Buber, 1937/1970) with followers where each develops a true integration of self from the synthesis of provious life stages (Rost, 1984). Finally, generative leaders are seen as teachers, mentors, sponsors (Peters \& Austin, 1985), talent scouts, and people-growers (Levinson \& Rosenthal, 1984) who are committed to the development of future leaders and the establishment of a world that transcends the one in which they now live.

The review of literature also shows that organizational transformation is affected by the symbolic behaviors of leaders (Bormann, 1983; Brown, 1978, Eoyang, 1983; Foster, 1985; March, 1984; Peters, 1978; Pondy, Frost, Morgan \& Dandridge, 1983). Organizations are symbolic constructions of reality (Baldridge \& Deal, 1983; Pacanowsky \& O'Donnell-Trujillo, 1982; Putnam, 1982; Smircich, 1983a; Smith, 1982) created out of the intersubjective experiences of organizational members. Transformational leaders are seen as organizational actors (Goffman, 1959; Pacanowsky \& O'Donnell-Trujillo, 1983) involved in carefully scripted performances designed to help followers identify with the mission, purpose, and values of the organization (Burke, 1969; Cheney, 1983; Tompkins \& Cheney, 1983). As organizational actors, leaders use metaphors (Contar, 1983; Eisenberg, 1984; Koch 
\& Deetz, 1981; Krefting \& Frost, 1985; Pondy, 1983; Smircich, 1983b), myths (Bolman \& Deal, 1984; Carabaugh, 1985; Mitroff \& Kilmann, 1975; Pettigrew, 1979), rituals and ceremony (Deal \& Kennedy, 1982; Owen, 1984; Trice \& Beyer, 1984), and stories (Brown, 1984; Clark, 1979; McCoy, 1985; Perrow, 1979; Schein, 1985; Wilkins, 1983) to reinforce or change and modify the established assumptions and beliefs of followers. This is to say that transformational leaders embrace symbolism as a primary means by which leaders and followers affect organizational transformation.

While Burns' (1978) Pulitzer Prize-winning volume on transformational leadership was published almost ten years ago, it has only been in the last five years that we have seen a proliferation of other works on this theme. Burns indicated then that "the fundamental crises underlying the mediocrity [of leadership] is intellectual. If we know all too much about our leaders, we know far too little about leadership" (p. 1). Burns' treatise has been the catalyst for a new intellectual movement that is challenging the way we think about leadership. On the cutting edge of this movement are a number of contemporary scholars (Adams, 1984; Bennis \& Nanus, 1985; Bolman \& Deal, 1984; Burns, 1984; Levinson \& Rosenthal, 1984; Naisbitt \& Aburdene, 1985; Peters \& Waterman, 1982; Schein, 1985; Tichy \& Devanna, 1986) who are beginning to develop a "new 
consensus" about the nature and practice of leadership (Rost, 1985) . To suggest that these scholars have made significant contributions to our understanding of leadership is, perhaps, understating the case, for the impact of their contributions has radically changed the nature of our understanding of leadership and its practice inside many of our most successful national and international corporations.

Missing from the literature on leadership are in-depth studies of how leaders specifically bring about organizational transformation. What is needed are actual case studies that illustrate and describe how the theoretical concepts offered by general leadership theorists are being operationalized. Qualitative case studies that rigorously examine specific leaders in particular contexts from various industries will, in part, address Burns' request for more broad-based research and advance the field of leadership. To that end, the purpose of this investigation is to build upon an already growing body of literature by examining the theory of transformational leadership in practice. 
CHAPTER III

RESEARCH DESIGN AND METHODOLOGY

The purpose of this study is to determine the degree to which a chief executive officer in charge of a major American corporation exemplifies transformational leadership and how he puts this particular model of leadership into action. The questions that this investigation sought to address are embodied within the naturalistic research tradition (Bantz, 1983). They are necessarily qualitative questions that warrant an understanding of the attitudes, values, beliefs, and underlying assumptions of the leader and followers being studied. The basic function of the questions levied in this study is to provide the researcher with the fullest, richest, most comprehensive description of transformational leadership in practice.

Qualitative research has been described as evolutionary or emergent in that the research in progress is guided by an interpretive process (Putnam. 1982). This investigation may be characterized as a qualitative case study because it draws, in part, from two approaches that are aimed at interpretive understanding. As Tesch (1984) has pointed out, 
Phenomenology and ethnography are alike in that they describe not external events, but subjective experience. They are different in that ethnography seeks to depict a culture . . while the focus of phenomenological research is on individual experience which does not necessarily need a social context to be meaningful to the individual. (p. 26)

While Tesch (1984) has suggested that there is a distinction to be made between phenomenology and ethnography, these two concepts are not mutually exclusive. Rather, phenomenology and ethnography employ methods that are interrelated and therefore make these two approaches similar in nature.

This investigation cannot be characterized as a phenomenology or an ethnography. More accurately it is a case study inspired by these two qualitative approaches that has attempted to paint a thick description of a transformational leader in operation. The study has drawn from these two approaches in that the researcher sought, in part, to understand how the intersubjective experiences of one leader (a phenomenological concern) shape and influence the social construction of organizational realities ( $a$ concern of ethnography). Hence, while this study was neither purely phenomenological nor unconditionally ethnographic, it may be helpful to briefly examine the 
characteristics of these two approaches to research given that they have influenced this investigation.

The Phenomenological Approach

Phenomenology attempts to illuminate the complexity of individual perception by probing into what Husserl (1964) has called the "life-world" of an individual through his or her inner experiences. Phenomenologists seek to understand how individuals experience themselves and how they experience things external to themselves. Rather than examine the world objectively in a scientific sense, they examine the world subjectively from a perspective of an individual's own understanding and experience (Wagner, 1983). BY exploring the life-world of an individual through his or her own perceptions, the phenomenologist discovers the meaning that he or she attaches to particular experiences.

\section{Phenomenological Research Procedures}

In order to understand the life-world of an individual and the rules by which that person interprets his or her inner experiences, the investigator enters into a phenomenological interview. This kind of interview is more than a simple question-and-answer endeavor; as Tesch (1984) has noted, "it is an experience of immersion in the phenomenon, of intense introspection" (p. 29). She suggested that the phenomenological interview can be viewed as "dialogic introspection" in which the researcher and the participant 
or significant others engage in a dialogue. At this point, the individual being interviewed is described as a participant because he or she participates in the introspective process of sharing his or her experiences with the researcher. In this sense, the participant and the phenomenologist become co-researchers involved in a relationship where descriptive data are gathered so that each will have an in-depth knowledge and understanding of the phenomena.

The Ethnographical Approach

Those who operate within the naturalistic research tradition argue that "the social scientist cannot understand human behavior without understanding the framework within which the subjects interpret their thoughts, feelings, and actions" (Wilson, 1983). This is the aim of ethnography. In practice, ethnographical studies attempt to depict a culture by uncovering and explicating the methods by which individuals "come to understand, account for, take action, and otherwise mangle" the social construction of their realities (Van Maanen, 1983). "'Culture' is the major concept and point of departure for most American anthropologists, and ethnography is the anthropologist's descriptive account of what he has observed and understood of another culture" (Wolcott, 1983, p. 25). While the anthropologist looks at the processual nature of culture, recognizing that it is dynamic and 
on-going, the ethnographer seeks to "hold it still" Iong enough to take a snapshot of it. This picture of the dynamic process is how the ethnographer illustrates the ways in which people organize themselves into interacting social systems.

\section{Ethnographic Research Procedures}

As with the phenomenologist, the ethnographer uses the information that emerges in an investigation to guide and direct subsequent data collection. The ethnographer's essential research instrument for this process is the researcher himself or herself. Thus, the primary method used in the practice of ethnography is participant observation. In this sense, the ethnographer becomes immersed in the realities of those being studied as well as the context in which these realities are being constructed (Sandy, 1983). As a participant observer, the ethnographer is able to discover the meaning structures of those under investigation in whatever forms they are expressed.

In an ethnographic study, participant observation is supplemented by a number of other information-gathering devices (Pelto, 1970). The method most relevant to this particular investigation is that of key-informant interviewing. Here, the ethnographer becomes involved in openended, non-structured interviews with participants so as to gain access to the conceptual worlds in which they live (Geertz, 1973). By adopting "an informant's mode of 
thought while retaining full use of his own critical facilities" (Mead, 1959, p. 38), the ethnographer develops an understanding of the methods social actors use in constructing their realities.

Through the process of participant observation and interviewing key informants, then, the ethnographer enters into empathic relationships with participants whenever he or she shares in their daily lives and systematically works to understand "the meaning particular social actions have for the actors whose actions they are" (Geertz, 1973, p. 27). Thus, the researcher attempts to develop an understanding about social actors in a specific context and describe what the knowledge gained from these individuals demonstrates about the social life within that very context.

Borrowing from methods rooted in phenomenology and ethnography, the researcher in the present study sought to understand how the leader of one of the most successful airlines in the industry built and maintained a system of meaning that establishes values and invokes purposeful action among his followers.

\section{Participants}

\section{National Leader}

Herbert D. Relleher, the Chairman of the Board, President, and Chief Executive officer of Southwest Airlines Co., is the focus of this case study. Kelleher 
was selected because he is believed to be a transformational leader. His selection was based upon some evidence of his transformational leadership qualities gained from newspaper reports, magazine articles, television reports, and initial interviews with southwest employees about him. Hence, prior to the data analysis phase of this investigation, the researcher was not able to conclude that Kelleher is indeed a transformational leader. This is because an a priori argument of this nature was unwarranted without the information gained from the actual data collection procedures. However, subsequent to the data collection phase of this investigation, the researcher will make some judgments about the degree to which Herb Kelleher demonstrates transformational leadership. These conclusions are presented in Chapter v.

\section{Followers}

Key informant interviews were held with Southwest Airlines employees from different levels and a variety of positions within the corporation. These participants are members of Kelleher's immediate staff (executive vice presidents, vice presidents, and general legal counsel), flight attendants, pilots, and various employees from departments in Southwest such as corporate services, marketing, schedule planning, and ground operations. Additionally, the researcher solicited participation from significant others who are related to, but not directly 
employed by, Southwest Airlines. These respondents included executives from a competing airline, executives from the public relations firm used by southwest, and customers who have flown on Southwest Airlines.

\section{Number of Participants}

Tesch (1984) noted that most phenomenological studies incorporate between 10 and 15 participants with as few as five and as many as 25 . In his discussion of naturalistic research methods, Mintzberg (1983), who has a long history of studying executives, argued that qualitative researchers should not apologize for samples of one if in-depth data are the objective of the study. In addition to Kelleher, this investigation included interviews with six senior officers, twelve individuals from various other positions in the corporation, one of the principals from the company's advertising agency, and two executives from another airline. These individuals were key informants who taught the researcher about kelleher, his influence upon Southwest Airlines, and the company's impact on the airline industry. While the researcher observed and interacted with other employees of southwest Airlines for brief periods, these individuals did not serve as the primary sources of information for this case study. Thus, congruent with qualitative research methods, the small sample cited in this investigation is a function of the researcher's desire to gather in-depth information and 
develop a thick description of transformational leadership in practice.

\section{Site Selection}

In order to maintain an environment in which maximum interaction would be facilitated and the participants could respond to the researcher's questions comfortably, the interviews were conducted in the work settings of the participants. In most situations, interviews were conducted in the corporate offices of southwest Airlines at Love Field in Dallas, Texas. Other interviews were conducted in Phoenix, Houston, and San Diego so that the researcher could obtain a perspective from those southwest employees who are physically removed from the corporate headquarters. By going to the work settings of the participants, the researcher also had the advantage of firsthand observation of the organization in operation during his visits.

\section{On-Site Observation}

On two different occasions the researcher spent the equivalent of one week at the corporate offices of Southwest Airlines in Dallas, Texas. During these two visits the investigator observed the daily operations of the airline, interviewed participants and absorbed the company's cultural artifacts le.g. pictures and plaques, memos and announcement, fixtures, logos and posters that 
make up advertising campaigns) in office settings, reception areas, pilots' lounge, flight attendants' lounge, hallways, ticket counters, boarding gates, baggage claim areas, and training facilities. The investigator also spent a day at Southwest's facilities in Houston's Hobby Airport and another two days in Phoenix where Herb Kelleher addressed a large number of southwest employees at two different meetings. These on-site observations were complimented by brief visits with employees at the Southwest facilities in Los Angeles and San Diego. Finally, the researcher invested a significant amount of time talking with pilots, flight attendants, and ramp agents and watching them work on Southwest flights to and from these locations.

As an inflight observer and through the observations made at the airline's different locations, the investigator was able to develop a broader perspective of Southwest and, in turn, see the larger impact of Kelleher's leadership abilities. The researcher observed Herb Kelleher's interactions with members of southwest both individually and corporately. He also observed the chief executive in his interviews with him.. In addition to these observations, the investigator focused on how southwest employees related to each other and how they dealt with customers. By observing these relationships, the investigator was able to experience a part of the Southwest 
culture and make some interpretations about Kelleher's role as a transformational leader.

\section{Interviewing the Participants}

Interviewing has become very common in qualitative research and naturalistic studies of organizational symbolism. Bantz (1983) pointed out that investigators in the naturalistic tradition use interviews to confirm, adjust or disqualify the meanings they attach to their observations. He argued that while qualitative researchers using this method need to account for their own tendencies to construct meanings and develop expectations, interviews enahle researchers to clarify the assumptions they have made. However, as Levinson and Rosenthal (1984) noted in their study of six chief executive officers,

unlike studies at lower levels where people remain essentially within a plant or within a limited territory, top leaders go everywhere. Their work takes them literally around the world and into such a range of activity that to document their varied behavior one would have to be with them every moment for a long period of time. (p. 8)

The observation of these researchers apply to the present study as well. In the truest sense of pure ethnography, it was unrealistic to assume that the researcher in this particular study would have the opportunity to take up long-term residence within offices of Herb Kelleher and his 
top executives. Therefore, interviews with Kelleher, his senior officers, other Southwest Airlines employees, and significant others outside of the corporation serve as the primary method of data-gathering.

With the exception of Herb Kelleher, each participant was interviewed for approximately two hours. In Relleher's case, the interviews were approximately one hour; however, the researcher was able to meet with him on several separate occasions. Colleen Barrett, Vice President of Administration and perhaps Kelleher's closest senior officer, graciously made herself available to the investigator throughout the course of this project for interviews, for scheduling interviews with others and in helping the researcher acquire a wide array of corporate documents.

The researcher used the interviews to gain new information and to validate the accuracy of the assumptions, interpretations, and conclusions he had drawn from observations and previous interviews (Bantz, 1983). The interviews were unstructured and open-ended; therefore, the actual time taken in each interview depended upon the quality of interaction between the participants and the researcher. While all of the participants were very interested in talking about Kelleher and Southwest Airlines, the uniqueness of the relationship established between the interviewer and each interviewee varied. As a result, some interviews were better than others. In 
addition to his warm and friendly demeanor and the experiences he has gained from being interviewed countless times in the past, Kelleher's genuine desire to talk openly about the people of Southwest Airlines made the interviews with him quite extraordinary. His unique ability to immediately put the researcher at ease greatly enhanced the dynamics, and thus, the quality of the interviews.

\section{The Interviewing Process}

"The interview has a long and noble history" wrote Levinson and Rosenthal (1984, p. 8). Interviews were their primary method for gathering data in their investigation of six business executives. In each case the interview yielded substantive and comprehensive information that provided the researchers with rich and valuable insight about how these CEOs did what they did. Bennis and Nanus (1985) used interviews extensively in their study of 60 corporate presidents and chairmen of boards and Kanter (1983) employed this method in more than 100 companies in her work on organizational change and innovation. Finally, Peters and Waterman (1982) and Peters and Austin (1985) used interviews effectively to develop an understanding of the common denominators in America's most successfully run organizations. Hence, the interview has been widely accepted as an appropriate method for gathering data by contemporary scholars in the fields of organizational change, organizational theory, and leadership. 
The interviews for this investigation were conducted like exploratory dialogues between the participants and the researcher. In the context of an unstructured, nondirective, and open-ended dialogue, the participants became co-investigators (Tesch, 1984). Consistent with the emergent approaches of phenomenology and ethnography, the researcher used the information generated in each interview as a guide for subsequent data gathering. Bennis and Nanus (1985) likened this approach to the way oil drillers explore for oil: "You chivvy around for the best position for the drill and keep probing and testing until you 'hit.' Then you stay there until it dries up. Then move to another spot" (p. 24).

In order to facilitate the dynamics of a dialogical interaction between the participant and the researcher, the investigator: (1) posed a number of open-ended research questions, (2) repeated and restated participant responses for clarification, (3) used empathic responses to elicit participation, (4) created hypothetical situations to which the participant reacted, and (5) expressed ignorance so as to probe more deeply into the participant's experience.

Given that the researcher wanted to encourage dialogue and interaction in each interview, the interviews were audiotape recorded. While it is difficult to maintain the effectiveness of communication between the participant and the researcher when taking extensive notes, recording the 
interview provided the investigator with the freedom and liberty to concentrate on building a rapport with the participant and involving him or her in an in-depth dialogue. Moreover, recording the interviews reduces the researcher's tendency to parcel out information during each interview based on his or her biases (Borg \& Gall, 1983). Finally, recording the interviews enabled the researcher to study each interview more thoroughly by replaying each tape several times for careful analysis.

Additional Data Gathering Procedures

Organizational Documents. Gantz (1983) described organizational documents as those messages that are generated by members of the organization and have $a$ permanent structure. Bantz explained that since these documents are produced by organizational members they are indicative of the internal dynamics of the organization. "Documents provide a naturalistic researcher with historical data of private situations (e.g., the Watergate tapes), long lasting information, (e.g. the Constitution), and information available only in documented form le.g., financial records). In addition to the interviews, the researcher collected data by reading annual reports, new employee packages, brochures, newsletters and magazines distributed by Southwest Airlines. Also, the researcher analyzed letters from customers to kelleher and southwest Airlines as additional sources of data. Finally, the 
investigator examined various forms of written, audiotaped, and videotaped correspondence from kelleher to southwest Employees.

Organizational Outputs. Messages that are distributed publicly in an effort to project a particular corporate image have been labeled by Bantz (1983) as organizational outputs. These outputs can take the form of speeches, press releases, radio and television commercials, and other types of advertising (e.g. billboards, brochures, logos and slogans on vehicles). As with organizational documents, organizational outputs provide the naturalistic researcher with yet another perspective of the organization. In the present study, the researcher was able to review major speeches given by Herb Kelleher to a variety of audiences as well as the radio and television commercials produced by Southwest Airlines. Additionally, the investigator acquired a number of press releases put out by southwest periodically throughout the company's history and a large number of news reports and magazine articles written about Kelleher and the organization.

In summary, an examination of Southwest organizational outputs, organizational documents, and audiotaped and videotaped correspondence combined with the interviews and observations constitute the methods by which data were gathered in this investigation. 
Data Analysis

\section{Transcription}

Tape recordings from each of the interviews were transcribed so that the researcher could review and analyze the manuscripts for common themes. A common theme was established when various pieces of information were naturally interrelated. The researcher then attempted to determine if and how these themes were related to the seven aspects of transformational leadership previously outlined in the review of literature. From the interviews the researcher paid particular attention to the process by which Herb Kelleher brought about organizational transformation at Southwest Airlines and the communities that it services. Specifically, the investigator looked for concrete examples of transformational leadership by drawing inferences from: (1) the language used by Kelleher and his followers, (2) Kelleher's behavior as reported by himself and his followers in the interviews, and (3) the symbolic elements (e.g. metaphors, myths, rituals and ceremony, and stories) that he used to articulate his vision, shape values, and direct the future of Southwest Airlines. Finally, the researcher looked for themes of transformational leadership that were apparent in the organizational documents and organizational outputs of southwest Airlines. 
Descriptive Analysis

It is virtually impossible to fully grasp the nature of Herb Kelleher's leadership without understanding the history and development of southwest Airlines prior to his arrival as chief executive. This is because so much of his passion for this company and its people has emerged out of the significant events of the past. Therefore, Chapter Four is a brief description of the -historic events that have shaped Southwest Airlines and undoubtedly strengthened Herb Kelleher as a leader.

Chapter Five of this project is a written analysis describing the methods or mechanisms by which Kelleher operationalizes Burn's (1978) concept of transformational leadership. This analysis attempts to go beyond those of Bennis and Nanus (1985), Levinson and Rosenthal (1984), Maccoby (1981), and Peters and Austin (1985) by offering a more through, in-depth, and comprehensive treatment of the ways in which Herb Kelleher has affected significant institutional change at southwest Airlines. In a form similar to journalistic accounts, Chapter Five provides facts, examples, and illustrations that exemplify Kelleher's leadership behavior. In turn, these examples serve as the basis for a discussion about how Herb Kelleher operationalizes the components of transformational leadership. 
In Chapter Six the researcher draws some conclusions about Herb Kelleher as a transformational leader and develops a composite summary highlighting some of the manifest attitudes and behaviors associated with transformational leadership. 
CHAPTER IV

\section{AN INDOMITABLE SPIRIT OF PERSEVERANCE: THE HISTORY OF SOUTHWEST AIRLINES}

The most stable fact about organizations.. . is that they change. Change can be a major overhaul or a cosmetic afterthought, a substantive renovation or a lively ritual, a response to crisis or an opportunity for excitement and adventure. But whether changes are minute or monumental in scope, the constant in our modern society is that organizations are always shifting, changing, transforming, and realigning (Baldridge \& Deal, 1983, p. 1, 2)

Perhaps nowhere is the reality of chanse more evident than in the American airline industry today. Wrought with bankruptcies, acquisitions, mergers and hostile takeovers, the airline industry is a highly complex and shifting environment. It is characterized by competing corporations trying to capture more market shares by reducing fares, cutting costs, shaping and reacting to governmental policies and finding newer and better ways to service their customers. OnIy recently we have witnessed the demise of Frontier Airlines to the highly acclaimed People Express. We then saw Texas Air take over People Express subsequent to its previous acquisitions of Eastern and Continental. Other mergers among the airlines have included Delta with Western and Northwest Orient with Republic Airlines. At the very time of this writing, san Diego-based Pacific 
Southwest Airlines announced its takeover by USAir and rumors run rampant that Northwest orient, Transworld Airlines, and Texas Air have interests in acquiring other smaller airlines. Thus, the present condition of the American airlines industry is anything but stable; it is an intensely competitive environment in which only the strong survive.

In the midst of this dramatically turbulent and often volatile milieu stands a remarkable leader who has demonstrated the tenacity and intestinal fortitude to build one of the most successful airlines in aviation history. His name is Herbert David Kelleher and his company is Southwest Airlines (see Figures 1 and 2). As the chairman of the board, president, and chief executive officer of southwest Airlines, Kelleher is known by all 4,800 employees as Herb. He possesses a unique, special, and highly revered relationship with the people of Southwest Airlines, and this is evidenced by his willingness to slug it out with anyone on their behalf, even if it means going all the way to the United States Supreme court. In a business sense, Kelleher is recognized as a street fighter whose competitive drive and legal acumen have not only enabled Southwest to survive major attacks from larger, more powerful airlines, but have also made his company and the people of Southwest a dominant force in the American airline industry. This is a story about an organization that was 


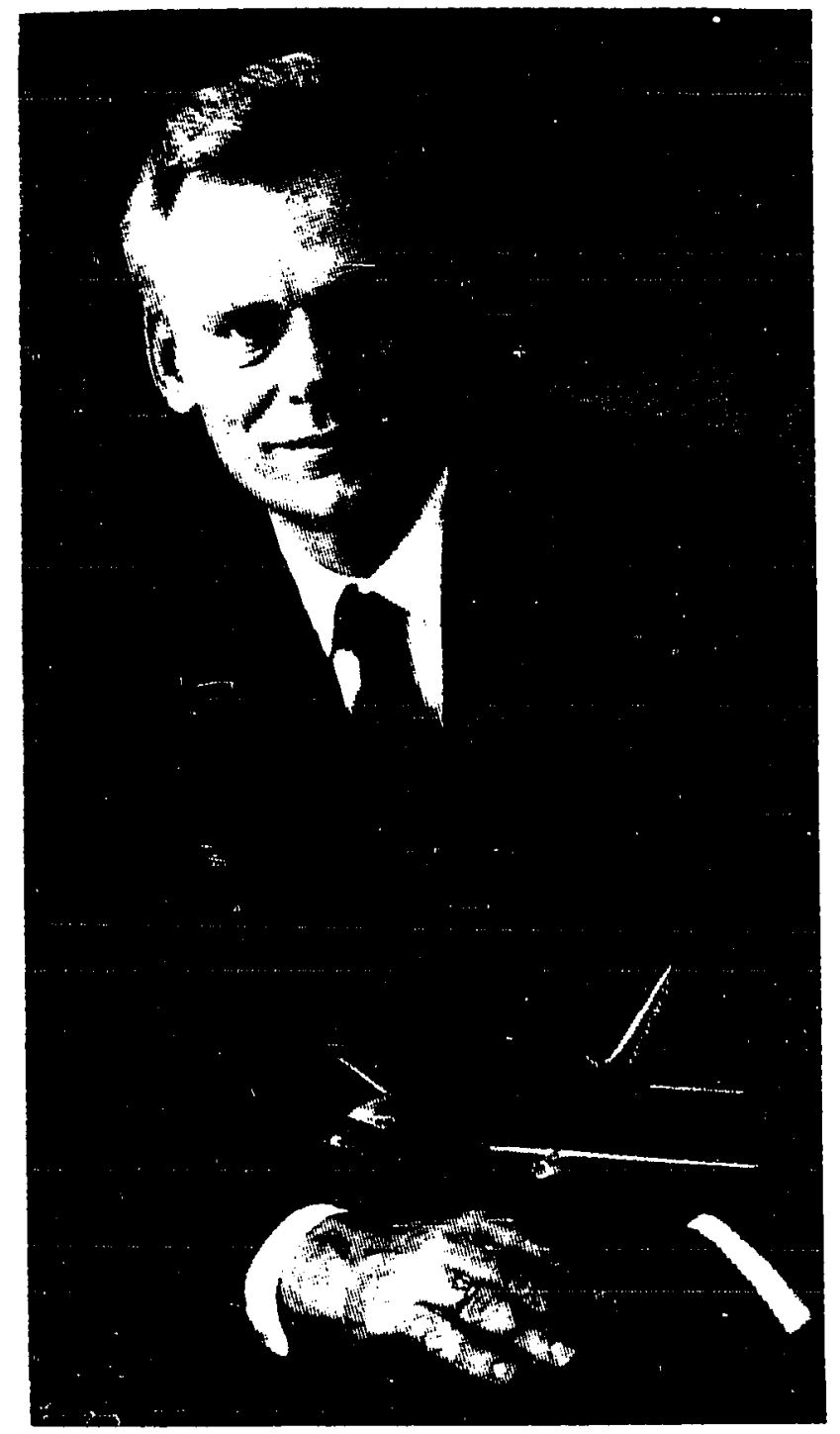

Figure 1. Herbert D. Kelleher, Chairman of the Board, President, and Chief Executive Officer, Southwest Airlines. 


\section{Herbert David Kelleher}

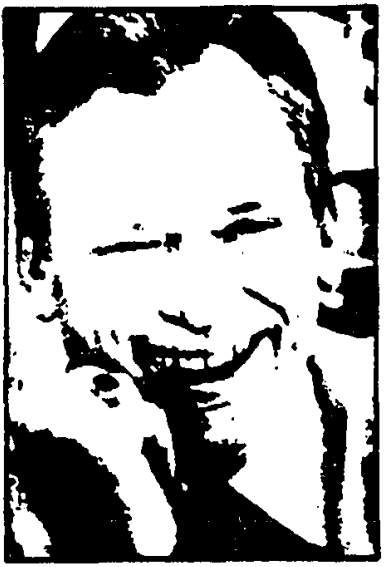

Birthdate and place: March 12, 1931 in Camden, N.J. Occupation: Chairman and president of Southwest Airlines. Favorite comic atrip: Peanuts.

My mother's beat advice was to: Enjoy work.

If 1 were reincarnated, I'd be a: Novelist.

My woret habit is: Absent-mindedness about possessions.

If I could buy any car, I'd buy a: Bitter convertible.

Favorite all-time television show? The Carol Burnett Show.

Favorite animal in the zoo? Giraffe.

The entree I would choose for my last meal: Enchila. das.

The four guests at my lantasy dinner party would be: My four children.

My hero is: Winston Churchill.

Favorite city outside Texas: London

Favorite fast food: Club Schmitz hamburger.

Favorite color: Blue.

Favorite restaurant: Old Warsaw and The Palm.

The person who has had the most impact on my life?

My mother, and Arthur T. Vanderbilt.

My best asset? Perseverance.

If I gave a high school commencement addrese, my

theme would be: Learning is forever.

Favorite rames: Scrabble, Poker, Pitch, Airline.

The last book I read completely was: The March of

Folly: from Troy to Vietnam.

Favorite president? Harry Truman.

I really regret: Not having been a quarterback.

Favorite eport: Football.

Fevorite eong: My Way.

Time my alerm is eet for: 6 a.m.

If I had to choose another profescion, I'd be: A novelist or columniat.
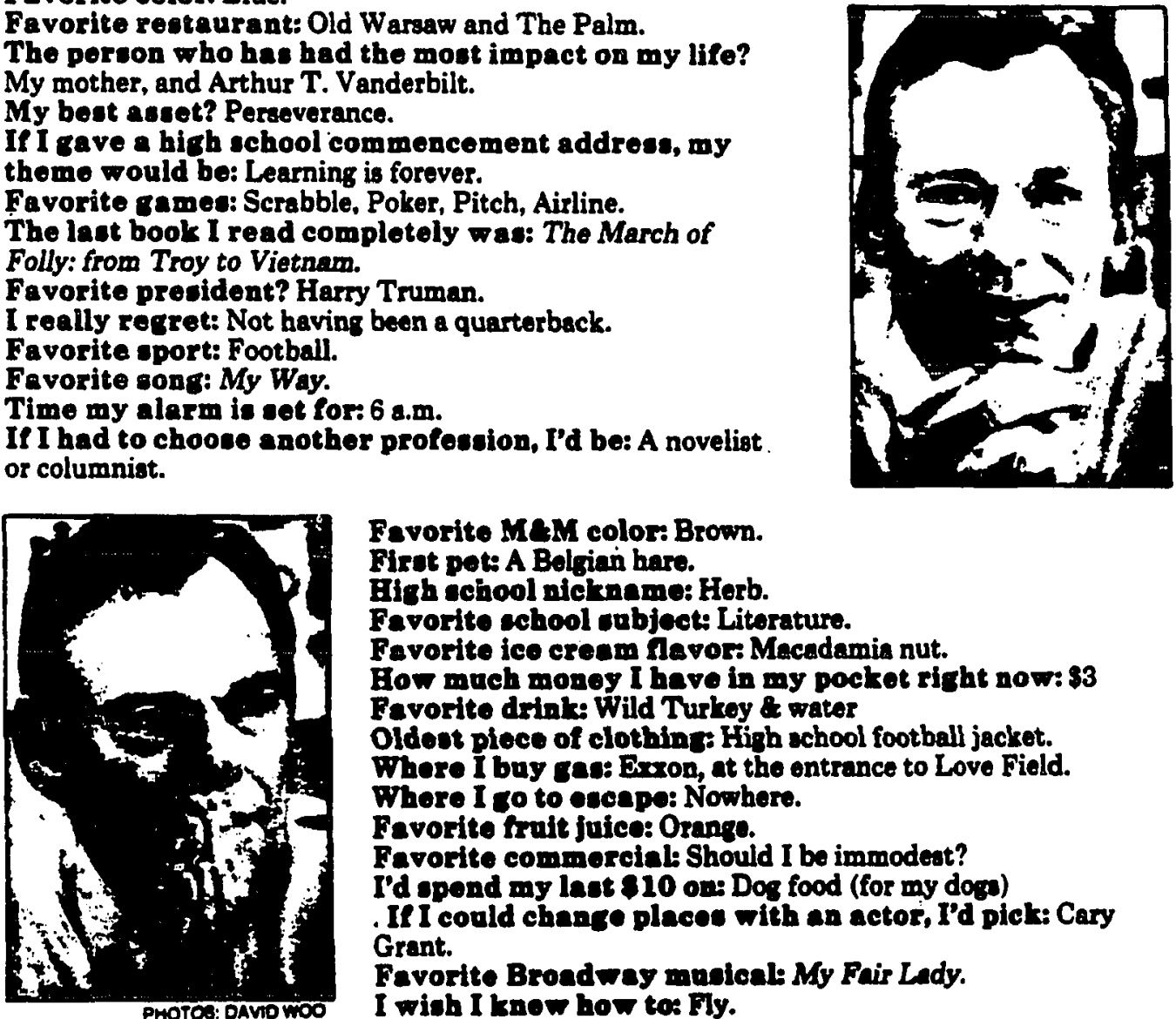

Favorite MEM color: Brown.

Firat pet: A Belgian hare.

Bigh rechool nickename: Horb.

Favorite school oubject: Literature.

Favorite ice cream flavor: Macadamia nut.

How much mosey I have in my pocket right now: $\$ 3$

Fevorite drink: Wild Turkey \& water

Oldeat ploce of elothing: High echool football jacket.

Where I buy gas: Erron, at the entrance to Love Field.

Where I to to escape: Nowhere.

Favorite fruit juice: Orange.

Favorite commercial: Should I be immodest?

I'd epond my last 110 on: Dog food (for my doge)

If I could change places with an actor, l'd pick: Cary

Grant.

Favorite Broadway mualoal: My Fair Lady.

PHOTOL: DAViowoo I wish I knew how to: Fly.

Figure 2. Profile Characterizing Herb Kelleher. 
conceived in the heat of competition and conflict and a group of individuals who faced incredible odds to realize their vision for the future.

The history of Southwest Airlines is a story that is often told by members of the company at every level. It powerfuliy portrays the indomitable spirit and perseverance of two men, Rollin w. King and Herbert D. Kelleher. Even today, the legendary beginnings of Southwest Airlines have become a ritual in the company's personnel department. During orientation, every new employee is shown a videotape that depicts Southwest's first years in operation. The purpose of this ritual is to instill within each new member of the company the values upon which southwest was founded. From the videotape, new employees see that southwest Airlines really became a cause for which King, Kelleher, and the original members of the organization fought. Consequently, they begin to learn that the same spirit and perseverance of the early years is what makes southwest such an outstanding company today. Thus, the history of Southwest is terribly important not only because it represents particular values that are operative for the organization today, but also because it is a story of which every member of the company is extremely proud and loves to tell.

The idea for Southwest Airlines was actually the brainstorm of Rollin King, a San Antonio entrepreneur. In 
1966, King owned a failing commuter service in San Antonio, Texas, and hired Herb Kelleher as his attorney to handle the legal matters in dissolving the operation. King had been discussing with his banker, John Parker, the idea of starting a larger, intrastate airline that would service Houston, Dallas, and San Antonio. Parker had complained to King that it was inconvenient to travel between the three cities on the existing carriers and suggested that he should start a new commuter line. In early $1967 \mathrm{king}$ marched into Kelleher's San Antonio law firm and approached him with the grandiose idea of starting a new airline. As one journalist reported,

It's hard to imagine how king could have been luckier in his choice of legal counsel. There was no way of knowing in advance that the bold and brainy Kelleher would become the . . . [catalyst] so critical to Southwest's development, winning the early court battles for the company at great odds and finally taking over years later as board chairman. (Bancroft, 1986, p. 4)

As the story is told, Kelleher's skepticism was overruled by his desire to take a risk and explore the merit of King's idea. When King had finished pitching the dream to Kelleher, the attorney responded by saying "Rollin, you're crazy. Let's do it!" Figure 3 shows the three-city route King sketched out on a napkin as he pitched the idea to 


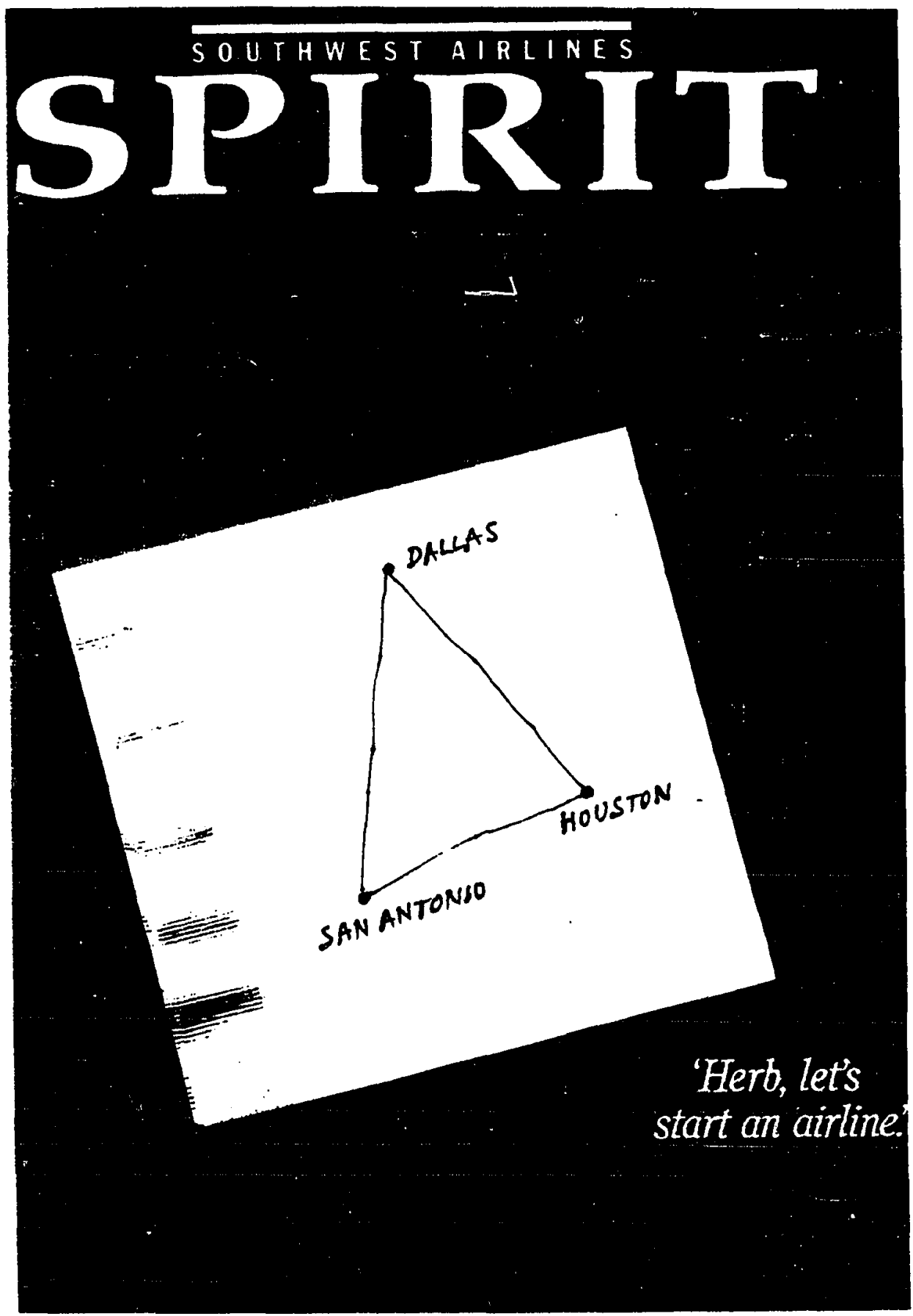

Figure 3. The tri-city route Rollin King sketched on a napkin as he approached Kelleher with the idea of starting Southwest Airlines 
Kelleher. This napkin has become a symbolic representation of the day the idea for Southwest Airlines was consummated. The napkin is set in a beautiful wooden plaque that hangs on the wall in Herb Kelleher's office today. The words "Herb, let's start an airline," and "Rollin you're crazy. Let's do it!" are etched in the plaque as a reminder of how a dream became a reality for two men and the people who followed them.

Kelleher, a brilliant corporate attorney, had graduated at the top of his class from New York University Law School and spent two years as a clerk of the New Jersey supreme court. He was an outstanding litigator who was particularly skilled at doing appellate court work. Kelleher began looking into San Diego-based Pacific Southwest Airlines as a model for the new airline while King took to raising the necessary capital. In the first two rounds of financing, Kelleher and king managed to raise an impressive $\$ 543,000$ from some of Texas' most influential political and business leaders. Both men had the foresight to see that their new venture could become a highly charged political battle in the state of Texas and therefore, sought to attract leaders that would bring credibility to their endeavor. Having the first two rounds of financing secured, Kelleher filed an application to fly between Dallas, Houston, and San Antonio with the Texas Aeronautics Commission on November 27, 1967. 
On February 20, 1968, the Texas Aeronautics Commission (TAC) approved Southwest's application to fly between the three cities. This marked the beginning of a three-year war that would severely test Herb Kelleher's legal skills and almost put Southwest Airlines out of business before it even had a chance to put a single plane in the air. The very day after the TAC approved Southwest's application, Braniff, Trans Texas (later Texas International), and Continental obtained a temporary restraining order that prohibited the TAC from issuing the certificate. In a hotly-contested trial that was characterized by uncontrollable tempers and emotional outbursts, the opposition argued that there was enough service to the three cities and that there was no more room for competition. one account explains that the trial even included a few incidents of comic relief.

At one point a witness named Ned Heizer of Allstate Insurance (then southwest's prime potential investor), on being extorted by Braniff's lawyer to speak up, explained that he couldn't, because he was wearing the choking collar of a borrowed shirt in the aftermath of Braniff's having lost his luggage. The courtroom rang with laughter. (Bancroft, 1986, p. 5)

The outcome of the trial was that Dallas, Houston, and San Antonio were adequately serviced by the existing carriers and these cities could not support a new competitor. 
Kelleher filed an appeal with the state court of civil Appeals, which upheld the lower court's ruling seven months later. With Kelleher's anger mounting, he refused to give in and filed another appeal with the Texas state supreme Court. Meanwhile, members of southwest's board began to waiver. The original $\$ 543,000.00$ had been eaten up in legal expenses, the corporation's liabilities grossly exceeded its cash, and there were still no pilots, no airplanes, and more importantly, no additional financing on the horizon. A meeting was held and members of the board concurred that the economic strength of the opposition was just too much to overcome. While they all agreed that King's idea was a good one, most thought it would be wise to count their loses and dissolve the corporation before they all expired. At this point, Kelleher's street fighting spirit and perseverance came out as he said, "Gentlemen, let's go one more round with them. I will continue to represent the company in court, and I'Il pay every cent of legal costs out of my own pocket." After much debate, the board agreed to stake their bet on Kelleher and give it one more shot.

Kelleher argued southwest's case before the Texas Supreme Court, which overturned the lower court's decision and granted southwest the TAC certificate. Kelleher had argued the case with so much vigor and passion that even the attorneys for the opposing airlines were impressed. In 
late 1970, the United States Supreme Court refused to hear an appeal in the case and let the ruling of the Texas Supreme court stand. Southwest had won a major victory; however, over the next several years Kelleher would defend Southwest in state, district, appeals, and supreme courts, and the U. S. Supreme court in repeated lawsuits.

Four years from the time of its incorporation in 1967 , Southwest was finally ready to fly. King and Kelleher were looking for an industry veteran, someone who could run the operation from buying airplanes and equipment to hiring pilots, flight attendants, and ground crews, when they came upon Lamar Muse. Muse, a retired airline executive at 50, had worked for a host of other airlines and jumped at the opportunity to become the chief executive officer of an upstart airline that had suffered enough under the oppression of the big carriers. Muse negotiated with Boeing to buy three 737-200 aircraft at a tremendous price, with Boeing financing 90 percent of the deal. Due to the recession of the early seventies, many very talented people in the airline industry were out of work and others were seeking retirement. This enabled Muse to recruit some of the best people in the industry. By the time Muse had finished recruiting, he had assembled a senior staff that ranked among some of the most seasoned veterans and best executives the industry had to offer. 
While Muse was building his team and making deals with Boeing, Kelleher and King were attempting to finalize Southwest Airline's public stock offering. With $\$ 142$ in the bank and $\$ 80,000$ in over-due bills, the corporation was in desperate need of capital. At the same time, Braniff and Texas International had filed complaints with the Civil Aeronautics Board (CAB) suggesting that southwest was likely to violate its restrictions as solely an intrastate carrier. They argued that if interstate passengers initiated or concluded their trips on a southwest flight, the carrier was in violation of its exclusivity. Again, the company was to rely on the legal experience and expertise of Herb Kelleher. Kelleher immediately flew to Washington $D$. C. to address the complaints filed with the $\mathrm{CAB}$ and wrote a legal opinion to assure the underwriters that the complaints would be negated. Two days prior to Southwest's inaugural flight, Kelleher received word that the Braniff and Texas International complaints had been nullified by the CAB. However, he was also notified that Southwest was about to receive another restraining order from an Austin judge prohibiting southwest from initiating service. It seemed that Braniff and Texas International were hell-bent, bound, and determined to keep the upstart airline grounded.

Kelleher flew directly to Austin and headed straight for the supreme Court Building where he found Judge Thomas 
Reavely. Reavely had written the 1970 opinion in favor of Southwest. Kelleher described the situation to the judge and asked him to throw out the restraining order. Fatigued from the preceding weeks of travel and long hours, Kelleher had arrived at Reavely's office looking like a battle-worn soldier. The story was told that:

Studying Kelleher's appearance and obvious fatigue, Judge Reavely probably felt a twinge of compassion. Kelleher explained what was happening. Reavely nodded, then said, "You're in luck. There's a reception this evening, and the whole court will be there. I'Il tell every judge to be here tomorrow morning, and you can read your case to them." (Bancroft, 1986, p. 7)

Once again, the indomitable spirit and perseverance of Herb Kelleher had paid off for Southwest Airlines. The stock offering had gone through, and after presenting his case to the Texas supreme Court the next morning, Kelleher telephoned Muse and told him that the supreme court had overruled the Austin judge and to "put the planes in the air." The very next day on June 18, 1971, Southwest Airlines was literally off the ground.

While Southwest was up and flying on schedule, it was by no means a financially stable enterprise. Through private investors and the public stock offering, king, Kelleher, and Muse managed to put seven milition in the 
bank. However, by the end of 1971 the company had lost thirty-seven million and things did not appear to be getting any better. Passenger loads were very inconsistent, on some days southwest would carry as few as one hundred fifty passengers on its eighteen daily round trip flights between the three cities. At one point, Kelleher got a phone call from his sister-in-law recounting the magnificent service she had received on a Southwest flight. When Kelleher inquired as to how many passengers were on the flight, his sister-in-law responded by saying there were two pilots, three flight attendants and herself. Perhaps one of the biggest breakthroughs for southwest Airlines came when it began to service Houston's Hobby Airport. All of the major carriers vacated Hobby in 1969 and moved to the new outlying Intercontinental Airport. Even though Hobby was in downtown Houston and perfectly suited to Southwest's commuting business passengers, the assumption was that passengers would not use an airport occupied by only one carrier. Forced to question their assumptions because the company was failing miserably at Intercontinental, Southwest gambled and initiated service to the vacant Houston Hobby Airport from San Antonio in late 1971. The results were dramatic. Almost overnight the passenger load factor doubled. So dramatic were the increases in passenger load factors that southwest moved its remaining Houston service from the Intercontinental Airport to Hobby. 
Southwest's move to Houston's Hobby Airport is an extremely important part of the company's history because it established a pattern that would significantly affect the airline's future in years to come.

Infuriated by the move, Braniff and Texas International also transierred parts of their Houston Service back to Hobby. Rather than slugging it out in the court room with these big carriers, Southwest would now do battle with them on the marketing front. The move by Braniff back to Hobby turned out to be a blessing in disguise for Southwest. Although the new upstart had little money to develop an advertising campaign that could compete with Braniff, it would eventually run the bigger airline out of Hobby with the strength of its outstanding service. While its fares at Intercontinental remained the same, Braniff came back to Hobby advertising the same low fares as Southwest. Before long, Braniff, Texas International and Southwest Airlines were all servicing Hobby Airport with identical fare structures. However, by the mid-seventies, Braniff and Texas International had discontinued their service to Houston Hobby, and Southwest emerged triumphant. The reason, as Kelleher explained,

We were simply giving them better service--prompter, faster, with no late planes and no slow lines at the ticket counter and a ten-minute turn around. And then of course we would write things and put them on the 
planes . . just things reminding them that Braniff and Texas International would never have reduced their fares if we hadn't come into Hobby with our low fares first. We suggested they fly us whenever they could because we were the only thing they had to keep the other guys honest.

Since its inception, Southwest has been a leader in the airline industry, and two of its innovations stand out as significant factors in the company's ability to compete with Braniff and Texas International. The first was Southwest's two-tier fare system which has become a bench mark in aviation history. When southwest started, it had undercut the major carriers fares of $\$ 28.00$ to $\$ 20.00$ dollars between Dallas and the two other cities. These low fares had expanded Southwest's market, but not by much. During this time Muse decided to experiment with a $\$ 10.00$ fare for the last flight of the day in each direction between the three cities. With no advertising, Southwest was turning people away during the second week of the trial. The experiment had worked. However, the $\$ 10.00$ fare was only a break even point for the company, so in 1972 Muse raised the day fares to $\$ 26.00$ and the night fares to $\$ 13.00$. This brilliant marketing strategy initiated the two-tier fare and became a model used by other companies throughout the industry for years to come. 
Also during this time, in an attempt to force Southwest out of the tri-city market, Braniff decided to cut its regular day fares between Dallas and Houston to $\$ 13.00$. The majority of Southwest's business came from the DallasHouston run and losing this market would have put the company in bankruptcy. Again, Muse rose to the occasion with a counterattack that would go down as one of the cleverest marketing ploys the industry has ever seen. With an ad that took up two full pages in the Houston and Dallas papers, southwest informed potential customers that it would not only meet Braniff's $\$ 13.00$ fare, but it would also provide them with an alternative. Any passenger that paid the full fare of $\$ 26.00$ would receive a complimentary fifth of Chevas Regal Scotch, Crown Royal Canadian Whisky, Smirnoff Vodka, or a leather ice bucket. (Obviously the cost of these gifts was much more than $\$ 13.00)$. The magic of this campaign lay in the fact that a business traveler (Southwest's predominant customer) could pay for his or her trip via a company expense account and take a bottle of liquor home free. The success of the promotion was clear. Southwest had initially increased its full-fare passenger load by seventy-six percent. While this percentage dropped when corporate controllers began insisting that their employees travel at the $\$ 13.00$ fare, the promotion was enough to cause Braniff to terminate its Dallas-Houston service. The $\$ 13.00$ fare war had also captured the 
interest of the media. Bancroft (1986) suggested, "Both television and newspapers . . portrayed the BraniffSouthwest skirmish as Goliath trying to stomp David into the ground." However, as in the past, the indomitable spirit and perseverance of the underdog airline would enable it to overcome the big guys. (p. 7)

The Airlines's second major accomplishment, an innovation for which it is well-known throughout the industry today, is its ten-minute turnaround. Bill Franklin, then Southwest's vice president of ground operations, is credited with increasing promptness and productivity by keeping enroute stops to a maximum of ten minutes. This means the total ground time for each airplane, from the time it reaches the gate and leaves again, is no more than ten minutes. While the savings to the company are immeasurable, Colleen Barrett, vice president for administration, suggested, "Even today, if we were to take the flights that are now at ten-minute turns, and increase them to fifteen-minute turns, we would need about five additional airplanes to service the same schedule." With a price tag of more than eleven million dollars per airplane, one quickly recognizes the significance of Franklin's innovation.

While brilliant marketing strategies and prompt service enabled Southwest to maintain its competitive edge in the Dallas, Houston, and San Antonio Market, another 
storm was beginning to take shape. As the construction of the new Dallas-Fort Worth Regional Airport (DFW) drew near to completion, a hearing was also underway in the United States District Court regarding Southwest's desire to remain at Love Field. As with the Houston Hobby Airport, Love Field (only ten minutes from downtown Dallas) was ideal for Southwest's business passengers who needed quick and easy access to downtown. In accordance with the 1968 Regional Airport Concurrent Bond ordinance, the other airlines had contracted to move to DFW. The cost of the new facility would be subsidized by the income generated from the landing fees paid by the major airlines. ivot only were these airlines obligated to pay landing fees, they were also responsible to cover the losses the airport incurred. As a consequence, DFW officials tried to prevent any airlines from staying at Love Field.

At the time the ordinance was initiated in 1968, Southwest Airlines was still involved in legal battles and had not been operational. The airline was not contractually bound by the ordinance and, in fact, had no intentions of transferring its service to an airport that was forty minutes away from the city it was servicing. The major airlines, still agitated over southwest's move from Houston Intercontinental to Hobby Airport, were now outraged at the airline's refusal to join the others at DEW. A joint suit was filed against Southwest on June 6 , 
1972, by the cities of Dallas and Fort worth and the Regional Airport Board. They wanted to force Southwest to move to DFW on the basis that DFW's revenue would decrease causing the new airport to fail if Southwest remained at Love Field. However, the fallacy of their argument existed in the fact that the major airlines (Continental, Delta, Braniff, Eastern, American, and Texas International) were obligated to pay for the losses incurred by DFW. Therefore, it was the major carriers, not DFW, that were vulnerable to losing money. Once again, Herb Kelleher and his team of lawyers would go up against the best litigators the major carriers could afford, and between them, money was no object.

After thirty-two days of deliberation, Federal Judge William Taylor ruled in favor of Southwest Airlines stating that Love Field could remain as its base as long as the airport stayed open. The case then went to the United States Fifth Circuit Court of Appeals where the lower court's decision was upheld, and finally to the United States supreme Court where it was denied a hearing. In time, all of the major carriers bound to DEW would try to remove Southwest from Love Field. One of these cases would also go as high as the United States Supreme court and lose. According to Kelleher, the battle fought over the right to remain at Love Field was terribly significant. 
Had the judge not ruled in its favor, Southwest would have been bankrupted by the move to DFW.

In 1973 the fight for Love Field was over; however, the courtroom battles with the major carriers ftotaling thirty-one separate judicial and administrative proceedings) continued until on February 14, 1975 (Valentine Day) Braniff and Texas International were indicted by the United states Government for conspiring to put Southwest out of business. With the predators out of the way, it seemed that the young airline could finally shift its undivided attention from the courtroom to the runway and focus on expanding its markets. By the spring of 1977 , Southwest Airlines was servicing Corpus Christi, Austin, Midland-Odessa, Lubbock, and El Paso, Texas. The Deregulation Act of 1978 allowed Southwest to become an interstate carrier and by late 1979 the company had expanded its routes to New Orleans, Tulsa, Oklahoma City, and Albuquerque.

In the period from 1978 to 1981 several significant things happened at southwest Airlines. As the story is told, Muse, apparently involved in an internal conflict with the board of directors, stepped down in March of 1978 as president to start a new airline called Muse Air. With Muse gone, Kelleher took over on an interim basis as chairman of the board and the company brought in Howard Putnam from United Airlines as president. In september of 
1981 Putnam left to become the head of Braniff International and Kelleher took a leave of absence from his San Antonio law firm to take over as full-time chairman of the board, president, and chief executive officer. Whils Kelleher had been an intimate part of the airline from the beginning, his day-to-day involvement with southwest really began in 1978. After his arrival as full-time chairman in 1981, the airline began service to Kansas City, Las Vegas, Phoenix, and several cities throughout California.

When Kelleher came in to run Southwest in 1981, Muse Air, billed as the non-smoking airline, had already started competing with southwest in its Dallas-to-Houston market. Kelleher, by now a seasoned veteran in the airline industry and a fierce competitor, was unmoved by Muse's attempt to go head-on with southwest. Leaving Muse Air alone, Kelleher stayed focused on keeping costs down and providing excellent service to southwest customers. Consequently, it wasn't long before Southwest Airlines would watch Muse Air expire on its own. In late 1984 Muse announced the sale of Muse Air and Kelleher, still friends with Lamar Muse, became interested in the company because it had airplanes, its gate positions at Houston Hobby Airport were good, and it had investment tax credits and losses of which southwest could take advantage. Kelleher arranged for a meeting with Lamar and as he recounted, "When Lamar walked through the door, I asked him whether he was more interested in running 
an airline or fishing in vancouver. When he said 'fishing in Vancouver,' I knew I had a deal." Jim Parker, now vice president and general legal counsel for southwest, described the way the deal was eventually negotiated.

The acquisition deal, unlike most of the deals you read about in the Wall street Journal, was not negotiated between Wall street brokerage firms or between high-priced lawyers, it was negotiated on a one-on-one basis between Herb Kelleher and Lamar Muse who both deal in the same kind of straight talk. That was a deal that was negotiated between two individuals and then the legal work was put together afterward. When asked if it was really a couple of good 'ol Texas boys who sat down over a beer to discuss the details, Parker nonchalantly responded, "I think it was probably hard whiskey."

In 1985 Southwest Airlines acquired Muse Air as a wholly-owned subsidiary. The name of the company has been changed from Muse Air to Transtar and operates as a compliment to southwest in many of its existing markets. Where southwest is a short haul, high-density, and low fare carrier that does not serve meals or provide passengers with executive class service, Transtar offers more long distance service, meals, and executive class flights. Comparing the idea to General Motors offering customers the 
choice between Cadillacs and Chevrolets, Kelleher explained,

We're trying an experiment that has never been done before in airline history. We're offering two types of service in the same market. It is the first time an airline in effect has flown against itself. But, we're making it complimentary rather than adversarial. On June 25, 1985, Kelleher moved Bill Eranklin from vice president of ground operations at southwest to chief executive officer of the newly acquired Transtar. Kelleher remained as chairman of the board for both companies. Since 1985, Southwest has expanded its markets to Nashville, Chicago, and St. Louis, and with the acquisition of Transtar, it now services several cities in Florida.

From the near bankrupt days in its early beginning, Southwest Airlines has become a company with assets that exceed one billion dollars and earnings over 206 million in the last five years. Its fleet has grown from three airplanes to 72 , and it now serves 26 cities in 12 states with over 650 flights a day. The company's passenger boardings have increased from several to over 21 million, and its passenger complaints per passenger carried have been lower than any other airline in the industry. With Transtar, the company has approximately 4,800 employees. In January of 1973, Southwest established the first profit sharing plan in the industry and by 1984, the employee's 
share of southwest profits exceeded ten million dollars. Southwest also pays its people well, the annual average salary of Southwest employees is significantly above the industry average of $\$ 44,000$.

Today, Southwest Airlines continues to profit in an industry that has been characterized by overwhelming losses and failure. Since deregulation in 1978, 120 carriers have gone out of business. Conversely, in December of 1986, Southwest will complete its 51st consecutive quarter of profitability. While the first quarter of 1986 was financially the worst the industry has ever seen, Southwest managed to make a net profit of $\$ 2.7$ million. As things improved, the second quarter brought the second highest profit (\$17 million) in the company's history, and in the third quarter the airline realized the best quarterly returns ( $\$ 12$ million) in Southwest Airline's 15 year history. 


\section{CHAPTER V}

\section{HERB KELLEHER'S PASSION FOR SOUTHWEST AIRLINES}

As illustrated in the preceding chapter, the indomitable spirit, courage, and perseverance of southwest enabled the airline to withstand tremendous pressure from other institutions and emerge as one of the most successful national carriers in the United states. Why has Southwest Airlines been so successful? How has it been able to consistently achieve the largest profit margins and lowest employee turnover rates in the industry? Mike Derchin, a financial analyst for First Boston Corporation in New York would suggest that the company is obsessed with keeping its cost structures low. Robert Joedicke, another analyst with Shearson, Lehman, Bros., could point to the fact that Southwest has stayed focused; it has created a niche in the market, remained within that niche, and expanded it. Christopher Lovelock of the Harvard Business School would point to the two-tier fares, Bill Franklin would identify the ten-minute turn, and Herb Kelleher would adamantly argue that the credit should go to the employees of Southwest Airlines. While there is no single answer to these questions, this chapter points to the qualities of 
transformational leadership exemplified by Herb Kelleher as major factors underlying the success of the airline.

This chapter, then, is a descriptive analysis of how Herb Kelleher manifests transformational leadership at Southwest Airlines. It is a continuing story that illustrates the magnificent spirit of the people of southwest Airlines and their steadfast commitment to follow a man they love and respect. It is a story about an individual who is a fierce competitor and unafraid of conflict when it comes to meeting the needs of his people and advancing corporate objectives. It shows Herb Kelleher as a man with vision who takes great pride and joy in charting the company's future and developing new markets. Symbolically, this chapter describes the members of Southwest Airlines as a family, as individuals bound together by a common purpose in pursuit of a greater societal good. It focuses on Herb Kelleher's natural ability to lead by example, to instill values by maintaining a posture in the corporation that is very consistent and highly visible. It also shows Herb Kelleher as an individual who has a passion for the people of southwest and uses his power and political sophistication to fight vehemently for their cause. Finally, the chapter illustrates the consistency this leader demonstrates in developing the humanity of his followers and the priority he gives to moving them toward higher levels of moral development. 
Competition and Conflict

As the historical beginnings of the company show, Southwest Airlines was born in the heat of competition and conflict. While perhaps more malicious then, as opposed to now, the competition between airlines today is nevertheless as intensive. Internally, leaders in the American airline industry must compete for the very best employees and maintain corporate environments in which those employees are encouraged to take up long-term residence. Externally, one has only to look at fare wars and a host of clever marketing strategies to see industry leaders also competing with each other for passengers. With that in mind, there is no doubt that Herb Kelleher is a fierce opponent when it comes to competing for employees and passengers.

It seems very clear that Kelleher's competitive nature is one of the primary reasons that the airline survived the brutal dogfights of the past with other major carriers. Herb Kelleher loves to compete and sees competition and conflict as very beneficial for his airline. "I love competition," he said. "The airline business is the closest thing to war in peacetime. Iife to me is a competition, and you distinguish yourself by succeeding in the competition." Kelleher described the impetus behind his competitive drive in the early days.

I am sure I would have had a much easier life had I stayed with my law practice full-time, but I became 
deeply involved in Southwest when I saw what the other airlines, the old Braniff, Texas International, and, to some degree, Continental, were trying to do to this airline. I felt I could not allow them to pervert the system of justice in this country and prevent southwest Airlines from getting into business. In retrospect, I would say that my early entry in the business took the form of a protest.

Really, at that time my motivation was more in terms of wanting to win, and I felt that we were doing something that had a lot of societal good, and that the opposition that we were getting was rather unprincipled. So I got angry. I wanted to vindicate the system.

In another account, Kelleher pointed out that competition and conflict kept the company alive. He explained that had it not been for the competition, Southwest Airlines would have folded on its own.

Southwest Airlines would not be in existence today had not the other carriers been so rotten, trying to sabotage us getting into business, and then trying to put us out of business once we got started. They made me angry. That's why Southwest is still alive. I'm not going to let anyone take advantage [of me]. They were too stupid to realize the psychology of the situation, so they just kept plowing ahead. 
While Herb Kelleher loves victory, his desire to win must not be seen solely as ego gratification; rather, behind his competitive drive there is a cause that he believes in and a group of people he will defend at any cost. Such was the case with the inception of Southwest Airlines. Kelleher saw that the real needs of airline consumers and employees were not being met and sought to provide both groups with some alternatives. Kelleher, an individual who enjoys interacting with customers and employees, possesses an uncanny ability to identify and promote their individual and collective goals. This can be seen in Southwest programs that range from senior citizen discounts to the first employee profit sharing program in the industry. For consumers, he wanted to establish fares that were affordable to more people, while increasing the frequency of short-haul flights to offer those people a wider range of choices. For the employee, he wanted to create a working environment where people have fun and enjoy coming to work. Even today, as a man who deeply respects people, Kelleher recognizes that each of his employees have chosen to work for southwest. He understanas that any one of them could opt to work for another airline. Aware of this fact, Kelleher is devoted to establishing relationships with his people in which they are treated with dignity and respect. In this sense, Kelleher cannot be seen as a figurehead who relies on positional 
power to run Southwest Airlines; rather, he must be viewed as a leader to whom the employees of southwest have delegated authority. In fact, he dislikes the use of formal titles and has suggested that titles are overused by individuals who are insecure with their positions. In observing and talking with southwest employees, the researcher quickly began to see that these people are genuinely excited to be a part of the southwest family. Employees are committed to Herb Kelleher and his vision for Southwest Airlines. As Dale Foster, manager of the dispatch department, pointed out, "people are doing their job because they want to, not because they're in a union and they have to, like I've seen with larger carriers . . . . In fact, my wife keeps saying that 'you're having too much fun to call it work." "

Kelleher's passion for the people of southwest Airlines is so great that he admits to walking a fine line between meeting the needs of the individual shareholder and meeting the needs of his employees. His concern is minimized, though, by the fact that shareholders have fared extremely well as a result of his devotion to southwest employees. Kelleher has estimated that an original investment of $\$ 1,000$ in the publicly-held airline fifteen years ago would be worth more than $\$ 350,000$ today. However, whether the objective is to satisfy the needs of the consumer or to stand behind the motives of his employees and 
shareholders, Kelleher's competitive spirit is driven by his desire to advance the mutual goals of each group. Jim Parker, vice president and general legal counsel, outlined the cause that stimulated Kelleher's competitive zeal in the early days.

We were the renegade, we were entering a highly regulated industry in which there was a high level of customer dissatisfaction and everybody knew it. Everybody knew that the existing airlines didn't exist for their customers; they were callous, they were cold, they charged high fares, and they fought intensely to keep Southwest Airlines from ever flying. And it was Herb Kelleher who fought the fight to get us in the air.

There are people out there who don't want us to exist. But we exist for a purpose, and that is to provide low fare, convenient service for the consuming public. And it was really born as a consumer's airline. It was really created and invested in initially by people who were airline passengers. They weren't airline executives, by and large, who created this thing. They conceived it from the passenger's standpoint.

So the birth of Southwest Airlines was Kelleher's attempt to address the real needs of passengers through low fares and frequent flights. Kelleher broadened the range of 
alternatives from which customers could choose. As he recently wrote, "The product of free price competition and market entry has been an unprecedented array of service alternatives for the consumer" (Kelleher, 1985, p. 314).

As a major advocate of deregulation, Kelleher would agree with Burns (1978) that competition and conflict are necessary conditions for leadership. Kelleher believes that competition makes a company better and more responsive to the needs of the consumer. His security in a competitive environment stems from his confidence in southwest employees and their tremendous efforts in addressing the consumers' wants and needs. One cannot observe Herb Kelleher for any length of time without walking away with the awesome realization that he would pit his employees against the best the industry has to offer. Simply put, his faith in his people is the basis for his security with competition and conflict. When you sincerely believe that your people presently serve the customers better than anyone in the industry, you see competition as a condition that will only make them better. Kelleher recounted:

Coming through the crucible of competition made our employees very dedicated and very mission-oriented, with a desire to get the job done. When your very life is hanging by a thread, as ours was in our first years, our employees formed a very close knit, high 
spirited group because they knew our survival was at stake.

Metaphorically, Kelleher noted that Southwest Airlines was fashioned in the heat of competition in much the same way that a sword is shaped in a fire. He was also quick to acknowledge some of the other positive effects that competition has had upon the company.

We've always existed in a deregulated environment, even back when we started in 1971, when we commenced operations, because in the state of Texas for the carrying of intrastate passengers, there were absolutely no limitations on what the other carriers could do. And so we were really tempered in that fire. And I think that it accomplished a number of things, just like a fine sword is tempered. It made us very close, the original employees and those who came along shortly thereafter. It made us very competitive. It made us quick-response minded because if we didn't respond quickly, we were done.

It made us, I think, innovative. We had to be innovative out of necessity. And it made us very cost conscious, which I think is the primary prerequisite for being successful from a financial standpoint. And that has persisted as more or less a tradition within the company. 
Its ability to succeed in an environment of competition and conflict made Southwest Airlines an exemplar of the benefits of deregulation to both the industry and the consumer. In fact, Southwest was a catalyst in bringing about deregulation. According to Paul Seligson, Southwest's Washington lawyer, "Deregulation is a perfect example of the side of southwest that people don't know. Long before the deregulation movement really got going, Southwest was working very quietly behind the scenes to bring forth the movement." In 1975, a senate committee headed by Senator Edward Kennedy investigated the possibilities of airline deregulation. Kennedy's committee used Southwest to build a case favoring deregulation. Since the Airline was not regulated by the federal government, it increased its passenger loads by 50\% each year, and it had the highest return on investment in the industry, while charging fares that were lower than those of the major carriers. After three years of investigations by Senate and House committees, Congress passed the Airline Deregulation Act of 1978. This bill eventually enabled Southwest to compete on any route, in any state, with any airline in the industry. A story is told by Kelleher that characterizes his competitive spirit in those days. He remembered coming home one night and complaining to his daughter about how intense the competition among carriers 
had become. "She looked at me and said, 'stop whining Dad, you started it,' and I guess that's true."

Kelleher believes that the failure of so many airlines since deregulation is not an indictment of deregulation, but rather a natural result of the competitive process. He explained that "you can't take an industry that has been sheltered and protected and supported by the federal government for forty years and suddenly expose it to very fierce competition and expect some of the old-line carriers not to suffer severely." Kelleher likes the competitive process in a free market because, as he pointed out, one organization's problem will become another organization's opportunity. He feels that the opportunities are unlimited for those who can provide a newer and better service or an existing service more efficiently.

In a freely competitive market, the future can never be predicted with certainty. The one certainty of the future is that as long as the temptation to let the government do "just a little" re-regulating can be resisted, a deregulated airline industry will deliver its product efficiently and economically. We can be assured of this, not by any government edict, but only by the competitive forces of the marketplace which dictate that the slothful, the unresponsive, and the arrogant will not survive. (Kelleher, 1985, p. 318) 
As the number of passengers in the industry today is grossly exceeded by the number of airline seats available, Kelleher has responded to the needs of customers by initiating the industry's first peak and off-peak fares, highfrequency flights, discount ticket books, frequent flyer programs, and senior citizen discounts. He has taken the airline into markets such as Phoenix, Las Vegas, and Los Angeles, and cut fares 40-50\%. Additionally, he is considering a third tier fare, lower than off-peak fares, and further fare cuts in selective markets to keep the airline on the leading edge of the industry. In 1987, the company has experimented with a program that gives customers the added convenience of obtaining their tickets through their 24-hour bank machines. Each of these innovations has emerged as a result of competition and has been facilitated by Kelleher's desire to make the airline more responsive to the needs of the consumer.

As noted earlier, another consequence of fierce competition is that Southwest Airlines, although 4,800 employees strong, can maneuver quite rapidly because it is bureaucratically lean. This is a fact of which Kelleher is extremely proud. He explained that one of the things that makes the airline industry so competitive is that "your capital asset is moving at over 500 miles an hour." Pointing out how rapidly airlines can develop new marketing and operating strategies, Kelleher argued that 
Airlines are not shoe factories. If you build a shoe factory in seattle and it doesn't work for you, you can't move it to San Antonio by 9:00 the next morning. If you're serving Seattle, and it's not working out for you, you can have your airplane in San Antonio the next morning.

Kelleher cited Braniff as an example of how quickly things happen in the airline industry. He indicated that when Braniff ceased operations on the afternoon of May 12, 1982, United, Northwest, and Midway Airlines were at the airport by 8:00 the next morning serving Braniff's routes.

Southwest Airlines has been able to respond to the competition in this highly turbulent industry with a great deal of alacrity--a term Kelleher uses quite frequently when describing the airline. Recently, Southwest was interested in going into Little Rock, and Kelleher knew that there was room for only one carrier in the Little Rock-Dallas market. So when Hughes publicly announced its intentions to enter the Little Rock-Dallas market, Kelleher immediately mobilized his resources and initiated service to Little Rock days ahead of Hughes. The point, as far as Kelleher is concerned, is that southwest, the far bigger carrier, took less time to rally itself and move into action than the smaller Hughes. As Kelleher explained, "The statement that I made to our people after that was 
that we may be big, but we're still nimble as a cat; and we've still got that quality."

Herb Kelleher attributes the alacrity of the airline to its lack of bureaucracy. He argued that the downfall of so many airlines since deregulation is that they have been too hierarchical to make quick decisions.

We've always had less management. . . We don't allow anybody to have assistants . . and we have very few committees. The way I like to do things is on an ad hoc basis. So you've got a problem, you call in the people that have some knowledge on that problem, and it's not necessarily the officers either. It's people from the field, because you need to go to their field, to get their feel for what is going on. They're extremely knowledgeable. Get them all together just on an ad hoc basis and then solve the problem. This is all. So you don't have a myriad of standing committees that are always trying to expand their jurisdiction.

Thus, Kelleher has established an organizational structure that enables Southwest Airlines to quickly adapt to the wants and needs of customers. As an adaptive corporation, Southwest Airlines has increased its competitive position in the industry because of its ability to take action almost immediately. With competition and conflict being so much a part of Southwest's heritage, Kelleher has also used 
competition as a rallying point for employees. As Kelleher communicates the intensity of the competition in the industry to southwest employees, they rise to the occasion with excitement and enthusiasm. This is because he shows them how important they are in the process of successfully competing with other airlines. Symbolically, this is a theme that is promoted by Kelleher and pervades every nook and cranny of the organization. Gary Barron, executive vice president of corporate services, pointed out that Kelleher is very good at making it absolutely clear that there is a cause at Southwest Airlines worth championing. As the primary spokesman for the company, Kelleher has a unique ability, says Barron, to "package and sell" causes that impassion employees to vigorously compete for the company.

Barron indicated that Kelleher has had his employees involved in almost every controversy southwest faced. Through speeches, memos, and most importantly, personal interaction, Kelleher responds to his employees' needs to be involved in a cause by drawing them into the latest conflict. Barron showed how this was the case with Southwest's fight to keep its base at Love Field in Dallas.

I go back to Love Field again and again, but it's always there. It could have been fought just in a political way between Herb and the City Council. He could have gone down and made presentations to the 
City Council and not have gotten employees actively involved in writing letters to City Council people, getting petitions signed, and encouraging them to come to City Council meetings.

He argued that competition and conflict have been good for the company and that the employees have always been willing to support and rally around the cause Kelleher is promoting. One certainly gets the impression that the whole employee group at Southwest Airlines genuinely feels that Herb Kelleher needs them and wants them to be involved in company matters. Barron stated that getting employees involved in the controversies is just another way in which Kelleher shows them how important they are. "Even without the controversy, they would know that he needs them and cares about them . . but it's just another way in which it's manifested, his caring about the employees."

Burns (1978) indicated that transformational leaders recognize the capacity for competition and conflict to motivate, energize and jolt people into action. This is certainly true of Herb Kelleher. In "Herb's Message To The Field," an annual speech in which he informs employees about the state of the company, Kelleher's ability to instill courage and confidence in the people of Southwest Airlines is evident. His remarks show that he sees competition as something to embrace and confront rather than something to be suppressed and avoided. 
Seven or eight years ago . . fifty percent of all our revenues were derived from the Dallas-Houston route. We ourselves were subject to being knocked out of the box by a lightning strike by some other carrier that took us on between Love Field and Hobby Airport. Today, approximately eight percent of our revenues are derived from the Love Field-Hobby route. That means that if you want to exterminate southwest Airlines you'd better be prepared for a war in the Pacific. You'd better bring your flamethrowers, you'd better bring your hand grenades, because it's not going to be a long-range artillery duel, you're going to have to go to Albuquerque, Austin, San Antonio, Midway Airport, Kansas City, Nashville, in order to dispose of us. And again, that expansion is a form of protection. It looks aggressive, it looks offensive, but at the same time is the most marvelous defense that you can possibly have.

By making statements like the foregoing, Kelleher motivates his audience to take pride in the company and inspires the followers to engage the competition with confidence. As a result, southwest employees are proactive and passionate when it comes to advancing those objectives that will enhance the company's competitive position. This proactive stance regarding competition is also upheld in the philosophy of Don Valentine, a transplant from Pepsico and the 
company's vice president of marketing. Valentine argued that the company attempts to maintain a marketing strategy that keeps the competition reacting to southwest instead of Southwest reacting to the competition.

While the employees of Southwest Airlines love to work for Herb Kelleher, they are by no means shy about expressing their dissatisfactions to him. Consequently, Southwest is not without internal conflicts. As the review of literature shows, transformational leaders see conflict as a means by which healthy organizational change is facilitated. Kelleher is not shaken by the internal conflicts at Southwest. He sees conflict as a sign indicating that employees are interested and involved in the well-being of the airline. Kelleher's relationship with his employees is closely aligned with Lindblom's (1968) notion of reconstructive leadership. In this sense, both Kelleher and his people are involved in a mutual influence process where Kelleher seeks to satisfy their motives as he learns about their needs. Thus, conflict becomes another tool used by the chief executive to stay in tune with the goals and aspirations of his people.

I like to have [the employees] grumble about the way our company is being run because to me it's a very healthy sign of concern. They tell me what they think should be done rather than going around with their heads down saying, in effect, "I don't care how this 
company is doing." I really love to get all their suggestions, complaints, and questions.

What's really rewarding for me is to go into one of our pilots' organization meetings and have them express concern about what's going on in all of the other departments of the airline--not just their own area. We not only have job cross-over, we have concern cross-over between departments. At southwest our employees help other employees to get their job done.

\section{Accomplishing the Mutual Goals of Leader and Led}

To say that Herb Kelleher is interested in accomplishing the mutual goals of leader and led is, perhaps, an understatement. Whether one is talking with the ground operations people who load bags into the airplanes, or one of the senior officers of the corporation, they will all say that Herb Kelleher would do anything he can within reason to further their goals. If there is one thing that stands out with regard to Herb Kelleher, it is his ability to integrate his own goals with the goals of his employees into a formidable force that unifies the company. The employees at Southwest Airlines trust Kelleher because he consistently demonstrates that he is looking out for their best interests. They know this because he involves them in almost everything he does that affects the company. While many in the organization point to kelleher as the individual most responsible for the success of the airline, he is 
very reluctant to take credit for it and immediately likes to shift the praise to the employees. As the people of Southwest Airlines take note of this day after day, it's easy for them to see that he is genuinely interested in their wants and needs. When asked what will distinguish the airlines that thrive in a hotly competitive environment, Kelleher responded by saying that new approaches to leadership and management must be developed. He said:

The - . approach must differ radically from the past. I think we must create the feeling that it's "one for all and all for one," a sort of Three Musketeers' family feeling where there's a willingness to sacrifice and take care of each other in order to prosper. That way we'll bring on new generations of employees who will have very secure, well paying, enjoyable and fun jobs.

As a consequence of the tremendous bond that Kelleher has with his employees, Southwest has reached that stage of integration where leaders and followers establish a spirit of trust, openness, and cooperation (Buckley \& Perkins, 1984). The resonance or harmony that Harrison (1984) described when talking about attunement (oneness) between leaders and followers is very evident at southwest Airlines. I have frequently traveled on the airline, and through observation for this investigation I could not help but notice the state of balanced wholeness that emanates 
from the commitment that southwest employees share when working together.

Symbolically, the accomplishment of mutual goals and the concern Southwest employees show for one another is most powerfully expressed in the metaphor of the family. Talk with any Southwest employee and the majority of them will tell you that working for Southwest Airlines is like working with one, great, big family. During the course of the research I found that employees at every level of the organization refer to "we" (the southwest family) when talking about the company. This is depicted in a brief conversation with the manager of dispatch, Dale Foster. He pointed out that,

The guy who empties the trash here is just as important as Herb Kelleher, and I talk to him just as friendly as I do to Herb Kelleher because he's just as important. If he didn't pick up the trash, within two weeks we wouldn't be able to operate around here.

Is that the kind of attitude Herb Kelleher has, I asked? That's right, and this is what he's done. It's always "We at Southwest have done this, the people of Southwest have done this." so, he does give you credit where credit is due, and that love and affection flows back the other way. I'll give you another case. Back here in June he had a little birthday party, it was Herb's birthday, but it was also Duran's birthday, the 
maintenance guy who changes the light bulbs; and they had a cake for both of them in the same room at the same time.

Dale Foster's remarks are very consistent with my own observations. It really doesn't seem to matter who he is talking with, Herb Kelleher looks beyond a person's title and position to the individual and treats that person in the same manner as he would anyone else. Colleen Barrett, vice president of administration and Kelleher's long-time Iriend, confirmed that Herb enjoys and is comfortable talking with people at every level of the corporation. It is obvious that Kelleher's ability to refrain from giving any one person or group preferential treatment has helped legitimize the family metaphor. Captain Paul Carter, manager of flight operations, described the impact the metaphor has on the employees.

First of all, the feeling we get at southwest is that you're not working for the company, you're working with the company - . it's more a matter of "we." When speaking in reference to the company, most of the people you speak to within the company refer to the company as we. Sometimes, you almost feel guilty going to work feeling so good . . . Sometimes I'm amazed that I get paid to do something that I love so much. 
The "we" attitude and the family metaphor used so consistently by southwest employees are indicative of the mutual goal attainment philosophy held by the majority of people in the corporation-as a result of Kelleher's leadership. The passion with which these people describe their company as a family causes one to see how much they truly believe Kelleher wants the very best for them.

The fact that southwest employees view themselves as a family is not surprising when one listens to the way Kelleher talks to them. His opening remarks at a speech given in Phoenix to some 750 employees show his feelings for this extended family.

It really is an overwhelming delight to be with you this evening. [A person] from san Diego came by my office not too long ago and he said he'd heard that people at Southwest Airlines were pretty special, and I told him that I thought that was the case. And after giving a glowing report on all of you, your sprightliness, your can-do attitude, your joy, your concern, your caring for other people, I think that [this individual] thought I was a typical Irish B.s.er and that he was going to be very disappointed when he met all of you. And then he sallied forth to meet the people of Southwest Airlines. And he returned to my office that evening and he said, "Herb everything you've told me is absolutely true. They are 
wonderful, they do have spirit, it shines from their eyes, and it's truly a remarkable company."

And that's the reason why I am so enthusiastic about every opportunity to be with you. I have said, on at least a hundred occasions, that I would rather be with the people of Southwest Airlines, no matter what the occasion, no matter when it is, than make a trip to Paris . . . or do anything else in the world people think is of an exalted nature and very desirous.

But the truth is, you know, there was a Spanish explorer named Ponce de Leon, who was looking for the Fountain of Youth . . . He believed that if you dipped yourself in it, even for the shortest period of time, you would shed 20 or 30 years off your chronological lifespan. Well, I found my Fountain of Youth in the employees, the people of Southwest Airlines. Because every time I have the opportunity to be together with you, it reminds me how wonderful you are, it rejuvenates me, restores me and refreshes me. While these remarks may be passed off by some as merely inspirational rhetoric, Southwest employees point out that these words are consistent with and confirmed by his daily actions. Kelleher rarely misses an opportunity to communicate his love and appreciation for southwest employees. This, in turn, contributes to establishing the family 
atmosphere at Southwest because the employees tend to model this behavior with each other. Consequently, there is a very giving, sharing attitude at southwest that facilitates mutual goal attainment among family members.

Kelleher's openness about company matters with his employees also reinforces the family metaphor. Much like a family would sit down at the kitchen table for a private discussion, Kelleher will sit down with individual employee groups to discuss the various aspects of a particular decision. He is adamant about making sure that the employees are informed about any new programs prior to their implementation and any public announcements that are made regarding them. With few exceptions, employees have the security of receiving vital information about their jobs and the company personally from Herb and other senior officers rather than through the media and customers who fly on the airline. knowing that they will be informed first about important issues helps to establish a family tie, a spirit of cohesiveness among the members of southwest Airlines. For example, before Kelleher publicly announced Southwest's acquisition of Muse Air (now TranStar), he sat down with each employee group to inform them about the decision that had been made and answer any of their questions. As Colleen Barrett explained, "He doesn't ever want any employee group to read something in the newspaper the first time about us that's different or new, 
that's newsworthy." She added that he insists that other officers talk with employees before public announcements are made as well. At a meeting with colleen Barrett, Paul Carter, and Jim Amos, vice president of flight operations, the three of them remembered a story that shows how this attitude has become deeply embedded in the organization. Kelleher, who loves to play pranks on his people, decided to make a point to his senior officers during a seminar called the Excellence Program. The point he wanted to make was that in an industry plagued with acquisitions and hostile takeovers, where rapid change is the norm, the only airlines that will survive are those that respond immediately to industry changes. In order to illustrate how rapidly the industry was changing, Kelleher sent a message with the facilitator of the seminar to the senior officers. The message indicated he was sorry that he couldn't make the meeting because he was at the hotel finalizing the press announcement to announce the southwest had just been acquired by USAir. Upon hearing this, the seventeen officers in the room immediately began to laugh in disbelief. Once the laughter had subsided, the facilitator asked why no one had believed the message? Colleen Barrett related the story; "And Amos said just right off the top of his head, 'Because Kelleher would never announce anything like that to the outside. He just wouldn't do it.'" He added, "I've seen deals go down before where he's 
made sure, with every effort, to get us on a sunday, like it was with the Muse thing, and let the officers know."

When confronted with a question about how realistic it is to look at a corporation with almost 5,000 employees as a family, Kelleher said it is very easy. He maintained that it's a matter of priority. If you put it high enough, if you value your people enough, you simply work harder to do those things that welcome people into the fold. Relleher's philosophy is that a corporation is an organization of people who are striving for cooperation and coalescence in the pursuit of a common goal. He disagrees with the statement "the business of business is business." Pointing to the fallacy of this statement, he argued that: "The business of any business is people. If you don't pay attention to your people, if you don't respect your people, you're going to find that the best idea in the world and excellent management and adequate capitalization is of no avail."

Southwest employees are well aware of how hard he works at putting this philosophy into practice. They describe him as a person who is highly in tune with employee's needs, a person who gets out into the bowels of the organization to find out what's really going on. While walking the floors of Southwest Airlines often makes him vulnerable to the complaints of employees, Kelleher said that getting out with his people is really the finest part 
of his job. He remembered that in the first quarter of 1986, he was so consumed with cutting costs and restructuring, remarketing, and repricing the airline that he didn't have the opportunity to get out and be with the people of Southwest.

And a remark I made to some people here was that if I had another quarter like this, I was going to quit, because the thing that's really the exhilaration for me, the part I enjoy most, is getting to be with the people of Southwest Airlines.

sure, they have complaints, they'll gripe, and somebody needs to hear their complaints and in many cases they're well justified. I think every company needs an ombudsman, and that's what I try to be in a sense. When I feel that our people are getting hurt in a way that our rules here never intended to accomplish--you know, that wasn't the objective, but the rule appears to cover it--well, you make an exception to the rule.

As a result of demonstrating this attitude so consistently, employees write and visit Kelleher frequently to express their feelings about the company. One such individual is Paul Quinn, vice president of schedule planning, who recounted a story that illustrates how comfortable employees are at talking, even arguing, with 
Herb. Quinn remembered Kelleher's interest in his knowledge and input as a dispatcher,

The first time I ever met him was when we were going into the Transport Workers Union. He took us out to dinner and he asked us, "Could you give me 90 days?" And maybe the two of us had a little too much, and we got into one hell of an argument. I mean it was one hell of an argument. About unions and what I thought was going on in the company that I didn't like. But then the next morning, walking into work, I had no idea what was going to happen. And he came down and I started to apologize to him and he started to apologize to me, and he said 'I'll never drink with you, you crazy Irishman, again!' And that just settled it for the two of us. And he didn't give up on me.

Quinn also mentioned another incident that took place some time after his argument with Kelleher. Upon recognizing that the interests of the Transport Workers Union (TWU) did not necessarily coincide with Southwest Airlines' philosophy, quinn went to Kelleher and asked him for support in pulling the dispatchers out of TwU to form an association. After listening to quinn intently, without putting anything in writing, Kelleher gave his endorsement. While Paul Quinn went to work on the deal, the dispatchers trusted kelleher enough to risk loss of representation based on a verbal agreement. Quinn showed how kelleher 
subsequently bargained to reach some common agreements with the dispatchers in which the needs of both could be met. When we got out. . . we were naked. We didn't have a thing. And kelleher kept his word. He sat down and negotiated a contract in a couple of days. And we had a letter of agreement stating what our pay would be. And ten years later it's still working.

Kelleher's efforts toward mutual goal attainment can also be seen in his desire to celebrate with the employees after a contract has been negotiated. Thus, he communicates his interest in their needs not only by negotiating with them fairly, but also by showing them how much he likes to be with them on his own time. It's not unlike Kelleher to frequently reserve an entire restaurant and bar for drinks and dinner to show his appreciation for a particular employee group (e.g. dispatchers, flight attendants, pilots) for their willingness to negotiate a good contract. When he does this, the employees will tell you that they're never sure whether the bill is coming out of company expense or out of Herb's own pocket. This is one of the ways in which he shows them that his interest in them goes beyond the roles they play at Southwest to who they are as individuals. This is also his way of rewarding and reinforcing the employees for working to accomplish goals that are mutually beneficial for themselves and the company. As Dale Foster pointed out, 
He is a very sharing person, and I think as a result of that, the company really leans back and trusts him. He is the leader, and he's taken it from the days of three airplanes to sixty-three, and a very successful airline. So there is a lot of trust and a lot of validity involved in what he says and what he does.

In another interview, flight attendant Tona Weigelt affirmed that "Herb is real fair, he's a real good-hearted man. He likes to have a good time. He likes to show his employees that he cares about them, and Herb has been doing this for years."

According to those who have been at the bargaining table with him, Kelleher always looks for a way to set up a win-win situation in which the common good of the corporation and the individual employee is achieved. Tona Weigelt indicated that "with Herb, you know that he's going to be fair and just. He is going to give you all that he possibly thinks he can give you without hurting another group, without making other groups angry." Weigelt explained that Kelleher is particularly adept at knowing how far he can go in the negotiation process before it becomes detrimental to the company. She added, "Herb's willing to find a fair place to negotiate with you but still think about the company's long-range goals so that. - nobody loses their jobs, goes on furlough, and we don't have to take a decrease in pay." She pointed out that the 
flight attendants have always been able to strike a deal with Kelleher that is mutually beneficial for all involved. So we do get to a point where we say, "okay, this is a good deal for us, it's a good deal for the company." And the fact that he's honest with you and comes right out and tells you, you know where the stopping point is - . When you go into the bargaining table with a guy like kelleher, you trust him and trust the fact that he's looking out for the best interest of everyone involved.

However, Kelleher is quick to suggest that it is the employees who give the company what it needs by way of contracts in order to remain competitive. He consistently argues that the employees are the ones who have made the difference at southwest.

By working to accomplish the goals of southwest employees as well as his own goals, Herb Kelleher receives a lot from his people in terms of productivity. In an article he wrote, Kelleher (1985) reported that,

In 1981 Southwest's fully allocated cost per passenger for a 200 mile market was $\$ 24.00$ as compared to $\$ 58.00$ for United. This cost difference was due in large part to the higher productivity of southwest's employees. Southwest's pilots and flight attendants flew more hours than their counterparts with the regulated carriers. Southwest's pilots flew 73 hours 
per month in 1981 while United's pilots averaged only 43 hours per month. Southwest operated its aircraft 9.5 hours per day in 1981; United operated its aircraft only 5.2 hours per day. (p. 317)

Dale Foster added that while Southwest dispatchers do approximately 80-90 plans (routing airplanes) a day, United would do only 20-30 plans daily. The productivity of Southwest employees is not only brought out in the statistics, it can also be seen in the observations made by customers. Kelleher proudly recounted the statement of a customer about what happened when a southwest aircraft pulled into the gate.

The customer said: "You know when that airplane is approaching the gate, your people are racing across to it, the provisioning trucks are coming and the tugs are coming and the baggage carts are coming and the whole thing is just a sea of motion." Then he added "When I'm on other airlines and pull into the gate, everybody's just kind of sitting there with their hands behind their head, reading the newspaper, waiting till the airplane is stopped."

Kelleher believes that the production capabilities of employees are a result of their commitment to collectively accomplish a common purpose. It is evident that every member of the southwest family feels a sense of ownership and takes responsibility for the well-being of the company. 
Another way in which Kelleher communicates his interest in the needs of employees is by soliciting their feedback. Formally, this is done through a suggestion box which Southwest employees do use because they know that all suggestions are presented to Kelleher and many of them are acted upon. In this sense, he involves the employees in the process of establishing goals and objectives that address their collective interests. As Greg Roessner, manager of ground operations, pointed out,

He's interested in what you are saying. He's not an egotistical type person that's interested in blowing his own horn or impressing you with who he knows or who he rubs elbows with. He's interested in you, listening to what you're saying. And he's assimilating all of it, and possibly using it.

We have a thing right now: it's called "Help Herb," that Colleen circulated, soliciting feedback from operations, flight attendants, ramp people, everyone, on suggestions as to better ways to serve the customer.

And do people actually send suggestions in, I asked? Oh God, yes. Definitely. Sure. They know that it's not going to wind up in the wastepaper basket because - . of his whole personality, his whole method of operation. 
Roessner's remarks were confirmed in a statement made by Kelleher regarding the willingness of Southwest employees to respond when called upon.

They want action. All you have to do is say to them, "This is something we have to do" and boy, they're on top of it with eyes alight, ready to go, and you're gonna get thousands of ideas. We bring in the people that are actually involved with something. If we have a new program, for instance, we bring in the operations people and the supervisors and say, "What do you think about this? What can we do to make it better? What can we do to perfect or better fix this thing?" And they respond; they love it.

When asked if his passion for Southwest Airlines is as great today as it was back in the days of the hard-fought wars with other carriers, Kelleher responded by saying, "It is. It's really a passion for the people of the company, and their security, job security, wage security." This points to another area where the mutual goal attainment of leader and led is quite evident at Southwest Airlines. Kelleher firmly believes that one of the best ways that he can help employees is by insuring the profitability of Southwest. Whether it's for a magazine article or a speech given to update his employees about the company, there is a philosophy to which Herb particularly likes to refer. He refers to this philosophy frequently because it illustrates 
his attitude about the importance of profitability to the employees. According to Kelleher,

Samuel Gompers, founder of the American labor movement, said "The greatest injury you can do the working man is to have an unprofitable company." He knew that's when people start getting fired and laid off. - . Without profitability there can be no expansion, there can be no growth. That means that gradually there is a withering away, reduced pay, less jobs. And ultimately a disappearance of your company.

To most, this philosophy may represent simple-minded, common, business sense. However, in an industry that has been flogged with bankruptcies and hostile takeovers, the employees of Southwest Airlines clearly understand the importance of Kelleher's statement and recognize that profitability is a contributing factor in mutual goal attainment. Kelleher sums it up by saying: "It's difficult to have profit sharing if the company doesn't make a profit."

Dale Foster remembered a time when he was in San Francisco and one of the gate agents was picking things up. and cleaning in between flights. When Foster inquired as to whether or not she had a cleaning crew, the gate agent responded by saying, "Oh, no, they're here, but I'm just doing it because this is my profit." Thus, one cannot underestimate the impact that Herb Kelleher has when he 
says he wants to maintain a profitable company for the employees.

In 1987, Southwest Airlines is the most employee-owned carrier in the industry. Employees own $12 \%$ of the company and have benefited significantly from the company's profit sharing program. Southwest initiated the industry's first profit sharing program back in 1973 to reward employees for their dedication to the company. Kelleher eagerly clarified that the profit sharing program was not an attempt to gain from employees concessions such as reduced wages or less stringent work rules, but rather a way of allowing them to participate in the profits they helped produce. Profit sharing is another innovation that was brought to the industry by southwest Airlines. Seven years after the company began this program, other airlines, beginning with Eastern, followed the example set by Southwest.

Through the expansion of the company, Kelleher has also helped accomplish the goals of individuals and communities around some of the smaller, less-traveled airports that southwest services. Kelleher explained that when Southwest went into the little town of Harlington, Texas, the traffic at that airport tripled immediately. He acknowledged that the increase in traffic helped the economy by increasing paid parking and car rentals. The same could be said for Dallas' Love Field and Houston's Hobby Airport. The cities of Dallas and Houston were losing money on these 
airports until the arrival of Southwest Airlines. Southwest helped to double the traffic at these two airports and today they are both very profitable. Kelleher also believes that southwest has contributed to the development of Chicago's Midway Airport, one of the fastest growing airports in the United States.

Finally, one of the most significant ways in which Kelleher and the people of southwest have manifested the notion of mutual goal attainment is by their annual "Home for the Holidays" promotion with senior citizens. Tonda Montague, manager of employee communications, explained that this program "affords a select group of senior citizens, who might otherwise not be able to travel, an opportunity to be with friends and relatives during the festive season when home and family are so meaningful." Persons 60 years of age or older were given a trip to go home and be with their loved ones. While the seniors benefited tremendously from this promotion, the company also did very well. Southwest carried approximately 120,000 senior citizens during the promotion, which made its load factor $60.8 \%$, the highest in the industry. The company received at least three times as many favorable letters from customers as it had with any other promotion and finally, the company made a minimum of $\$ 1.5$ million as a result of the promotion. 
Whether it is his attempt to make flying affordable to more people, devising new ways to service the customer, meeting the needs of employees, or enhancing the communities southwest serves, there is no question that Herb Kelleher is motivated by helping people accomplish their goals. His ability to understand and meet the needs of those around him contributes to his success as a leader. When a leader is continually looking for new ways to encourage and promote people, as is the case with Kelleher, his people will obviously bend over backwards to accomplish his objectives, as is the case with the people of southwest Airlines.

\section{Vision and Alignment}

It has been said of Peter Ueberroth, President of the 1984 Los Angeles olympic organizing Committee, that he has a magnificent way of turning things into a cause. The same must be said of Herb Kelleher. He has turned southwest Airlines into a cause for which he, and the employees who have followed him, have fought for the last fifteen years. The cause was fashioned as Kelleher became exposed to the oppression of the major airlines in the early years. As a result of this cause, he has maintained a vision of creating an airline where people have job security, where their humanity is enhanced because they grow as individuals and have a lot of fun, and where profits are made because 
of an uncompromising commitment to serve the customer through frequent flights and low fares.

One of the reasons that the chief executive has been able to maintain this vision and watch it become a reality over the past fifteen years, is because of what he calls "longheadedness." According to Kelleher, "longheadedness. - is the vision to look ten years into the future. To do things that are necessary in order to be alive and viable ten years down the line." Kelleher emphasizes "doing things that are necessary" because he makes a very important distinction between means and ends. He noted that in many cases people preoccupy themselves with things that have little or no consequences on what they're supposed to be achieving. Kelleher illustrates this point by suggesting that:

Computers are means, not ends in our business. And I see companies get carried away with information systems. Suddenly, they are really determining what the company can do, what its goals should be and that's wrong. That's not the way it should be. In other words, every time you're going to do something that's going to add cost and/or complexity to your business, saỹ: "What business am I really in? How does this promote what I'm really doing?"

In essence, Kelleher has concluded, along with Bennis and Nanus (1985), that there is a difference between doing 
things right and doing the right thing. As his example clearly shows, and as the history of southwest Airlines confirms, Herb Kelleher is a leader because he has been concerned with doing the right thing.

Rodkin (1985) reported that Herb Kelleher has been acclaimed by industry analysts as having "an acute sense of evolving industry trends" (p. 11). Perhaps this is because Kelleher thinks in terms of the Airline's long-term future. My passion for now really is to try to focus on 1995 and the year 2000. Because there are lots of other people who are focusing on today, next week, and next month, even. And what I'm trying to do is to establish a niche for southwest Airlines that will enable the company to continue to be successful for the benefit of its employees and shareholders.

Kelleher's vision is inspired by Samuel Gompers statement that the best thing a company can do for its people is to make a profit. He states firmly: "MY goal is to leave a company that is absolutely entrenched, absolutely solid, absolutely profitable, and able to provide job security for everybody. My eye is really on that future."

Kelleher is a forward tisinker with his eye on the big picture. Philosophically, he noted that "in the 80's, airline management must realize that those who only do things for the short run won't be around for the long run." His future-oriented, proactive attitude combined with his 
willingness to give employees a lot of responsibility for realizing the vision has made southwest one of the most innovative, trend-setting airlines in the industry. In talking with a southwest passenger on a flight from san Diego to Houston, I learned that Southwest is considered a very progressive airline by other carriers. This individual, who had formerly been in flight operations and later dispatch with USAir and Frontier Airlines, explained to me that one of the ways in which southwest has demonstrated its forward thinking is by purchasing highly fuel efficient aircraft (Boeing 737-300) that are more quiet than other planes. This change was made, Kelleher said, long before the noise abatement restrictions forced airlines to go to more quiet equipment at smaller airports.

Through speeches, videotaped presentations, annual reports, and the company's newsletter, Kelleher consistently furthers the cause by articulating his vision. It doesn't matter in which form the message is packaged, the message almost always centers upon his concern for the employees and their future. Recently, Southwest employees had the opportunity to hear Kelleher speak after they had watched a slide show depicting the fifteen year history of Southwest Airlines. An excerpt from this presentation exemplifies the manner in which Kelleher articulates his vision. 
When I look at that slide show and I see all those folks that have really spent their blood, sweat, and tears getting southwest Airlines into the air . . . it makes me very nostalgic, because at one time . . there weren't very many people in the world who would give a plugged nickel for the success of southwest Airlines. And what overcame that was the strength of people. People. people, people. People striving against all odds, against all difficulties for something they believed in. Really like a crusade, like the early Crusades that were motivated by religion. This was motivated by the idea that we are the best, we are going to do something for the public that is exceptional, we're going to give them better service at lower fares, and it's a lot of fun making a success out of this company.

And I've often said . . that if the airline industry lasts a thousand years, I believe that people will say that you, the people of Southwest Airlines, represented its very finest hour, and its finest people. I respect you, I enjoy being with you, and indeed I do love you. And I'm not ashamed to say that. And I thank you for all of your magnificent contributions to Southwest Airlines over the years. While more specific examples of how Kelleher shares his vision will be recounted, the foregoing example is very 
important because he inspires his people to look toward the future by reminding them of their past. Again, it must be emphasized that these messages are much more than mere lip service. It doesn't matter if he's speaking to a group of 1,000 or one, the message and the daily actions that support it are always the same. He is believable to Southwest employees because he is very consistent in communicating his message. Gary Barron's comments reflect the impact of Kelleher's ability to instill vision by recounting the past. As southwest employees are reminded of where they've been and what they've accomplished, it's obvious that they develop an assertive or aggressive posture and a sense of confidence about the future. Barron pointed out that,

Those early days of being the underdog created an atmosphere of closeness among the employees. It started with 200 employees and it continued. Those other airlines weren't going to knock southwest Airlines out of business. That same . . close-knit, everybody pull together attitude . . . has continued. Now, 5,000 employees and we're spread from New orleans and Chicago all the way to the west coast. It's not as easy as it once was to maintain that closeness. And I guess Kelleher really is the common thread that unites people--everybody loves Herb. He's the common denominator. 
One of the most significant things that Kelleher has accomplished in terms of promoting the vision at southwest is to keep the history of the company alive. The constant reminder of the company's heritage motivates employees and instills within them an excitement and enthusiasm about the future. Symbolically, the company's heritage has been housed in a story that is told with pride by every southwest employee. Kelleher talked about Southwest's heritage this way:

I've laughed about it, and I've said I have to invent crises for our people; that's when they really perform best. They don't like things being dull. They don't like normalcy. They want to get into a spot, they want to get into a battle. They want to have a cause - . they want to be on a crusade. And fortunately, I think we've always had an opportunity to do that. And I think that [the older] employees have certainly passed that on to new employees; to a certain extent, we pass it on; part of the orientation program is the history of Southwest Airlines, which I think is a fairly inspiring history.

And then you've got to manifest it every day in everything that you do. Not necessarily big programs or policies, but little acts that are symbolic in and of themselves. 
Kelleher's vision is pervasive throughout the company. It is obvious that it has had an impact on employees because most of them can describe, in no uncertain terms, exactly what his vision entails. Employees at every level of the organization recognize that their job is to provide unmatched service to the customer and to have as much fun as possible in the process. Greg Roessner indicated that Kelleher is very enthusiastic about communicating his vision. He says,

Has a clearly defined philosophy and vision and his goals and priorities are clearly set. In strictly business terms, his commitment is to provide the best possible service in high frequency flights and low fares to the traveling public. That's just the business facet of it. The personal facet of it, I think, is one of instilling in people self-confidence, pride in their work, drawing out their potential, committing themselves to a larger goal, larger than themselves . . He genuinely cares about people, he really does love people and that warmth comes across. And I think that that just can't help be communicated when he talks to people.

Kelleher has established an interconnectedness between organizational objectives and individual development at Southwest. There is no doubt that the employees at Southwest Airlines are committed to his vision and have taken 
ownership in it. One gets the feeling that kelleher and the people of Southwest have reached that degree of alignment where the various parts of the organization perform as an integrated whole. Consequently, it is evident that there is a oneness between individual and organizational purposes at Southwest. That is, there is a clear sense that people are doing their life's work instead of just doing their jobs. Kelleher states,

I want it to be a meaningful experience for them. I want it to be something that's special for them. You know Robert Frost said "Isn't it a shame that we get up in the morning and our minds are active until we get to work." I want those minds to work furiously after they get to work. I want it to be something that they look forward to... like going to a Broadway play, going to a show.

Kelleher described the personal sense of fulfillment he gets from helping to create an environment where employees find meaning and purpose in their work. He remembered hiring some mechanics that had been working for another airline for a long, long time. The mechanics had worked for Southwest approximately six months when one day as Kelleher was talking with them, one of them said, "I've been a mechanic for 30 years and this is the first time in 30 years that I've ever looked forward to going to work. 
Always before I felt that I was compelled to go to work. Now I want to go to work."

As a part of the vision he communicates, Kelleher insists that employees have fun on their jobs. As an individual who will tell you that work is both his vocation and his avocation and that southwest is his niche in life, no one has more fun with the employees and customers of Southwest Airlines than Herb Kelleher. He believes that the way employees think and feel about each other will ultimately be manifested in the way they treat customers. "I think that's the reason why for four years in a row, Southwest has had fewer complaints from passengers filed with the Civil Aeronautics Board per 100,000 passengers carried than by other airlines. I tell our employees, 'I want you to have fun every day in what you do.'"

Kelleher, who recognizes little if any difference between work and play, has effectively created an atmosphere at southwest where employees thoroughly enjoy pursuing the cause he has laid before them. As Captain Dick East, a pilot for the company, explained, this includes having fun. One of the things he learned from Herb, he said, was that "you go to work and you enjoy yourself, and that makes the world go."

Most of the employees would confirm that Herb Kelleher has a special and unique way of motivating them. He does it, in part, by genuinely and sincerely articulating his 
vision, a vision that has drawn them into a cause and aligned their purposes with the purpose of the company. This can be seen in the final remarks of "Herb's Message to the Field."

And we are a family, you're my family, and $m y$ fondest hope for all of you is that you will be secure in your jobs, that you will be favored in your wages, but beyond that, that you will derive a certain spiritual or psychic fulfillment from being with Southwest Airlines. And $\mathrm{my}$ fondest hope and $\mathrm{my}$ fondest dream is that in the year 1995, and 2005, and 2020, that when you're sitting around talking to your grandchildren, you'll be able to tell them, "You know, Southwest Airlines was really something very, very special. It was something that ennobled and enriched my life. And something that made me better, and bigger, and stronger than I ever could've been alone."

And if, indeed, that happened with your grandchildren, then that will be the best contribution that I could have made to Southwest Airlines and to its future.

Shaping Values and Educating by Example

Peters and Waterman (1982) as well as Greenfield (1984) concluded that the great organizations are characterized by the unification of people around a clear sense of mission founded upon particular values. Southwest 
Airlines is no exception to what these writers have observed. Employees at every level of the corporation share the same primary values and have a unified sense of purpose. There are many in the company who would argue that Herb Kelleher is responsible for shaping the values that the people of Southwest Airlines live by. Kelleher, the highly visible chief executive, is a powerful example to the people of southwest. He spends an incredible amount of time with the company and is very accessible to employees. These two factors alone enable them to watch him closely and learn first-hand from his example about the values he deems most important. Moreover, because Kelleher is an individual who is extremely likeable, employees throughout the organization will jump at a chance to "get a word with Herb." This obviously intensifies and, in turn, facilitates the learning process. There is no question that Herb Kelleher, more than any one single person, has shaped the values that influence the way people think and act at Southwest Airlines.

The values that constitute southwest's character and define its direction are housed, to a large degree, in the company's mission statements (see Figures 4 and 5). The values that emerge from this mission statement and the values that are consistently lived out at southwest have to do with employees and customers. While this may not seem surprising for a business that is as labor-incensive and 


\title{
THE SOUTHWEST AIRLIHES' PEOPLE MISSION
}

\begin{abstract}
In addition to maintaining our low cost structure and our nigh employee productivity, which, in turn, enable us to continue to earn a good rate of return on investment for our sharenolders and an enviable profit sharing return for our employees, the "mission" of Southwest Airlines shall be to endeavor to cont inue to provide excellent shorthaul, high frequency, air service to the traveling public, and cowards this end, to do everything within its power to develop the best notivated

employees (from the person at the top of the Company to the newest hire at the bottom), with warm courteous, and cooperative personalities who will constantiy and consistently do all within their power to accomodate our customers in an efficient and quick -- but with just as much emphasis on friendly and fun -- manner -- a manner wich will keep customers -- and employees -. smiling and always ready, willing, and eager to come back again the next day.
\end{abstract}

\section{Goals Towards Effectuating the "People Mission"}

In order to facilitate the People Mission, it is imperative that all levels of management boldly and overtly accomplish the following imediately:

1. Be responsible for assuring that all employees it the management level (again, top to bottom) understand - and com:renend -. that the foremost commodity that we have to sell which is $d \cdot i$ ferent from other airlines is the dttitude, behavior, and friendliness of our enployees themselves.

2. Be responsible for assuring that all employees -. managenent, as well as non-managenent -- realize that we are in business to be of service to our customers; we want and need our customers to know and appreciate this fact; and all of us need to remind ourselves of that fact at the beginning of each day.

3. Encourage bending "toward" the customer instead of "away from" the custoner in all gray areas; and more importantly, we should inform all employees of this feeling on our part.

4. Encourage creativity and participation; we need to recognize special talent; we need to display .- and encourage .- a sense of humor; we should not take ourselves too seriously; we need to pay attention to and consider our employees' needs and suggestions; we need to show appreciation for excellent work when it is being performed; we need to correct, guide, and counsel those workers who are not. performing satisfactorily; and we need to remove those employees who have shown that they either will not or cannot perform the jobs they were hired to do.

5. Hire only those employees who are "other" (as opposed to "me") directed, energetic, cooperative, friendly, and wa will contribute materialiy to the success and progress of Southmest Airlines; no hiring for any other reason.

It must be understood at the outset that this statenent of position covers only the "people" aspect of our "mission" and does not cover the much broader operational "airline" aspect of our intssion. Nor does it supplant the overall definition (or concept) of our Company and its ohllosophies and bustness strategies as prevlously auti ined in our annual reports.

\section{Figure 4. Southwest Airlines's mission statement as it} appears in the company's personnel package. 
1. Southwest Airlines resolves to deliver 130 million genuine smiles to our customers in 1986 . That averages to about 10 smiles per customer, smiles you'll see from the minute you arrive at the airport to the minute you leave.

2. Southwest Airlines resolves that 14 million beverages will be served to customers within a quick twenty minutes of takeoff. On those early morning short flights, you can count on a second or maybe third cup of coffee, especially when you really need it.

3. Southwest Airlines resolves to introduce air travel to thousands of people as we enter at least two new markets. In every market Southwest has entered in the last fifteen years, our everyday low fares have allowed many people to travel by air that previously could not.

4. Southwest Airlines resolves to serve 8 million free cocktails, including wine and beer, on our Executive and Spoiler Class flights.

5. Southwest Airlines resolves to fly over 250,000 flights in 1986 as we continue to provide our customers with whatever travel convenience their schedules demand.

6. Southwest Airlines resolves not to charge a fee for a canceled reservation. We don't believe in penalizing our customers simply because their plans change. We never have.

7. Southwest Airlines resolves to maintain one of the highest profit margins in the airline industry. This will keep our stockholders happy, but, more important, it will allow us to continue to offer everyday low fares and convenient schedules to our customers.

8. Southwest Airlines resolves to deliver 11 million customers to their destiration on time. This means 85 percent of our trital flights arriving within fifteen minutes of their scheduled time, continuing one of the best on-time performances in the industry.

9. Southwest Airlines resolves to return 100 percent of personally identified items that are left on our planes. This unusual service may be explained by the fact that our employees own 12 percent of our company. With that much at stake, everyone works a little harder.

10. Southwest Airlines resolves to continue offering simple, everyday low fares to our customers. You will never have to wonder if the person flying next to you paid half the fare you paid because he or she made a reservation a day before you did.

\section{Figure 5. Herb Kelleher's mission statement as it appears in the August, 1986 edition of the company newsletter.}


customer-oriented as the airline business, the degree to which Kelleher has embedded, emphasized, and reinforced these values in Southwest Airlines is quite extraordinary.

That Loving Spirit. Southwest is perhaps best known as the 'Luv Airline' with the most spirited employees in the industry. This is an image and underlying value system the company works very hard to promote. Kelleher firmly believes that the way he treats his employees and the way they treat one another will directly affect the way the customer is treated. When he says that his passion for Southwest Airlines is really a passion for the people of Southwest, no one questions his sincerity because he lives this value on a daily basis. While customers bring in revenue and keep the company alive, Kelleher recognizes that the key to satisfying customers is quality service and that quality service begins with employees. Hence, his number one, primary interest is the people of southwest Airlines. Kelleher's care and concern for his people has been communicated so clearly that, like a pebble dropped in a still pond, it ripples through every level of the corporation until ultimately it is transferred to the customer.

I was particularly struck, through my own observations, by the care and concern that Southwest Employees show one another and also by the genuine, helpful attitude with which they accommodated me. Upon arriving at the company's Dallas headquarters, I was immediately made to 
feel like an insider, as if I were a member of the southwest family. It didn't matter if people knew the reason for my presence or not, everyone with whom I talked was not only willing, but excited to share a bit of their experience and a part of their company with me. The people with whom I talked seemed to love their jobs and exhibited such a great deal of pride in the company; it was almost as though it was "show and tell" time. The spirit of care and concern was so overwhelming among the employees that I began to question whether or not their responses to my inquiries were rehearsed. However, as I spent more time in observation, I realized that the attitudes and behaviors of the people of Southwest Airlines were simply too pervasive and too consistent to have been rehearsed. It wasn't long before I began to understand that the consistency of Southwest employees is a direct reflection of the consistency demonstrated by their chairman in his ability to shape values and educate by example.

One of the company's flight attendants pointed out that "that loving spirit" theme was inspired by the company's home base, Dallas Love Field. In its earlier years the love theme was more tangible than it is today. In the past, love potions (soft drinks and liquor) and love bites (peanuts) were served by the Love Airline on a Love Flight that probably originated from Love Field. Hokey? Yes, but it communicated a message to the employees about 
the kind of feeling the company wanted to project toward customers, a message that has persisted for almost 15 years. While "that loving spirit" is a theme that has been with the company throughout most of its history, Kelleher indicated that its manifestation is much more spiritual than tangible today. However, the company has retained its heart-shaped logo as a symbol of its theme and the values it wants to communicate (see Figures 6 and 7 ). And what are the values it wants to project? Tona Weigelt explained, "that we love our passengers, and we care about them . . . like you treat family, with that loving spirit." when asked if this is a theme that Herb Kelleher adheres to, she responded by saying,

Most definitely. He always makes you feel special. He always makes you know that he cares about you. I mean, meet him one time, he never forgets your name, he calls you by name on sight, he pats your back, he tells you what a good job you're doing.

He really feels that without good employees he's not going to have any passengers on the airplanes and it's one of those circles where if he takes good care of the company, takes good care of his employees, his employees in turn, take good care of the passengers.

The love that he puts out to us and the things that he does just make you reciprocate that, not only to him, but you pass that on to the passengers. 


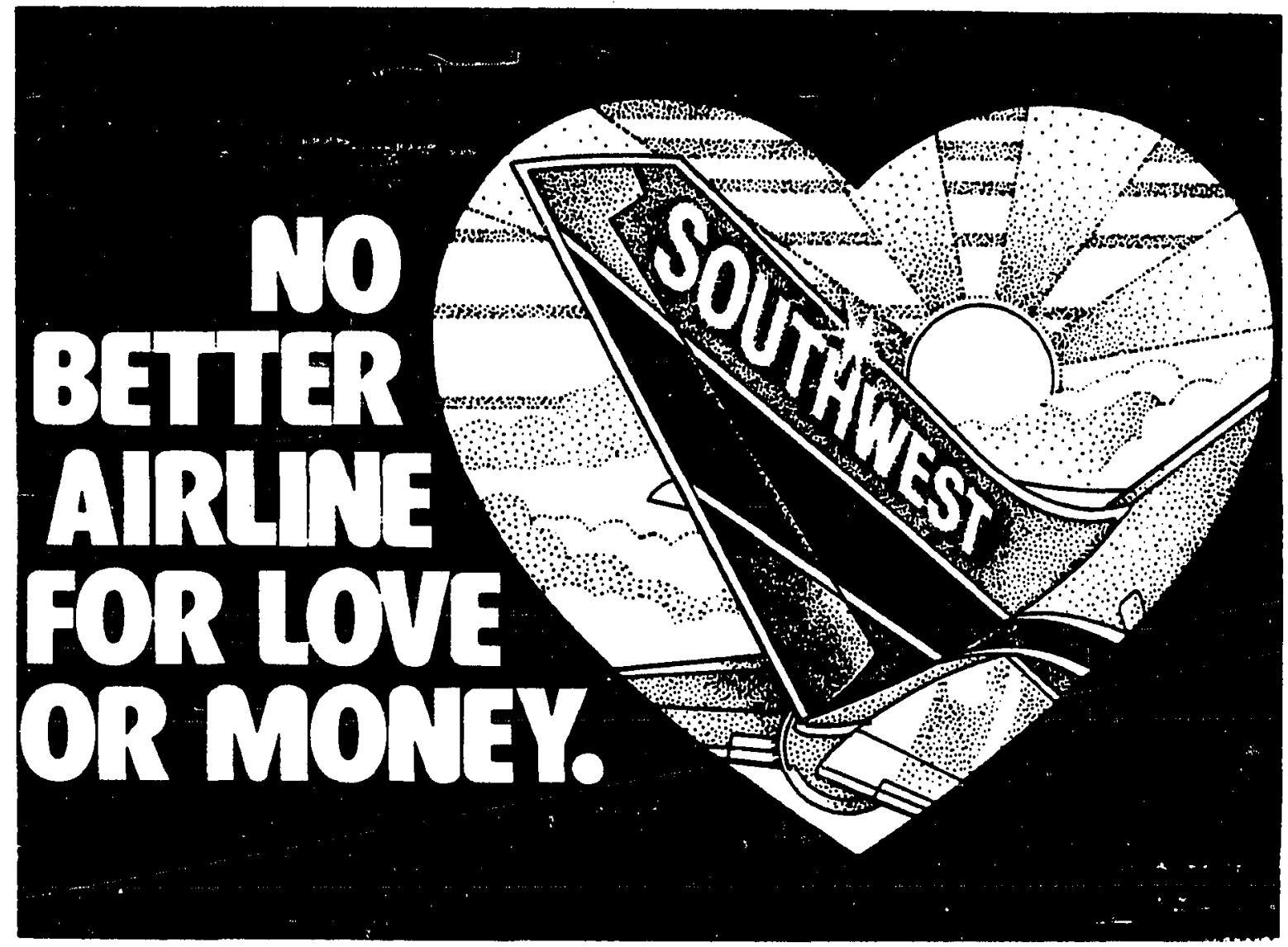

Figure 6. Southwest's heart-shaped logo as it appears in company advertisements. 

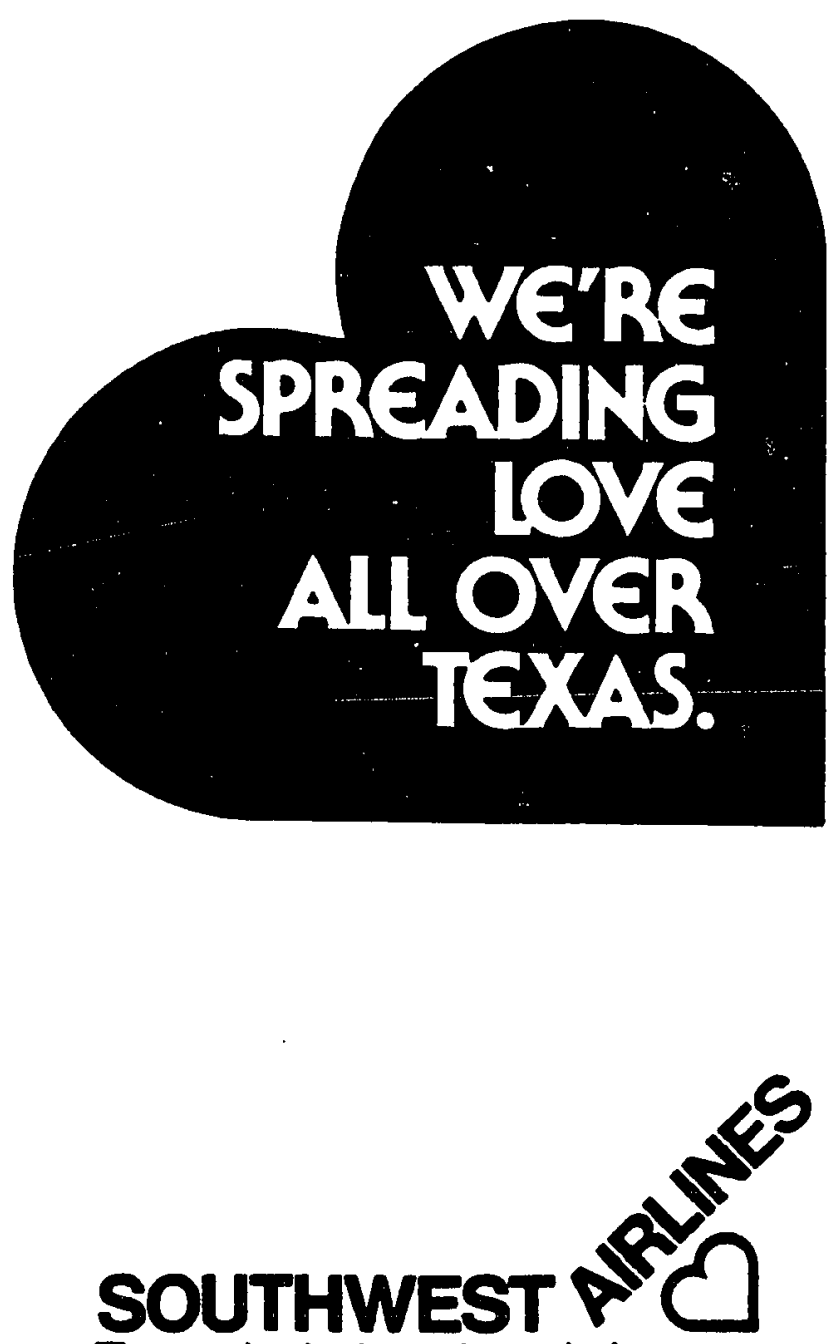

The somebody ebe up there who boves you.

Figure 7. Additional versions of Southwest's heart-shaped logo as they appear in company advertisements. 
Telling you that he heard you got a good letter in your file. Letting you know that he knows about you and that he's willing to get out there and put in the extra effort really makes you feel that you need to do that too. You need to give that $110 \%$.

Gary Barron suggested that Kelleher is believable when showing his care and concern for the people of Southwest because he's sincere. Barron explained that Kelleher's sincerity stems from the fact that he himself is always willing to do whatever needs to be done and that he would never ask someone to do something he is not willing to do. Colleen Barrett, who has worked with Kelleher since before the inception of Southwest, confirmed Barron's point.

In my earlier years with him I did far more mailings than I care to remember, many of which were political in nature. And it was not at all unusual for Kelleher to be sitting right next to me at 2:00 in the morning, licking and stamping, and sealing envelopes. He would never, ever expect me to stay there working on something if he wasn't right there too.

Another way in which Kelleher manifests his sincerity is by his willingness to get involved and put forth the extra effort to help his employees whenever he can. One of the best illustrations of his ability to shape values through vivid, living, personal example comes from an incident that usually takes place on Black Wednesday, the 
day before Thanksgiving and the busiest day of the airline industry. People in the industry call it Black Wednesday because it is typically characterized by an abundance of delayed departures and arrivals, angry passengers who are trying to get home for Thanksgiving, and a tremendous amount of difficulties getting luggage through the system. As the story is told, on the busiest day of the airline industry when Southwest Airlines is desperately trying to make its ten-minute turn, Herb kelleher can be found in his orange jump suit down on the tarmac helping the guys load baggage into the planes. Rick Bowman, a ramp supervisor for the company in Dallas, elaborated:

He comes down here on Wednesday before Thanksgiving, which is the biggest day of the year. He jumps right out there. - . and he'll tell stories. Oh goodness. Herb has got some good stories. He's a likeable guy. He'll come out here and talk with anybody.

Herb's that way all the time. Any time he comes in and out he always comes down by the ramp and stops and talks to the guys. Was it last year we had all the rain? He came out here, and I tell you what, he was soaked, and he was whipped by the end of the night. He stayed right with them, though. He stayed till about ten o'clock. He got here about noon, and worked till about ten, and I'll tell you, it was a bad 
Wednesday. A bad Wednesday before Thanksgiving. And he was whipped, he was dragging, by the time he left. The people in ground operations explained that Kelleher's willingness to pitch in helps morale a lot. Thus, by his very example Kelleher conveys that loving spirit to his employees and, in turn, expects them to pass it along to southwest customers. While there may be no adequate way of measuring the impact he has on these people, it is certain that his presence shows them how important they are to him. As I worked my way through the various levels of the corporation observing some people and talking with others, it was interesting to me that the individuals in ground operations, more than any other group, displayed a special kind of appreciation for Herb Kelleher. That, in itself, is a significant statement because almost everyone at Southwest appreciates Herb in a special way; however, these people were radiant with pride when they talked about the chief executive. I got the impression that they deeply respect him for making the effort to get involved with them and for becoming "one of the guys." In this sense, he has communicated more about the spirit of Southwest through his personal example than his words could ever express.

Jim Amos related another story that shows how much Kelleher likes to be involved with the airline and its people. Amos remembered one day when the whole airport had 
been shut down for an entire day because of a big ice storm. The runways had been so glazed with ice that all arrivals and departures at Love Field were delayed. Kelleher, who loves to participate in every part of the company, was one of the few people at the airport muddling through each department and overlooking everything. Amos said that when he finally went out to check the runway conditions to determine when the first plane could move, Kelleher was right there standing alongside of him. Southwest employees will tell you that these incidents are not isolated cases, rather they are only a few of the many stories that exemplify Herb Kelleher's spirit and passion for the company. Again, the value that he communicates here is that southwest employees should do whatever it takes to convey that loving spirit to their customers and their peers. As Gary Barron pointed out, "His sincerity is sort of something you have to experience. When he tells the employees that he loves them, they believe him because it's true."

The obvicus question that one might ask is "if Kelleher is so involved with the Airline, where does he find the time to do all of this?" In his response to that question, he said, "If you work 110 hours a week you set aside a normal work week for this, then you've still got 80 hours left to do the other things. So the amount of time you really spend is very important." While Kelleher does 
not expect his people to become workaholics, he does expect them to work hard and his example in this respect has made quite an impact on the people of Southwest Airlines. For example, Gary Barron indicated that "Herb works 18 hours a day at his job. He asks people to work hard, but they all know that he works harder than they do, so most people don't mind, because they know that he's doing more." Paul Quinn said,

You've probably heard about the hours he puts in. He thrives on 18 hours a day. You know, it's really funny, if I want to talk to him on the weekend, I know where to call. He's right here [at the office]. He just thrives on it. It'd kill me. And I'm not half his age.

Tom Volz, former vice president of marketing, also confirmed that "Herb operates like a 24-hour 7-Eleven. He lives, eats, sleeps, and drinks Southwest Airlines." Kelleher is usually up by 5:30 and in the office by 7:00, seven days a week. His working habits are not confined to the office either. Kelleher noted that:

I can dispose of a huge amount of paper work on long flights. I always take a full brief case. I recently flew to London to meet with some bankers. The flight left Dallas and, about 10 hours out, they'd already shown the movie, all the lights were out except mine. I was working away. After a few more hours a guy 
turns to me and says "Why did I have to sit next to the only nut on this airplane?' I guess I am a nut if that means someone who works long hours.

whether it's checking a runway glazed with ice, loading suitcases, or working 18-hour days, Herb Kelleher's personal example in the mundane events of every day sends a powerful message to the employees at Southwest Airlines. They know that he wouldn't go the extra mile with them so frequently if he didn't sincerely care about them and their future. The employees, in turn, are willing to make personal and professional sacrifices not only to meet the needs of Herb Kelleher, but also to meet the needs of their fellow workers as well as their customers. Thus, through Kelleher's example, a particular value system has been established at Southwest Airlines, a value system that instructs and guides employees at every level to work hard and to spread that loving spirit. Kelleher argued that "If you're going to start out with a new business and expect it to grow, you have to be prepared to work harder than almost anyone who's working for you. How can it be important to them if you don't manifest that it's important to you?"

Kelleher also communicates his loving spirit for the people of southwest through his phenomenal ability to remember names, facts and figures, events, and people. As I talked with him on a number of different occasions, I was amazed at the ideas he could recall and the details he 
would remember from our previous discussions. Several employees mentioned that he will meet a person once, and a year and a half later he'll remember that individual's name. This was the case with an operations agent that I had the opportunity to talk with in Dallas. According to Rusty Brodmax, "I met him one time, and then I had to get a note to him. I hadn't seen him for about a year and a half, and he shook my hand, knew me by my name. I didn't have a name tag on, he remembered."

"How did that make you feel," I asked?

Good. Like I was somebody. I was in the hospital one time and I got plants from him, Colleen, Jim [Amos], and then I got three cards from him while I was in there.

"How did he know you were in the hospital?"

Somebody got word to him. Like they say, it's just a big family. He comes down to a normal level, like a lot of fellows, you know, with the wealth that this man has, won't waste their time talking to some of the people that work for them, in the way that Herb does. He makes you feel warm inside like, this man is acting like he isn't any better than the rest of us.

Perhaps no one could have said it better than Rusty Brodmax himself. Herb Kelleher's ability to remember names and identify with his people helps the employees of southwest feel significant--like they are important. This, in turn, 
has a tremendous impact on their productivity, as steve Cole and Rick Donley pointed out. Cole and Donley, part of the ground operations crew, are two of the individuals whom Kelleher joined to load bags on Black Wednesday. Cole proudly related that for 18 months in a row ground operations was below budget in terms of baggage damage. He explained that Kelleher believes in ground operations as a vital part of the airline and shows this by consistently recognizing their efforts with letters of appreciation and personal visits.

Confirming the fact that Kelleher has a great memory, Colleen Barrett and Paul Carter explained that he reads the employee evaluations on every employee and remembers them. Carter showed how important the employees are to Kelleher by stating,

We evaluate employees. And the uncanny thing about it is--he can tell. you what you've said about your employees. He memorizes people's names. Our ramp agent can walk up to him, he's been here three months, and he'll call him by his first name.

Once again, it's important to note that kelleher's primary mechanisms for shaping values are not new policy manuals or high-priced training programs, but rather the little things like consistently remembering names in the seemingly unnoticed events of every day. By remembering names he is essentially showing the people of southwest how important 
they are to him. The underlying value system being inculcated, then, is that southwest employees should consider every moment of every day a symbolic opportunity to show those around them (especially customers) how much they are valued and appreciated.

When Herb Kelleher says that dealing with the people of Southwest is truly the best part of his job, he is very sincere. Greg Roessner suggested that it is not unusual to see him wandering through the terminal spreading that Southwest spirit to everyone with whom he comes in contact. Roessner expressed that,

He's gone outside to see the ramp people, He'll stop and talk to the ticket agents, stop and talk to the mechanics. He'll go down on the ramp and talk to the guys who are loading the plane.

Kelleher, who enjoys working the galleys with flight attendants, serving drinks, and handing out peanuts on southwest flights, brings a certain level of intensity to working with his people. Getting out among the people of Southwest Airlines makes him one of them, and no one has more fun with employees than he does. Jim Parker explained that,

Walking through an airport with Herb is like walking through a crowd with a politician. He will know everyone from the station manager to the sky cap at Southwest Airlines, and they'll all call him Herb and 
most often he'll shake hands with everyone and ask about their husbands, their wives and kids . . .

You might think, just watching him, that it's sort of superficial, all a put-on, for public relations purposes, but I don't think that's true. I've been with him privately and heard him discuss these people. He knows these people, he'll ask about them, he cares about them . . . It's a genuine caring situation.

While Herb Kelleher is out wandering around, his people are watchful, alert, and consciously aware of the priority he gives to staying in touch with employees and the extra effort he puts forth to help them out. Consequently, the people at southwest tend to model his behavior as they relate to customers and each other. For example, Paul Carter indicated that in many cases, pilots will take it upon themselves to go out of their way to go down on the ramp and load bags. "You don't see that on any other airline. As a matter of fact," Carter explained, We've had ramp people out on the west coast where the unions are very strong, and some of the union people, the baggage people, threatened some of our pilots and flight attendants who've gone down on the ramp to help, trying to expedite matters. The baggage people out on the west coast. . . told them they would be sued for interfering with their jobs. 
Kelleher's example has also rubbed off on people like Paul Quinn and Gary Barron. They too, have adopted the philosophy that it is difficult to show their people the spirit of Southwest Airlines unless they do it through personal example. Thus, like Kelleher, they demonstrate that loving spirit to southwest employees by interacting with them frequently and doing whatever it takes to help them do their jobs better. Quinn, who likes to get out and talk with the operations agents and ramp agents said,

I could sit here and look at numbers the rest of my life. . but if I want to find out what's going on with the schedule, where the problems are, I go down and talk to the people who do the jobs. And I get a whole bunch of good information.

Barron is in charge of approximately 800 people, and he gets out with them as often as he can.

I don't do it as much as Herb does, but . . I know lots of flight attendants, lots of pilots, lots of ground people, and like them. I enjoy being out with them. They're friends and I don't think of them as employees--us as management and them as labor--even though a good part of my work in the past has been labor negotiations.

Unquestionably, there is a special spirit at southwest Airlines that has radically affected the perceptions and dispositions of southwest people. It is a loving spirit of 
care and concern in which people are treated as human beings, as individuals. It is an unselfish spirit that reinforces that special "can do" attitude by promoting people who make an extra effort to help out their associates.

It is a spirit where each individual is recognized for his or her contribution, and it is a spirit where employees are highly valued and respected as the individuals respon. sible for making the whole thing work. Gary Barron characterized it as an infectious spirit and that is quite accurate because it is very contagious. I think it would be difficult for anyone to spend even a minimal amount of time with the people of Southwest Airlines and fail to experience and, in turn, exude that loving spirit. No one in the company will argue with the fact that Herb Kelleher is the catalytic agent who keeps the spirit of southwest Airlines alive. This can be seen not only by the way he lives and breathes that loving spirit in his daily example, but also by the way he communicates with employees in formal documents such as the quarterly and annual reports, and in his presentations to various employee groups.

Figure 8 shows Kelleher's concluding remarks in a series of quarterly reports to southwest shareholders. These closing comments show the consistency with which he gives credit to the employees for the success of Southwest Airlines. Kelleher personifies that loving spirit by 
In 1984, our very proud, caring, and smiling employees for the fourth consecutive year generated the fewest customer complaints per 100,000 custoners carried among the major and national carriers. This unprecedented string of "championships" speaks eloquently of the concern and friendliness our people constantly radiate to the customer and to each other. In the vernacular of "Star Wars", our people are our "force" and their worth is an immeasurable contrib. utor to our goodness and success.

Most sincerely.

\section{Herbert D. Kelleher}

Chaiman. President.

and CEO

April 27, 1985

As always, the magnificent spirit, "can do" attitude, and comaraderie of our employees is the key to our excellent results, and I thank them for thei: efforts and good will. towards each other and our valued customers. It makes the difference.

Most sincerely,

Herbert D. Kelleher

Chairman, President and CEO

July 22, 1985
In short. Southwest represents an amalgam of all the importunt factors necessary to produce success today and to presage success for the future. plus one extra ingredient - the magic elixir of our beautiful people who each day share their special spiril with our cus. tomers and make them want to bask in its warmth again. As long as the glowing ambiance of our people persists.

Southwest Airlines itself will both persist and prevail. Our loving people are the heart and soul of Southwest Airlines - today, tomorrow, and forever.

Most sincerely,

Herbert D. Kelleher

Chairman. President. CEO

February 4. 198;

Figure 8. Kelleher's concluding remarks as they appear in a series of quarterly reports distributed by the company. 
giving credit to his people and elevating them whenever possible. This message is also illustrated in two different presentations to southwest employees. Describing the airlines quarterly results during "Herb's Message to the Field," Kelleher stated that:

What's truly astounding, and I think that each of you should know this because I think each of you deserves a tremendous amount of credit for it, and each of you should glory in it because it's a product of your efforts that Southwest Airlines did something apart from the pack - . - is that among the national carriexs, which is our peer group, of those just below the Americans and Northwests of the world, of which there are 24 of you, the people of southwest Airlines, in the first six months of 1986 , made $67.3 \%$ of all of the operating profits of all 24 carriers in the national carrier group in the united states of America.

And I think that that is a signal achievement and it makes the hair stand up on the back of my head when I talk about it and again I want to thank you.

Kelleher's humility and special affection for the people of Southwest is also depicted in an excerpt from an article in the company's newsletter written by Tonda Montague (see Figure 9). The excerpt is a brief description of what happened at one of the company's banquets in 
Following the presentations, Herb made one of those infamous speeches that only he can do - one of those that brings tears to your eyes and puts a lump in your throat.

He began by recounting some of Southwest $s$ remarkable growth statistics, since its beginning in 1971. In enumerating these statistics, Herb said he did not mean to sound cocky or complacent. He added. "By and large. complacency and cockiness have destroyed every successful organization in the history of mankind." Then Herb said, "It is the vision you have; the kind of cooperation you manifest everyday; the 'can-do' attitude that says 'let me get the job done and please don't get in my way'; the love and caring we have for each other and our own customers; and the humor, the irreverence and the fun. All of these things have brought these records to pass."

In closing, Herb cited a few words from a song he feels epitomizes the dedication of Southwest employees, and said although he had been honored with many awards in the past, he never stopped believing that it is the employees who make Southwest what it is today. At that point, Herb introduced Marvin Porter, who came to the spotlight and sang the song Herb had cited, "The Wind Beneath My Wings."

I was the one with all the glory While you were the one with all the strength

Only a face without a name I never once heard you complain. It might have appeared to go unnoticed But I've got it all here in my heart I want you to know I know the truth I would be nothing without you.

Did you ever know that you're my hero And everything l'd like to be I can fly higher than an eagle 'Cause you are the Wind Beneath My Wings.

\footnotetext{
Figure 9. This excerpt from an article written by Tonda Montague appears in the August, 1986 edition of the company newsletter.
} 
which awards are given to outstanding employees. It reflects Kelleher's genuine care and concern for his people and shows why he is the catalyst behind that loving spirit.

Pride and Confidence. In addition to the spirit of Southwest Airlines, Southwest employees display a tremendous amount of pride and confidence in their company and its leader. As a member of the southwest family, pride and confidence in your fellow employees is highly valued. It is often described as, and manifested in what Kelleher calls a "can do" attitude, suggesting that southwest people can do anything they put their minds to. When I asked Dale Foster what enabled southwest dispatchers to work 50 to 80 flights a day compared to United's dispatchers who average 20 to 30 flights daily, he said,

Just the pride of it. It's something that's been built into the ramp guy since he was making a tenminute turn to an ops agent getting everybody on and everybody off. And it's just something that's been ingrained and those of us who have come from another airline have said, "Wow, I didn't know you could do this much." It's something that is expected of you, and you don't want to sit back and be embarrassed by not doing it.

Foster explained that there is always a friendly competition going on among the dispatchers to see who is using the least amount of fuel and doing the most runs each day. He 
said that when people take pride in the company, it enhances their credibility.

To me, first of all, it's personal. As I hold myself accountable, my credibility increases. And my credibility and my accountability go hand in hand. And that's something I try to express to the dispatchers out here, that it's a two-way street. The more accountable you hold yourself, the more credible everybody is going to hold you. And I see that in Herb too. He does hold himself accountable and his credibility is tremendously high here, you know. We come to work 8 to 5 . But if I've got stuff to do, it doesn't bother me to go to 6 or 7 or $80^{\prime} \mathrm{clock}$. Because, you know, if you don't get the job done, then there's not going to be a job here to do.

Rusty Broadmax said that his pride in the company stems from its ability to outlast many of the other carriers. He is especially proud of the fact that so many of the airlines in the industry have used southwest as an example.

You take 13 years, and as small as this airline started out to be, we're still here; the other ones have gone down so far . . . First, they said Southwest, they'll never make it, they'll never make it. Now, you see them coming to our ways. Paul Carter contended that, 
our operation is just very streamined and very efficient. It's probably the most professional airline that I've ever had the opportunity to be associated with. I've flown all over the world, flown not only for other airlines, but in the cockpits of other airliners, and I would put our airline against any other airline.

The employees take pride in Southwest Airlines because they recognize the indomitable spirit that brought the company through the turbulent times of the past and they experience the benefits of its success today. However, the employees also take pride in this company because they have a great deal of confidence in Herb Kelleher as a leader in the industry and recognize the pride and passion he displays on behalf of Southwest Airlines. As an industry leader, Kelleher has received a number of business awards and honors of which the employees of Southwest are very proud:

"Best Chief Executive Officer, Airline IndustryFinancial World. Best Financial Management, Airline Industry Air Transport World. Best Chief Executive Officer, Regional Airline - Wall street Transcript. One of Three "Best Managed Companies," Airline Industry - "Quality of Management Report" Investment Decisions. Herbert D. Kelleher/MCorp ProfessorshipUniversity of Texas at Austin Business School. 
Certificate of Distinction, CEO Honor Roll, Airline Industry - Einancial World."

In relationship to his pride and passion for the company, Jim Parker confirmed that,

Southwest Airlines is his passion. He, of course, is the creator of Southwest Airlines and has, through that vehicle, brought about tremendous change in the American airline industry. And it is, really, almost an all-consuming passion--Southwest Airlines and its people.

Gary Barron added,

There's no doubt in anybody's mind, when you watch him make a presentation dealing with Southwest Airlines or just follow him around and see him do this job, what a passion he has for Southwest--it's like his child.

It is motivating to watch Kelleher work. So great is his passion for Southwest Airlines that it is difficult for the employees not to get drawn into it. As they experience the magnetism of Herb's excitement and enthusiasm for the company, a certain level of pride and confidence wells up within them. In his straightforward way of dealing with them, Kelleher gives the people of southwest every reason to believe in their company. In a recent meeting with employees, Kelleher addressed one of their major concerns, the possibility of a takeover by another airline. This is a particularly frightening possibility for southwest 
employees because a takeover could not only threaten their job security, but also the cohesiveness of the southwest family and all of the physical, emotional, and spiritual benefits derived from it. After a complicated discussion regarding the legal precautions taken by the company to prevent a takeover, kelleher reiterated,

I guess what I'm really saying is that $I$ want to assure you that the policy and objective of southwest Airlines is to continue as a very special company, and we don't want to be taken over. We're not soliciting anyone to buy Southwest Airlines, and $I$ would be tremendously offended if anyone came in and tried to buy us.

While the threat of a takeover looms over the corporate offices of almost every small carrier, there is a distinct confidence portrayed by the people of Southwest Airlines. Unless it is a very sweet deal for the shareholders and employees alike, Herb Kelleher and the people of Southwest Airlines, who are no strangers to fighting for their cause, will be extremely difficult to deal with. As Paul quinn pointed out, "I look at different managers, and I say: 'Would I follow that man into combat?' And Kelleher I would. He's a good leader. He's not going to ask me to do anything he wouldn't do. That he's proven."

Work is Fun. One of the values that has been a central part of the southwest spirit is that work should be 
fun. In fact, no one at Southwest Airlines has more fun than Herb Kelleher. He believes that if the employees are having fun with their jobs, they will pass that attitude along to customers. Kelleher, who loves to be involved in a good prank, is a walking example of what having fun at Southwest Airlines is all about. The value is significant because it is incongruent with the values of most Fortune 500 corporations. Somehow we have gotten duped into believing that work is only fun if people aren't doing their jobs. It is also signifisant because the level of stress associated with high-level executives usually precludes anything as outrageous and nonproductive as having fun. Yet, Kelleher and the people of southwest work very hard to make fun a dominant part of their value system. Having fun at work is a value that is so embedded in the organization that it has become a key ingredient looked for in the hiring pxocess at southwest. Kelleher explained,

One of the things I tell the personnel office is I want to hire people with a sense of humor, because I think that's very important. A sense of humor is one of the things that enables you to work better, not exalt things way out of proportion; relieve strain, produce cooperation, work better with the public, not get dejected as quickly. You know, there are a lot of things connected with it. 
Speaking of his relationship with the dispatchers, Dale Foster confirmed that,

We kid and joke with each other a lot. And it's something that Herb has always said. All of us have to have the ability to laugh at ourselves. It's easy to laugh at someone else, but you still have to have the ability to say, 'Yean, I screwed that one up too!' The airline does a number of things to promote the notion of having fun at work. For example, employees are encouraged to dress up in costumes on Fridays, Saturdays, and sundays during holidays such as Christmas, Easter, Valentine Day, and whenever the company is introducing a new promotion. This past summer Southwest Airlines introduced a new promotion from June though september, the theme of which was "Southwest Airlines passengers have more fun." Tona Weigelt indicated that the company's attitude during these promotions "goes beyond just having that loving, down-home spirit. Herb wants everybody to have a good time, and he wants this to be the fun airline." she noted that the company will often furnish employees with different types of outfits to show that southwest is a fun airline. In this particular promotion employees were given jams to wear, which are long, baggy shorts with various types of flowered prints. Jams are something one would see the surfers wearing in southern California or Hawaii. Weigelt explained, 
We were able to wear jams and tennis shoes and $t-$ shirts on the airplane, and on the back of the $t-$ shirts it said "Southwest passengers have more fun." We truly believe that in our hearts. I know Herb truly believes that in his heart and wants the employees to pass that feeling on.

If Kelleher's behavior is indicative of his support for this value, then weigelt is right. Herb really does want everybody to have fun. Figures 10 and 11 show Herb Kelleher and the southwest crew sporting their jams. Colleen Barrett confirmed that Kelleher's participation in the promotion was anything but tentative.

Anything you ask our employees to do Herb will be out there doing it. . . We had a theme of bringing the fun back to Southwest Airlines, . . and Herb was the first one in on the first day with the jams on. Nobody could quite believe it. Not only would he wear them, he went out in them. Not that he would just wear them for an hour, sneak into the office, take them off, but he wore them to Houston on the airplane. There he was with his jams and his little black briefcase. I laughed all day at the thought of him being on that plane. He really does get into the spirit, you know. He is the spirit, I guess you could say. He participates in all sorts of things like that. 


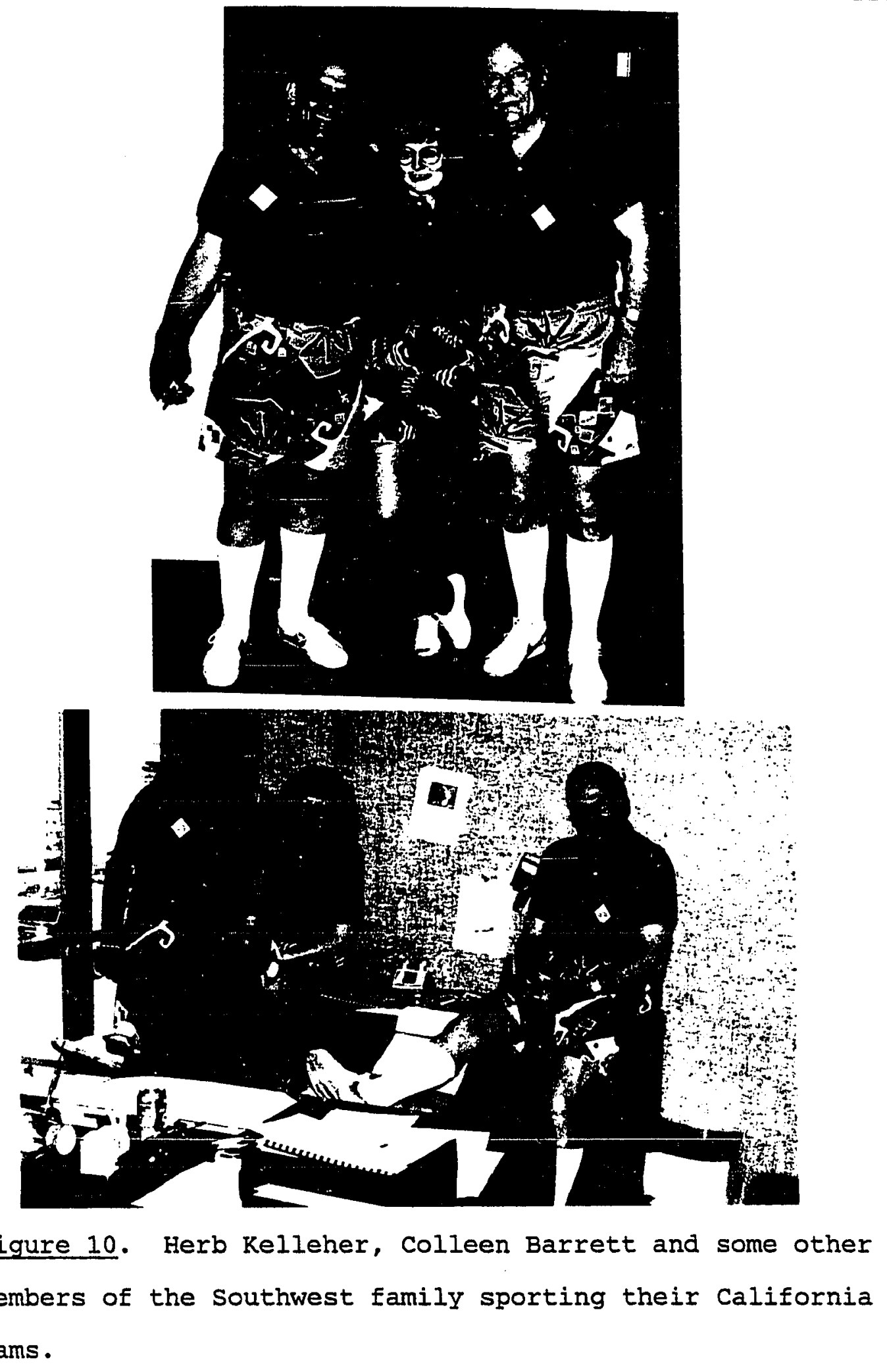



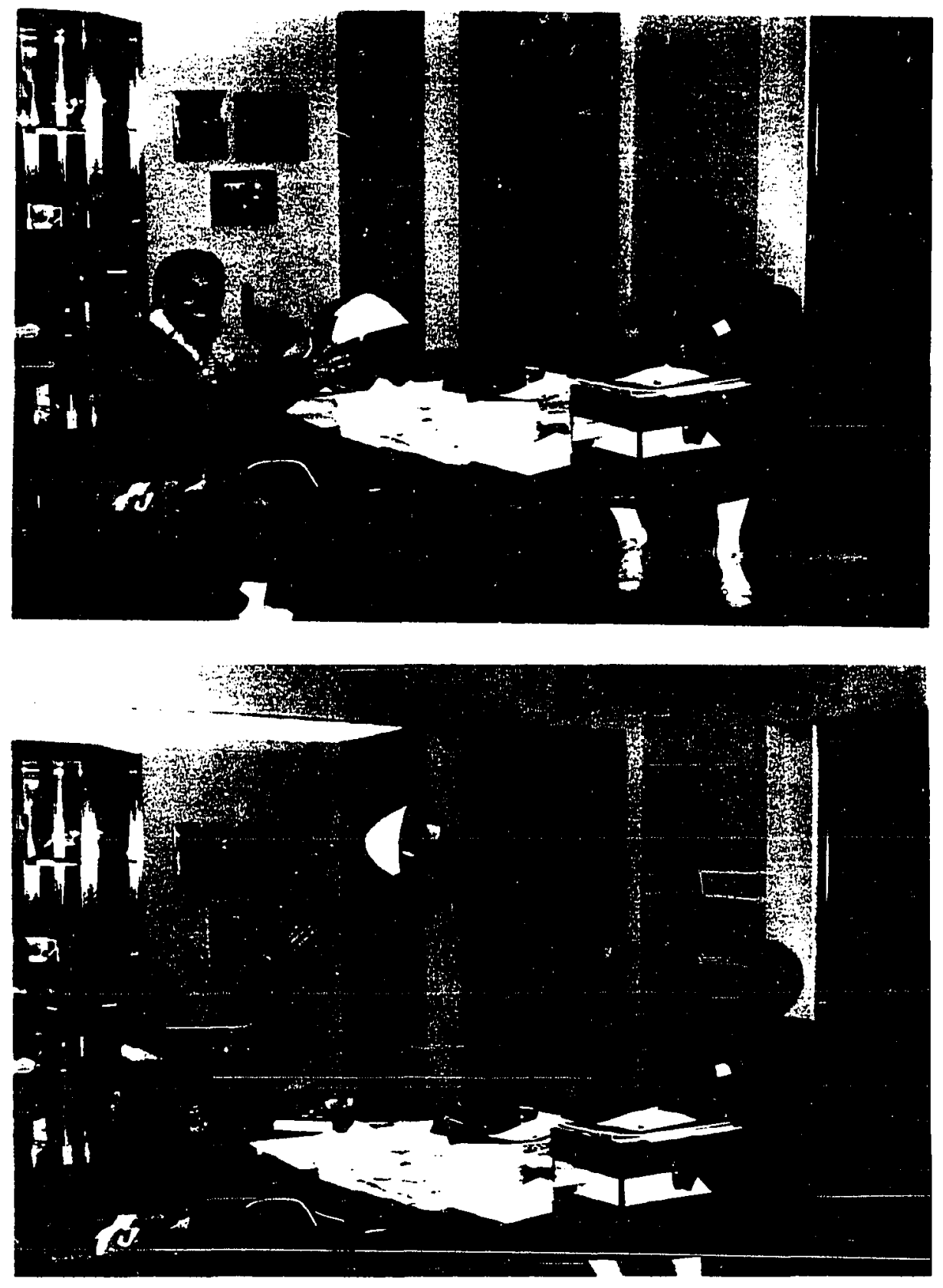

Figure 11. Herb Kelleher and Don Valentine playing around with the official company beach ball in Kelleher's office. 
Whether it's the company's chili cookoff, Halloween party, or Christmas party, Kelleher is usually the first one there and the last one to leave. At the chili cookoff Kelleher can be seen sitting on a ducking stool drinking beer and having a good time as employees step up to take their chances at throwing the lucky pitch that will drop him in a tank of water. He even had the honorary distinction of winning the cow chip throwing contest at the chili cookoff. His participation in these events has a significant impact on the people of Southwest Airlines. They believe him when he says in a speech that he'd rather be with them than anywhere else, because given the opportunity to be elsewhere, he chooses to get involved with them at these parties. As Weigelt pointed out,

He has always been a part of our functions. It makes us feel that he doesn't think he's too good to party with the rest of us. He relays the fact that he is part of the family. He's the leader of our team, and he gets out there and goofs around just like the rest of us. He's with us $100 \%$.

Colleen Barrett held a MASH theme party for the company a year ago at Christmas, and Kelleher, much to his surprise, showed up as the MASH character Klinger (see Figure 12). Barrett recounted the story:

I didn't tell kelleher what he was going to be, I found out that if you don't give him a lot of time to 


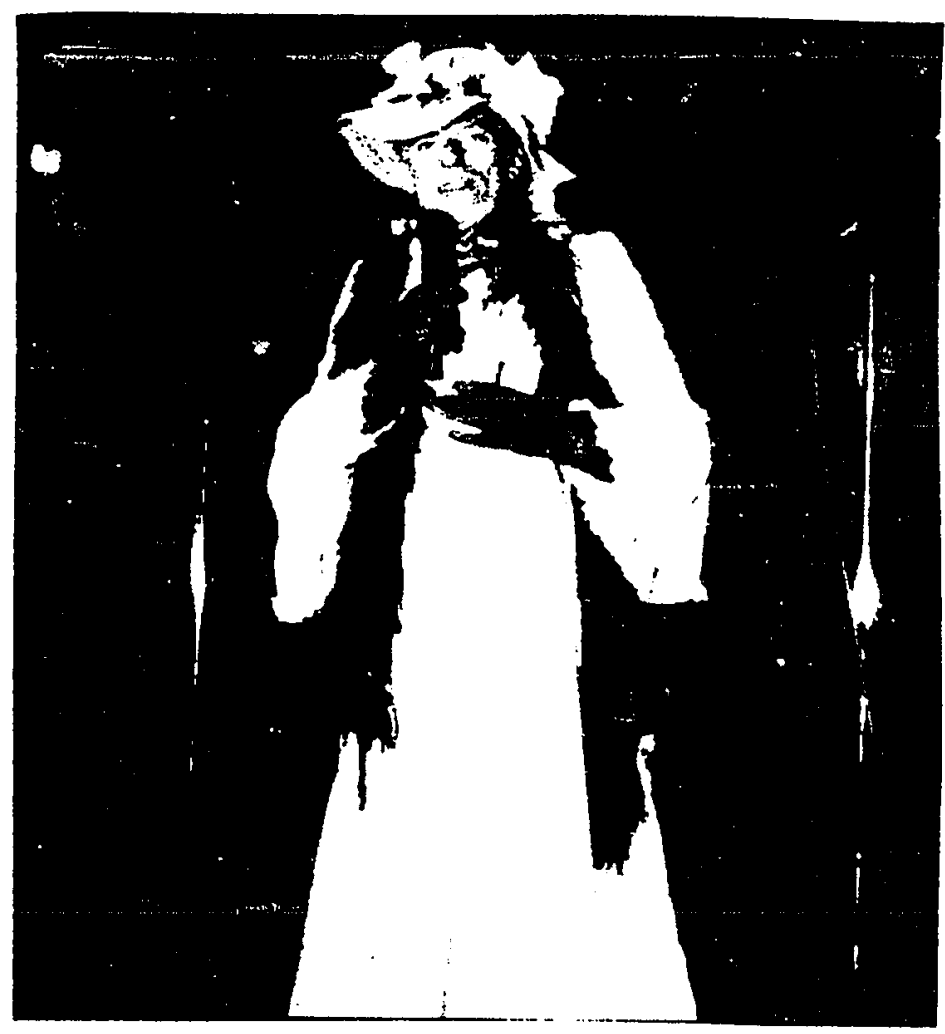

Figure 12. Herb Kelleher, aressed up as the MASH character Klinger, sings to the troops of Southwest Airlines at the company's MASH theme party. 
think about it, he can't come up with a lot of reasons why that wouldn't be appropriate. So about 30 minutes before the party I went in with his costume in the box, and I put it on his desk and said, "Well, I've got to go, Herb." And he was Klinger. It was too much. But he's such a good sport, he'll do anything like that.

At another company party, Kelleher, dressed up as Elvis Presley (wig and all) and sang a couple of Elvis's songs for the Southwest people there. At the cockpit, a bar frequented by Kelleher and a lot of other Southwest people, it was not uncommon to see him challenging employees to a game of Pac Man. As a result, the employees got together and bought him a Pac Man machine for his office. Now, if they are willing to pay a quarter, Herb will challenge them to a game in his office.

Recently, Kelleher took a planeload of employees to Chicago to participate in the St. Patrick's Day Parade. The trip was part of a promotional campaign celebrating Southwest's arrival at Chicago's Midway Airport. The mood of this trip was reported by Diane Reischel (1985) in an article that appeared in the Dallas Morning News. An excerpt from this article illustrates just how much fun Kelleher has with his employees:

The head of Southwest Airlines is a brainy, freewheeling competitor, a soft-haarted Irishman whose 
party antics and hectic schedule set the tone for this company's unconventional spirit.

Herb Kelleher is dancing in the airplane aisle. It's 8:30 a.m.-- but there's no easing slowly into this day. Herb is already bumming cigarettes, cavorting with flight attendants to the music of Flashdance, and sipping a screwdriver. The plane lurches left and then right as the unseen pilot tells passengers to sway with the motion.

The gaiety "is enough to unhitch a stomach. But not Kelleher's. "I feel better already" says the president, chairman, and chief executive officer of Dallas-based Southwest Airlines in a voice that booms above the airplane roar.

In top-siders and derby, 54-year-old Herb is leading his adrenaline-hyped troops to chicago. The planeload of Southwest employees . . will march in the St. Patrick's Day Parade to publicize Southwest's new flights to St. Louis and Chicago.

Herb heads for the parade by chartered bus, occasionally hugging or kissing an employee. "He's not a flirt. He's just Herb," explains one flight attendant.

Herb finally leads his marchers and the Southwest float past Chicago's winter-weary faces. He darts about like a drum major, passing out his free airplane 
passes. That evening, [his] laughter enters the hotel banquet hall. Still wearing the green blazer he donned for the parade, Herb lets out a hoot when he sees one tipsy Southwest captain arrive for the dinner in a green bathrobe and leather shoes.

At the banquet, Herb schmjoozes with flight attendants, mechanics, and ticket agents. Then as cocktails give way to dinner and speeches, Herb eases out the door. He catches a night flight from Midway to St. Louis. Another new market. Another work day ahead. (p. 1, see Figures 13 and 14)

on the wall in Herb Kelleher's office is half of a neck tie and shirttail that have been cut off, positioned inside a nicely-framed wall hanging. Kelleher explained that after his first solo in the flight simulator, the pilots cut his shirttail off, which is a traditional custom. However, knowing that he had a dinner engagement to attend that evening, they not only cut his shirttail off, they cut his shirt half way up his back and cut his tie off as well. Refusing to let the pilots get the best of him, Herb showed up for the dinner engagement that evening with his little tie and a well-vertilated shirt. Stories like this one abound at Southwest Airlines. Somehow, Herb Kelleher and the people of Southwest Airlines have figured out how to maintain a high level of integrity 


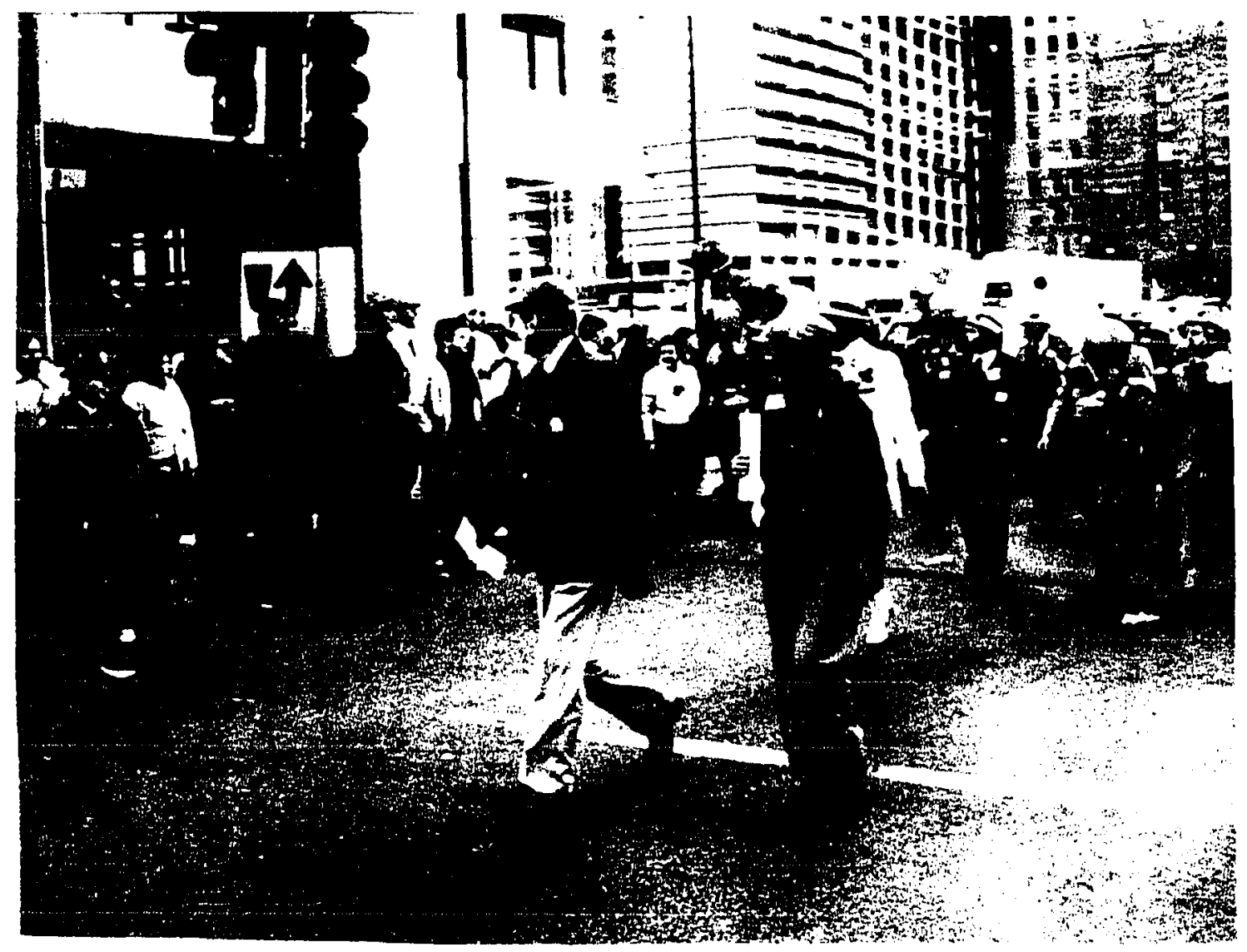

Figure 13. Herb Kelleher leading Southwest employees through the streets of Chicago during the st. Patrick's Day Parade. 


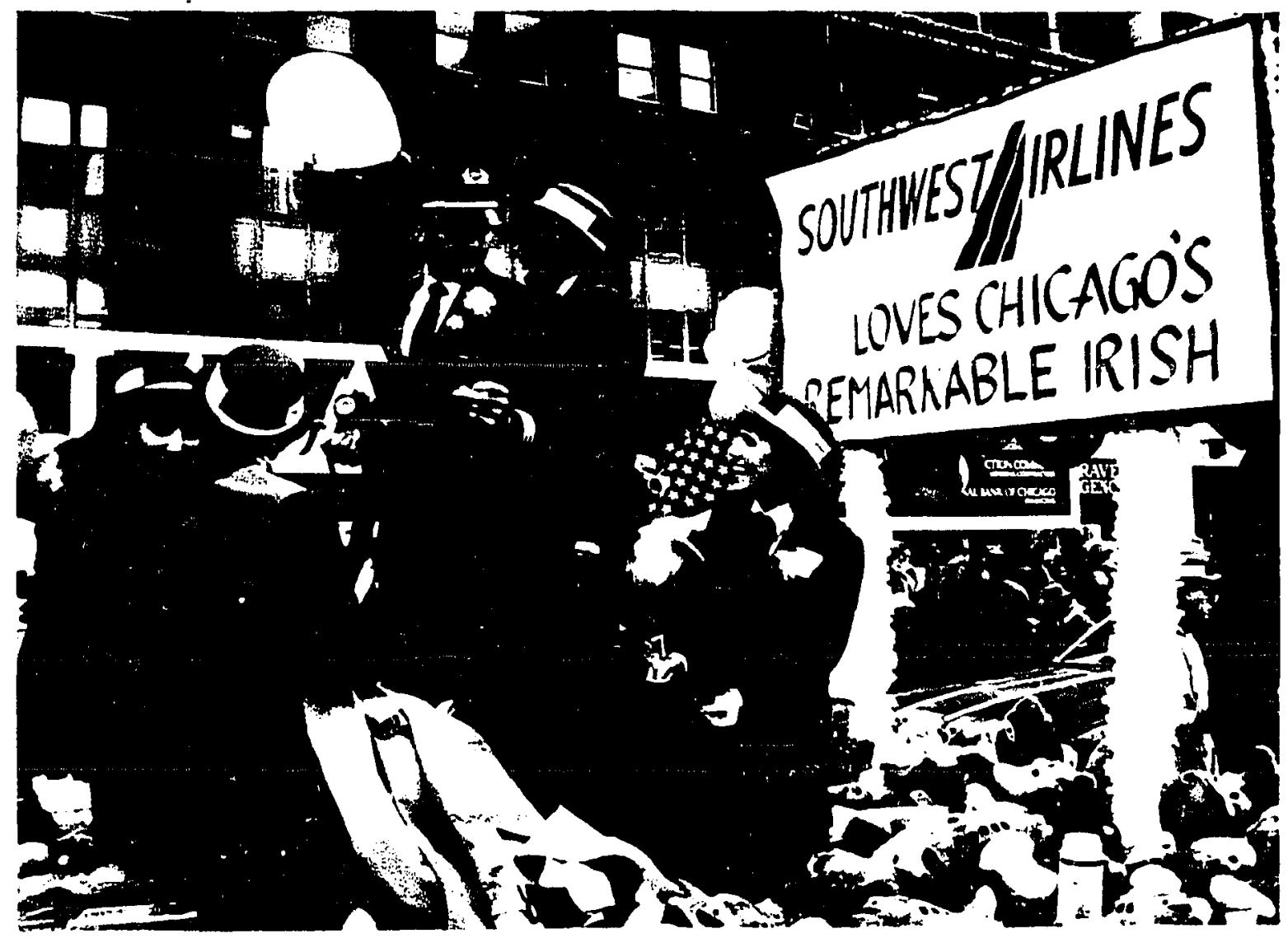

Figure 14. Southwest employees on the company float during Chicago's st. Patrick's Day Parade. 
and professionalism while having an extremely good time at what they do.

Kelleher pointed out that sometimes he will even bend the rules and look the other way when he knows that people are having fun. He remembered talking with a ramp agent in San Antonio who had a broken finger. When he inquired about the injury, the ramp agent sheepishly told Herb that the conveyor belt wasn't working and that someone had dropped a great big bag on his finger. Upon closer examination, Kelleher told him that it really looked more like a football injury. While the ramp agent, obviously a bit embarrassed, didn't respond, Kelleher knew that he had broken his finger while throwing the football around on the ramp.

The atmosphere at Southwest Airlines shows that having fun is a value that pervades every part of the organization. The joking, cajoling, and prank-pulling at Southwest Airlines are representative of the special relationships that exist among the employees in the company. As I observed and heard about these special relationships I couldn't help but conclude that maintaining the value of having fun has been a significant part of Kelleher's formula for success. When people have as much fun working as the employees of Southwest Airlines do, work ceases to be work and becomes another aspect of life in which their needs for fulfillment are realized. In this sense, the 
people of Southwest Airlines have achieved a unique and enviable integration of life and work.

Service to the Customer. Kelleher is extremely customer service-oriented and strongly believes that when employees find meaning and purpose in their work, they have a positive affect on customers. He operates on the premise that when people feel good about themselves and they have strong self images, they are better able to serve others. Thus, Kelleher spends a tremendous amount of time encouraging his people and making them feel worthwhile. However, this encouragement must not be solely construed as his attempt to enhance customer service, for Herb Kelleher genuinely cares about his employees and would treat them with dignity and respect regardless of the impact on the customer. Nevertheless, customer service is one of the predominate values in operation at Southwest; and Kelleher has embedded this value in the organization by first creating an internal culture where people are made to feel significant and second, by holding that culture up as a model for the way customers should be treated. In other words, Kelleher's method for inculcating customer service at southwest is to serve his employees and encourage his senior officers to do the same thing. In this respect he is very effective at educating by example. When employees experience Kelleher's care and concern for them, they quickly begin to understand that this is an attitude that 
should be passed on to the customer. Jim Parker remembered his first experience with Southwest Airlines as a customer. I knew it was a low fare and the cheapest way to get to Houston, but the pleasing part was the level of service. And once I got there, the people were friendly, they seemed to exude the type of personality Herb tries to instill. They were warm, they were caring, they were friendly. It was just a fine, friendly type of atmosphere.

A lengthy discussion with Tona Weigelt revealed some of the reasons behind Jim Parker's comments and the comments of those who have sent letters (see Appendix A) to Kelleher commending southwest for its excellent customer service. Weigelt's remarks leave no question as to whether or not Kelleher has articulated this value clearly.

His main purpose and goal is to have repeated business, and our objective is to service the passengers and to make them feel as comfortable and as wanted as we possibly can. Our whole thought is to treat the passenger as part of the family. We have that downhome southern kind of attitude and most of the people that we hire have that attitude.

If you have somebody that gets on the plane that's happy to begin with, you make them happier than they were when they got on the plane. Often times I have had people who have gotten on in a real sour mood 
and by the end of the flight you've turned that person around and have changed their whole attitude and once they get off the plane they're telling me that this is the best flight they've ever had. So not only are you reminded by the passenger, but you know that they're going to come back again. . .

You really feel like you've done something, You've accomplished something. That's really the reward we get as individuals who are part of southwest Airlines.

In addition to the way he treats employees, Kelleher reinforces this particular value in the speeches he gives and in the stories he tells about employees who exemplify customer service. One such story that kelleher loves to tell is about Gigi Perry, who is a ticket agent at Love Field in Dallas. According to Kelleher, Perry is a superb example of the kind of customer service that is displayed at Southwest Airlines. Her care and concern for a customer was demonstrated when she helped a 70-year-old woman who had recently had heart surgery. The woman was on a flight bound for Amaril10, Texas, which was grounded in Dallas due to heavy fog in Amarillo. Some two and a half hours after a bus had departed to take the stranded passengers to a hotel, Gigi noticed the woman outside of the terminal standing on a curb. She had obviously missed the bus. Gigi drove the woman to the hotel and stayed with her the 
entire night because the woman was afraid to be alone. The next morning Gigi saw that the woman made her departure and arrived in Amarillo safely. Like a proud parent who can't wait to talk about his kid's latest earth-shattering accomplishment, Herb Kelleher loves to recount this incident and stories like it to anyone who will take a moment to listen. He is genuinely proud of the way his people go out of their way to make that special effort for Southwest customers. Referring to Gigi Perry and her compassion for the customer, Kelleher said, "Our people do that type of thing all the time. I mean they have big, big hearts."

Another way in which Kelleher shows the importance of customer service to his employees is by incorporating the value in every speech he gives to them. The following excerpt from a speech given to southwest employees shows him communicating the values of customer service.

Excellent customer service is surely how you win this game of inches. Where everybody else is flying airplanes, everybody else has ticket machines, everybody else has the hardware, the software of success in the American airline industry is you. The software of success is treating our customers well, whether they be customers inside the company--and to a certain extent, you know, our departments are all 
customers of other departments--or whether they be customers outside the company.

If people are treated well by an airline, they go back. If they're not treated well, they don't come back. And southwest has the greatest record of treating people well. You've done an absolutely splendid job in that respect. And one of the things that I think is significant is we have to treat each other well. We have to have a lot of respect; we have to have a lot of care, we have to have a lot of concern for each other. Because the atmosphere inside will really produce the atmosphere that's radiated to our customers.

So let's be respectful of one another, let's enjoy one another, let's be helpful to one another. Let's have fun while we do the job. Let's not be too damn serious about everything and that will radiate and reflect out to the people that we serve.

These renarks show just how much Kelleher believes that team work is a prerequisite to outstanding customer service. Listening to him deliver this speech gave me the impression that Relleher not only believes in customer service as a tool for making profits, he believes in it as a method by which the people of Southwest can contribute to and enhance the humanity of others. In this sense, Kelleher sees customer service as the company's moral and 
ethical responsibility as well as a part of his fiduciary mandate.

Customer service is also reinforced at southwest Airlines through various articles (see Figures 15 and 16) that appear in the company's newsletter. These articles remind employees that the mission and purpose of Southwest Airlines is to "champion the cause for the short haul business traveler." As Figure 17 shows, Southwest does not hesitate to show its employees just how well they have accomplished their mission. The results in Figure 17 indicate that customer service has indeed become a wellestablished value at Southwest Airlines.

Lean Bureaucracy. Given that Herb Kelleher values his people so highly and believes that they are the key to quality customer service, he and the other senior officers have worked hard to minimize the bureaucracy at southwest Airlines. This means that there are very few levels of management between an entry level position and Kelleher. since this type of lean structure encourages senior officers to get out and interact with employees at every level of the organization, it has become established as a value that is consistently promoted at southwest. For example, while an organization with 5,000 employees must have some rules, Kelleher is very much against establishing rules and regulations unnecessarily. He believes that the downfall of some organizations is that every time an 


\section{The Difference Just One More Can Make!}

\begin{abstract}
A $t$ the end of a hard day's work, have you ever reflected back and thought, "I should have shown that Customer a little more consideration," or "I should have tried a little harder today to make a good, lasting impression." You will be astounded to learn what a tremendous impact just one more additional Customer per flight can make on our financial position, which in turn has a direct influence on our future.

Looking back to 1985, Southwest flew 208,368 trips. Therefore, if we had carried an additional Customer per flight, we would have carried an additional 208,368 Customers. Simple enoughl At an average fare of $\$ 50.59$, one more Customer on each flight would have increased our revenue by $\$ 10,542,250$ - yes, over TEN MILLION DOLLARS. Our load factor would have increased from $61.2 \%$ to $62.3 \%$. You can see what a tremendous impact only a slight increase in load factor has on revenues.

How do we go about getting one more Customer? The answer is quite simple - service. And that's what an
\end{abstract}

airline sells - service. The manner in which the service is provided makes or breaks the airline.

To be better than the rest we must simply continue to strive as we have in the past to provide better service than the other guy... by always doing that "Tittle extra" for our Customers.

In a service-oriented company, it's the "little extras" which make the big difference. In our industry all airlines are basically the same, having similar aircraft and ground equipment, charging similar fares and using the same airports. So if the product is basically the same, why choose one over another? Same simple answer service.

It is the responsibility of each and every Southwest employee to offer the best possible service to our Customers. Just as one additional Customer per trip can have tremendous impact on our financial results, an employee providing extraordinary service can have a great impact on our Customers' decision to choose Southwest.

Complacency is the worst enemy of good Customer service. Each and every one of us must continually motivate ourselves to prevent getting into a rut. In this ever-increasing competitive environment of ours, there is no such thing as "business as usual." We must be more alert than ever. We must be flexible, and we must always continue to go that extra mile for our Customers.

A nice smile, a good attitude, calling a Customer by name, looking a Customer in the eye, the extra time taken to listen to a problem, an extra arm to carry bags. . . all of these things add up to "service" - service which leaves a great impression on our Customers. An attainable goal at Southwest (attainable only if each of us commits to giving the best "Customer Service" possible to each Customer we have the opportunity to serve) would be to have each Customer across our system automatically "THINK SERVICE - THINK SOUTHWEST"!

Just remember the difference one more Customer can make and most importantly, remember the difference YOU can make. The potential is unlimited!

\section{Figure 15. This article appeared in the september/October, 1986 issue of the company's newsletter.}




\section{A CUSTOMER}

\section{A CUSTOMER}

is the most important person in any business.

\section{A CUSTOMER}

is not dependent on us. We are dependent on him.

\section{A CUSTOMER}

is not an interruption of our work. He is the purpose of it.

A CUSTOMER

does us a favor when he comes in. We aren't doing him a favor by waiting on him.

A CUSTOMER

is part of our business - not an outsider.

A CUSTOMER

is not just money in the cash register. He is a human being with feelings, like our own.

A CUSTOMER

is a person who comes to us with his needs and his wants. It is our job to fill them.

\section{A CUSTOMER}

deserves the most courteous attention we can give him. He is the life-blood of this and every business. He pays your salary.

Without him we would have to close our doors.

Don't ever forget it.

Figure 16. This poem appeared in the December, 1986 issue of the company's newsletter. 


\section{Where Do We Stand}

7 he November 10 Wall Street Joumal ran a story explaining the woes Customers face as air carriers expand services. The article states that our industry faces a "threat far greater than any fuel crisis or government intervention - an unhappy customer." As you can see from the tables listed below, the SOUTHWEST SPIRIT does pay off and our Customers have had to

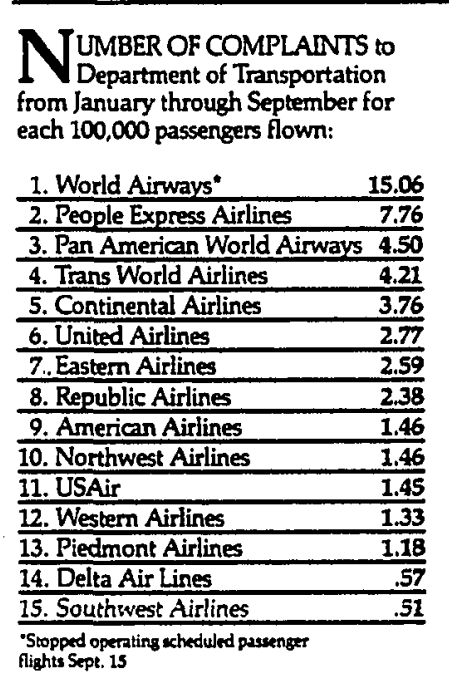

ASSENGERŚ DENIED

boarding" (bumped) in August for each 100,000 passengers flown on selected major carriers:

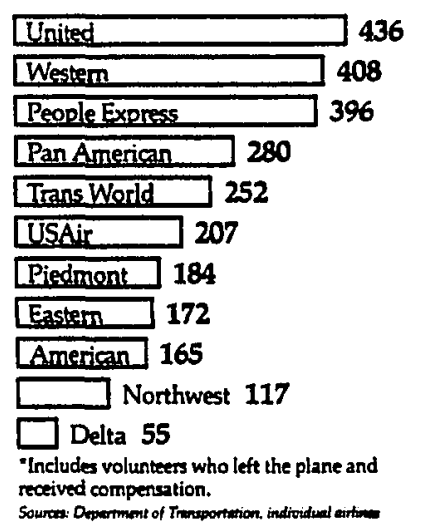

face very few misfortunes. We were clearly "the" winner in all three tables. In fact, we had so few denied boardings that we didn't even qualify for the "Passengers Denied Boarding" table!

Keep that special WINNING SPIRIT flowing and our Customers will come back again and again! $\bullet$

OST COMMON COMPLAINTS of airline passengers, January through September.

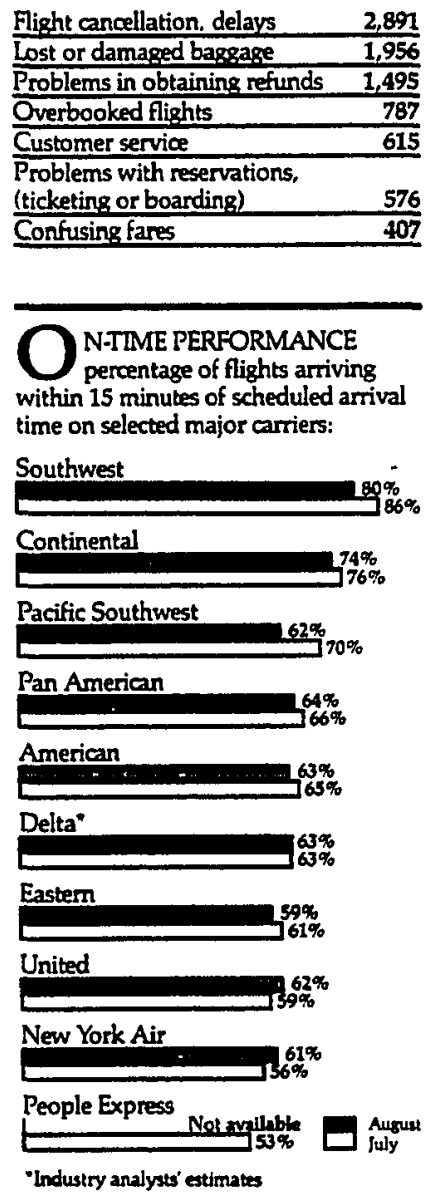

Figure 17. Results of Southwest's customer service performance that appeared in the December, 1986 issue of the company newsletter. 
employee makes a mistake, someone establishes a rule so the mistake won't happen a second time. According to Kelleher, this is a problem because it unnecessarily penalizes every employee when the mistake was made by only one person. He suggested that policy manuals are the scars of mistakes made in the past because when someone fails or makes a mistake, a new policy is usually established. From Kelleher's point of view, this is why many corporations have policy manuals that come in volumes.

Rather than establish a new rule or policy every time a mistake is made, Kelleher chooses to address the problem more directly. Consistent with his desire to have personal contact with his people, Kelleher's approach is to confront the individual who made the mistake personally. He explained that:

There's one form of management that says, OK, something has happened here that we don't like and we're going to put in a ruie. Well, if you have enough rules, you really don't need managers. You just say well, that's the rule.

The environment that I try to develop is one where you say OK, somebody did wrong in this particular instance, but that's somebody. Kevin did wrong, not all the employees at southwest Airlines. So we're going to talk to Kevin about his behavior. We're not going to slam in a rule that penalizes everybody 
across the company simply because Kevin went astray. And that's very important, too, so that people feel that they're being looked at individually.

In concert with Kelleher's philosophy, Gary Barron stated that "manuals are for those people who don't want to manage--they make rules." Barron, one of the chief advocates of a lean structure, also suggested that he refuses to establish rules and policies without ample justification.

I used to be in charge of the flight attendant department. And I'd occasionally have someone come in and say, "You've got some flight attendants out there and they're screwing up." And I'd say "Tell me who they are." The purpose of them coming in was: "You need to send out a memo." But the flight attendants weren't all screwing up. If you've got someone who's screwing up, you tell me who it is and we'll fix it. I'll talk to that person. But we're not going to put out a shotgun memo that will have a negative effect on the morale of the people out there who are busting their butts doing a good job just to get at a few. It's much more efficient in that area to use a rifle than a shotgun.

People who don't want to make hard decisions, hard management decisions, will come out with the rules. And then when an employee is brought in, 
they're able to say, "I really wish I could do something about it, but it says here in the rule that I don't have any choice, and this is what I've gotta do."

Kelleher indicated that because Southwest Airlines is lean bureaucratically, the company is able to respond very quickly to the shifting demands of the market place. He explained that with a lean structure employees are able, and in fact expected to make decisions quickly. This is because the company has sought to alleviate much of the red tape that employees would normally have to go through in order to get approval on important decisions. Essentially, a lean bureaucracy is an extremely important value to the people of southwest because it communicates that they are respected enough to be given a lot of autonomy. Kelleher pointed out that when you give people the freedom to make decisions they will not only shift into action more quickly, they will also feel more significant about their role in the company. Both Kelleher and Barron indicated that their jobs are to remove the obstacles and pave the way for employees to do their jobs. Barron suggested that: We give managers flexibility to do their job. If I made all the decisions for them, I wouldn't need them. I can't make the decisions for them. They know a hell of a lot more about their jobs than I do. I think it's my job to grease the wheels, to make their job 
easier and in turn, it's their job to do that for the people who report to them. All the way down the line. Kelleher added that he encourages every manager to do the little things that support employees and enable them to accomplish their objectives more easily. He remembered a situation where a problem arose because someone in a particular department needed an adding machine. Kelleher explained that there were an abundance of machines not being used in another department and that someone should've gotten one of those machines to the person in need. He affirmed that,

one of the things that you try to encourage among all of your managers is not to let the employees develop disaffection and resentment of little stuff. In other words, if there's something the employees need done, then do it.

If you don't take care of those little things, then people logically, and naturally, and normally say, "Hey, they don't care about us." so one of the things that you do is say, "Do the little things. Don't let them fester and become sources of real disaffection."

When Kelleher makes these kinds of statements to his employees he speaks with a great deal of credibility. This is because every employee has come to know by his very example that Kelleher is often the first one to recognize 
an employee's need and do something about it. Whether it is licking envelopes with Colleen Barrett until two o'clock in the morning, loading bags with steve cole and Rick Donley down on the ramp, serving peanuts on the airplane with Tona Weigelt, or helping Dale Morrow la Southwest mechanic) with engine maintenance, Herb Kelleher is willing to help his people with the little things.

While there are many values that have been established at Southwest Airlines, that loving spirit, pride and confidence, work is fun, service to the customer, and lean bureaucracy are the ones that appear to be lived out most evidently in the organization. The primary reason these valies have been so well embedded in the company is because Kelleher passionately exemplifies them in his daily behavior. His consistency and his ability to communicate these values with tremendous clarity have enabled the people of Southwest Airlines to develop a unified sense of mission. These are the values, then, that constitute the character and identity of Southwest Airlines.

\section{Power and Politics}

While Herb Kelleher has been identified as a jovial individual who loves to laugh and joke with his employees, he is also seen as an individual who is extremely sophisticated politically. He is very skilled at using power resources and politics to satisfy the wants and needs of his people. Kelleher strongly believes that power in an 
organization should be shared. As mentioned previously, titles are really unimportant to kelleher because they often lead to the abuse of power and authority. He believes that true leadership precludes titles and can exist at every level of the corporation. As he spoke about the leaders he admires at the various levels of southwest Airlines, Kelleher mentioned that,

I tell them, you know, this title crap, people who are insecure want titles in many cases just so they buoy themselves up. The kind of people that build country clubs to keep other people out. They can only make themselves feel special through the process of exclusion. Titles are for organizations, but they're not significant from a standpoint of the way you should treat people.

One only needs to spend a day watching Herb Kelleher interact with the people of southwest Airlines to see that he makes them feel powerful by giving them the autonomy to make decisions and accomplish things on their own. Kelleher is an extremely powerful individual simply because every employee knows that he is oriented toward meeting their needs and serving the institution rather than his own self aggrandizement. Consequently, there is nothing the people of Southwest wouldn't do for Herb Kelleher. In this sense, he has essentially gained a tremendous amount of 
power and respect at Southwest by respecting his employees and making them feel powerful. He pointed out that,

I hate the word power. I don't even use the word power. Power is really responsibility. And if you look upon it as responsibility then you can give it up without embittering yourself. You're being relieved of responsibility. But figured as power, when you don't have it any more, you're going to be destroyed because there's nothing left for you.

The employees of Southwest Airlines will tell you that one of Kelleher's greatest strengths is that he gives them the freedom and responsibility to do their jobs. He's not a power wielder who relies on his position to get employees to comply. An incident that happened during Kelleher's first year as chief executive of southwest illustrates his concepts of freedom and responsibility. As the brand new president of the company, many of the employees didn't know who he was right away. Boarding a Southwest flight bound for Houston, Kelleher was hanging his suit bag in a closet near the flight attendant's galley. The flight attendant, who obviously didn't know him, told him that he couldn't hang his bag in the closet. When she inquired as to who he thought he was, putting a bag in that particular closet, Kelleher replied by saying, "I'm Herb kelleher, the president of the company." The flight attendant responded, "Yeah? And I'm the King of Siam!" Following her 
directions, Kelleher laughed, removed his hang-up bag and promptly took his seat.

Whether you are talking about pilots, dispatchers, flight attendants, or mechanics, Southwest employees are given an inordinate amount of responsibility. This is largely because Kelleher has a great deal of faith in their abilities and is not afraid to give them power. They, in turn, entrust him with the power and authority to make decisions on their behalf because they recognize that he considers the common good of everyone involved at southwest when making these decisions. Moreover, the employees at Southwest are well aware of the company's rough history and they have seen Kelleher as a protector of their mutual interests.

Kelleher is also very good at mobilizing resources and using power wisely. This can be seen in the acquisition of Muse Air. When Southwest acquired Muse, the new company had a tremendous amount of debt outstanding for its size. Kelleher, an expert at utilizing resources, opted not to merge the two companies into one because then southwest would be responsible for Muse's debt. As a wholly-owned subsidiary, Muse is obligated to retire its own debts. While southwest has taken a risk by pumping capital into Muse, the new company is an added resource that will increase southwest's share of the market. With the financial strength of southwest, Relleher was able to use 
his power to capitalize on an opportunity that has enabled Southwest to grow and expand.

Like any other organization, Southwest Airlines is political in nature. Each employee group (e.g. pilots, flight attendants, dispatchers, etc.) has its organization which fights for the group's own interests. Kelleher recognizes that the political dynamics within the company are natural and even productive. So rather than attempt to squelch the political energy exhibited by employees, he seeks to rechannel that energy in directions that are productive for everyone. This is not to say that southwest Airlines is without internal political problems; rather it is to suggest that the political problems that emerge within the company are seen as opportunities and not liabilities. Kelleher, who is more comfortable than most in the heat of competition and conflict, is a very straightforward negotiator when it comes to working out contracts that satisfy the interests of various employee groups at Southwest Airlines. This attitude has created a culture within the company where political activity is usually very positive and overt. That is, because kelleher sees politics as an inevitable part of the internal workings at southwest, and because there is such a family atmosphere among the employees, people tend to be very open and straightforward with their political behaviors. As mentioned previously, employee groups such as the flight 
attendants have no problem joining together and approaching Kelleher openly with their needs because they know he will deal with them in a straightforward manner. Perhaps this is one of the things that has distinguished southwest Airlines from other companies; in most cases the political behavior at southwest is open, honest, and above board while in other companies the politics is covert and often malicious. In this sense, Kelleher would argue that the politics within Southwest is healthy because it maintains a friendly tension between employee groups that causes growth and keeps the company moving forward.

While various employee groups bargain among themselves and with kelleher to advance their own agendas, the political behavior evidenced within Southwest Airlines has been constructive because of the political atmosphere outside the company. Over the years southwest has fought so many hotly-contested battles with forces outside the company that the employees, out of necessity, have joined together and formed a very cohesive, tightly knit family. As a result, any political shenanigans that would advance the interests of some employees while hurting others are simply against the norm at southwest and kept to a minimum. Thus, while the pulling and hauling we call politics is definitely a part of the culture at southwest, it is usually channeled in such a way that the organization serves the interests of the employees and visa versa. 
Through the negotiation process, Kelleher is a master at creating win-win situations where compromise results in satisfying the needs of employees and advancing organizational goals.

As a political actor, Kelleher has assembled a team of extremely talented senior officers (see Appendix B), some of whom had worked with him in the San Antonio law firm fighting for the southwest cause from outside the company. These individuals are not only experts in their respective fields, they are individuals who have been loyal to Herb Kelleher. Given that he puts so much faith in his people and provides them with a tremendous amount of autonomy, Kelleher has been very careful to surround himself with people who adhere to the type of values he so stringently promotes. That is, while the senior officers at Southwest Airlines are by no means "yes men and women" who agree with Kelleher on every issue (Kelleher actually encourages open disagreement), they are people that can exemplify the values he articulates, people who can mobilize resources in such a way that the mission and purpose of southwest Airlines is advanced.

Herb Kelleher's political sophistication is also evidenced in the way he cultivates stakeholding audiences. He is very comfortable dealing with people from a supreme court justice to a local city council member to an executive from Boeing Company. In each case Kelleher is a 
master at establishing action channels that provide Southwest Airlines with a host of opportunities and organizations. One only needs to look at the list of boards on which he serves as a director to see that Kelleher knows how to network and cultivate resources (see Appendix c). As Jim Parker confirmed,

Herb has been politically well-connected and I think he brought to the airline business something that historically was lacking in all the airline business, and that's a real political instinct. Herb perceived opportunities through political channels that the standard business executives would not have been creative enough to think of. I think southwest has probably done more to cultivate the political landscape than anyone I'm aware of.

Herb has gone out of his way to get to know the members of the legislature, most of them would know him by his first name. I can't imagine that they know too many other airline chief executive officers by their first name. And he contributes well to a lot of campaigns. He probably contributes to more individual campaigns than almost anybody else in Texas.

Gary Barron added, "He's very good politically. The politician that he supports he will support with money, time, effort, and political fund raisers." 
Kelleher's political instincts have helped to create a lot of opportunities for Southwest Airlines. Jim Parker pointed out that by being well-connected politically, Kelleher has been able to mobilize some pretty significant resources. For example, when southwest decided to service Chicago's Midway Airport, Kelleher was urged by Colleen Barrett to show a group of local officials in Chicago what could happen with Midway by exposing them to Houston's Hobby Airport. The following discussion with Jim Parker illustrates the impact southwest has had by recognizing the importance of the political process in accomplishing its objectives. Describing Kelleher's political sophistication, he said,

His [political acumen] pays off. In terms of access to people who need to hear not just southwest Airlines, but the Airline's side of the story on a number of issues such as proposals to tax jet fuel, which comes up in almost every session of the legislature. Herb, because he knows the political ins and outs in Austin, is of tremendous value in that regard.

I think he really brought that political instinct to bear when we went into Chicago, which is probably the most political city in America. One of the first things we did was put together a charter flight on which we took a number of civic, business, and political leaders from Chicago, where we went into 
Midway Airport, which is an older, inner city airport that we're working to revitalize.

Like Love Field, I asked?

Yeah. We took them to Houston. We analogized it to Houston Hobby Airport which was an old abandoned inner city airport--we revitalized it and it's now a hot bed of airline activity. We took them on a tour of Hobby Airport, we had dinner for them. Lieutenant Governor Bill Hobby (see Figure 18) came out and spoke to these folks from Chicago, welcomed them to Texas, told them what a swell guy Herb Kelleher was, and by realizing the importance of doing something like that, we gave them an education.

First of all, we showed them that we cared about them, and we gave them the opportunity to see what we're all about. I don't think very many airlines would have done something like that to attempt to cultivate and drum up support.

The upshot of all this was when the Chicago City Council started considering a jet fuel tax, we just sort of assumed that United Airlines (which is one of the biggest corporations in Chicago) would have a little influence with the city council of Chicago. But we found out that that wasn't the case, and they are looking to southwest Airlines to try to carry the ball to beat the jet fuel tax because we bothered to 


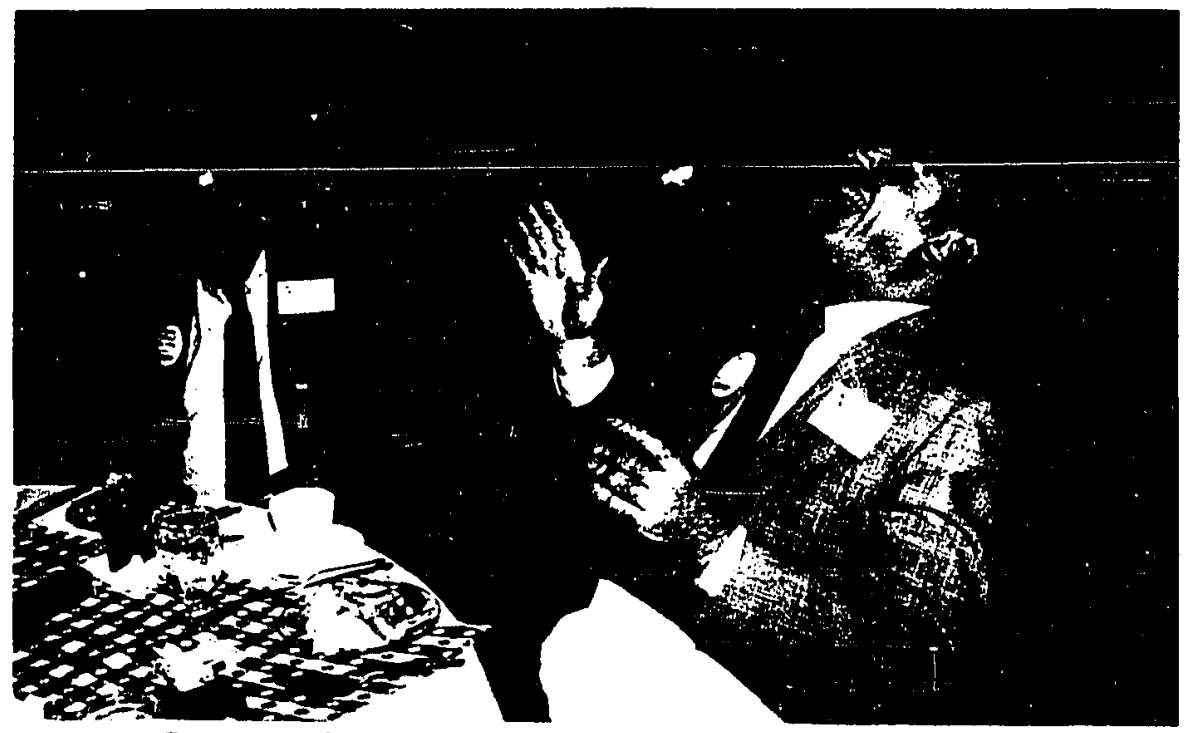

10 Houston Intercontinental Airport opens. All eleven airlines at Hobby : roved to the new facility. Hobby is closed to all but general aviation.

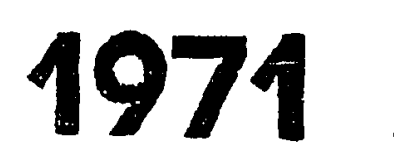

Southwest Airlines begins serving Houston Hobby, with 24 flights daily between Houston and Dallas. By the close of 1971, over twenty thousand customers have flown commercially into and out of Hobby.

10 For fiscal year 1978, Hobby serves over four million customers - more than in 1969, when Intercontinental opened.

Hobby begins construction of a $\$ 22$ million,
3,700 -car parking facility and a $\$ 20$ million
renovation of the 80 -acre terminal tacility.

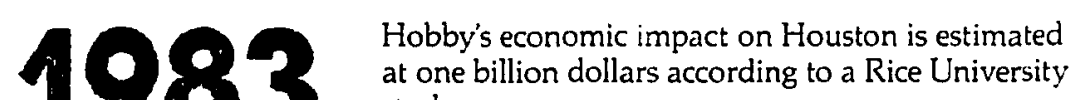
study.

Customers at Hobby exceed 7.1 million and revenue exceeds $\$ 22$ million.

\section{(1) Twelve airlines, with more than 400 flights daily, serve Houston Hobby. Southwest Airlines provides almost half of those flights.}

Figure 18. Herb Kelleher sharing a laugh with Lieutenant Governor Bill Hobby followed by statistics that show the impact Southwest Airlines has had upon the Houston Hobby Airport. 
get to know the Mayor and the City Council members and let them know that we care about them and how we want to be good citizens of Chicago.

It's just a matter of attempting to become familiar with the local elected leaders, the local civic leaders, business leaders, and find out who they are and let them know we want to be a part of the community.

In addition to the chartered flight, southwest Airlines had donated money to the City of Chicago for improvements at Midway Airport (see Appendix $D$ ) and participated in city events such as the St. Patrick's Day Parade. The result of these political maneuvers is that the City of Chicago is considering an amendment to exempt Midway Airport and thus, Southwest Airlines, from the jet fuel tax. If the amendment passes it will mean a savings of millions of dollars for Southwest.

Another way in which Kelleher's political skills are brought to bear on the success of Southwest Airlines is in his ability to use power to protect the values that have been so deeply, embedded in the company. Like an angry mother who would scratch an intruder's eyes out for attacking her child, Herb Kelleher has the ability to play political "hardball" with anyone wishing to exploit or harm Southwest Airlines. As the history of the company shows, it was Kelleher's political skills and legal acumen that 
kept the company from buckling under the pressures from outside forces. He is quick to point out that southwest Airlines is his extended family, and when he is defending his family he can be an extremely competent political strategist. The passion with which he speaks when talking about defending southwest is evident. He indicated that, "I'll take on anybody on behalf of Southwest Airlines. And when I do, I'm fierce too." Jim Parker and Gary Barron echoed Kelleher's statement when describing the chief executive from a political standpoint. Said Parker: "He's fierce when he's in a combative mood. Absolutely. He's tough and fierce. And he doesn't give much slack." Barron concurred: "Anybody attacking Southwest Airlines, they would be better off to attack him personally than to attack Southwest Airlines. He takes it a lot more personally."

Barron finted out that Kelleher has been a successful political strategist partly because he is bright and always very well-prepared. These two qualities have earned Kelleher a tremendous amount of respect among stakeholding audiences in the City of Dallas and the airline industry at large. This respect, in turn, has enabled him to mobilize a variety of resources on behalf of southwest Airlines and it has caused opposing forces to think twice before engaging the company in any type of political battle. Barron argued that, "He's the best lawyer I've ever met. Best one I've ever seen, in terms of being smart. He's 
extremely smart. But he's also extremely well prepared. And that's a combination that's hard to beat."

He suggested that the same skills that made Kelleher a successful lawyer are the very same skills that have enabled him to politically outmaneuver his opponents today. He worked 18 hours a day at the law firm the same as he does here. And in that amount of time, you can get pretty well prepared. He left no stone unturned. When he walked into the courthouse, he had gone over the material he was going to present many times. He knew what was going to happen. His preparedness was something that most lawyers don't have. Most lawyers have a concept of what being prepared is. And it's nowhere near what his is.

He's also very believable with other people, other than just employees. When he's in court, practicing law, he had that same ability. And when he's speaking to the city council or some governmental body, they know he's sincere... . I've seen people running departments that try to say different things, and I do believe they were sincere, but they didn't come across as sincere, and perception is a hell of a lot more important than reality.

Jim Parker concurred:

It's tough to work for somebody who's a better lawyer than you are, though, when you're a general counsel. 
That's the case with me. I mean, Herb is just flat out a better lawyer than I am. He's a better lawyer than just about anybody.

At present, Southwest Airlines is fighting a battle with the City of Dallas over an issue that has been raised many times. The issue centers around the noise from the jet engines during take off and landing at Love Field. According to southwest officers, the City of Dallas, via one adamant city council member, has threatened to impose unnecessary restrictions upon the company. However, out of all the airlines servicing Love Field, Southwest was the first to take some major steps toward reducing the noise level before it ever became an issue with the city council or the citizens of Dallas. Kelleher affirmed that, Even before noise at Iove Field became a controversy, we were following noise abatement flight profiles coming into and out of Love Field that were designed to minimize the amount of aircraft noise shed outside the perimeter of the field itself. And in the absence of anyone rising up and saying "you must do something," we did all those things voluntarily before we even knew that it was an issue.

Politically, Kelleher has rallied his troops at Southwest and asked them to get involved in the controversy by writing letters to the city council, standing on downtown street corners in uniform getting people to sign petitions, 
and attending city council meetings. Kelleher has also made weekly trips to city council meetings to plead his case. He has suggested that Southwest Airlines is not only a major employer of the City of Dallas, it is also a significant source of revenue. Moreover, he pointed out that the airline is taking additional steps to reduce the noise at Love Field.

While kelleher has been pleading his case with the City of Dallas, he has also maintained some very important ties with city officials in San Antonio (see Figure 19), a city in which he is highly respected. Kelleher's law partner, Stanley Rosenberg, and former city attorney, Jane Macon, both agreed that behind the scenes, Kelleher is one of the most powerful people in San Antonio. Apparently, San Antonio officials have been trying to get Kelleher to move Southwest's corporate headquarters to their city for years. They have even tempted him with the idea of building a new airport and a new base for the airline. Obviously, Relleher has been reluctant to do this because the Dallas market constitutes some $12 \%$ of the company's gross revenue. However, the pressure from the City of Dallas has recently caused his patience to wear thin, and he has threatened to pack up the whole operation and move it to San Antonio or Houston. At the time of this writing it appears that Dallas City Council members have receded in their efforts to impose restrictions upon the airline. 


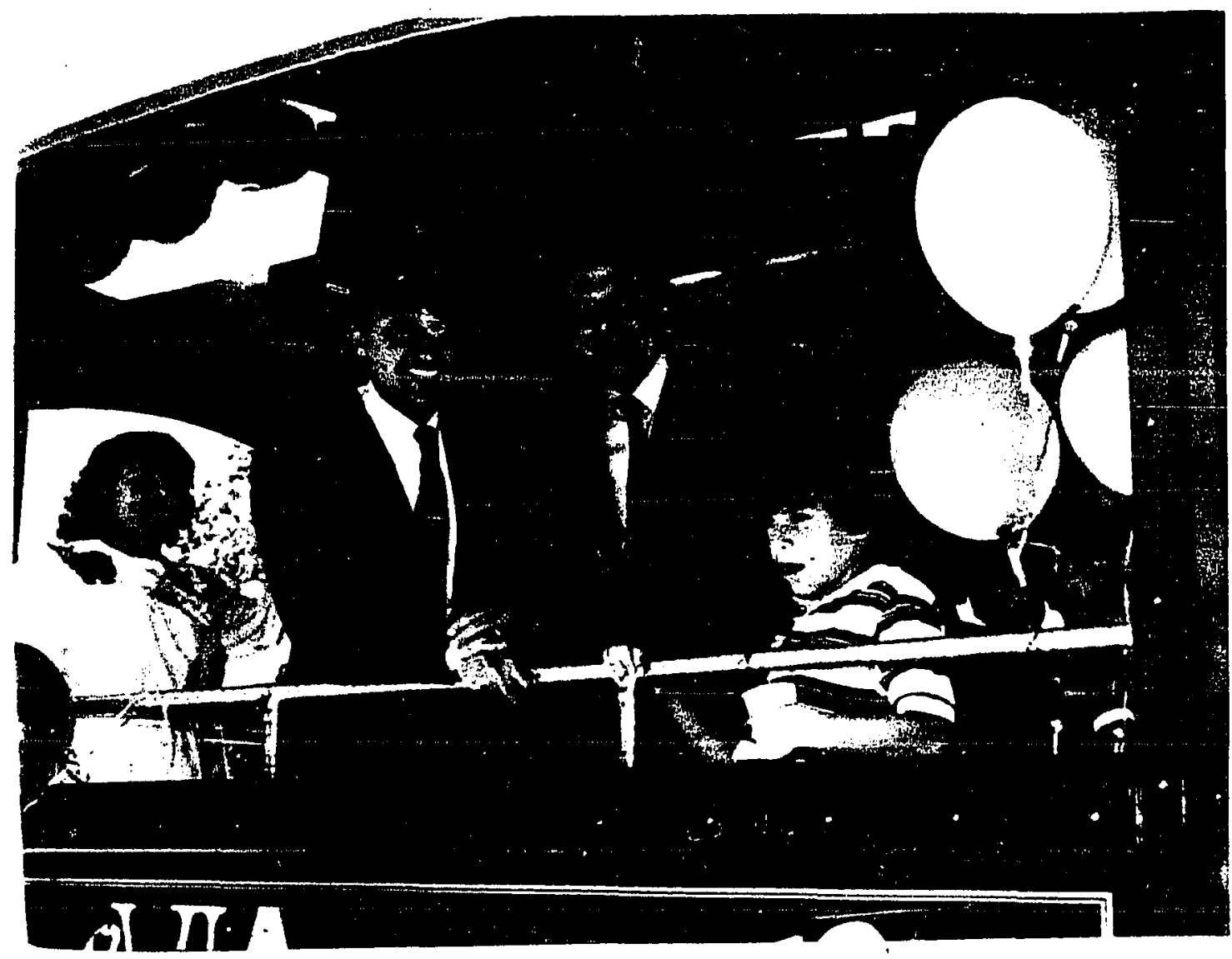

Figure 19. San Antonio Mayor Henry Cisneros chatting with Herb Kelleher aboard a San Antonio trolley. 
While all of the details of the arrangement have not been revealed, apparently Kelleher has negotiated a deal whereby any restrictions imposed upon southwest by the city of Dallas will result in the city's legal obligation to purchase the company's Dallas-based assets. Kelleher's legal skills and political connections with the City of san Antonio provided him with the leverage needed to negotiate a deal that now protects Southwest Airlines. Once again, by understanding the politics of the situation and by using his power to mobilize resources, Kelleher was able to withstand the pressure from outside forces.

According to Jim Parker, Herb Kelleher has a unique style of negotiating. He indicated that whether kelleher is slugging it out with the city council, negotiating labor contracts with the employees of southwest, or dealing with another corporation, he approaches the bargaining table consistently in the same manner.

I've learned a lot about negotiating from working with Herb. He has his own style. A lot of young lawyers, especially, tend to think the way you negotiate is you set unrealistic demands and you expect the other side to - . be suitably awed by the demand you have made and probably be intimidated into submission. But Herb's approach is really quite the opposite.

He recognizes the strengths of his own case and the weaknesses of his own case as well. And he will 
essentially determine what he needs out of a deal, and he will make his best offer his opening offer. There may be a little play in it, but not much puffery.

I recall one incident . . . [when] we evaluated our case, being a young lawyer I wanted to ask for much more, but he said we would accept a half-million dollars in settlement of a case we had against another airline for their anticompetitive conduct against Southwest. Herb thought the airline couldn't give us any more, and he thought realistically that a halfmillion dollars was a reasonable price. We would have settled it for half a million dollars, but the officials did not correctly perceive that when Herb Kelleher said he'll settle for a half-million dollars, that's not a bunch of bullshit.

Parker continued by explaining that the other airline counter offered with $\$ 100,000$ and threatened to disqualify Kelleher's San Antonio law firm from the case because he would be a witness in the trial. Refusing the counter offer, Southwest filed suit. When the general counsel for the other airline learned that the suit had been filed, the airline sought to immediately settle out of court. Having been convicted of criminal antitrust violations already, the officers of the other airline realized that Southwest was going to win the lawsuit. Southwest ended up settling 
for twice the amount for which Kelleher initially offered to settle. Parker concluded the story by recounting that, Their general counsel called me back and asked if we'd filed it and then said, "Aw, shit, I knew you were going to do it but the guy upstairs wouldn't believe me." I reminded Herb that in at least some variations of poker games people who stayed in to see the last card had to match the pot, and I thought that they had stayed in at least to see the next card and they ought to pay a little more, and he agreed. So we doubled the demand. When they came to see us the second time, we told them we'd take a million dollars.

But as I said, there's usually a little slack in what Herb says, and not much, and the lawyer on the other side was very engaging and said, "Look, you guys gotta give me something to take back to my client, I can't go up there and tell him I took your first offer." So Herb said, "Okay, $\$ 900.000 . "$

That is the kind of approach that I think Herb will respond to, if a negotiator says, "Come on, you gotta give me a break. You got me, I know what the cards are." It's sort of a no-bullshit negotiating style. He tries to be realistic and straightforward, and he expects people he's dealing with to be the same way. 
While it is perhaps more difficult to observe and describe political behaviors in a company than it is to identify the company's vision or value system, there can be no doubt that the appropriate use of power and the political sophistication of an executive like kelleher have contributed significantly to the success of Southwest Airlines. Kelleher is an individual who understands the political environment and recognizes that political activity necessarily pervades every aspect of business. Through his legal background he has become a highly competent negotiator, and he has skillfully used his ability to negotiate to mobilize resources on behalf of Southwest Airlines.

\section{Generativity: The Development of Followers}

Whether it is helping the people of Southwest Airlines find transcendent meaning in their work, or encouraging them to take responsibility for the larger social environment within which southwest operates, Kelleher's most recognizable strength is his knack for raising the people around him to higher levels of motivation and morality. He has a tremendous concern for the future of southwest employees, and he has been able to create an element of synergy at southwest where employees see that their work is connected to a larger whole.

For Kelleher, raising his people to higher levels of moral development begins with something as simple as 
recognizing that each person that comes to work for Southwest is significant. He understands that when he treats people with dignity and respect and shows them through his daily actions how important they really are, those individuals reciprocate by displaying the same type of behavior. As far as Kelleher is concerned, his employees are the most important part of his life and southwest's success. He said:

One of the things that I think is very important is valuing them as individuals, not just as employees. I don't use the word employees very much, and I never use the word management. I just refer to the people at Southwest Airlines, and we really try to treat them as people and think of them as people and recognize each one's individuality.

Kelleher has a unique ability to develop within his people a sense of significance, a sense of purpose through which their work takes on meaning. This can be seen in the way he builds people up by giving them credit for southwest's success. Jim Parker's comments reflect this attitude.

He has respect for southwest people which I think is real and heartfelt. He is always the first person to give credit to others for his own accomplishments. And I think that is one of the things that, at least for me, and I think for a lot of other people, makes him one of the greatest people in the world to work 
for. He is always the first one to congratulate others on doing a good job. He is always the first to pass along credit for things that are really more his doing than anyone else's. And that type of sharing and caring attitude is all a part of the persona, the charisma, that he exudes.

When asked if he was grooming a successor for the future, kelleher responded by saying that he is attempting to groom a string of potential successors.

I've tried to bring very good people to southwest, and I think I've done that, so what I'm really doing is grooming a lot of potential successors. By the time I'm finished, I hope that over the next twenty or thirty years there will be a natural succession set up.

This is evidenced by the fact that he engages in a host of generative relationships with the people at southwest. While there are only a few individuals with whom he has developed long-term mentor/follower relationships, there are many throughout the company who have grown from a moral development standpoint because of Herb Kelleher. Quite frankly, it is difficult to encounter kelleher and not walk away with a renewed sense of humanity. He has a tremendous ability to bring out the best in people and as Paul quinn indicated, "make you feel seven feet tall." Also, because he is so visible and accessible to the people of southwest, 
the employees have many opportunities to interact with him, opportunities through which the process of generativity is facilitated. In watching Kelleher deal with his people, one can see that they have his undivided attention and that he consistently encourages their strengths. Thus, it is very obvious that Kelleher's primary agenda is to enhance the motivation and morality of everyone he comes in contact with at Southwest Airlines. By his very nature and his unwavering example, Herb Kelleher is a developer of people. When talking with southwest employees at meetings, Kelleher never misses an opportunity to appeal to their needs to be heroic. In this sense, he has created an atmosphere at southwest where the employees find fulfillment and significance in the work that they do. As Kelleher establishes a framework in which paths for heroic deeds are created, the people of Southwest Airlines have responded by seizing opportunities to perform heroically. When this happens, Kelleher is the first one to recognize the performance and the first one to broadcast it to the rest of the troops. As the following excerpt from one of his many speeches shows, Herb Kelleher takes great pride and joy in talking about the heroes and heroines of Southwest Airlines:

I think Southwest Airlines, thanks to you, has created an atmosphere . . where people come to work and they say, "Hey, give me a challenge, give me a problem, 
give me an emergency, and I will turn on and pitch in to make sure that we are successful." There has never been any occasion, in the history of southwest Airlines, no matter how threatened we were by other airlines, the City of Dallas, the United states Congress, the Texas Legislature, you name it, that I haven't been able to call on the people of Southwest Airlines and say, "Please, rally to the cause. Please help us. We want to show them that we are right and they are wrong," and in every case, the people of Southwest have really pitched in.

Recently I was asked, "Who are your five greatest heroes? Upon whom do you look as being the five greatest leaders you have ever known?" And I mentioned winston Churchill and somebody else, and then I said "Gigi Perry, Leon Tucker, and Dale Morrow." And there was kind of a stunned silence from this fellow who was asking the question, and he said, "Who are Gigi Perry, Leon Tucker, and Dale Morrow?" And I said, "They're great leaders, they're right at the top of anyone you can name in the entire history of humankind."

Gigi Perry is a ticket agent at Love Field. Just to give you an example, there was an elderly passenger that needed help. She took her to the hospital and slept on the floor of her hospital room all night 
except for when she was making telephone calls to her husband to appraise him of how she was doing.

Leon Tucker is a skycap at Love Field. We probably get ten to fifteen bouquet letters on Tucker per month. There are people who show up at the airport and say, "Isn't he the greatest introduction to southwest Airlines that anyone could have? He cares. He's attentive. Nothing's too much for him. He wants to make sure we get on the airplane, that our luggage goes with us, that everything's done right. And he's just a marvelous person."

And Dale Morrow, as some of you, I'm sure know, is a mechanic here in Phoenix. Dale Morrow is not just a mechanic, Dale Morrow is a leader. Dale Morrow will do anything and everything that is required to help make southwest successful. If a plane is late, he'll load bags. If someone needs a part from downtown, Dale Morrow will drive down and get it. He devotes seven days a week, sixteen hours a day of his time and attention to Southwest Airlines.

And really, when I mention those people, I mention them as being representative of all of you, because Southwest Airlines, I think, is the luckiest company in the world, because it is filled with great leaders everywhere in the company. People who by example, day in and day out, are showing what it takes 
to make the company successful, and inspiring those who may not have been here as long as us.

It is difficult to accurately describe the intensity with which the employees of Southwest Airlines listened to their leader as he delivered those remarks; however, I could see that they were filled with pride and elevated by Kelleher's words. The confidence and "can-do" attitude that he instills in them inspires them to have faith in their own abilities to do great things. This is one way in which Kelleher shows them that their work has transcendent meaning.

Another Southwest Airlines hero that Kelleher loves to talk about is Tommy Perryman. Perryman is a skycap from San Antonio who had never missed a day at work in ten years with the company. Kelleher gave him the Founder's Award, which is a very special award given to the person in the company who most exemplifies the southwest spirit. Tona Weigelt remembered the banquet where Perryman received the Founder's Award.

He was on cloud nine. You could tell he was. He was so proud that he had done that, and he was so proud that he had that award, that he was beaming and you could tell that Herb was real happy about giving it to him when he shook his hand and hugged his neck. The man is real dedicated to his job and real dedicated to the company. Herb knew that, and this was his way of 
telling him thank you. Tommy got a $\$ 1000$ check, a beautiful plaque, he got a replica of a southwest Airplane, and I mean the man was just beside himself. Kelleher's recognition of individuals such as Tommy Perryman has a ripple effect throughout the company. By holding people like Perryman up as heroes, he not only inspires Perryman, he also moves all of those employees who know Perryman to higher levels of moral aspiration. In this sense, Kelleher understands that the recognition of one individual can have a tremendous impact on the moral development of others.

When it comes to developing his people and causing them to grow, Kelleher keeps an open mind to a variety of possibilities. In his overwhelming optimism and faith in people, Kelleher believes that with the right attitude, people can perform heroically in positions that are above and beyond what others thought they were capable. He said, I think it's very important that we try not to allow our imaginations to be circumscribed by the suit someone is in. And by that I mean that when we're looking for someone to fill a job, we don't say automatically, all secretaries are ineligible, or all people that work in maintenance wouldn't be qualified to do this job. We pick some people out of some strange slots and put them in different slots and they do very, very well. 
And that's a wonderful feeling, if you can take somebody and put them in a different position that nobody would ever think of, and they just do a great job. What I've always said is that what I'm looking for is attitude more than anything else. You can be smart as hell and you can be industrious, but if you've got a lousy attitude, there's not much that we can do. If you've got a great attitude, we can give anybody an opportunity to do almost anything.

Kelleher's philosophy in this respect can be seen in the people at southwest that he has mentored since his days of practicing law in San Antonio. Three of these individuals, Colleen Barrett, Gary Barron, and Jim Parker, would agree that their relationships with Kelleher have contributed significantly to their moral and professional development.

Colleen Barrett began with Kelleher as a legal secretary in his San Antonio law firm. Barrett's superlative organizational skills are only surpassed by her passion for devising new ways to open communication channels and correspond with southwest employees. The Vice President of Administration will tell you that Kelleher is the person most responsible for influencing her life. Barrett is a primary example of Kelleher's ability to put an individual in a position where he or she is raised to higher levels of moral development. She plays a terribly important role at southwest and is recognized for it not 
only by Kelleher, but also by the employees at large. Kelleher described in no uncertain terms what an important asset she is to his office and the company as a whole. He indicated that she is an outstanding compliment to his efforts at southwest. In addition to maintaining Kelleher's schedule and coordinating the activities of the president's office, Colleen Barrett heads up the company's employee communication efforts. In this role there is no one more effective than colleen Barrett. She has a special knack for making the employees feel important by corresponding with them on those special occasions when a note from "Herb and Colleen" can make all the difference in the world.

Barrett is perhaps most respected for keeping Kelleher organized and on schedule. She pointed out that Herb would stop and listen to an employee's problems for hours if someone didn't keep him on track. Jim Parker pointed out that,

Colleen is a very creative person. She's worked with Herb more years than any of us, I think. colleen really brought to bear a lot of organization on Herb's office. She says his desk looked a lot like mine [files are stacked three inches deep on every side of Parker's desk] before she started organizing it back when he was a lawyer. 
There's no question in her mind that moving from legal secretary to becoming the vice president of a major corporation has caused Colleen Barrett to grow. More important, however, is the fact that she has been mentored by an individual like Herb Kelleher. Barrett is a leader who displays the same type of care and concern for the people of Southwest as Herb Kelleher. Like Kelleher, her passion is Southwest Airlines and its people and her primary method of leading is by example. When the employees of Southwest refer to leadership in the company, they will often refer to Herb and Colleen. This is because, together, Kelleher and Barrett make up an extremely effective team.

Another individual who has worked with Kelleher for many years is Gary Barron. Barron began as a clerk with Kelleher's law firm back in 1973. Although he had worked on the company's legal matters since he joined the law firm, he did not actually come to southwest until 1978. He is one of those people that Kelleher has moved in and out of a variety of positions during his tenure with southwest. Barron explained that Kelleher is particularly adept at assessing and accommodating his employee's needs for personal growth and development. In describing his relationship with Herb over the years, Barron pointed out that, 
He has kept me challenged. He knows that I have a tendency to get bored very easily. He has put me in positions that were rather unusual for a lawyer. Herb's had me involved in a lot of things . . always with more and greater responsibility . . . even though my title would have not indicated that I ought to be.

To me, it's been: "I don't care what your title is, I appreciate your input; I like your ideas so I want you to be involved in some of the decision making." That's about all it takes with me, and he's satisfied my needs in terms of money, which are not primary - . . The pay is not what motivates me to do anything. The challenge of doing it does and he's kept me challenged.

Barron started out as a lawyer handling southwest's labor relations and now serves as the executive vice president of corporate services. Barron explained that by moving him in and out of several different departments including a stint as general legal counsel, Kelleher essentially prepared him for the position he now holds. With regard to Kelleher, Barron said that, "I've never been able to tell him no when he's asked me to do something, even if it really wasn't something I wanted to do."

Jim Parker, general legal counsel, has also had a close working relationship with Kelleher for a long time. Parker and Kelleher met when Parker was an attorney in the 
Texas Attorney General's office. Parker went to work for Kelleher's law firm in San Antonio in 1977, a year after they had met. Parker's description of Kelleher gives us a glimpse of Kelleher as an individual committed to the process of generativity.

From the first days when I went to work for him, if he was introducing me to someone he would always introduce me in the warmest terms, as one of the smartest lawyers he had ever met, and any time I did a project for him he would, even if he had improvements to suggest, always be very supportive of the work. And to me, at least, that is the type of environment which stimulates one to attempt to excel; if you know that a person has confidence in your abilities, then it makes you want to reach your maximum potential.

Parker explained that attempting to produce a written product (which is often the nature of legal work) for Relleher's approval can be very challenging and very stimulating. Kelleher, a perfectionist and a master of the English language, is quite critical of work products that will ultimately be presented to the world bearing his name. However, Parker indicated that while he is very exacting with his criticism, Kelleher is very supportive when it comes to personalities. He indicated that Kelleher has the ability to criticize and correct, and yet make people feel valued and respected. Parker pointed out that Kelleher's 
tendency is to give people a lot of room to monitor and evaluate their own behaviors in mentor/follower relationships.

He pretty well knows that kind of standards people live by, and he knows that being your own critic is probably the most effective way to motivate other people. I think he expects other people to set their own standards and live up to them.

I'm not aware of very many circumstances in which he has bluntly had to tell someone he screwed up. He may tell them "I think you're wrong on this issue, I think we ought to do it a different way;" but its never a personal thing, its like "I think maybe we ought to take a different approach on this. Maybe we ought to expand this issue a little bit," something of that nature.

From Parker's perspective, it appears that Herb Kelleher has also grown as a result of his mentor/follower relationships with some of the people at Southwest. Parker explained that Kelleher has a tremendous mind for detail and that since he has taken over Southwest he has had to let go of the details and focus more on the bigger picture. He has had to almost undergo a personality transformation. It's an intellectual decision that he's had to make, running a major New York Stock Exchange corporation of this magnitude. He cannot review 
everybody's work product, so he has had to let go of the details to a degree that he never did as a lawyer. I think that's maybe been a little difficult for him. But he's made the transition amazingly well. Concurring with Parker, Greg Roessner expressed that, I was talking to him, and one of the questions I asked him was did he miss his law practice. And he said that he did the first two or three years when he became president. But there were so many different challenges in so many different areas that he just traded the challenges of the academic world with another variety of challenges.

The point here is that in the process of developing others, Kelleher has also been raised to higher levels of moral development.

In looking at Kelleher's relationships with Barrett, Barron, and Parker, one can easily see that he enjoys the process of generativity. He is very good at bringirs people along in the corporation and helping them to maximize their potential. These relationships also show Kelleher's commitment to people over time. He is very loyal to the people of southwest and committed to facilitating their morai development. The following remarks are indicative of how adamantly he believes in the process of generativity. When I asked him what stimulated his passion, Kelleher responded by saying, 
It has nothing to do with money. It has nothing to do with profits. I don't ever talk about the profitable, as such, you know, that that's an objective. What I talk about is, as I said at an awards banquet, "When you're sitting around with your grandchildren, I want you to be able to tell your grandchildren that being connected to Southwest Airlines was one of the finest things that ever happened to you in your entire life. That southwest collectively can enable your whole life, and give it a lot more meaning than anything you can ever achieve. That when you leave southwest I want you to think of it with the same degree of sadness that you experience when you leave your family."

According to kelleher, profits are simply a byproduct of doing something well to satisfy your own desire for excellence. He has made statements like "The essence of our excellence is our people." In other words, Kelleher's passion for Southwest Airlines is essentially motivated by the process of generativity. He argued that,

You ought to treat people right; it's a matter of morality. The way you treat people inside manifests itself in the way you treat people outside. And if you treat them lousy inside, they're going to respond the same way in handling passengers. 
And isn't it wonderful that it goes hand in hand with big business. So you can be moral and be a good business person at exactly the same time. You can't kick people around in your organization and then say, "Go out and be caring and warm and hospitable and entertaining and so on to the public."

Subsequent to one of my interviews with Kelleher, one of Paul quinn's managers was scheduled to meet with him next. In my discussion with Quinn this meeting emerged as a topic of conversation. Describing Kelleher's commitment to enhancing the motivation and morality of those around him, Quinn said,

In fact, the meeting after you left was with Pete, my analyst. He was up talking with Pete for about an hour asking different things. And when Pete came down Pete was a whole new person. Pete's only 5'7', when he came down he was 6'1", because Herb told him, "I really value your knowledge and your input." And he does. He'll listen to anybody. Quinn's remarks are significant because the incident with Pete shows that the process of generativity, like value shaping, is a result of the leader's consistency in the mundane events of every day. While some might argue that Kelleher's time with Pete was barely enough to make a difference, I would suggest that it was not the time he devoted to him, but rather the quality of time and the 
consistency of his behavior that ultimately made the difference. In Paul Quinn's opinion, Kelleher's meeting with fete is just another exemplification of his ability to treat people as individuals.

Several other incidents point to Kelleher's involvement in the process of generativity at Southwest Airlines. The first has to do with an operations supervisor in San Antonio named Larry Brennan. Brennan, 28 years old with a wife and three children, had contracted a rare form of cancer. As Brennan began to fight the disease, the employees of Southwest Airlines got together with Kelleher and devised a plan whereby people could donate a day of their vacation so that Brennan could continue to draw a paycheck while undergoing chemotherapy and radiation treatments. Through their participation in various fund raising events Kelleher, Barrett and the rest of the Southwest family sought to make sure that Brennan's family was financially secure for the future. Brennan died in June of 1986. As Greg Roessner pointed out, "Fortunately, his family will be well taken care of, and I'm sure that there were a lot of things that had been done behind the scenes that were not a part of the public record by Herb Kelleher and Colleen Barrett." A brief article about Larry Brennan appeared in the company newsletter and is shown in Figure 20. The article depicts southwest Airlines as a group of individuals with a moral concern for one of their 


\section{The Indomitable Spirit of LARRY BRENNAN}

"WHEN YOU ARE SORROWFUL LOOK AGAIN IN YOUR HEART, AND YOU SHALL SEE THAT IN TRUTH YOU ARE WEEPING FOR THAT WHICH HAS BEEN YOUR DELIGHT."

This verse trom Kahil Gabrins The

Prophet perhaps explains the sorrow fielt by so many Southwest employees who had the privilege of knowing Larry Brennan. Larry's steadfast humor and endless pranks brought so much joy and laughter into our lives, and now we are sad for losing that which made us happy.

In an atmosphere filled with love from family and triends and in the comtort of his own bed. surrounded by artwork made for him by his children. Larry Brennan died on the morning of June 20. Larry had been battling thymic cancer tor nearly a year and a half. He was 29 years old.

Born in Buffalo. New York. Larry lived in Cleveland. Kansas City and Dallas before settling in San Antonio with his wite. Barbara, his tour-yearold son Joseph. and Jamie, his twoyear-old daughter. Larny was a Southwest employee tor eight years and he utimately held the position of Operations Supervisor

During his tenure at Southwest. it seems Larry louched the lite of each employee he came into contact with in one way or another. His impact at Southwest was reflected by the etforts of rellow employees who donated thei vacation time enabling Larry to receive paychecks throughout his illness. The employees also held many tundraisers for Larry and his tamily. Among these was the now infamous "Brennan Benefit Blowout." a tour-day event. held on the Guadalupe River last September. These employees made it possible for Larry to leave his tamily debt free and with some savings in the bank.

These dedicated - nployees were ver precious to Larry. Hi unce confessed. "Southwest has got to be one of the best companies in the country. I say this with conviction because I have seen a kind of camaraderie that is rare. The triendship and heip given to myself and family has been nonstop. Sometimes you cant help but feel down and many times thinking of that camaraderie is what snaps me out of it."

Larry must have thought of his special triends a lot during his battle because his continued optimism comforted those around him. It's not uncanny that a man whose tavorite phrase was "Do it and like it" would have such a positive outlook. Patty Vovak. San Antonio's. Manager of Passenger Services, shares a story attesting to Larry's positive attitude.

"Mu most lasting impression of Larry isas the day latroie him to the Cancer Therapy Center for his treatment. Ea'en though Larry could hardly walk, and l'm sure he acas in much pain. he insisted thut / go inside with him to meet all his triends. Of course as aluays. Larry aus the friend

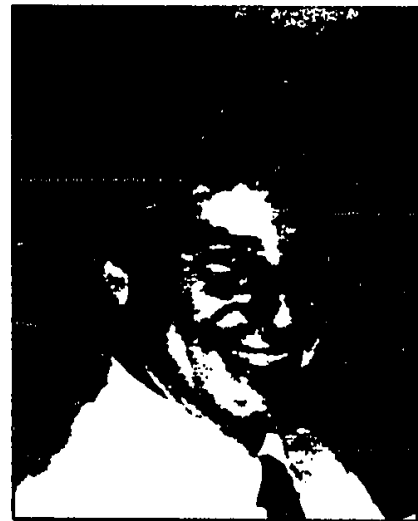

of all! It seemed us thought e'terything stopped and Larry was the center of attention. putting smiles on ereryone's faces! Larry atid not jeem: lihe :he patient. Viever a long tade. Iust ano:her wondertul day in his life no matter what the negatives."

Larry's unyielding love ot lite and love of the people surrounding him enabled him not only to contrent his illness. but to control it. He was alway's saying. "I'm comin back." L.arr. never gave in to his illness or stopped believing he could beat it. The man affectionately known as The Blade didrit lose - he merely ran ol:t of time. And the employees or Southwest Airlines didrit lose either - Larn. Brennan's indomitable spirit and the memories he shared with us ivill always remain.

Thanks for giving so much. Larr: $:$

Although "thank you" simply doesn't say enough, the family of Larry Brennan wants the employees of Southwest Airlines to know just how much they appreciate everything that was done for Larry. The entire family sends their love and gratitude.

Figure 20. This article about Larry Brennan appeared in the August, 1986 issue of the company's newsletter. 
colleagues and his family. This is the spirit of generativity that Kelleher and company work so hard to maintain at southwest.

As previously mentioned in the section that dealt with value shaping, Kelleher is guided by a purpose that goes beyond pure self-fulfillment. He is motivated by enhancing the humanity of his employees and therefore makes a special effort to unobtrusively get involved in their lives. With the help of Colleen Barrett, Kelleher stays in tune with particular events as they unfold in the lives of southwest employees. Dale Foster recounted an incident that illustrates his care and shows the impact he has upon the motivational level of employees.

I just got home from Indiana two weeks ago. My mother was sick, I was called home. I got back and she called me the next day and she said, "You know someone by the name of Herb Kelleher?" I said, "Yeah, he's the president of the airline. Why?" She said, "I just got some flowers from the guy and I don't even know this man."

Herb and Colleen sent her some flowers, cause she was sick. So did Jim Amos, the vice president of flight operations. She got two bunches of flowers from southwest. And it just blew her mind, she couldn't believe it. I called colleen and I thanked her for it and I said, "You know, in a little town in 
Northern Indiana, it's going to be the talk for the next year. Because things like that just never happen."

Foster welled up with pride when he shared this story and I could see that Herb and Colleen not only affected his mother with this gesture, they also had an uplifting effect upon Foster himself.

Tona Weigelt also described some of the little ways in which Kelleher shows his interest in the people of Southwest. She noted that the employees feel a tremendous sense of significance because kelleher goes out of his way to let them know how important they are to him.

Some of the things that he does that are priceless to me are that he never forgets my anniversary with the company. He never forgets my birthday. Not all companies do that. And he and colleen take the time to put in the effort to send you a note and tell you "Happy anniversary, we're happy you've been with us for eight years, looking forward to another eight years." That makes you feel good, like you've really done something, you're working for the right company, and you're accomplishing something.

Whether you talk with Dale Foster, Tona Weigelt, or the friends and family of Larry Brennan, the common message is that kelleher has raised them to higher levels of motivation and morality simply by taking an interest in 
their lives. Somehow when the leader of an organization shows this much care and concern for his followers, the result is that those followers are often moved to higher standards of human and moral development. When I asked Kelleher if he was aware of the symbolic implications of his gestures, he responded a bit defensively. This is because he wanted me to recognize that while he understands the positive symbolic ramifications of his behavior, his expressed interest in the people of southwest is not motivated by increased productivity and profits. With regard to the many things (e.g. sending flowers, anniversary cards, etc.) that he does for southwest employees, Kelleher said,

I think that I would have to be a real hypocrite if I told you that I was not conscious of the symbolic nature of those things. But, on the other hand, they don't proceed from that. That's not the primary motivation.

Kelleher would never admit to it, but several different Southwest people told me that he does things for employees covertly that most people never know about. For example, Paul Carter indicated that he had mentioned to Herb and Colleen that he was having some legal difficulties. Out of genuine concern, Kelleher became very interested in who was going to handle Carter's legal matters. He explained, 
When I told Herb and Colleen that I was going to go to court, he asked the name of my lawyer and he didn't tell me, but I know that he had the man checked out to make sure he was competent to handle that case. That's the kind of man Herb is. I can't speak highly enough of Herb. He's one superlative human being. I don't think there's another one like him.

While there are many other examples of how Kelleher has covertly supported his people, for purposes of confidentiality they cannot be disclosed. However, the point is that his interest in the people of Southwest Airlines is not merely a symbolic ploy to increase efficiency and productivity, rather, it is a heartfelt desire to convey his genuine interest in their lives.

Another way in which Kelleher has encouraged the moral development of his people is by getting them involved in projects that have a larger social purpose. By doing this he has been able to show them how their work contributes to raising the collective morality of society. Without a doubt, Kelleher and the people of Southwest Airlines have developed a passion for a project that has made a significant impact upon the growth and development of southwest employees. Moreover, Southwest's involvement in this particular project has provided many young people with a hope for the future. The project involves support for and endorsement of the Ronald McDonald Houses throughout the 
Southwest system. Ronald McDonald Houses are homes for families with seriously ill children. They were established by the McDonald's Corporation in memory of Ray $A$. Kroc to provide these families with homes close to the hospitals where their children are being treated. The homes enable families to join together in their time of need without the expense and seclusion of a hotel.

It must be understood that the Ronald McDonald Houses are much more than simply a charity through which southwest has been able to lighten its corporate tax burdens -nothing could be further from the truth. In one sense, this project has added new meaning to that special Southwest spirit and it has given the employees a new cause to rally around. Through company picnics, basketball games, and charity balls, the people of southwest Airlines have become intimately involved in the Ronald McDonald Houses. Southwest flight attendants are even selling a flight attendant cookbook and all the proceeds will go toward the project. In addition to the financial support that the company has given to the project it has provided the physical and emotional support needed to make the project a smashing success. Southwest employees have helped these children and their families by donating their time and energy at various houses in the cities that are serviced by the company. The children and their families have been adopted into the southwest family and they have 
become an intimate part of the lives of southwest employees.

One particular little girl has touched the hearts of Southwest employees in a special way. Her name is shea Runnels, and she lives in the Ronald McDonald House in Houston. Shea has become a symbol of the spirit and love that is generated when people reach out unconditionally to help those who must struggle to overcome hardship. She is a symbol of the special kind of perseverance that is so characteristic of Southwest people; and, as Figure 21 shows, Shea has definitely become a southwest p:s:son.

In November and December of 1985, Southwest Airlines aired a public service announcement on television promoting the Ronald McDonald Houses. The commercial features Herb Kelleher and Shea Runnels. As Kelleher (sitting Indianstyle in front of the Christmas tree at the Fort Worth Ronald McDonald House) says to the camera "We're here to spread the word . . about the special kind of love we've found." He is approached from behind by shea holding a Christmas present who says, "Merry Christmas, Herb." In a touching moment the chief executive and his young friend reach out to the heartstrings of the viewing audience. The commercial appeals to the viewer's emotions in such a way that it is difficult to watch with dry eyes. The pictures shown in Figure 22 were taken during the filming of it. As I watched this commercial, I couldn't help thinking that 


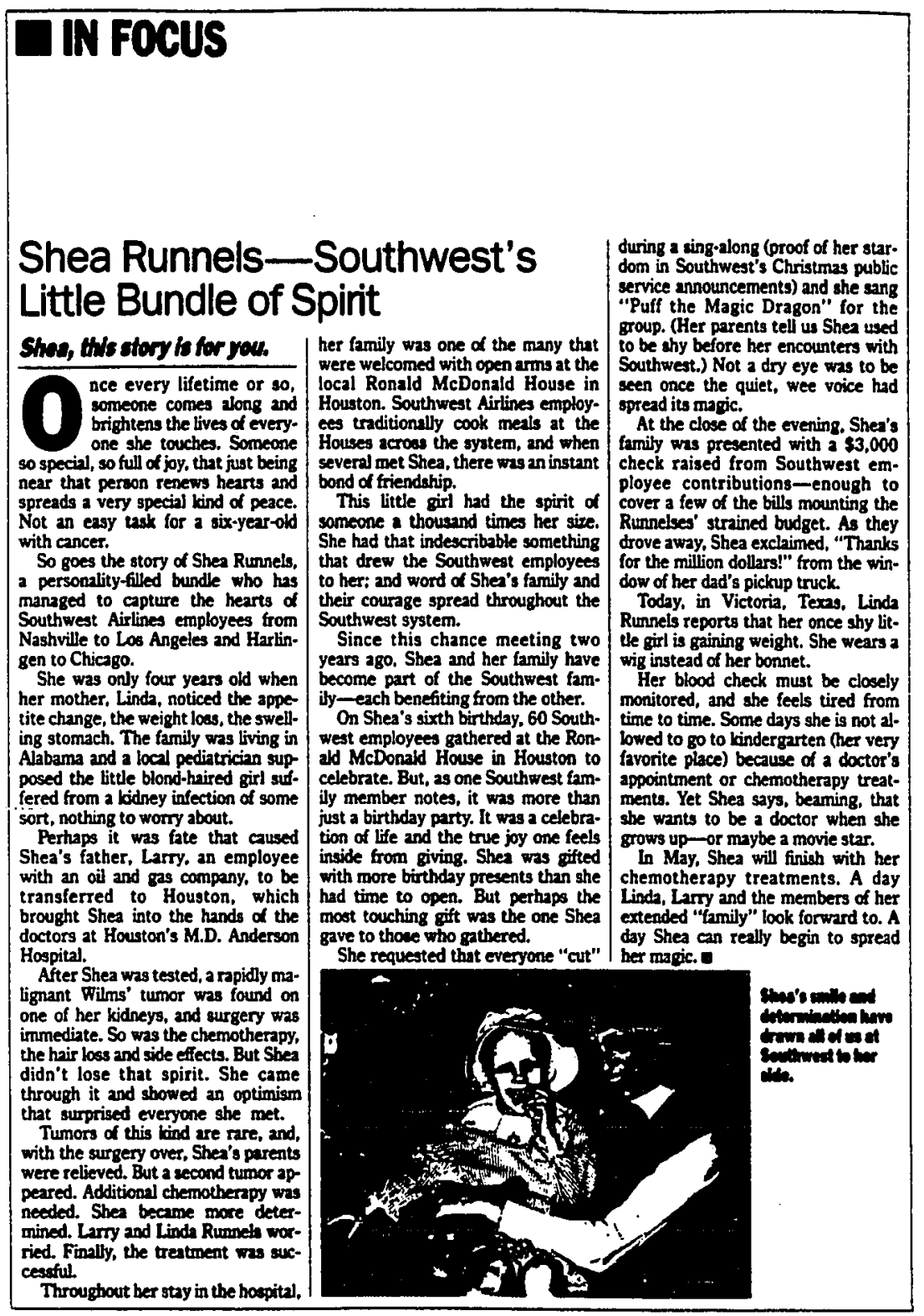

ט Lunury 1967

\title{
Figure 21. Shea Runnels featured in an article that
}

\author{
appeared in the January, 1987 issue of Southwest's Spirit
}

\section{Magazine.}



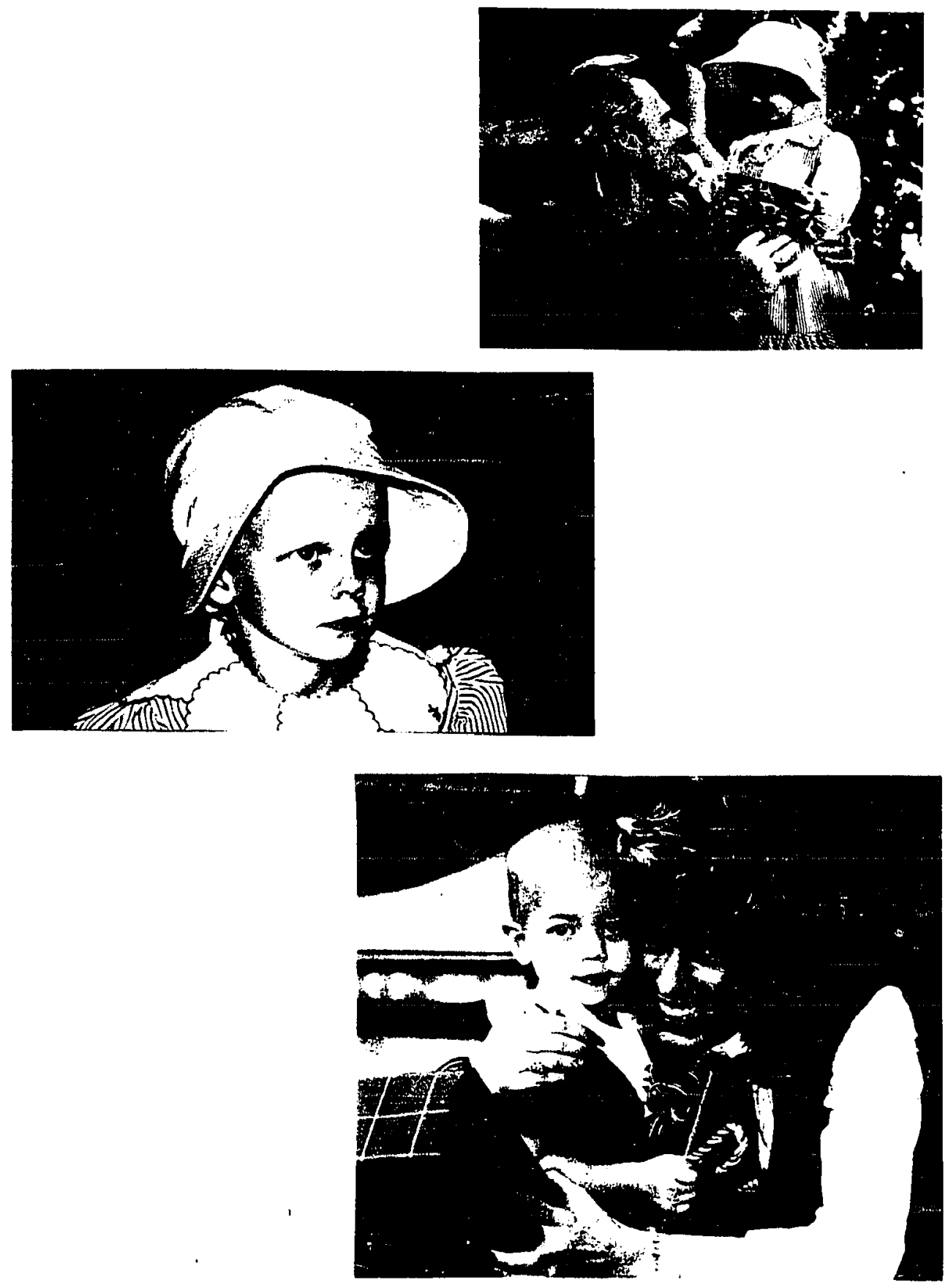

Figure 22. From top to bottom, Herb Kelleher with shea Runnels during the filming of the Ronald MaDonald House commercial, Shea Runnels, and Shea with Tonda Montague. 
the interaction between Herb and Shea is also symbolic of Kelleher's care and concern for future generations.

The Ronald McDonald House project has also provided Southwest employees with a cause that draws them together. The employees that have been involved with the houses seem to understand that southwest is committed to much more than simply pleasing customers. They recognize that running a successful organization is a means to a greater end. They understand that pleasing customers and maintaining a profitable company enables them to make a difference in the lives of young people like shea Runnels. Why do the people of Southwest Airlines have such big, big hearts? Some of them would respond by saying they give a lot because they get so much in the way of support from Kelleher and the senior staff at Southwest. Other employees would say that the joy they receive from reaching out to young people like Shea gives meaning and purpose to the work that they do. In any case, most would agree that Tonda Montegue's closing remarks in an article about shea Runnels exemplify their attitudes about being involved with the Ronald McDonald Houses. Describing an evening when fifty to sixty Southwest employees gathered at the Houston House to celebrate Shea's sixth birthday, Montague pointed out in the company newsletter that,

At the close of the evening, Southwest employees presented shea's family with a check in the amount of 
$\$ 3,000--a 11$ raised from employee contributions and the sale of stuffed airplanes. Needless to say, the family was truly overwhelmed and touched by how much we cared. Through misty eyes thanks were given. Perhaps Shea expressed her appreciation the best when the family drove away, and she shouted, "Thanks for the million dollars!"

But, Shea, our thanks belong to you! Thanks for the smiles you have given us, the happy memories you have shared with us, the love which has blossomed, and the peace we feel inside when you touch our hearts. We thank you for the millions you have given us. Another way in which the employees of Southwest Airlines have been drawn together by the Ronald McDonald House project is through fund raising events. One such event took place when Kelleher gathered a group of Southwest troops to play a charity basketball game against Channel 5 (KENS-TV) employees in San Antonio. Kelleher's team went fully equipped with uniforms, a game plan, and most important, Southwest cheerleaders. The pictures in Figures 23 and 24 show the camaraderie and fun Southwest people had in accomplishing their mission, which was to raise money for the Ronald McDonald House of San Antonio. However, fund raisers such as this one represent more than charitable contributions to the people of Southwest. They represent a unique spirit of team work, a spirit of 

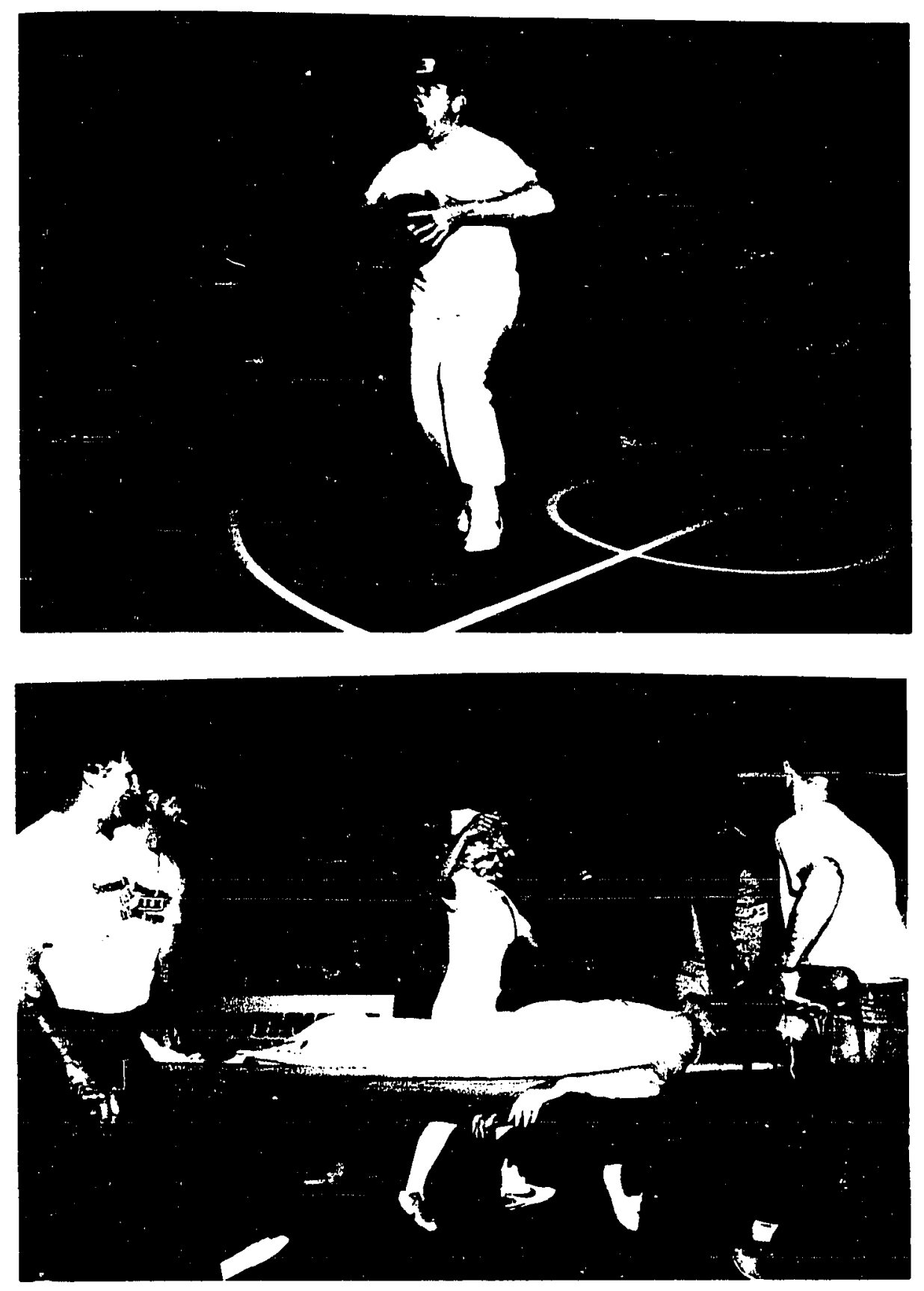

Figure 23. Above, Kelleher is ready to make a game-winning pass while below, the exasperated chairman is hauled off the court with the assistance of his loyal teammates. 


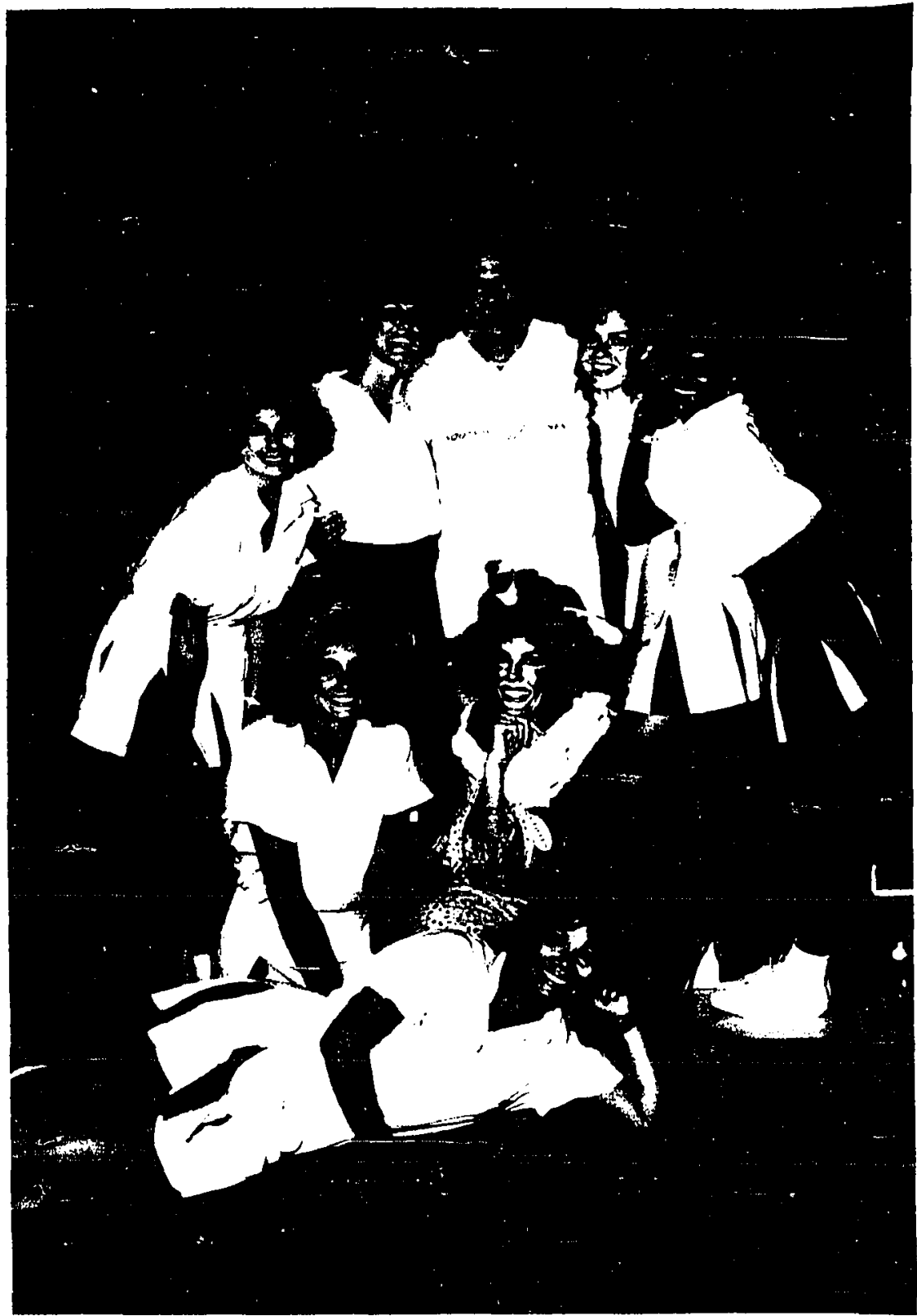

Figure 24. Herb Kelleher with the Southwest chetrleading squad at the charity basketball game in San Antonio. 
cohesiveness that develops when people come together in pursuit of a common purpose. A special relationship develops between Kelleher and his people when they see that he is willing, even excited, to get out on the court and knock elbows with them. When southwest employees come together in this manner its easy to see how they raise each other to higher levels of motivation and morality. As a consequence of this happening, they collectively establish a spirit of moral development that is much greater than any one of them could accomplish individually.

The Ronald McDonald Houses have given Southwest employees a channel through which they can contribute to a greater societal good. By creating a better world for future generations, Herb Kelleher and the people of Southwest Airlines are facilitating the process of generativity. The remarks from those who have been on the receiving end (see Figure 25) of that special Southwest spirit are indicative of the impact the company is having with this program. Additionally, magazine ads (see Figures 26, 27 and 28) put out by southwest capture the attitudes of Southwest employees who have been involved with the Ronald MeDonald House program. Once again, Tonda Montague summed it up best when she said in a recent article that, Southwest employees who have participated in the Ronald McDonald events throughout the year will readily agree--it's much more fun and rewarding to be 
Your leadership and commitment to our Ronald McDonald House and all the others has spread to all ends of your Southwest network. I wish we could describe the rapport that grows between Southwest volunteers and our residents. Perhaps your

Christmas ad conveys the warmth that floods the house when you all arrive.

\section{Gwen Irwin}

President

Dallas House

The spirit of your firm is heartwarming. Your gift will help to provide comfortable, low-cost housing for families of children being treated for cancer, leukemia and other serious illnesses. We thank you in their behalf as well.

Alan Hubbard

Chairman of the Board Chicago House

Words can't express our feelings for Southwest and the love that you and your employees have given to us. On several occasions that I have been by the house and Southwest employees were there cooking or getting ready for Christmas, the house just feels warm and alive with love.

Michael W. Elliott President Fort Worth House

When your employees arrive to prepare dinner for our families on various holidays, there is a visible lifting of hearts and minds. The families are always so grateful for the friendly care, love and concern they receive from your representatives.

Patty Slimak

Administrative Coordinator Los Angeles House

Figure 25. Remarks from staff members of the Ronald McDonald Houses throughout Southwest's system. 


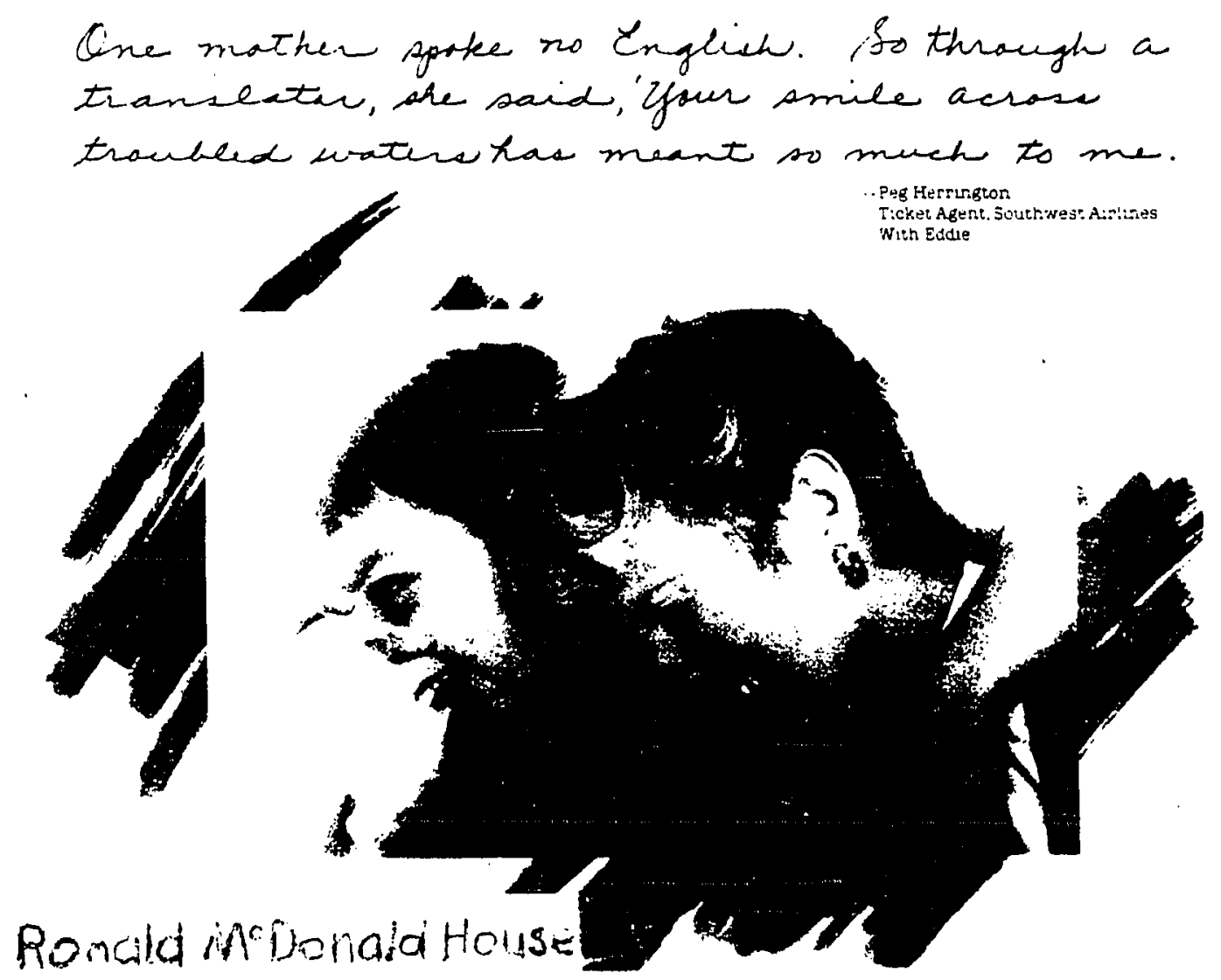

Figure 26. Remarks from ticket agent Peg Herrington that appeared in the Ronald McDonald House advertisements in Southwest's Spirit Magazine. 


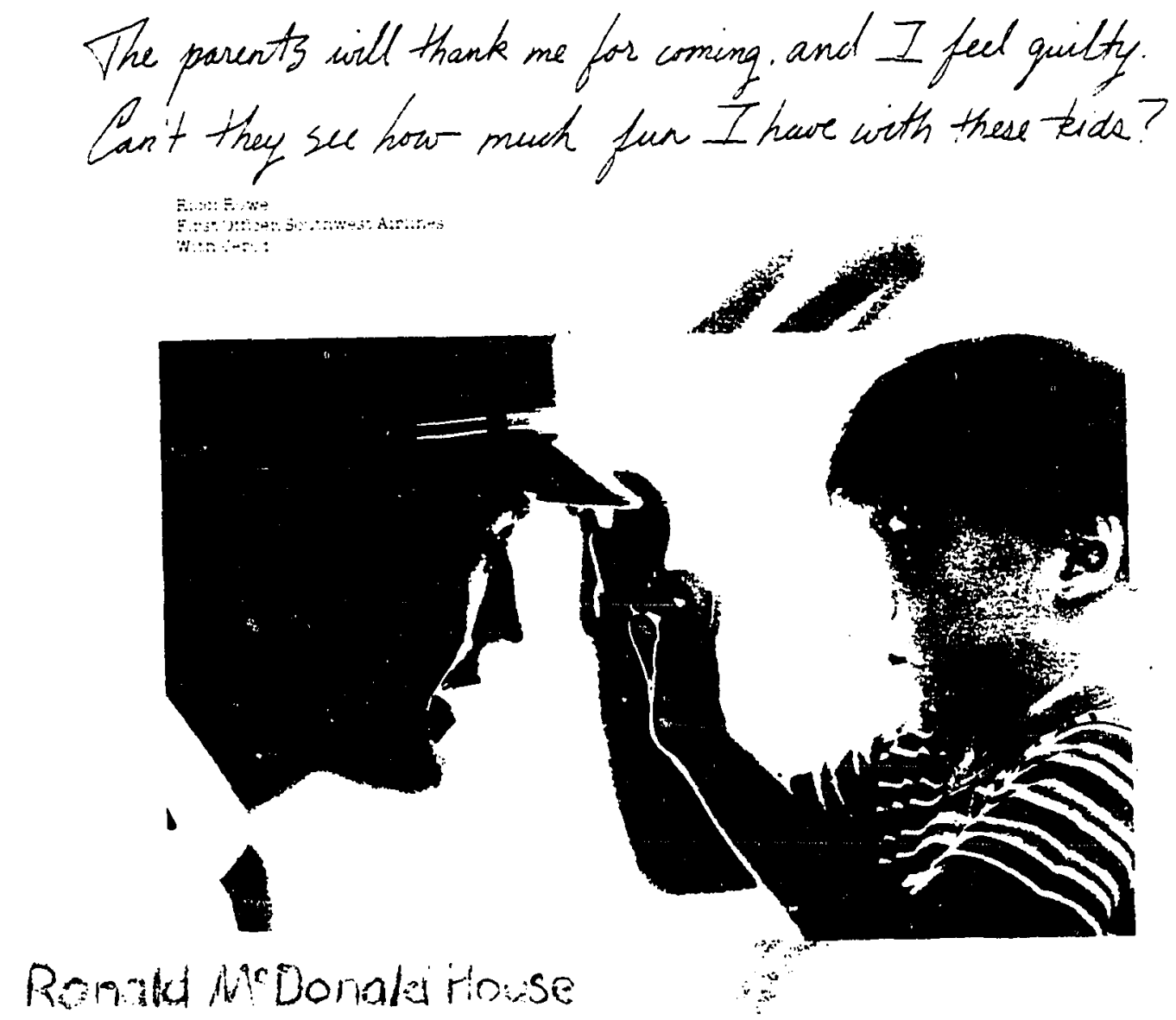

Figure 27. Remarks from first officer Ricci Rowe that appeared in the Ronald McDonald House advertisements in Southwest's Spirit Magazine. 


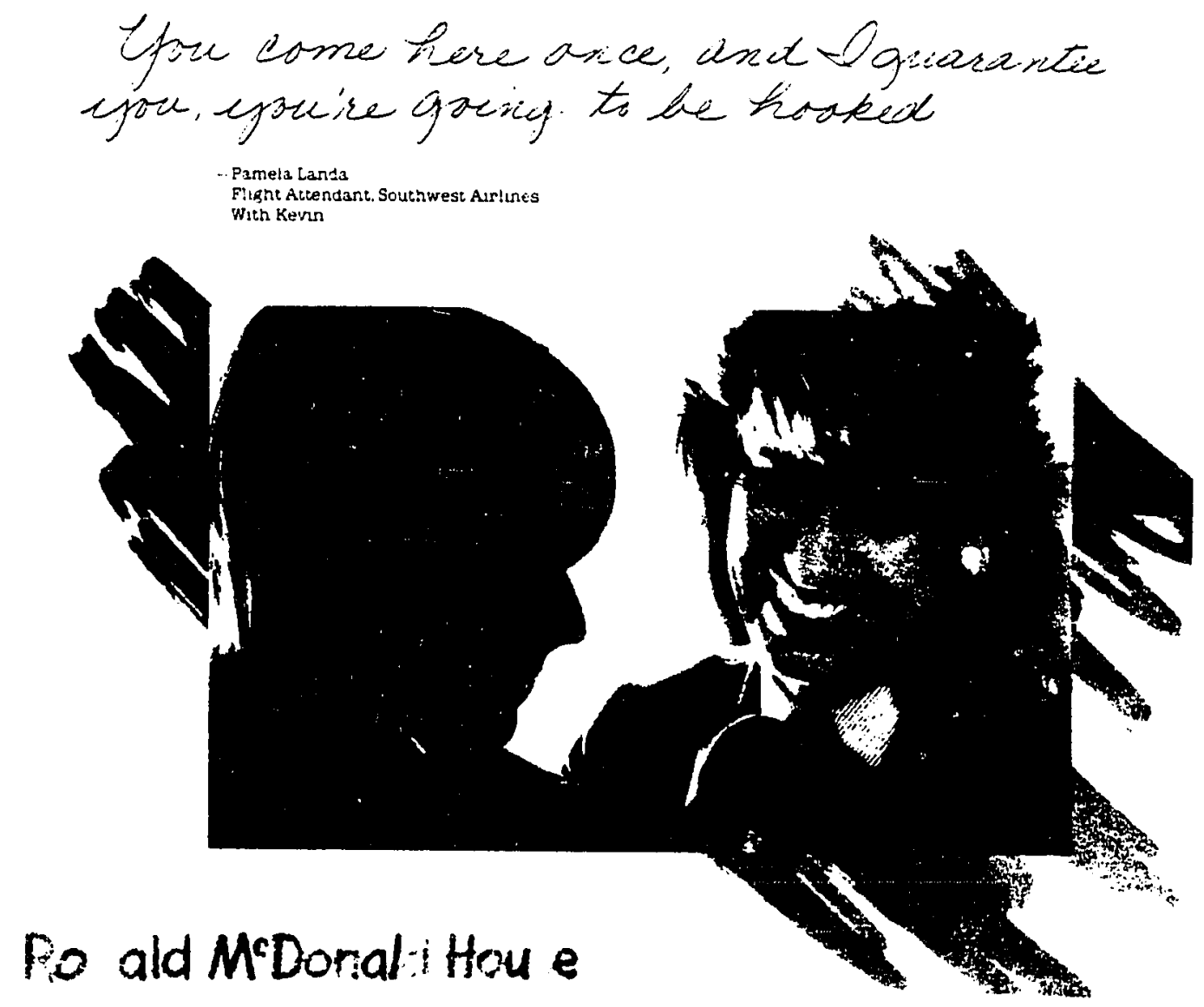

Figure 28. Remarks from flight attendant Pamela Landa that appeared in the Ronald McDonald House advertisements in Southwest's Spirit Magazine. 
on the giving rather than on the receiving end. When the "Airline that Love Built" visits the "House that Love Built," the spirit of Christmas seems to last all year long!

While the Ronald McDonald House project clearly shows Kelleher's commitment to generativity, the impact the company has had upon the moral development of its people is certainly not limited to this program. For example, Southwest Airlines was recognized by the National Women's Forum for its exceptional contribution to women's rights. Fifty percent of the company's work force is composed of women and close to $36 \%$ of these women hold management positions. As the official airline for Texas Women's Week, Southwest Airlines was the only Texas-based company to be honored by the National Women's Forum. The company has also been very active in Leadership Texas, an innovative program designed to promote women leaders in the country.

In addition to its contribution to women's development, Southwest Airlines sponsors the annual "Run for Luv" in Dallas. The Run for Luv is a $10 \mathrm{~K}$ race and benefits the Cystic Fibrosis Foundation. As a result of this fund raising event, Southwest Airlines is able to donate approximately $\$ 5,000$ a year to the foundation. The money is used to further research efforts in the development of a cure for cystic fibrosis. 
Whether it is promoting the Ronald Mcdonald Houses throughout the southwest system, protecting the rights of women, providing senior citizens with special opportunities to visit their families, organizing fund raising events to support various charities, there is no question that Herb Kelleher and the people of Southwest Airlines have a social vision. As they involve themselves in programs that contribute to a greater societal good, they establish a unique integration of life and work, an integration that is seldom found in American corporations. As a result, the people of Southwest Airlines, under the direction of their leader Herb Kelleher, have been moved to higher levels of motivation and morality. In this sense, Kelleher must be seen as an individual who truly cares about people and is committed to the process of creating a better world for future generations. Figure 29 shows a Christmas letter from Kelleher to the employees of Southwest Airlines. The letter is exemplary of his generative spirit and his passion for enhancing the humanity of those with whom he and the people of southwest come in contact.

\section{Organizational Symbolism}

If it is true that leaders send powerful messages to followers simply by what they pay attention to, then symbolically, Herb Kelleher sends a very clear and powerful message to the people of southwest Airlines. As previously mentioned, Kelleher spends 16 to 18 hours a day, seven days 


\section{A CHRISTMAS MESSAGE}

\begin{abstract}
Dear Fellow Employees:
First of all. please allow me to thank those of you who were kind enouxh to cuntribute to my great card on "Bosses Day. As you know. I am seldom at a loss tor words: but that was ewactly the case when the $C O$ emplove group presented it to me. I cannot remember the last ume I was so touched and I cuntinue to entoy reviewing it from tume to time as there is slways something new to be seen in it you ctrainly dont lack in onginality!! The piems were lust great. the drawings were superb: the creativity displayed throughout this ib-page cord tills me with pride and awe: and the sentiments both senol
than words can wy. I will cherish it always.

than words can wy. I will chersh it always.
Secundly. let me say that I hope that those of you who participated in our Ronald McDonald House Thanksyiving meals across our system enjuyed it as much as I enloyed participaling in the Houston dinner. I have iust reviewed the individual coordinator reports and $\mathrm{I}$ and delighred to report that slmost every department was represented at one House ur another and a good time was had by all. I had ample opportunity to talk with the various tamilies staying at the Houston House and I annot begin to tell you how inuch our spirited visits mean to these people. I feel extremely fortunate to be working with a group of such loving and oring people and I am sure that you agree with me that the personal time vou are giving while participating in these enriching vists is replaced tenfold when one of these very special children sits on your lap or gives you a hug! Incidentally, for those of you
who haverie heard. we recently produced a Ronald. MicDonald TV commercial which will be showing aeross our system during the Holidays (probabiy between Christmas and. New Years) whach I think each of you will truly enjoy. We hope that this commertial will give a very loud and clear mescage to the world about a truly wonderful organization that a group of fantastic employes has grown to love and dumire. The closing line in the commercin iss "FROM THE APY HOLIDAYS: I think you will be very proud of our Compuny when you see ti. Quite frankly. I Gannos and I thank exch of you from the botom of my hear for making this commercis a reality.

Finally, I want to thank each one of vou for continually displaying your special LOVE and SPIRTT thank each one of vou for continually displaying your specia recent promotional fare We relize that we had several operational problems as a result of the overwhelming response which this promotion getierated. and we are especially appreciative that each of you took the time to give us constructive. pusitive feedback as to how we could returucture the program so that it could work rur us - and for our Senion - more etfectively in the future. Since we have not been able to come up with an easy and dependable way oo limit seats as of this writing iNovember 23tht, we still do not know if we will offer a similar promotion during our traditional low laad factor months of lanuary and february, but plesse rest assured that we have listened to your input and every consideration will be given to your many suggestions before we introduce a promotion of this nature again. We all leam by our mistakes and there is no doubt that we made some mistakes with this particular promotion; but I hope that none of you will lose sight ot the tollowing: (1) we arried over 120.000 senions: (2) our load factor for Ottober was 0.8 \% $^{\circ}$ 'the highess in the industry!: 13 ) we received at least three times as many good letters" on this promotion as we have on any other single promotion since our inception and he letters are sill coming in by the dozens as of this writing: (4)

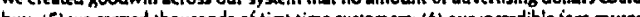
buy: many of those customers to pledge all their future traveling business to us: (7) our

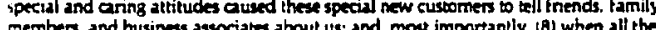

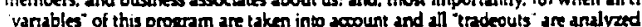
and conside And considered. we have determined that a 807 Tom DOLLARS was made from this promotion Was it all worth it - you be the ludge. Exch of your department heads istation/res manageni has a copy of several of these letters readily available for
\end{abstract}

difficult to read: some of them are not as articulate as they could be: some of them contain spelling and grammar errors. But alj of them contain very elear messages: Thanks. Snuthwest. Ior CARING Thanks, Southwest. for GITIC me ins spectal. unerpecied CIFT Thanks. Southwest. lor having such LOWI.NC
emplovees" Thanks Southivest. for such a nundertul OPPORTL:VITY" could unly hear prasse tor wur thoughes tor the elderly - It is CREATLY APRRECIATED Rest assured. we will patronize Southnest whenever possible" "we could not have had better service" .What a deal: What an difline! What WV!" "treated us tike we were VIP's" "it atrorded an upportunity to travel which we may not otherwise hase had" this was uur tirst time to lly Southwest. but it wonit be the last" "until we saw your newspaper ad we had no plans to make such a trip" We lalked to other Seniers who had acted spontaneously in response to your CENEROSITY "all personnel have been very courteous and helprul" "If and when we will be llying in the turure. we will certainly be using Southwest" it was a delightrul experience' "the courtesy and happy attitude of all your nice employees enhanced my pleasure Toverheard in Denver Daddy. I rold you how easy it would be to Hly from San Antonio to Denver. Now will you please do it again" "your employes were dbsolutely marvelous "it has been years since I had been able to ationd any
kind of vagtion and your KINDNESS and being so THOUCHTF L toward us was
like a BIT OF SUNSHINE.

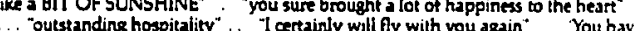
canainly brought much ioy and happiness o many iolk" you again " prasuy to ser much ioy and happiness o many tolks evervone - the flight crews the sky aps the coun or personnel - were 80 FRIENDLY" . "each and every employee of your airline was courteous. efficient. and KIND - even though they musa have gnown weary aring for so many old people" . "I assure you that any time l am able to take a trip in the future if Southwese flies there. I will be on a Southwert plane" ... "we have Rlown on nearly every arline in the states and some overseas, and we have never recrived such GREAT TREATMENT ., I would have nos taken either srip without your special rate" .. 'you really do what your ads sy 'SPREAD LOVE" . Thank you again for making our dreams come true" , "You have made many FRIENDS - not only the elderly, but all their childrent" ... it was such a pleasure to hear other traveters speak of your spectal treat and to observe the happy faces of 30 many elderly people. We shall surely think of Southwest Airlines when we travel in the furture". "It was the first time my husband had lown and now the ole codger is ready to 80 again!!" "all personnel were as helpful and gracious as they could be". "In my ninety years lan reall no greater bargain than the one you have just given me". We had never heard of Southwest. let alone flown with you. Our experience in every fight was super, and we lock forward to more

As I sad above. gang you be the iud - but l, for one. think that this promotion was a dymamite sucoss!

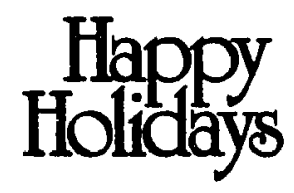

Figure 29. Herb Kelleher's Christmas message to Southwest employees. 
a week with the airline. At least half of that time is spent with the employees of southwest and because of this they know how important they are to him. stories about Relleher and his antics run rampant at Southwest Airlines and one particular story shows just how much he is preoccupied with the company. According to Colleen Barrett, Herb becomes easily detached from the material things in life. Kelleher, who is known for leaving a string of credit cards and cigarette lighters wherever he goes, claimed for weeks that somebody had stolen his company car. That is, he claimed it was stolen until it showed up at the dealer's lot where he had recently purchased a German import and saw it there. In another account of the story he reported,

I had left it at Brown Motor Works. I drove there last night because I wanted to see what new exotic cars they got in--just look at them through the window. And then I saw my own car. "Oh, God! There it is!"

I lose contact with the physical world. One of the reasons I'm absent-minded about possessions is because I'm thinking about something that's of concern to Southwest Airliñes.

This funny, little story not only demonstrates Kelleher's ability to laugh at himself, it also symbolizes his preoccupation with the airline and its people. Thus, as 
far as the employees of Southwest Airlines are concerned, there is nothing ambiguous about what Herb Kelleher values. Most of them would be inclined to agree with the comments made by Tona Weigelt. "His passion, his first love, of course, is this airline. It's his baby, so you don't do anything to mess that up."

Kelleher's detachment from materialistic things is also symbolized in the modesty of Southwest's corporate offices. The company's newly decorated offices display the pride and professionalism that Kelleher and his senior officers demonstrate so clearly. However, unlike the offices of some chief executives in highly successful corporations, Herb Kelleher has chosen to downplay some of the finer extremities in terms of office decor so as not to distance himself from the people he deems most important-the employees of Southwest Airlines. The corporate offices at Southwest clearly reflect Kelleher's values and attitude with regard to running the company. They are very impressive but not too extravagant. Kelleher is the type of individual who will pass the company's profits along to the employees in a profit sharing plan before he would allocate it for extravagant offices. It is much more important to him to be "one of the gang" than it is to symbolically separate himself from the employees by spending money on elaborate corporate offices. His own office is no exception in this respect. The walls are decorated with wall 
hangings and pictures that represent the special relationships he has with the employees. The furniture, though very professional and of high quality leather, is not lavish. The furniture is arranged so that the room is comfortable and conducive to conversation and the door is almost always open. The impression one gets from Kelleher's office arrangement is that the chief executive officer simply isn't interested in putting on a show for anyone.

Upon entering Southwest's corporate offices at Love Field, one can't help but recognize a large number of beautiful plaques on the wall in the reception area. These plaques are displayed with pride because they are the various awards that southwest employees have received for their outstanding contributions to the company. These awards contribute to a visitor's first impression of the company's headquarters, a first impression that seems to confirm what Kelleher has said about his employees, "The essence of our excellence is our people." Hallways and offices alike are decorated with a multitude of professionally framed pictures of Southwest employees interacting with Kelleher and with each other. Again, this is symbolic of the closely-held relationships kelleher has with his people. Prior to meeting with Kelleher or any other Southwest people, I got the distinct impression (from the awards and pictures) that the employees of this company 
enjoyed each other and their work very much. Later, my impressions were confirmed as I observed the personal and working relationships of these individuals. Walking through the halls of Southwest Airlines is likf looking through someone's family photo album. The pictures of Southwest employees on the walls tell stories about the special relationships between southwest people, the important events in the company's history, the pranks that have been initiated in the past (mostly by Kelleher), and the social gatherings (banquets, picnics, fund raisers, etc.) sponsored by the company. These pictures and awards are rich with symbolic value and represent the deeply embedded values and assumptions that are held by the people of Southwest Airlines. In addition to pictures of Southwest employees, the halls of the corporate headquarters are filled with pictures of airplanes (see Figure 30) and wall hangings of the corporate logo (see Figure 31). Tactfully displayed, these pictures are also representative of the pride Southwest employees have for the company and the tremendous spirit they demonstrate in their work.

Whether it is being exposed to the physical environment at southwest, reading the company publications, or observing the working relationships of employees, one quickly learns that the metaphor most consistently used by Southwest people is that of the family. The family metaphor is used by everyone, Kelleher and his staff, the 


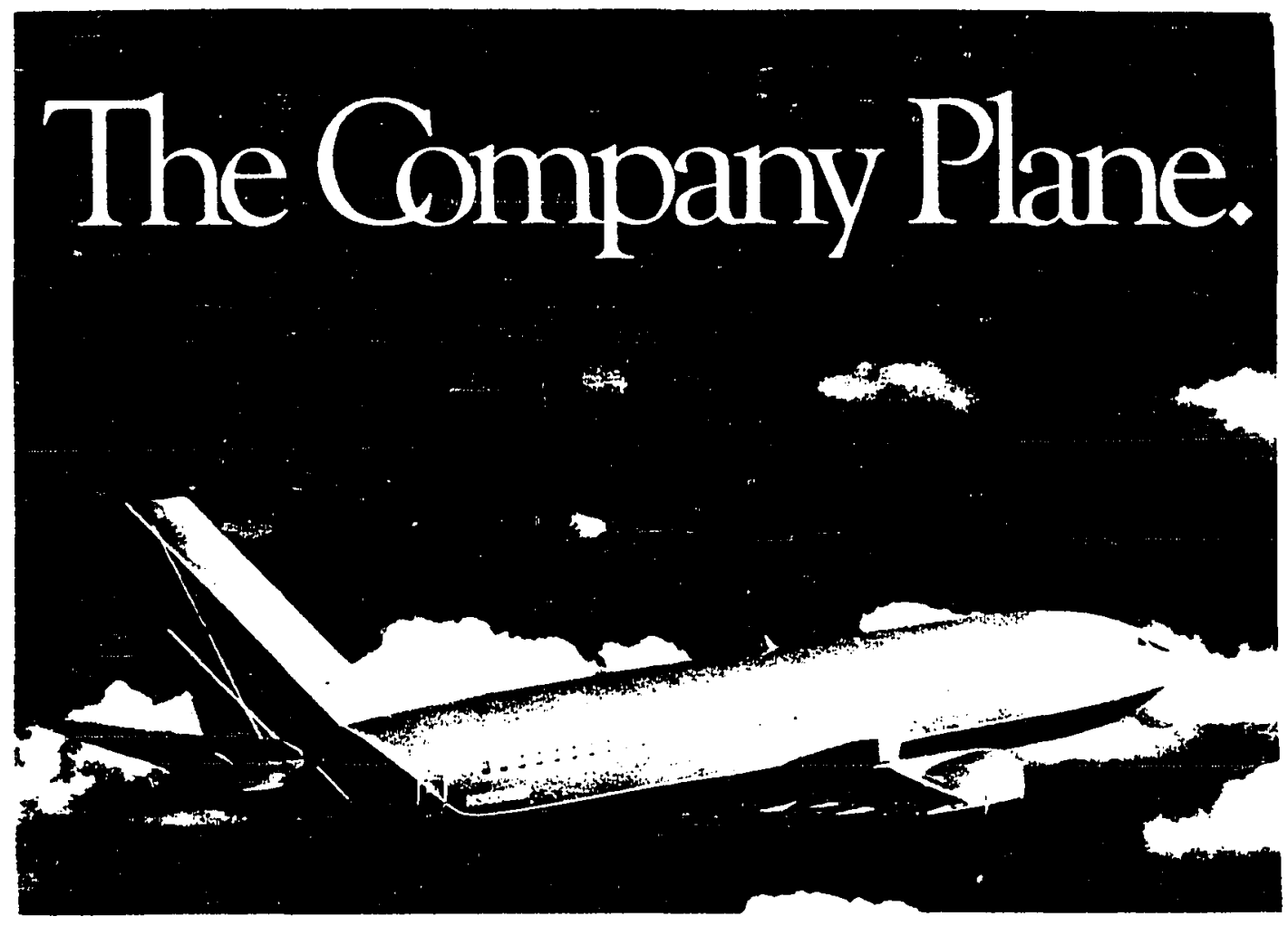

Figure 30. Southwest's Boeing 737-300 aircraft 


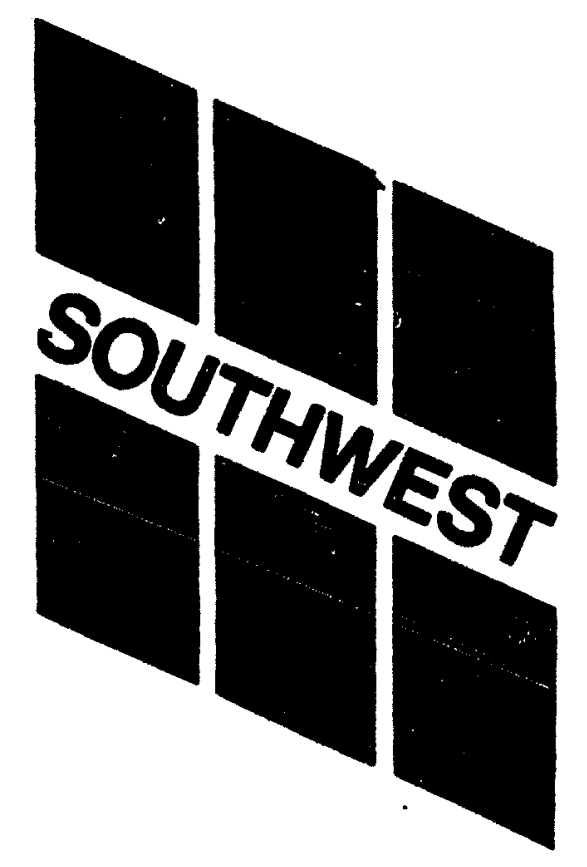

372

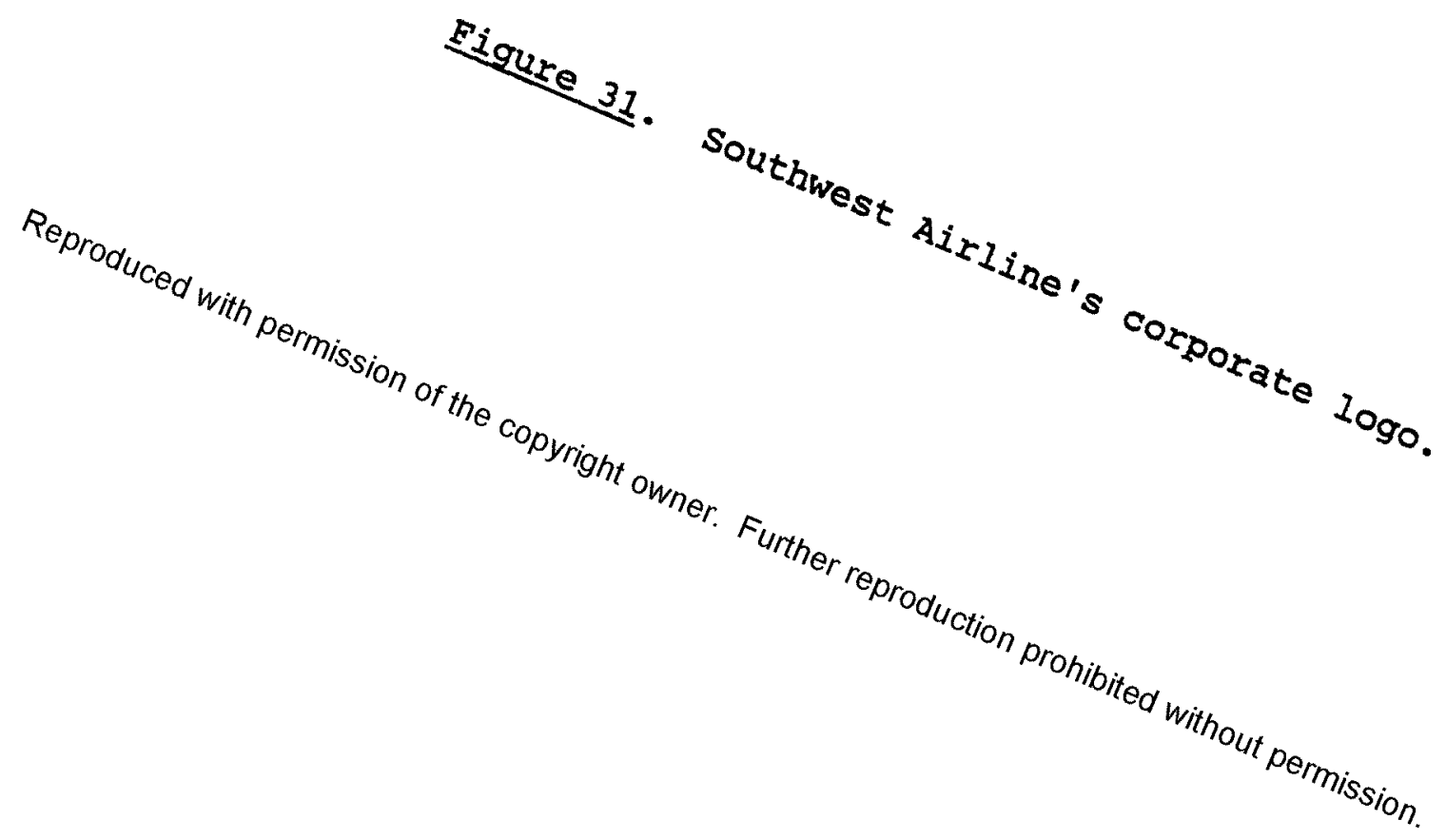


mechanics, pilots, flight attendants, and ticket agents all use it as a part of their everyday language. Tona Weigelt pointed out that the love and down-home southern family feeling is a theme that pervades Southwest Airlines. She said that,

It's something that is shared by most of the employees. Once you come to Southwest Airlines you become part of our family and you kind of take on that southern hospitality. When you work with other people that have that down-home comfortable feeling it just rubs off on you, especially if you work with people that have been here awhile.

Everybody feels much better when somebody takes them in and makes them feel like home, as opposed to just being on an airplane.

In comparing southwest to other airlines that he has worked with, Paul Carter described Kelleher and the senior management team:

They are different. It's more of a family here, more of a family atmosphere. Herb knows just about everybody by his or her first name. It's a very casual basis.

Congruent with Carter's perspective, Dale Foster expressed that,

I was with United Airlines for a number of years prior to coming here, and it's just a difference of night 
and day. The friendliness of the people, it's more like a family business rather than a big corporate enterprise like United was.

As one of the most powerful elements of symbolism at Southwest Airlines, the family metaphor is a directive that educates employees about how they should relate to one another. The use of the metaphor has contributed to shaping values and attitudes, and establishing a norm where people are treated warmly. Thus, the family metaphor serves as a guide by which southwest employees determine the appropriateness of their behaviors.

The publications put out by Southwest Airlines are rich with symbols that represent the company's values. Perhaps the most relevant in terms of symbolic significance is the corporate publication, Luv Lines. The very title (see Figure 32) of this publication is consistent with the love theme that has been a part of southwest almost since its inception. The pervasiveness of this love theme is also depicted by the hearts that are graphically displayed in every publication. If the three chevrons with the name Southwest running boldly through them make up the company's logo, then the heart is its trademark. This trademark and the love theme have also been an intricate part of Southwest's advertising campaign. Figures 33, 34, and Appendix $E$ show how the love theme and its trademark have been in Southwest's advertisements over the years. Much like the 


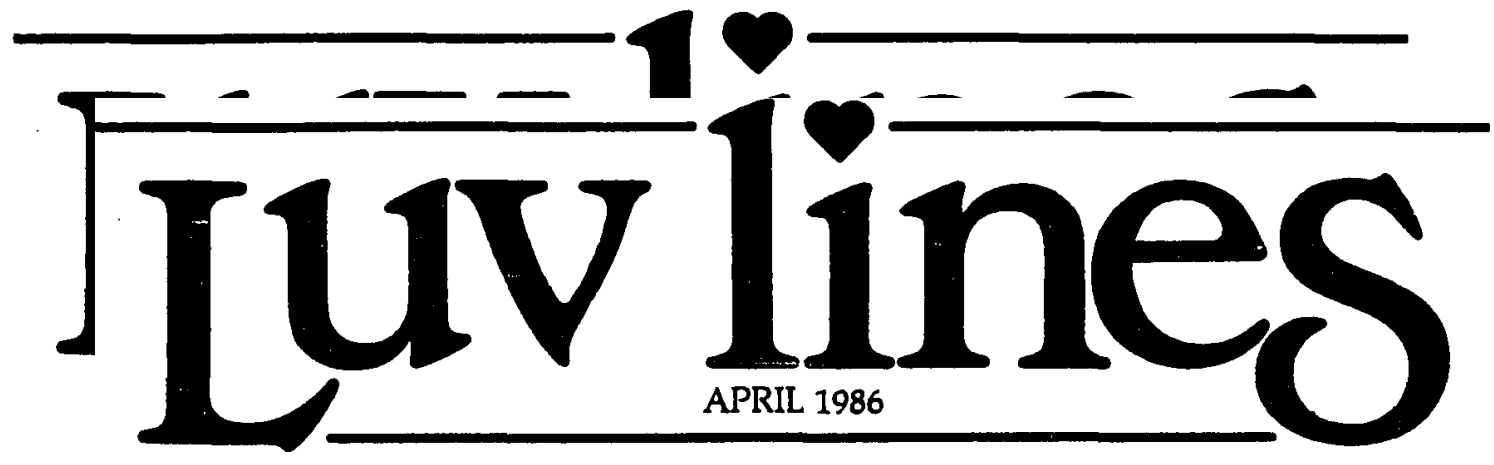

\section{Iuvlines}

Southwest Airlines P.O. Box 37611

Dallas, Texas 75235

RETURN POSTAGE GUARANTEED

Eigure 32. Graphic display of the title of Southwest's corporate newsletter. 


\section{WE'RE SPREADING LOVE ALL OVER TEXAS.}

This year Southwest Airlines has spread its service all over Texas.

From Dallas. Houston. San Antonio and the Rio Grande lialle!: Midland/Odessa and Austin.
Bringing low fares. good times, free drinks and beautiful service to the most conventent airports in Texas!

That's lov'e on Southwest Airlines

and we' re spreading it around.

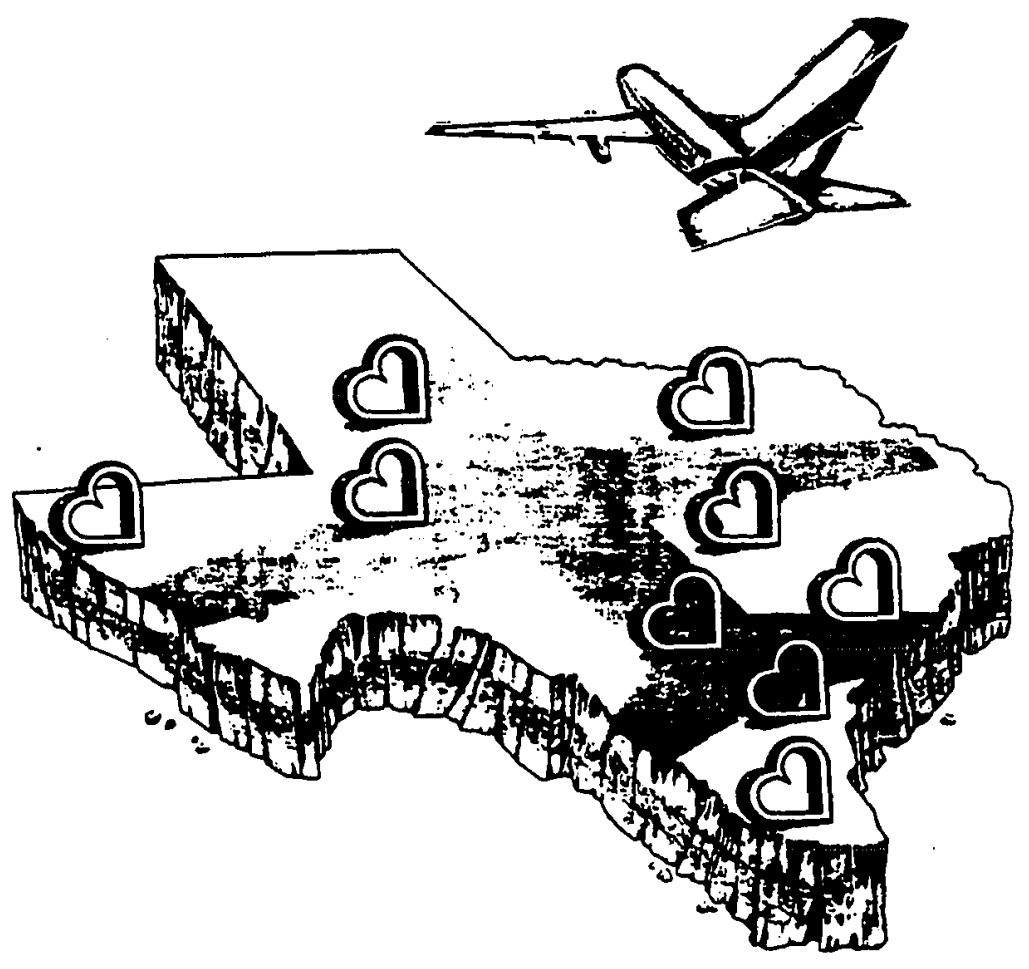

Figure 33. Southwest's love theme exemplified in its advertising. 


\section{When you want everyday low fares.}

- Super low fares-every seat, every flight, every day.

- No advance purchase.

- No penalty if your plans change.

\section{When you want more flights, more often.}

- We designed our schedule around your schedule.

- Over 660 daily flights to 25 great cities.

- More flights mean more freedom.

\section{When you want a comfortable flight.}

- Wider, more comfortable leather-trimmed seats.

- Entire forward cabin reserved for non-smokers.

- New 737-300-quietest, quickest aircraft in its class.

\section{When you want extras at no extra charge.}

- Coffee and donuts at most gates for early risers.

- Complimentary coffee, juice and soft drinks on all fights.

- Complimentary cocktails on Executive Class flights.

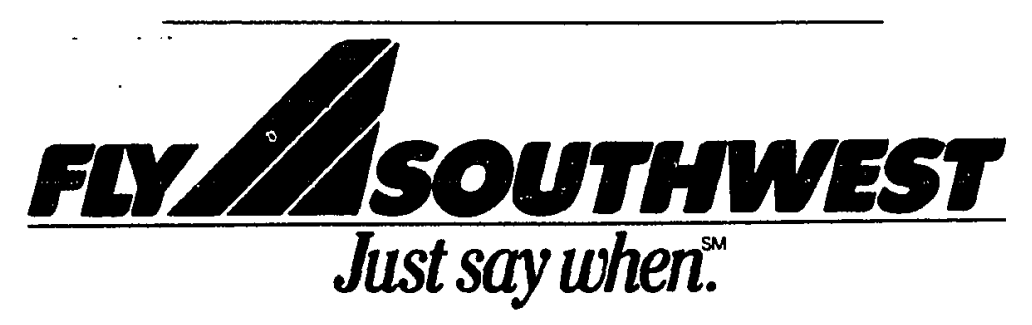

Figure 34. Southwest's love theme exemplifying the company's benefits. 
symbols in every American card store on Valentine's Day, Southwest's trademark reminds employees what southwest Airlines is all about. It reminds them to treat each other with that loving spirit so evident in close-knit families. It also reminds them about how the customer is to be treated. Initially, the love theme and trademark included in the printed material distributed by the company is seemingly a bit overwhelming and even superficial; however, it seems superficial only until one has the opportunity to experience that southwest spirit. The care, concern, and southern hospitality that southwest people show each other, as well as outsiders, are quite remarkable. When one sees the consistency between the attitudes of southwest employees and the symbols in the company's printed material, one recognizes that the love theme is anything but superficial. The love theme and the company's trademark are, in fact, accurate representations of the atmosphere that has been created within the company.

While many corporate newsletters bore employees with mundane information regarding the recent formulation of a new policy or an upcoming meeting they are required to attend, Luv Lines is used as an instrument to present the heroes and heroines of Southwest Airlines to the reader. The newsletter, edited by Tonda Montague, Manager of Employee Communications, reads like a story book with pictures of interesting people and exciting events. It is 
a very creative and informative tool that reflects Montague's excitement and enthusiasm for the people of Southwest. Iuv Lines is used effectively to showcase people who exemplify the values the airline was founded upon, people who possess that special Southwest spirit. It also clearly depicts the family atmosphere that is so evident within the company.

In addition to his informal way of elevating southwest employees to hightr levels of motivation and morality, Kelleher frequently recognizes his people with formal awards. One of these awards is the Winning Spirit Award which is presented to employees for their extraordinary efforts and job performance. Ritualistically, every month, Kelleher presents each recipient with an awards pin, special certificate, and two southwest passes. Also, these individuals are highlighted in an article in Luv Iines entitled "winning spirit" (see Appendix F). The article presents a brief story on each individual and his or her accomplishments.

The newsletter also includes two other regular articles entitled, "It's Your DaY" (see Figure 35) and "All in a Day's Work" (see Figure 36). These articles are devoted to special interest stories about various southwest employees. Similar to a personality profile, the articles provide readers with an opportunity to get to know other Southwest family members. Essentially, these two articles, 


\section{IT'S YOUR DAY}

When a certain lady is asked what she considers to be her stronge:jt asset, and she simply replies, "my age." you an certainly bet that she has led a very interesting life. But to say that SFO Marketing Representative Evelyn Kolowich has "led un interesting life" is somewhat of an understatement.

This vivacious lady believes that with age comes a wealth of experience and to visit with this strong willed individual brings one a wealth of knowledge. As they say. "mom always knows best" and a mother of tive boys and three girls and the grandmother of and three girls and the grandmother 18. must really know what's best.
Evelyn does consider her family her Evelyn does consider her tamily her
greatest accomplishment and described the group as "adventuresome." In fact. at one point in their lives. Evelyn and her husband. along with tive of the children embarked upon a sailing expedition which lasted for three years. They spent one year each in Switzerland. Spain, and England where the children attended school, and they sailed in the summers.

This particular sailing expedition. however, was probably not the one how which had he Evelyns life. The trip. which Evelyn took as a young girl along with her mom and sister irom homeland America. was probably her "biggest" America. was probably her "biggest
voyage. Evelyris father had arrived previously in America to begin work in Detroit. So. when Evelyn viewed Lady Liberty's celebration this summer, it was extra-special to her for it brought back memories of Evelyn's sailing past the statue upon her arrival in America. This U.S. citizen began work for Southwest in October 1983 after she decided a career change was needed. Evelyn described life at Southwest as "an ongoing experience" with "each day providing its own gifts." She especially enjoys her role as a marketing
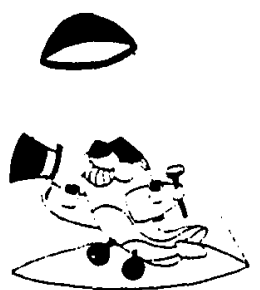

representative. Evelyn elaborated. "It allows me personal interaction and decision making. The role offers variety of things to do whil

encouraging innovation."

Variety and innovation may be the two perfect words to describe the job of Evelyn and her boss. C. I. Greenblatt. who is a district marketing manager. Evelyn and C. J. are responsible for approximately 2.010 travel agencies sering an estimated six million people in the San Francisco San Jose' people in the San Franciscorsan Jose Oakland area. They are responsible tor bo

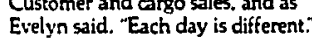

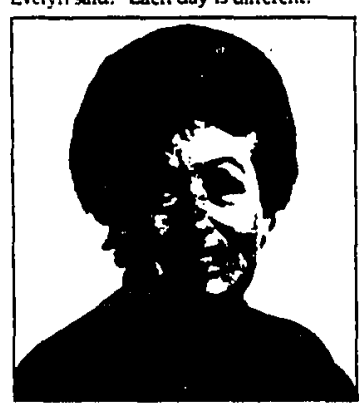

Due to the vast size of the geographic location which Evelyn and C. J. are responsible for, they rely primarily on teiemarketing. By utilizing telemarketing, more agencies $a n$ be contacted and made aware of Southwest's services.

However, these two individuals find themselves attending many civic activities to stimulate our marketing with community participation.

Evelyn said that she is motivated by challenges, and the role of a San

Francisco marketing rep certainly sounds challenging. So what does sounds challenging. So what does
Evelyn do to relax from these daily challengesi I check my brain at the box office and enjoy a movie. replied Evelyn.

She is an avid golfer and also enjoys fly fishing. For mental relaxation. this dynamic lady listens to bossa nova music Yes. there is truly variety in Evelyn's life!

She confessed that her worst habit is cutting out articles and sending them to people. "I resci everything that I on get my hands on," she added. which seems to be a good qualification for someone in marketing.

The spirit of Southwest Airlines is what Eveirn likes best about the What Evelyn likes best about the Company, and one of her most memorable experiences occutred du Our sales reps were out in full force blitzing" the citv. Evelynis territory turned out to be a Polish area. and the travel agents welcomed her with open arms when they recognized her married name was of Polish descent. Many of them sent Evelyn on her way loaded down with sausages to take home. Now, that's the spirit!

Evelyn's advice to a new sales rep Evelyn's advice to a new sales rep
would simply be to, "do your best, and someone might like it." She also believes one should never lose his/ her sense of humor and not take people too sense of humor and not take people to
seriously. Evelyn further added. "I seriously. Evelyn further added.
always believe you should have something to believe in and something to be enthusiastic about. I must believe

in something to give it my

Evelyn must believe in Southwest Airlines because she certainly gives he total 100 percent. Several months ago the San Francisco freeway leading to the airport and our sales office was closed due to an overumed was truck which an overturned tanker truck which caused a gas spill and traffic was blocked for hours. Did all this chaos stop Evelyn? No. she simply parked her $\mathrm{ar}$ on a side street and walked the remaining three miles to work. (Walking, however, is the only exercise which Evelyn believes is safe). Of course. this type of behavior could be expected of someone who when asked what she would do with her last \$10, replied, "l'd figure out a way to make 520 ."

That's what Evelyn Kolowich is all about - making the "most" out of every situation. And whenever Evelyn is around you an be sure the "best" is is around, you can be

\author{
Figure 35. "It's Your Day" appears monthly in the \\ company's newsletter and highlights the accomplishments of \\ Southwest employees.
}




\section{All in a day's work}

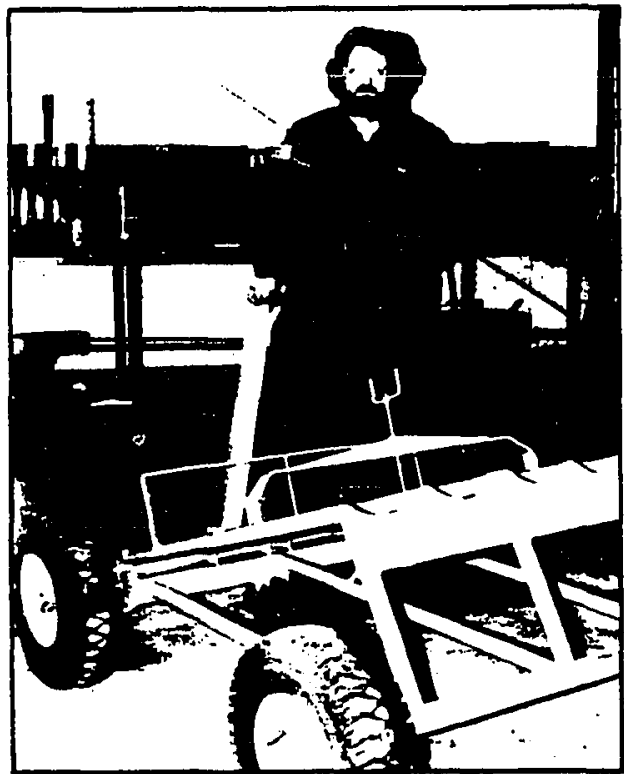

Bill Kraft displaus the aircraft landing gear strut sersicing cart he designed and built to hold nitrogen bottles for the PHX station. f you've ever thought about how you sound describing the problem youre having with your washing machine over the phone to the repairman, you might be able to somehow relate to a mechanic who services airline equipment by making "house calls" after receiving information from laymen in outlying stations.

Ground Service Equipment (GSE) mechanics at Southwest Airlines deal with this difficult problem every day. The sixteen mechanics based in either Dallas or Houston are responsible for approximately 690 pieces of ground service equipment which are owned by Southwest. The equipment includes provisioning trucks, push back tugs. baggage carts, belt loaders, airstart carts and more.

Southwest stocks between 1,500-2,000 different parts. The GSE mechanics are very familiar with these parts and know the majority of the part numbers by memory.

The GSE mechanics arrive at work each day usually not knowing where they will spend the next eight hours. Often they will not have much time to gather up all the parts and tools they will need before they have to dash off to catch a flight to a Southwest city.

Therefore, these guys are more than mechanics - they are schedulers,

planners and timekeepers. It is a GSE mechanic's responsibility to assemble the parts and tools he might need to fix a broken piece of equipment at a particular outstation. He must know the flight schedule in order to coordinate his day's activities at an outstation and return to his home base the same day. There are times when he does not complete a job and must spend the right.

If two pieces of equipment are down at an outstation, the GSE mechanic must know which piece is most needed to the operation of the airline. He must know priorities.

If the mechanic does not bring along the proper parts to ix the problem, he first tries to bortow them trom another airline. The next step will be to procure the parts from a local auto parts store. Finally, the mechanic will call Dallas to see if the parts are in stock if he cannot get them locally.

Bill Kraft, a five-year GSE mechanic said he likes going to other cities to repair the equipment. Each day is different and he enjoys meeting all the people. Bill said the hardest part of his job is talking with the people on the phone who are trying to explain what the problem is with a certain piece of equipment. The GSE mechanic must find out as much information as possible so he can ascertain what parts to take.

In addition to parts, the GSE mechanics must take along their tools. They must own their own hand tools which are valued at approximately \$2,500. Bill said that he otten takes up to 300 pounds of tools with him to an outstation. The mechanics must rely on other airlines for large pieces of equipment such as a cutting toreh, drill press or chain hoist to pull an engine.

CSE mechanics are trained to go downline and do just about anything to a piece of equipment. They must have two years of automotive repair experience. must be able to sprav paint proficiently and must be proficient at arc welding, gas welding and the use of a cutting torch betore they are hired by Southwest.

Bill Kraft's most challenging task has been to change a fuel truck in El Paso from standard to automatic transmission. This job, of course, took Bill several days.

As Bill said, "It's really not a glory job." The job of a ground service equipment mechanic may not be glorious, but it's definitely a very vital one to our airline's operation. Just imagine what the operation would be like without provisioning trucks and baggage loaders.

The GSE mechanics service the equipment that service the airplanes at the airline that love built. And guys, we appreciate your hard work and dedication! We couldn't do without you! 9

Figure 36. "All in a Day's Work" also appears monthly in the company's newsletter to highlight southwest employees. 
along with the article entitled "Winning spirit," illustrate three more ways in which the company (1) recognizes its people and makes them feel significant, and (2) instills values by celebrating those people who clearly exemplify its value system.

Whether it is reporting on Kelleher's antics at a recent Halloween Party, presenting his Christmas message to employees, magnifying the award-winning heroes and heroines of Southwest, or communicating vital information to employees about the financial health of the corporation, Iuv Lines is a photo album complete with rich and interesting copy that symbolically shows just how important the employees of Southwest Airlines are to the company. The newsletter is extremely well-written and possesses a special character of its own.

As shown in Chapter Four, the history of southwest Airlines is symbolic of the pride, perseverance, and indomitable spirit of Southwest employees. Tonda Montague and her staff have captured a part of that history in a commemorative 15 year anniversary issue of Luv Lines. The anniversary issue has been reproduced in Appendix G. The reflections and comments of the 15 year veterans at Southwest symbolize so many of the values that are deeply ingrained within the company. Represented in these remarks is the family spirit of southwest employees, their "cando" attitudes, their willingness to fight for a cause they 
believe in, their marvelous ability to have fun at work, and their appreciation for a company that has significantly contributed to their moral development. This issue of Luv Iines is also symbolic in that it holds the founding members of Southwest up as role models who possess the qualities necessary to succeed in this company.

The title of southwest's airline magazine is also symbolic of the kind of attitude the company portrays. It is titled spirit and encompasses the special interest stories and advertisements that are common in many airline magazines. Again, Southwest Airlines seldom misses an opportunity to promote its people. Included in every issue of "Spirit" is a one-page segment entitled "Southwest star of the Month" (see Appendix H). This segment highlights a new employee every month as another way of showing that Southwest is successful because of the spirited people the company employs. Figures 37 and 38 also show how the spirit of southwest Airlines has been incorporated into the company's advertisements.

Kelleher has established somewhat of an informal policy at Southwest that disallows people from outside of the company to be used in southwest's advertisements. That is, rather than seek out professional actors and actresses to be used in a company advertising campaign, Kelleher chooses to use Southwest employees. He believes that with the "most talented people in the world" at his fingertips, 


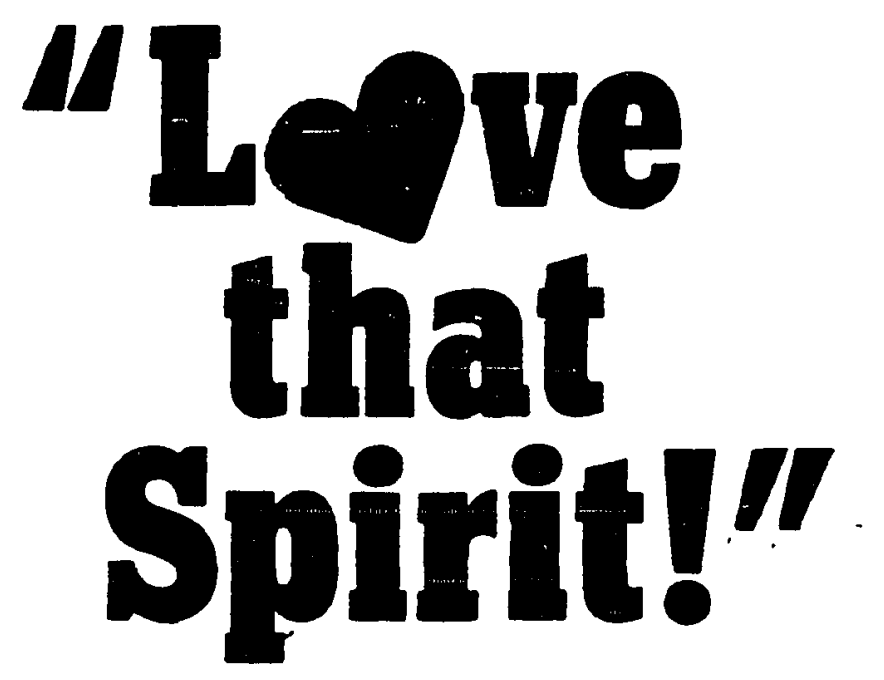

\section{Southwest}

Airlines

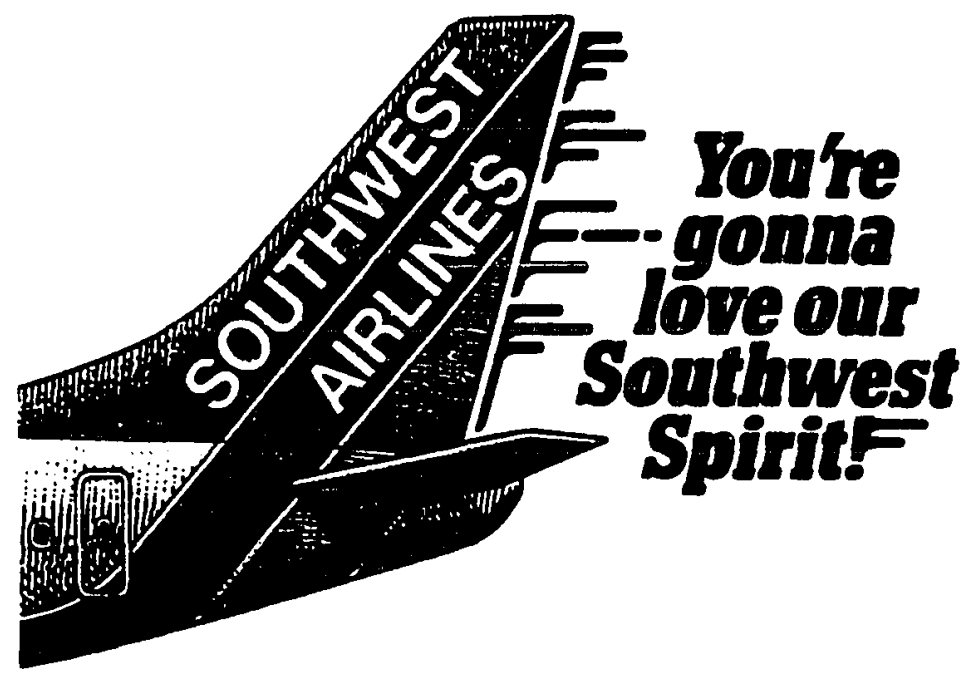

Figure 37. Southwest advertisements promoting the company's spirit. 


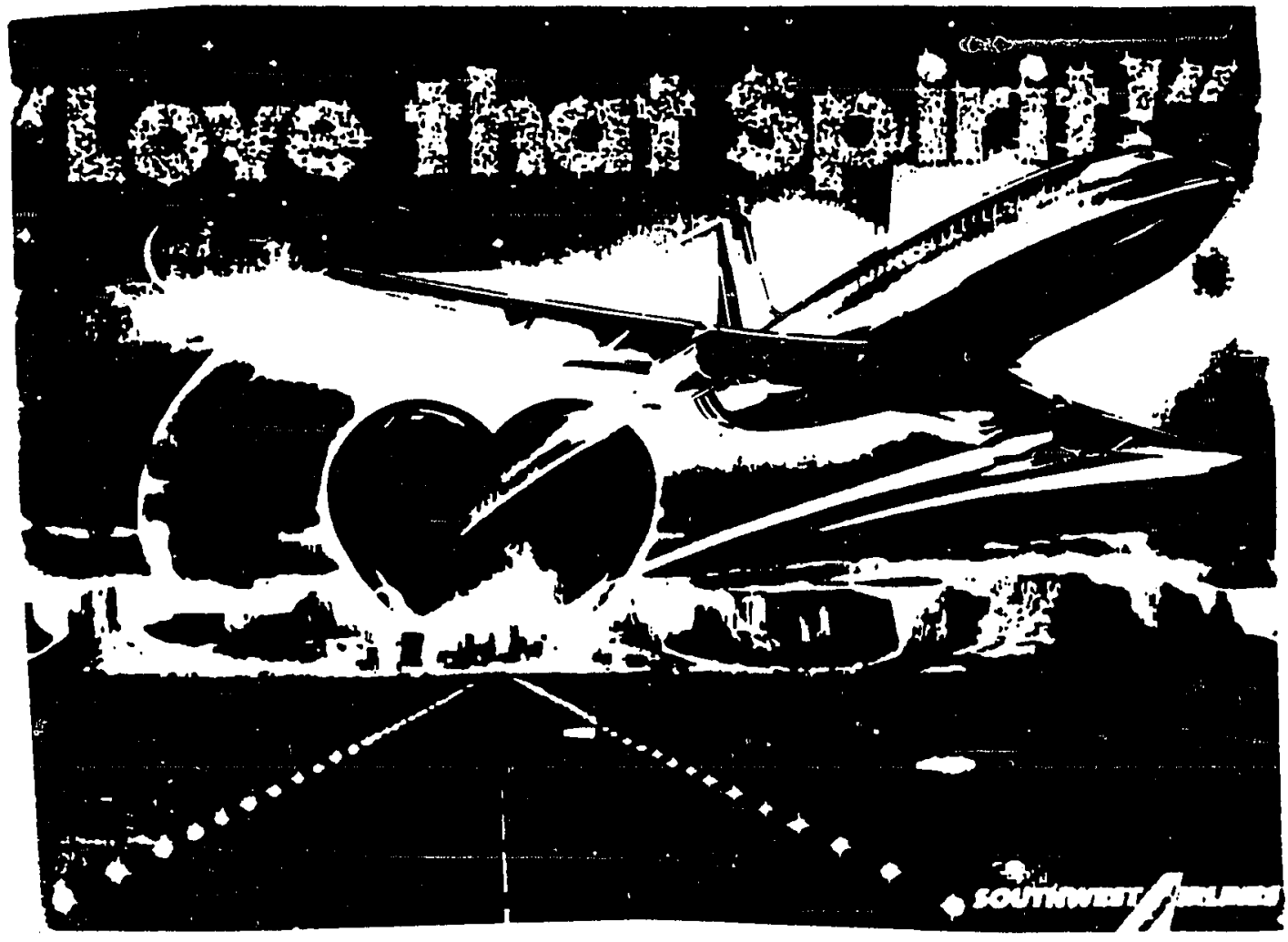

Figure 38. Southwest advertisement promoting company spirit. 
it is absolutely inappropriate to use professional talent. Thus, as shown in Figures 39,40 and 41 , Southwest people are used in every advertisement that goes out on behalf of Southwest Airlines. This is another way in which Kelleher shows his people how important they are to him. It is also his way of promoting an atmosphere of fun within the company.

As many Southwest employees will confirm, Herb Kelleher will never ask them to do anything he would not do first -- and playing the lead role in many of the company's television commercials and magazine ads is no exception. Roy spence, a principal in the advertising firm used by Southwest, pointed out that the type of customer (spontaneous and flexible) that southwest targets in its advertising identifies with Kelleher's character and personality. He said, "We're always going to come back to Herb, his personality overarches everything." Kelleher, who can laugh at himself with the best of southwest's pranksters, was hesitant at first to take part in the commercials. He said,

I didn't originate the idea, but the advertising agency and marketing people came to me and said they'd like to do it. At first I said no. I thought there were enough ugly executives on television pestering people about products. Then they came back and asked, "Would you do it if we spoofed you, made fun of you?" 


\section{WE WANT YOOU}

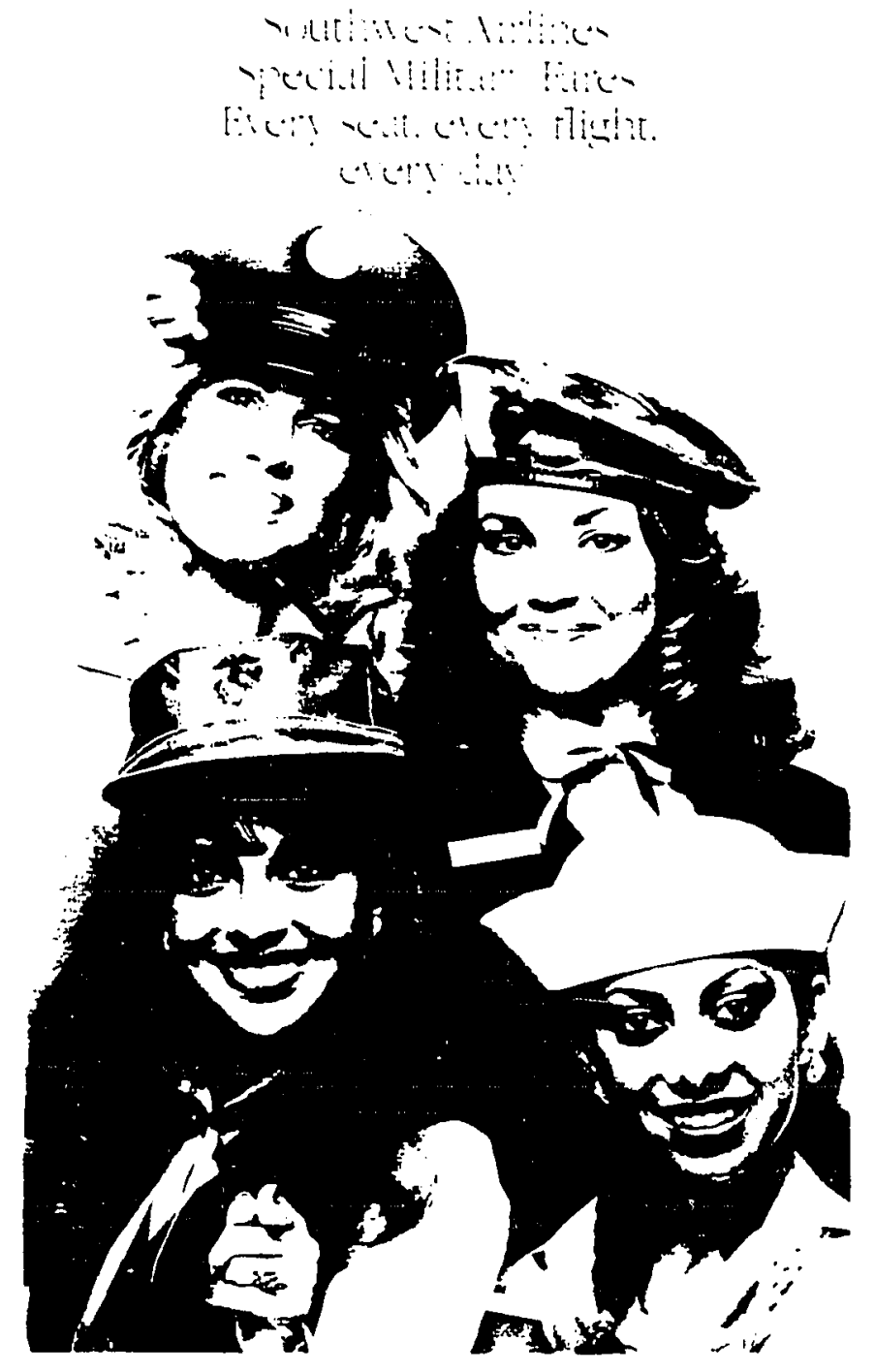

Figure 39. Southwest flight attendants promoting military fares. 


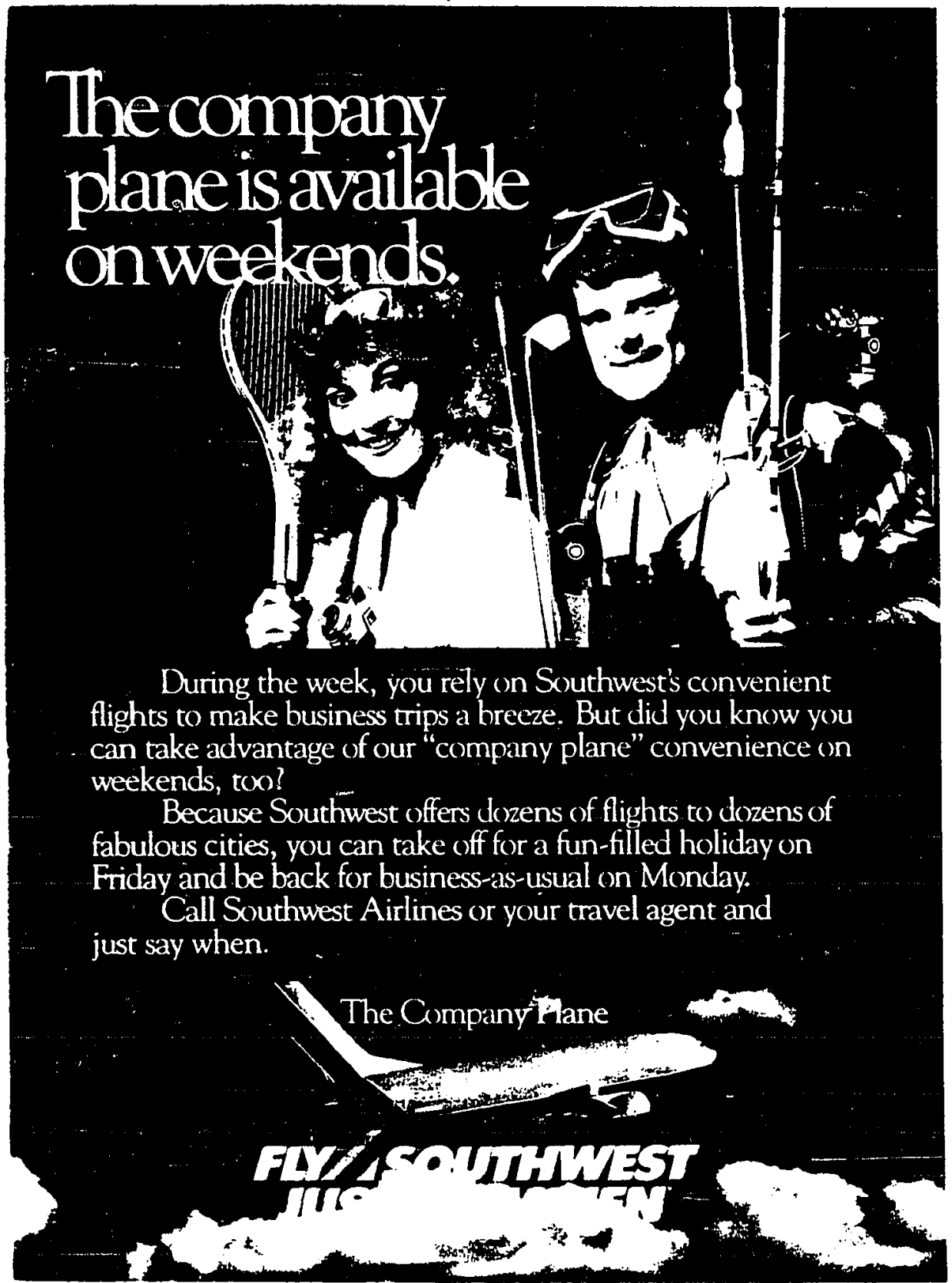

Figure 40. Southwest employees promoting the Company Plane theme. 
Howa junior partner gota seat on the
company plane.

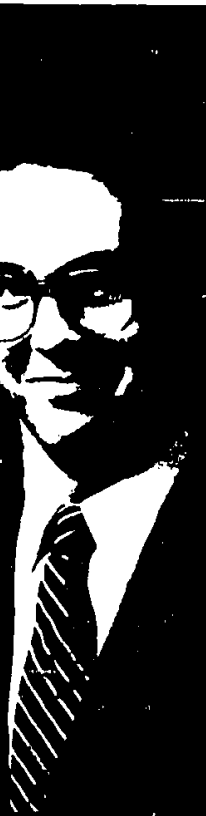

His dad isn't the president. Nor is the pikte a clese budky of his. So how'd he rate a seat on the company plane? Simple. He flies Southwest.

Becaluse (ur flights are $\dot{x}$ ) Eonvenient, (ur service ix) attentive and our fares $s$ ) low, business perople actually think of us as the company plane. So cin you. Just call Southwest Airlines or your travel agent. And just siy when.

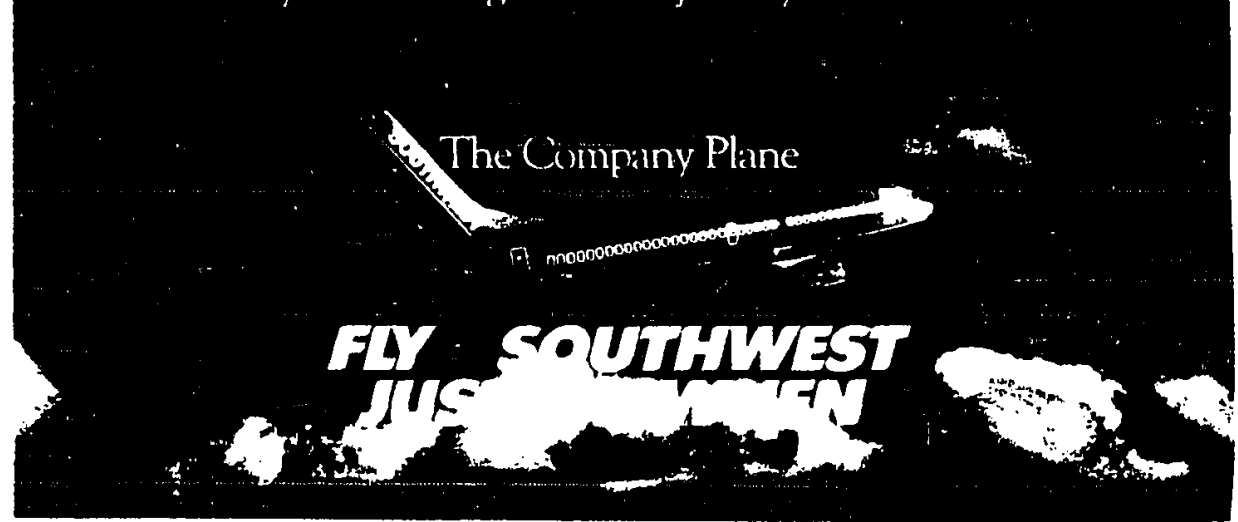

Eigure 41. Another version of the Company Plane promotion using a member of Southwest Airlines. 
And I said, "Yeah, I'll do that 'cause that's reflective of the attitude we want people to have most-fun!" So now you can see the boob on the boob tube. The television and magazine ads featuring the chief executive have been very effective. Figure 42 shows a magazine ad in which Kelleher is promoting the convenience of Southwest Airlines via its automatic ticket machines. The ad involves the southwest employees and Kelleher standing over a "Quicket Machine." Kelleher is seen to look casually perplexed as one employee scolds him for having an expired credit card, while the other cuts his card in half. Another ad shows Kelleher seated on a plane trying to avoid the aggressive gentleman seated directly across the aisle from him (see Figure 43). The spoof is that the man seated across from him also happens to be Herb Kelleher. The ad is promoting the convenience of open seating on Southwest Airlines. Finally, Figure 44 shows a series of small space advertisements that appeared in the southwest edition of the Wall street Journal. Each ad involves Kelleher promoting the many benefits one receives by flying Southwest Airlines.

Symbolically, these ads represent Kelleher's visibility and involvement in the airline. They are effective because his lack of seriousness and self-depreciating character leave customers with the impression that southwest is not only convenient, but it is also a fun airline 


\section{OUR QUICKET MACHINES ARE MORE RELIABLE THAN OUR CHARMAN.}

No offense. Mr. Kelleher.

But Southwest Airlines' Quicket" automatic ticket machines dispense thousands of tickets every day without a hitch.

You simply slide in your major credit card. punch in your destination. select Executive or Pleasure class. one-way or roundtrip. and out pops your ticket in just seconds:

In tact. about the orly ling that can go wrong is human error. Likie letting your credit card expire. Rught. Herb?

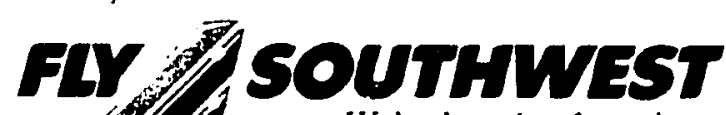

We're keeping fares lou and spirits high!

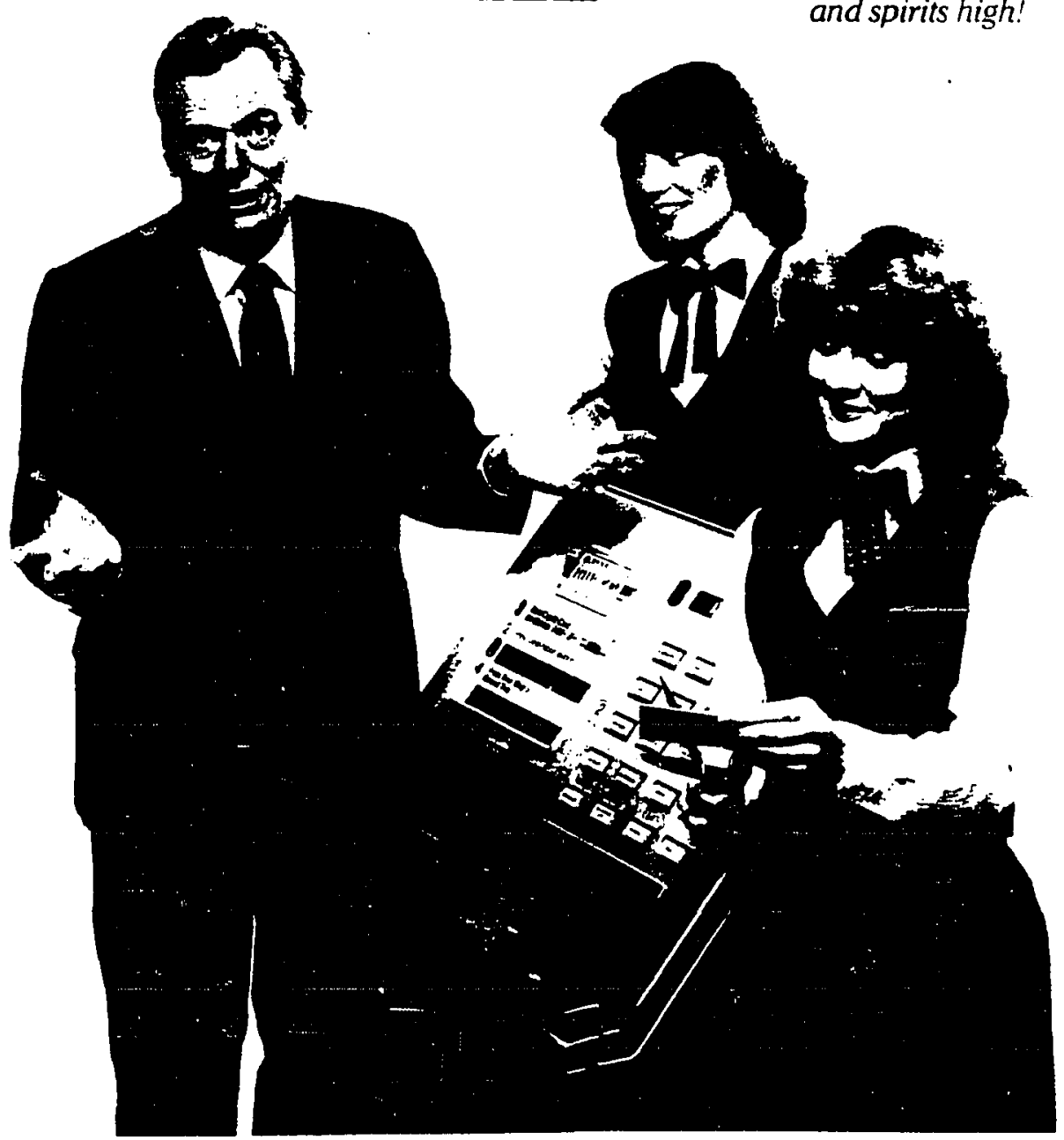

Figure 42. Herb Kelleher appears in a company advertisement promoting automatic ticket machines. 


\section{WITH OPEN SEATING, YOU CHOOSE WHO SITS NEXT To rou.}

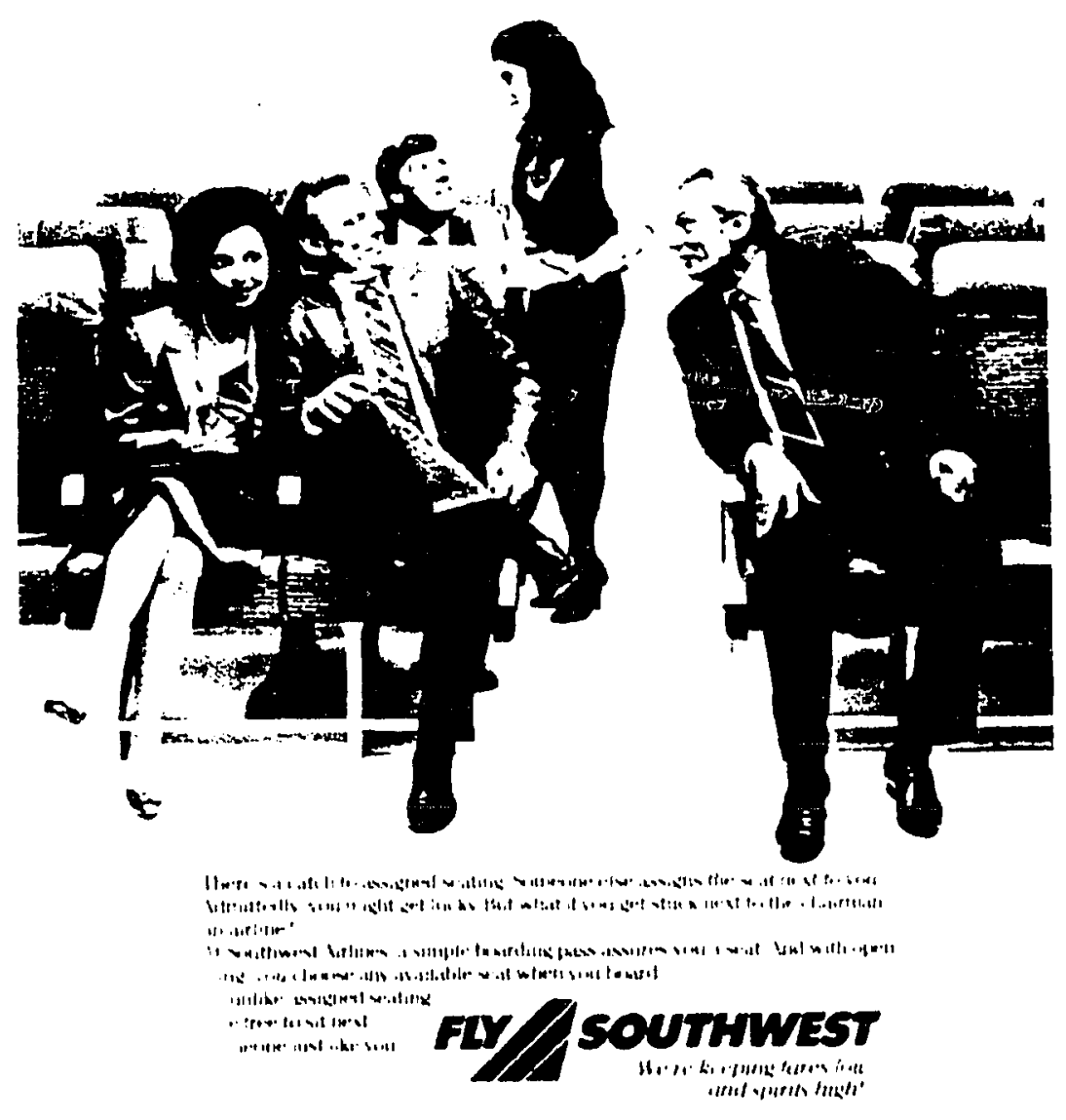

Figure 43. Herb Kelleher appears in a company advertisement promoting the convenience of open seating. 


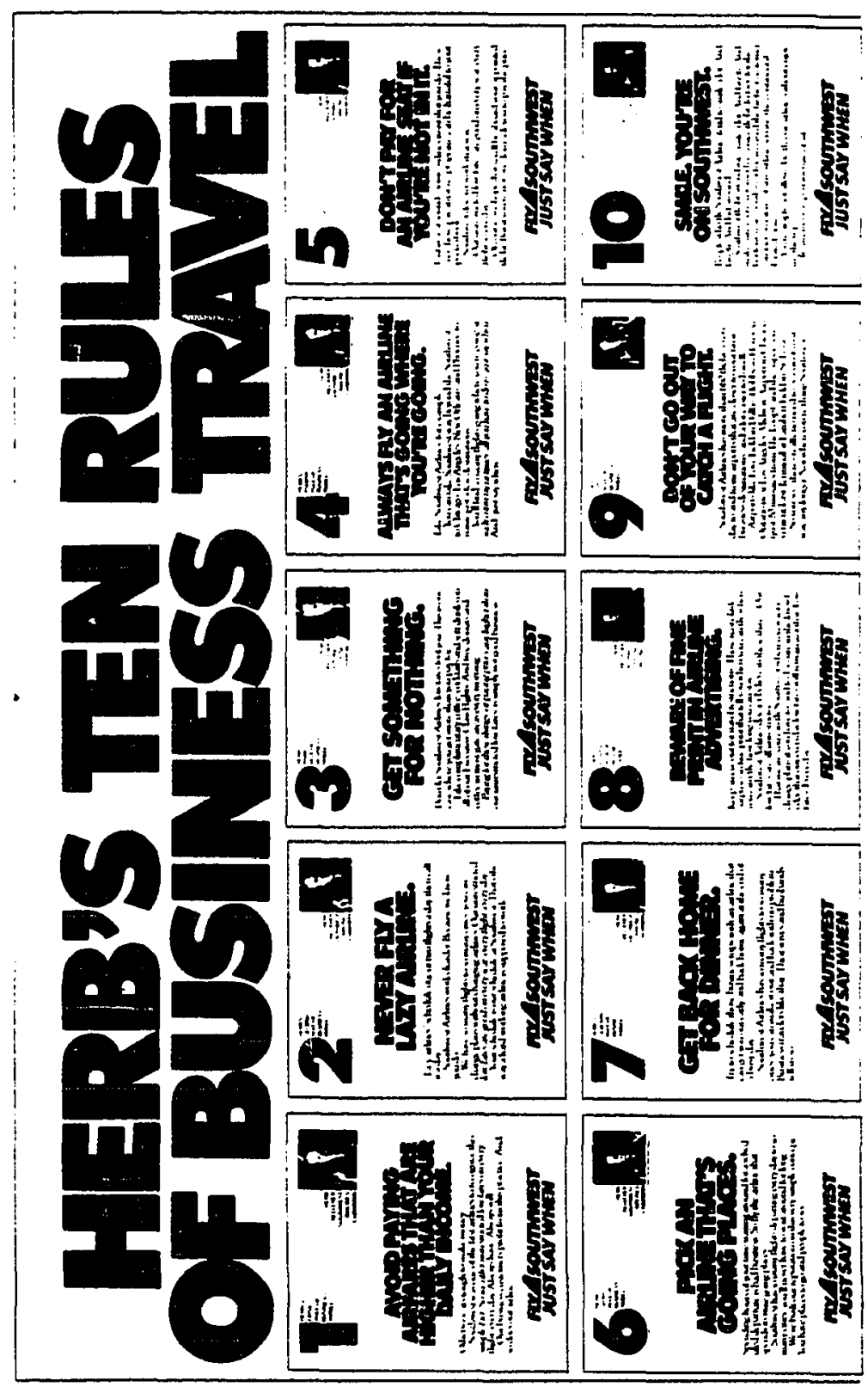

Figure 44. Herb Kelleher appears in small space advertisements. 
to fly. The ads also represent his ability to lead and educate by example. Through these advertisements the people of Southwest Airlines see that the image that Kelleher presents publicly is no different than the image he presents to employees when walking through the halls of Southwest. In other words, the images and ideas presented in the advertisements are a realistic portrayal of what actually goes on behind company doors.

One of the ways in which Kelleher symbolizes how much he cares about the people of Southwest Airlines is through rituals and ceremony. It has already been pointed out that he makes a consistent effort to practice what Peters and Waterman (1982) have labeled as management by walking around. It doesn't matter if you're talking to mechanics, ticket agents, or reservationists, they all confirm that Kelleher frequently gets out among them to find out how things are going and what needs they may have. Thus, his commitment to ritualistically visit the various departments of the airline shows southwest employees that he cares about them, that he values their input, and that he is interested in their work. This ritual also shows the employees how important their contributions are to the overall mission and purpose of the airline.

Holidays, birthdays, anniversaries and other special occasions are recognized and celebrated ritualistically by Herb Kelleher and Colleen Barrett. Again, it makes no 
difference what position is held by an employee within the corporation, he or she will receive a personal note or card from Herb and Colleen on these special occasions expressing their appreciation for that individual. Barrett, who is a very talented administrator and extremely creative, makes a tremendous effort to show the employees of southwest that they are speciar. In the Thanksgiving, Christmas, and Valentine Day cards shown in Figures 45, 46, 47, and 48) respectively, one can see the effort she puts into conveying the family attitude and spirit that is so characteristic of Southwest Airlines. Additionally, the holiday card shown in Figure 49 is also symbolic of the family spirit that is such a significant part of Southwest's organizational culture. In this very unique card the children of Southwest employees are exchanging gifts, dressed up in uniforms just like the ones that their parents wear at work. The card is a symbol of the unity that exists among Southwest employees and shows that the company's interest in its people extends beyond their job performances to their families.

Recognizing the people of southwest on special occasions by sending cards is a ritual that has a tremendous impact upon them. When discussing their attitudes about the company, many southwest employees expressed how much they appreciated getting a note from Herb and Colleen. They understand this ritual as symbolic of Kelleher's 


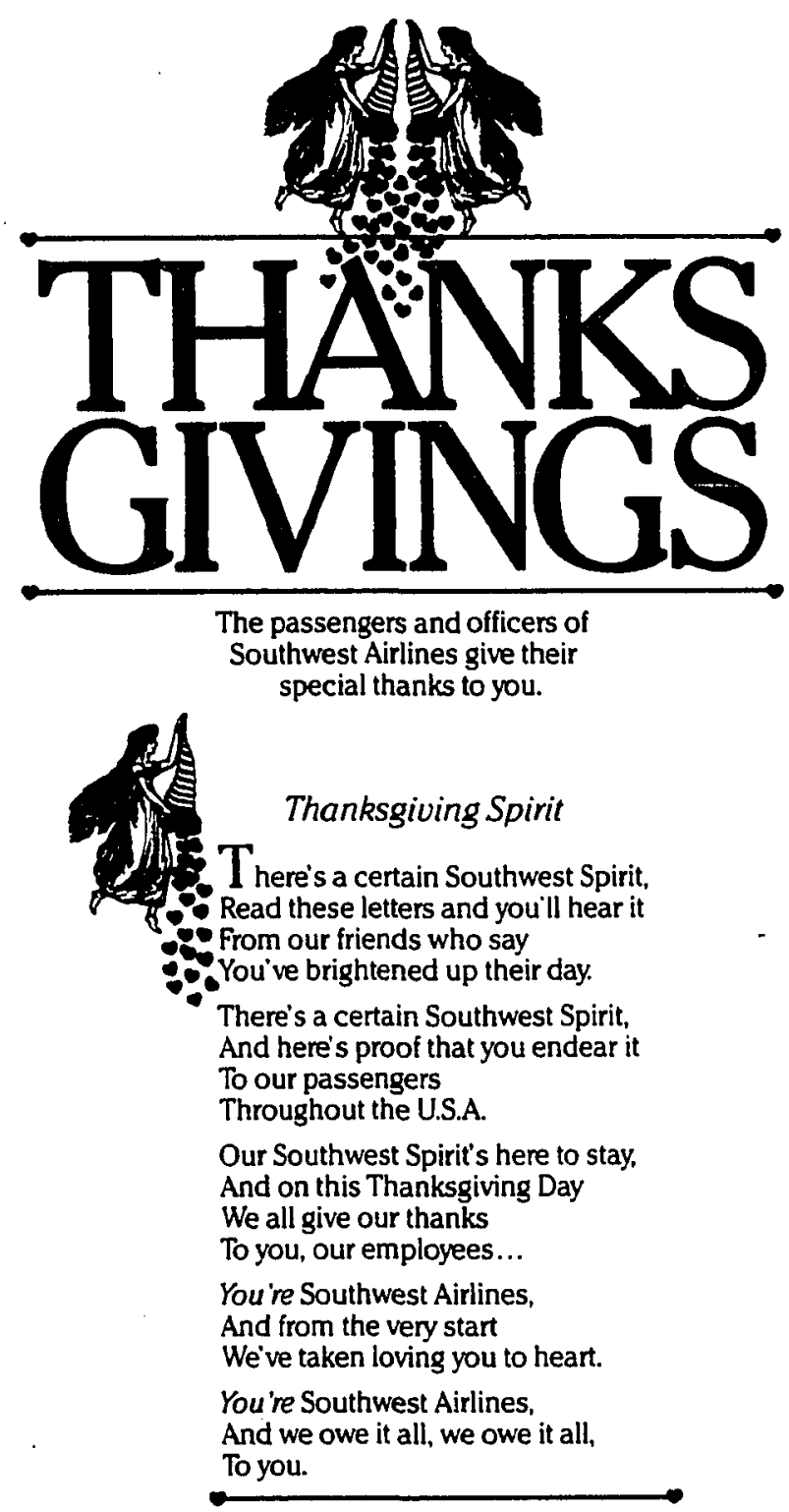

Eigure 45. The cover of a card sent to southwest employees at Thanksgiving. 


\begin{abstract}
Thanks to all of you throughout our Southwest family, there is a certain Southwest Spirit. We, the passengers and officers of Southwest Airlines, join in extending our heartfelt thanks at this special time of year.
\end{abstract}

Herbert D. Kelleher

\begin{tabular}{|c|c|}
\hline fimfamos & Thomas J. Hoff \\
\hline Colleen C. Barrett & Camille T. Keith \\
\hline Gary A! Barron & Marcy E. Lardon \\
\hline Sam Coats & Robert W. Lawless \\
\hline Eari L. Doolin & Sherry L. Phelps \\
\hline William W. Franklin & Harold F. Reilly \\
\hline Paul A. Granger & «ohn A. Vidal \\
\hline J.L. Herring & Thomas J. Volz \\
\hline
\end{tabular}

Figure 46. The inside of the Thanksgiving Day card sent to Southwest employees. 
'Twas the night before Christmas, and all through Southwest Every creature was stirring, everyons at their best;

The Res System lit up the crisp winter's night,

All planes were now full, to Herb Kelleher's delight.

Customers nestled in comfortable seats

While Ground Crews below them checked-off cargo sheets;

Ticket Agents ran tallies, their totals were flawless,

Which pleased Internal Audit and Dr. Bob Lawless!

When out on the runway arose such a clatter

That our Stock Clerks sprang to see what was the matter;

Fuel and Provisioning came to a halt,

Maintenance braced for a full scale assault.

To the tower we rushed for a view from above - -

There parading below us was one T. J. Love!

A cap on his head and a scarf at his neck,

T. J. was decked out for a Christmas Eve trek.

"I have twenty-five cities to visit tonight,

Though I know Schedule Planning has not cleared this flight;

Tve checked with Customer Relations and Marketing too,

Matter of fact, Personnel suggested my crew!"

"My Flight Attendants can't seem to reach the high shelves, They've got Spirit, all right, but the truth is they're elves;

And my First Offlcer sure strikes a fine pose

In spite of the fact that his shiny nose glows."

"My Captain's quite shy, so please hold your applause, He's a jolly old fellow who's named Santa Claus;

And he tells me he's anxious to get under way,

I just wish he would call me a plane, not a sleigh!"

And with that, T. J. lifted his wings to the sky, There was scarcely a moment to wish him goodbye;

But we heard him exclaim as he flew out of sight,

"Merry Christmas to all! And to all a good flight!"

Figure 47. Verses appearing on a Christunas card sent to

Southwest employees. 


\section{Happy Valentines}

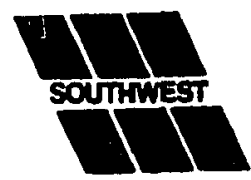

She loves me... she loves me not... As kfds we used to sey, I love you, Mom! I love you, Dad! As we went out to play. I love my little brother, I love my older sis, I'1 love you, Dear, forever -. Let's seal it with a lisel

But, hey, what's this - an airline inopiring so much LOVE? From people on the ground belor And in the air above? You see, we're one big family and you're included too, On Valentine's we're proud to say WE ONE IT ALL TO YOUn

Figure 48. Verses appearing on a Valentine Day card sent to southwest employees. 


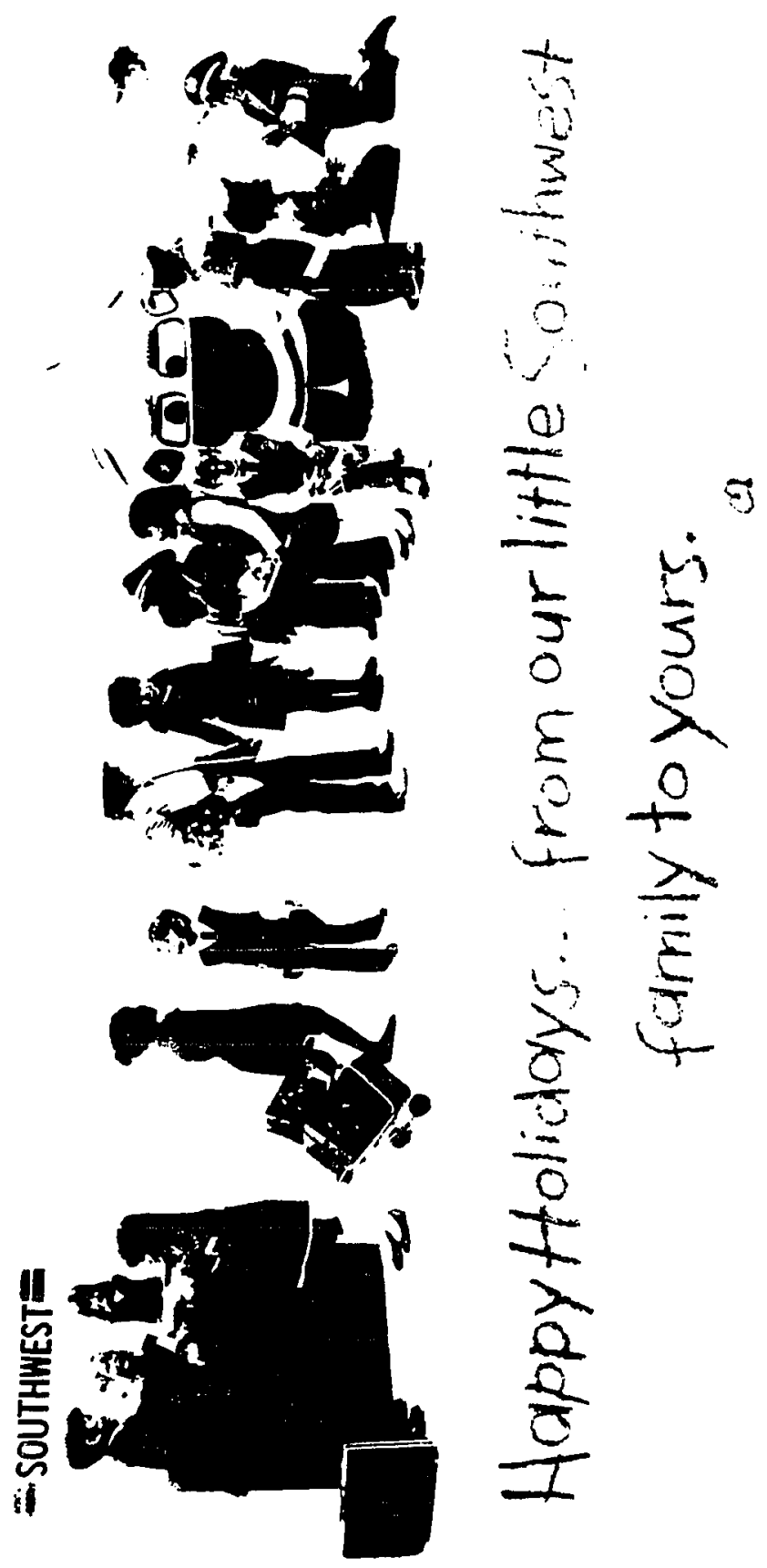

Eigure 49. Children of Southwest employees appear on a holiday card sent to members of Southwest Airlines. 
genuine interest in their lives. This, in turn, has a positive impact on their job performance and satisfaction and their commitment to the organization. Thus, the importance of the ritual to the company should not be underestimated simply because it is tangential to the seemingly more important daily operations of the corporation.

As a result of his love for the people of Southwest Airlines, Kelleher has established a number of events that ceremoniously recognize employees for their achievements. In addition to the Winning spirit Awards that Kelleher presents to employees each month in the corporate board room, he also presents a variety of awards at the company's annual employee awards banquet. This banquet is a festive occasion in which employees are recognized for their five, ten, and fifteen year commitments to the company. Additionally, the Founders Award, the Special President's Award, and the Good Neighbor Award are given to those individuals whose accomplishments and special contributions have made Southwest Airlines a better company. Southwest employees anticipate these awards banquets for months prior to their happening. They know that these events are more than just opportunities to receive awards; the banquets are also seen as opportunities to see friends, trade stories, and celebrate with Herb and the gang. As Figure 50 shows, there is perhaps no one who looks more forward to these 


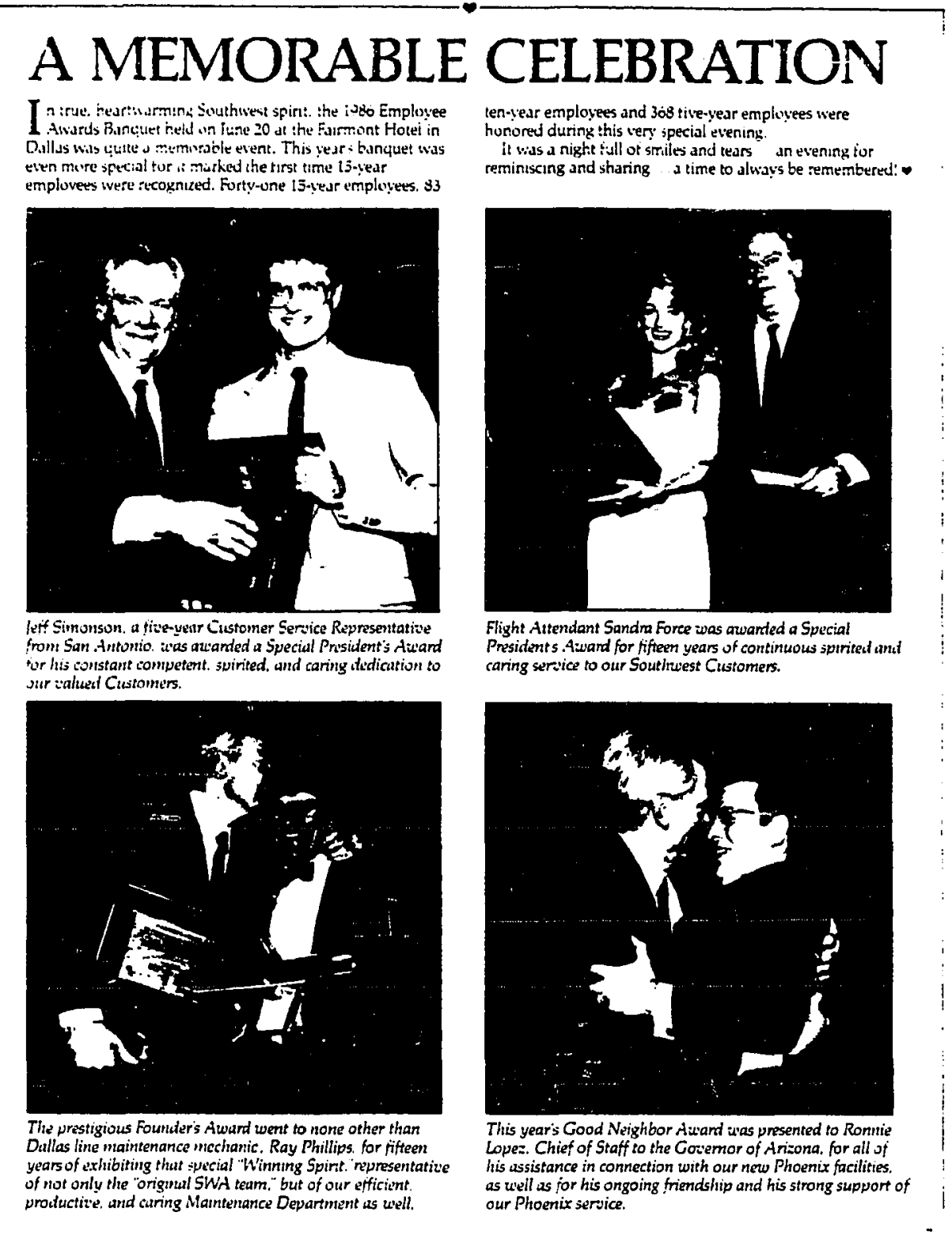

\section{Figure 50. Herb Kelleher presenting awards to Southwest employees at the annual awards banquet.}


events and celebrates harder than Herb Kelleher. He loves these people and thoroughly enjoys celebrating their achievements.

Inaugural ceremonies like "The Spirit of Kitty Hawk" are also a part of Southwest's symbolic repertoire. When Southwest made a $\$ 900$ million commitment to purchase 31 Boeing 737-300 aircraft. The company put on the gala event called "The spirit of Kitty Hawk" celebrating the acquisition of a new generation of larger, faster, less noisy, and more fuel efficient jetliners. The purchase of the 737-300's and the ceremony is symbolic of southwest's intention to be a dominant force in the airline industry in the next 10 to 15 years. Consequently, when Southwest employees see the company make this type of commitment in an industry where bankruptcies and takeovers run rampant, their confidence and pride in the company is strengthened. For this reason, ceremonies like the spirit of Kitty Hawk go a long way toward enhancing the motivation of southwest people.

The Inaugural Ceremony was also representative of Southwest's heritage and the 81st anniversary of the Wright Brothers magnificent flight. Having taken delivery of several new 737-300's, the company staged the event to take place on the very day of the Wright Brothers anniversary. symbolically, the company has named several planes after important people and important events. Airplanes named 
"The Herbert D. Kelleher" and "The Rollin w. King" remind Southwest people of the company's heritage, its heroes, and its legends. On the day of the ceremony, a new plane, "The Spirit of Kitty Hawk," rolled out on the tarmac (see Figure 51) to take 90 passengers on its three-city inaugural flight - "Flight 300." The flight, bound for Houston, San Antonio, and back to Dallas, was a re-creation of the original triangle route initiated by Southwest on June 18, 1971. As also shown in Figure 51, Brigadier General Charles E. "Chuck" Yeager, the first pilot to break the sound barrier, was a featured speaker for the day's activities.

The Spirit of Kitty Hawk ceremony concluded with an inaugural dinner for 700 people that held the theme "From the wright stuff to the Right Stuff." The ballroom in the Anatole Hotel in Dallas was filled with memorabilia from the Wright Brothers' historical flight to the development of the United States Air Corps to the introduction of Southwest's new aircraft. The biggest surprise of the whole ceremony was the guest appearance of Bob Hope as the evening's entertainment. Hope, led by two Southwest flight attendants, took the stage to bring the celebration to its finale by delighting the audience with his music and his humor (see Figure 52).

While ceremonies like the Spirit of Kitty Hawk are not an everyday occurrence at Southwest Airlines, they are 

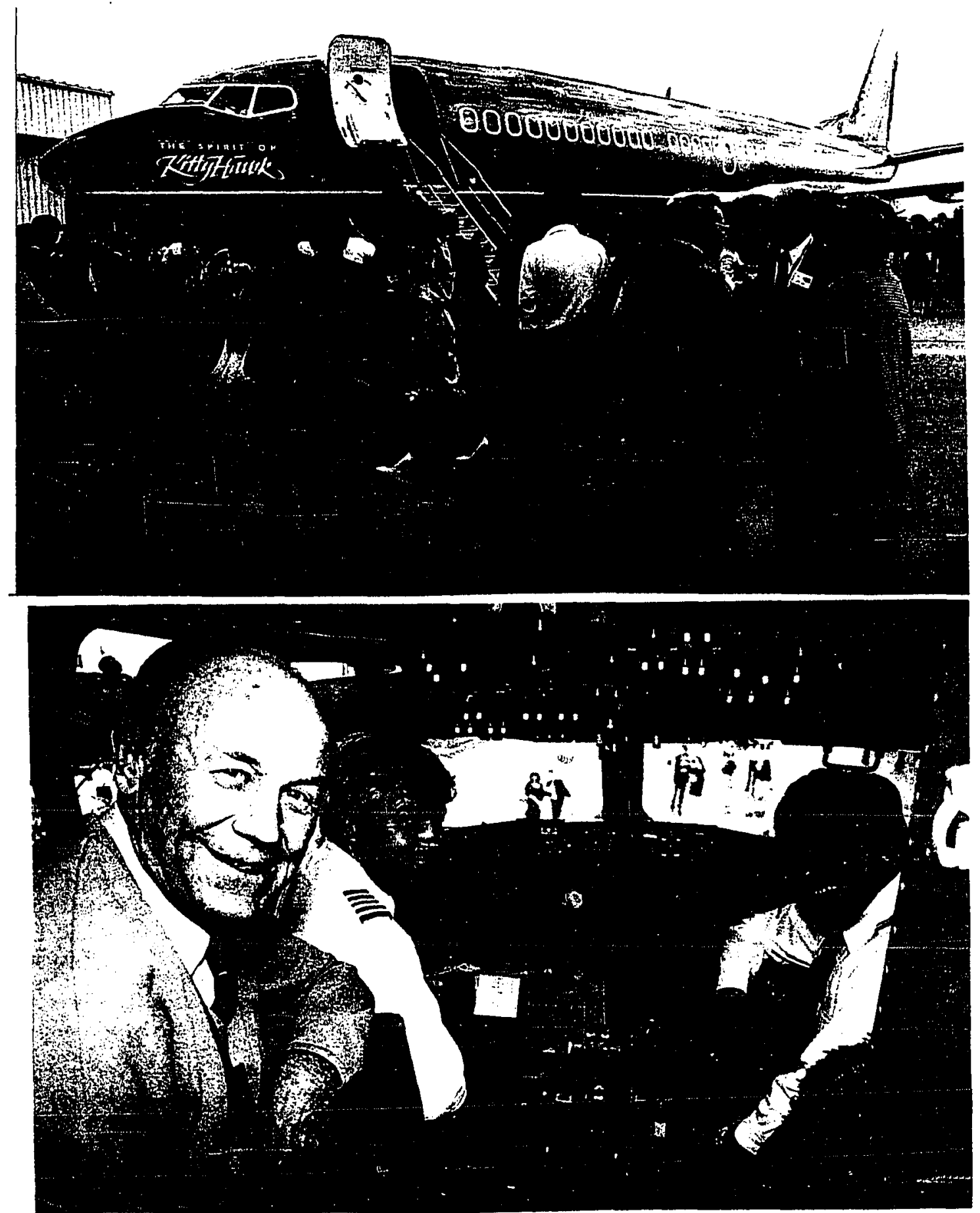

Brigadier General Charles "Chuck" Yeager joins Captains Earl Tomlin and Paul Carter in the cockpit of the new aircraft. 

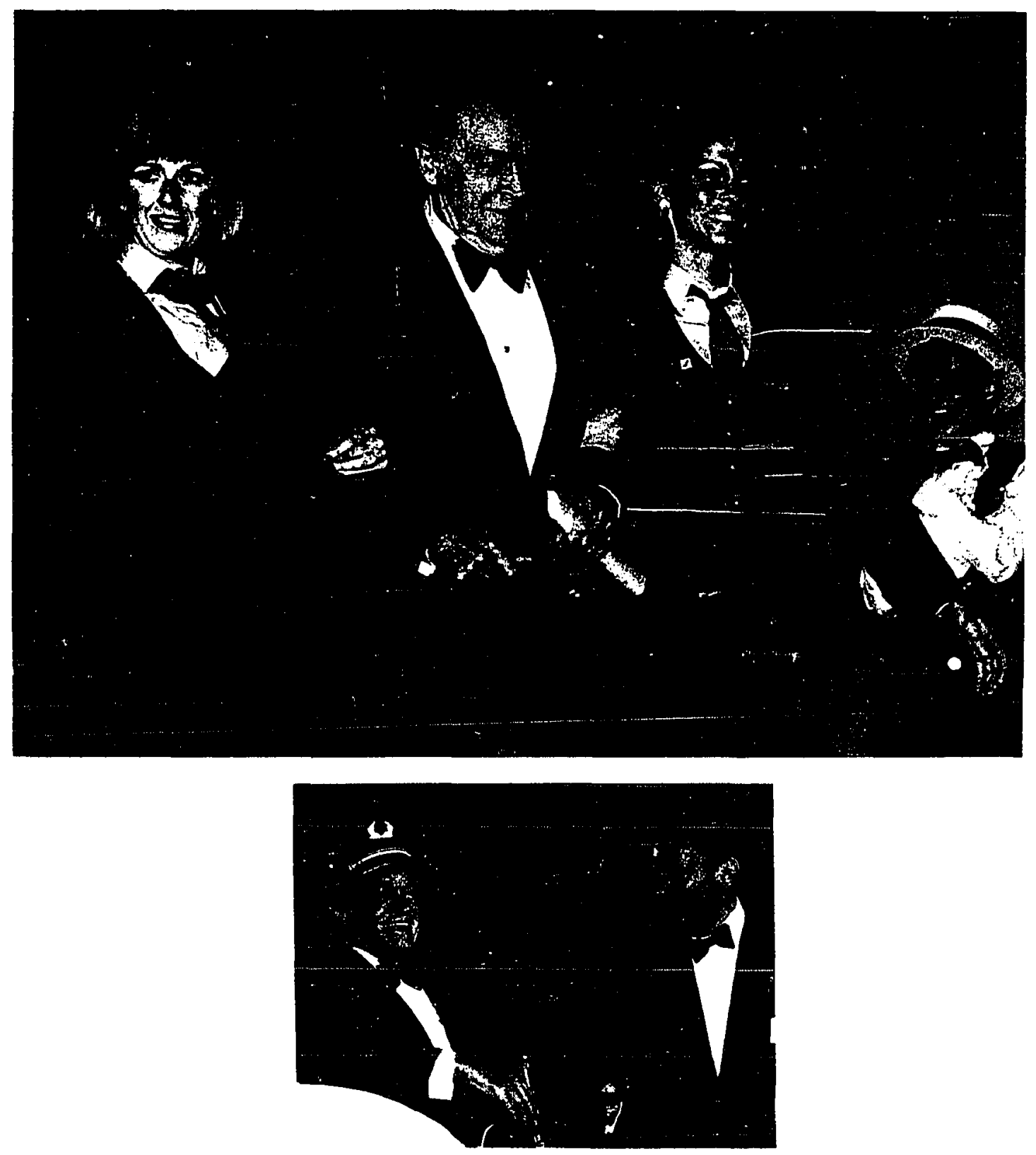

Figure 52. Above, Bob Hope is escorted by two Southwest flight attendants. Below, Kelleher presents Hope with a model of the company plane. 
important because they serve as rallying points that draw Southwest employees together. These ceremonies constitute one more way in which Kelleher has created a spirit of unity at southwest and symbolically communicated his passion for the company and its people.

Another way in which Kelleher symbolizes the importance of his people, his interest in their ideas, and his commitment to customer service is through a brochure the company sends out to employees entitled "Help Herb." The brochure, as shown in Figure 53, very briefly outlines the mission and purpose of the company and some of its new promotional programs. However, the major purpose of the brochure is not only to keep southwest employees updated about new programs the company is developing, but also to solicit their feedback in terms of improving customer service (see Figure 54). The brochure is symbolic of Kelleher's belief that those employees who are out on the line directly dealing with customers have the best ideas about how those customers can be served by the company. He genuinely believes that their ideas are valuable and, therefore, anxiously seeks their advice. As a result of participating in the Help Herb campaign, many of the employees have received winning spirit Awards for their outstanding ideas.

While Kelleher does much more communicating with the people of Southwest Airlines via face-to-face interaction 


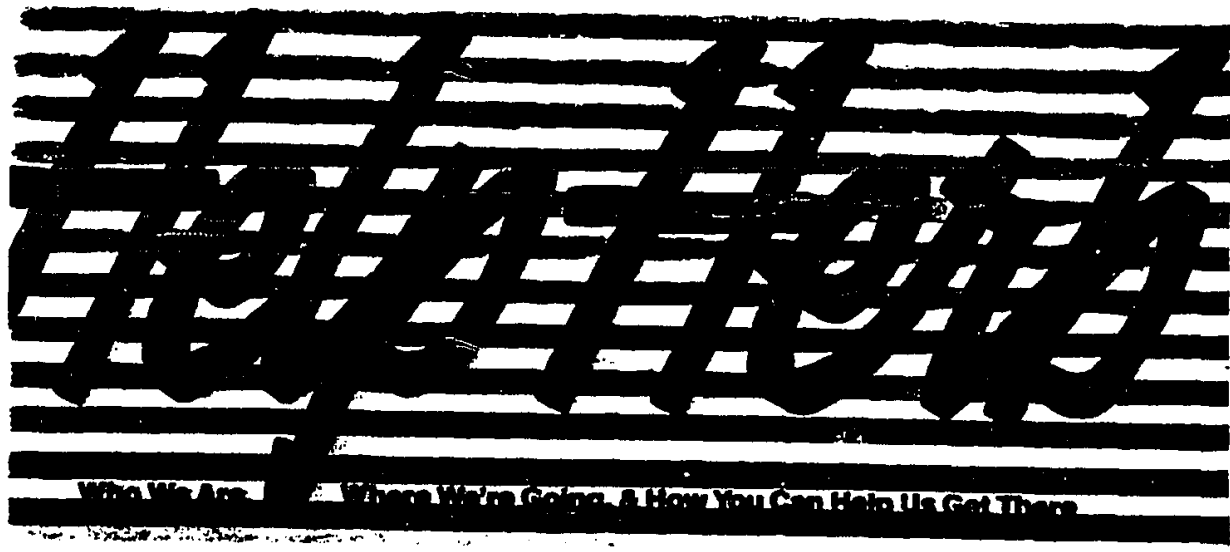

\section{Our Hero}

Southwest Airlines is the Champion of Shorthaul Business Travelers. Our everyday low fares save them money. Our convenient schedule. close-in airports and quick Close-in airports and quick
ticketing procedures save them time. And our genuine Southwest hospitality saves them from hassles.

The Compary Pane

We want Business Travelers to

think of Southwest as The

Company Plane. Ou: com.

mitment to great schedules

on-time performance and

hassle-free connections

should send a positive signal

to Business Travelers: Just

Say When.

\section{Fun Fares}

Southwest also wants to pro vide Pleasure Travelers the best value and the most fun to the cities we serve. We pioneered super low Pleasure Class (Otf-Peak) fares. Now we're introducing fun Fares fares so incredibly low you can fly just for the fun of it!

\section{-}

Help Is On The Way!

Herb! I've got a great idea about how we can better serve the $\square$ Business Traveler $\square$ Pleasure Traveler Listen to this:

$\overline{\text { Name (Please Print) }}$

1.0. Number

\section{Figure 53. Help Herb brochure that is distributed}

\section{throughout the company soliciting employees' suggestions.}




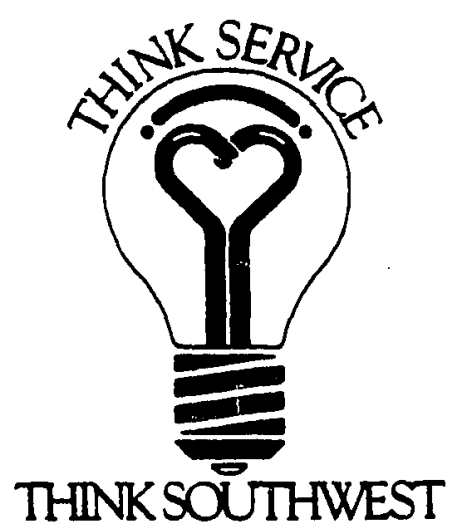

\section{Think Service. \\ Think Southwest.}

Please share your thoughts. If you have ideas on how we can

better serve the shorthaul

Business Traveler, or how we can better care for the Pleasure Traveler, jot them down and send them to me. Thanks for your thoughts. And thank you for you.

Figure 54. Logo promoting Southwest's customer service orientation. 
than he does through formal memos, he does communicate important ideas through memos as is evident in Figure 55 which demonstrates his commitment to the process of generativity. Kelleher and his senior Management Committee (SMC) have made a strong commitment in terms of time and money to the development of future leaders at southwest. A year-long program entitled "Toward Excellence" was inaugurated in 1987. This is a training program that is designed to explore the notion of leadership, and it is closely aligned with Tom Peter's (1982) work on the subject. The memo is also symbolic of his desire to maintain a sense of unity and team spirit within the company. Memos such as this one reinforce the messages Kelleher sends to employees in his daily behaviors. That is, by verbally promoting a "unified sense of team," "managing by wandering around," and the "Southwest spirit," Kelleher is essentially talking about the behaviors he models on a daily basis.

These examples of organizational symbolism contained show that the dominant values at Southwest Airlines are clearly represented and reinforced by the symbolic elements that pervade the corporation. Moreover, Herb Kelleher himself is a symbolic representation of the values that have made southwest Airlines an indomitable force in the American airline industry. 
IMTERUFFICE UEN

\begin{abstract}
70: The Leiders of Soutmuest Arilines
FRun: Hero kellener

aAte: Janury 6, 1987

SUvect: Leaderanip Developente

-The new lestership style requifes that unapers' roles at all levels oe

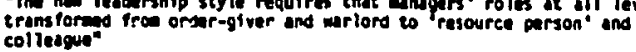

Wote from working Iosekmer

-...erket suceass depends on a suparior level of partorance. a level

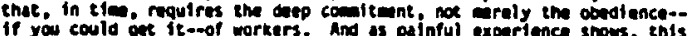
if you could out it-mof workers. And as painful experience snows; codel of control."

itroe Control To Comitent

The Hurvare Eusinass Deviles.

The ofy challempe of the lowe's is noe the ratraining of workers. but

Quote tron Rednvenz ing The Corporation

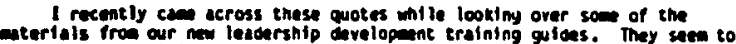

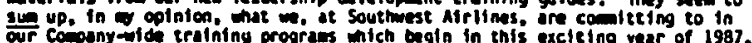
owr compony-ulde tralining prograes intch oegln in this excleing year of 1987. I nope that each of you nave had in opportunity to reed the overvite of the varlous progras in the movesoder issue of Luvelines. If you have, you thow

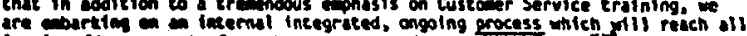

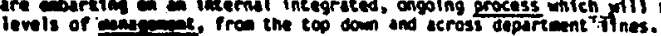

Our lang-range mol is to echieve a unitied "sense of ceas" which wlll

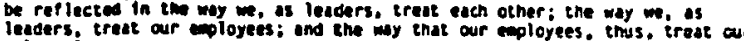
leaders, traet our coployees; ind the my that our employees. thus. trast our

You will learn bout "Mana" in 1987..e term our officers pleked up as w beyen this process in 1985 and early "Ho. "Manoginy oy mandering around" is

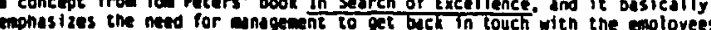
and to gat back in touch with the customers by spending time out on the line

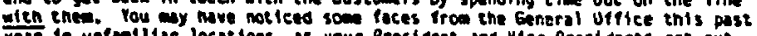
your in unfmillar locations, as your Prasident and vice Presidents got ous from behina our assks to gander around."

The offleers have been through the "Tomard Excellence" proyre and

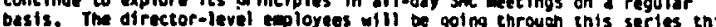
year. Beyond that, all other monogement level people will partictoate in

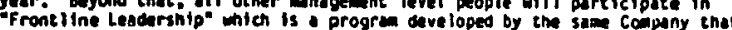
did "Toward Excellence." I have had an opportunity to review the aterfials from this progre and know that you will be as excited as I an about the

You my al so be interasted to know that 1 have asked Marcy Lawless to revise the Perforance Appraisal forms we currensly use for non-contrace people and to develog apoparate one for minagement tevel enployees th addition to deing evelusted on the "southmest spirit," you will be held responstble for exesplifying the basic principles learned in the leadership developaent process.

In clasiny, I mphasize to you that enere is t deep comituent from our officers 20 all of you and to the employees ho work for you to developing

The theme of traintiny this year is....

"Togather, we Make it Mappen"...

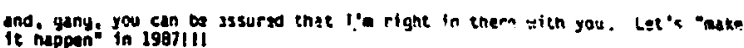

\title{
Figure 55. Memo from Herb Kelleher exemplifying his
} commitment to leadership development. 


\section{CHAPTER VI \\ SUMMARY, CONCLUSIONS, AND DISCUSSION}

The purpose of this study is to describe the degree to which the chief executive of a major American corporation exemplifies the primary components of transformational leadership as outlined by Burns (1978). The following segment of this report presents a summary of the significant factors which demonstrate that Herb Kelleher is a transforming leader. I included in this summary are the researcher's concluding arguments that point out why Herb Kelleher is such an outstanding example of this concept.

\section{Summary and Conclusions}

The story of Southwest Airlines is one that shows how a small band of people, through their courage, perseverance, and indomitable spirit, overcame adversity to build one of the most successful airlines in the industry today. The competition and conflict that the company encountered in its early years intensified the need for transformationalleadership. Fortunately for the people of southwest Airlines and for the airline industry as a whole, Herb Kelleher recognized the needs of the fledgling airline. 
Kelleher successfully used competition and conflict to create a cause for which the people of Southwest fought. In this sense, he used conflict as a means to strengthen the commitment of Southwest employees to the company and its future. Rather than attempting to avoid or suppress the competition and conflict the company faced, Kelleher used it to incite constructive behavior and move his people to purposeful action. In the courtroom, Kelleher used his tremendous legal skills to influence the intensity and scope of the conflict. His proactive stance enabled Southwest to consistently circumvent the oppressive forces of the major carriers. In the conference room, Kelleher and the senior officers of Southwest were able to design fare structures and advertising campaigns that enabled Southwest Airlines to establish a legitimate position in the marketplace. The point here is that Kelleher demonstrated his leadership abilities by engaging the opposition and embracing conflict as an instrument to be used rather than a force to be avoided.

As a major advocate of deregulation, Herb Kelleher is excited by the risks and rewards of competition. He views competition as a force that keeps the airline striving for new and better ways to serve its customers. Consequently, Southwest Airlines is recognized as one of the most innovative companies in the industry. Hence, Kelleher is a good example of transformational leadership because he uses 
competition as a strategy for motivating his employees and furthering the goals of the organization.

It is very obvious that the employees of Southwest Airlines put a tremendous amount of faith and trust in Herb Kelleher (see Figure 56). They are confident of Kelleher's desire and ability to satisfy their needs. Kelleher, in turn, exercises his influence with their wants and needs in mind. He has successfully created a culture at southwest where people grow personally while contributing to the company. This is consistent with Naisbitt and Aburdene's (1985) notion of creating a culture where people can integrate life and work. With this in mind, it is very clear that the employees of Southwest want to support Herb Kelleher. Southwest Airlines is made up of a host of extremely talented individuals, many of whom came to the company from other airlines. These individuals have had the opportunity to evaluate the claims and values (Burns, 1978) of chief executives at other companies. As a result, they have chosen to come to work for Southwest Airlines and follow a leader who has provided them with an opportunity to work in an environment where their wants and needs are satisfied. In this sense, Herb Kelleher is not in a place of headship (Kellerman, 1984) where his power and authority are the result of his position in the organizational structure at Southwest. Rather, Kelleher's power and ability to lead are founded upon the special relationships 
TO: Dallas Times Herald

FROM: Greg Roessner, Manager of Ground Operations, Southwest Airlines, Dallas Texas

RE: Nomination for Dallas Times Herald "Great Boss's Award.

Herbert D. Relleher, CEO and President Southwest Airlines

Mr. Kelleher exemplifies the ideals that have made Southwest Airlines one of the aviation industry's stellar performers: personal warmth, a dedication to excellence and the sheer hard work that brings that commitment to fruition. Personally, he is a caring, enthusiestic and generous person whose concern for the welfare of others is a well-known fact. His considerable personal charm and sense of humor are always effective in putting people at ease. Most imoortantly, he is a thoughtful listener whose ego never intrudes as might be expected.

As a leader, he combines a keen vision and an uncommon ability to communicate corporate goals with his infectious enthusiasm and a positive "can do" attitude. Foremost, he is an exceedingly articulate communicator of the realities of the marketplace and the priorities necessary to respond to them in order to retain a leadership position in the industry.

He sets an example of tireless dedication to hard work that is far more eloquent than mere words. His fierce competitiveness is complimented by his farsighted charting of the company's direction and goals as it expands and prospers. The foundation for this firm guidance is his through knowledge of the economy, the industry, the conpetition, and his concomitant preparedness for any vicissitudes that may adversely affect corporate health.

of equal importance to the foregeing is his accessibility to all enloloyees, of whom he is genuinely solicitous for feedback on ways to improve customer services. Often times he can be observed working with and inspiring his "fellow employees" as he addresses them with his down-to-earth manner and cheerful laugh. He is thus able to motivate people to realize their own potential; he has a real genius for drawing out the latent excellence in others. By including enployees in this unique method of participatory growth, he enhances their self-fulfillment. He uplifts people by helping them to recognize their own individuai importance to the team effort, as opposed to feeling like a faceless, numbered cog in the corporate machine.

His leadership by example is one of the manifestations of his aspiration to high standards. However, he never expects more of anyone else than he demands of himself.

His record speaks amply for him, but to sum up, let it be stated that he is that rare human being who has the singular ability to envision the larger reality of a situation while simultaneously never loosing sight of the all-important details. His oniy shortcoming is that he denies himself some of the singler pleasures of life since he is far too busy inspiring others!!

Figure 56. Greg Roessner's letter nominating Herb Kelleher for the "Great Boss's Award" of the Dallas Times Herald. 
he has cultivated with the people of Southwest Airlines. Thus, his genuine love for the employees in his company is one factor that legitimatizes Kelleher's leadership abilities.

Kelleher has a unique understanding of the collective aspirations of the people in his company. Southwest employees believe that no one is more concerned about their long-term job security than Herb Kelleher. Moreover, they understand that Kelleher has a very strong desire to make Southwest Airlines a place where employees are morally uplifted when they come to work. Essentially, the people of Southwest are committed to Kelleher because he has helped them create an environment where their goals for financial security and significance are being accomplished.

The trust, cooperation, and openness that exists between Kelleher and his followers have been established largely as a result of his sincerity and his consistency. When he tells the people of southwest how much he loves them, they believe him because he communicates this message consistently in his everyday actions. From this relationship of openness and trust, Kelleher and his employees have reached what Harrison (1984) labeled as a state of attunement or balanced wholeness at southwest. There is an element of oneness between Kelleher and his people that has been created by their collective efforts to pursue a common purpose. Southwest employees are committed to the mission 
and purpose of the organization because they play a significant role in establishing the company's mission and its direction. Kelleher values their advice and constantly solicits their feedback on company matters. He is genuinely interested in their ideas and works very hard to create $a$ mesh between their goals and the objectives of the corporation. As many southwest employees have pointed out, Kelleher's passion is a passion for the people of southwest Airlines. He has. successfully established an environment wherein the collaborative efforts of everyone at Southwest have kept the company on the cutting edge of an everchanging industry. Thus, Herb Kelleher can be seen as a transformational leader in that he has effectively created a purpose or cause that binds the people of southwest together in pursuit of their mutually-held goals.

Kelleher's passion for the people of Southwest Airlines is the motive behind his commitment to focus on the company's long range objectives. As an individual with a strong sense of vision, Kelleher possesses a global perspective that enables him to see the parts as well as the whole. His ability to focus ten years ahead allows him to understand how fuel prices, the economy, new technology, competition, and the like affect the airline industry and Southwest Airlines today. Through his global perspective Kelleher has a knack for understanding how each of these various parts impact on each other. Consequently, he is 
able to mobilize resources so as to put Southwest Airlines in an advantageous position in the marketplace. His vision for the future of Southwest enables him to recognize and capitalize upon opportunities that confront the company today.

In congress with Bennis and Nanus (1985), Kelleher is concerned with ends versus means. That is, his vision for the future of Southwest allows him to distinguish between doing things right and doing the right thing. His ability to use competition and conflict advantageously and maintain a "can do" attitude in the face of adversity is a result of his ends orientation. Kelleher pursues his passion with an unrelenting zeal that boarders on obsessive. Therefore, he is rarely pulled away from doing the right thing by a means issue. He does not allow the tactical traumas of the company's daily operations to cloud his vision. Conversely, his passion for the company enables him to see the mission and purpose of Southwest Airlines with laser clarity. In this sense, he is much more concerned with what Burns (1978) labeled as end values than he is with modal values.

Kelleher's vision for Southwest Airlines also serves as a rallying point for southwest employees. Their understanding of his vision for Southwest is what draws the employees together. The people of southwest know that if they are not (directly or indirectly) championing the cause 
of the customer (everyone is a customer at southwest Airlines) and having fun in the process, they would do well to change their behavior. He consistently promotes this vision by personally and publicly recognizing those employees who are contributing to the realization of the vision he has laid before them. In this sense, he is a master at creating images that excite people and move them to purposeful action (Zaleznik, 1983).

The images Kelleher creates when sharing his vision with the people of southwest instill within them a spirit of confidence. It is obvious that their confidence in the chief executive has enabled southwest employees to transcend their preoccupations with the present and embrace a valued-vision of what they can accomplish in the future. Kelleher has been able to bring about organizational transformation at Southwest largely because he communicates a vision that appeals to the higher aspirations le.g. heroism, dignity, significance) of his employees.

The result of Kelleher's ability to effectively package his vision at southwest is an awe-inspiring level of team work (kiefer \& Senge, 1984) on the part of southwest employees. There is a very evident sense of interconnectedness or alignment among the people of southwest Airlines. They operate as an integrated whole in which every person seems to be pursuing his or her individual goals through the mission and purpose of the organization. 
In this sense, Kelleher successfully transforms his vision into a shared organizational vision with which the Southwest employees are able to identify. It is very clear that when it comes to serving each other, the consumer, or the children at the Ronald McDonald Houses, the people of Southwest Airlines see the mission and purpose of the organization as an extension of their own personal purposes (Kiefer \& Stroh, 1984). As a result of aligning their own purposes with the purpose of Southwest Airlines, Southwest employees assume the responsibility for the company's success.

From the perspective of transformational leadership, Herb Kelleher's greatest strength is his ability to consistently shape values and educate by example on a daily basis. As a leader who sees his employees as individuals and respects them immensely, Kelleher gives his people a tremendous amount of autonomy. Consequently, he concentrates on shaping their long-range, more enduring, end values. He knows that if the people of Southwest airlines can adopt a particular set of end values le.g. that loving spirit, pride and confidence in themselves and the company, developing a sense of humor and having fun at work, servicing the customer, and maintaining a lean bureaucracy), those values will serve as the guideposts by which employees evaluate their daily behaviors. That loving Southwest spirit is a value that provides southwest 
employees with an understanding about how they should interact with one another. It also shows them the impact that an environment of care and concern can have upon serving the customer. In Foster's (1985) words, this particular value system is a guideline that shows the people of Southwest how to order their working relationships.

Promoting a spirit of pride and confidence among the employees is another way in which Kelleher has enhanced their level of commitment. He consistently shows them how much they are responsible for the company's success. This, in turn, increases their confidence in themselves and pride in the company. The overall result is that they are willing to make personal and professional sacrifices to accomplish organizational objectives. Moreover, they are able to achieve a level of attunement that enables them to rise to higher levels of performance and accomplish more collectively than they could ever dream of accomplishing individually.

Outstanding customer service is a company value that is accomplished at southwest through the employee's expressions of love and respect for one another and through their confidence in themselves and pride in the organization. Simply put, because they love the people with whom they work and the environment in which they work, and because they firmly believe that they work for one of the 
best companies in the world, the people of southwest Airlines overflow with a special care and concern for the customer. Many of them have demonstrated this by going way beyond the call of duty to satisfy the needs of the customers they serve. While the message of customer service is articulated over and over by kelleher, his real influence in promoting this message has come as a result of the fact that he serves his employees with a passion. They know that they are his number one concern and the reason he devotes 80 hours a week to making the company profitable. Consequently, they make a tremendous effort to support each other and their customers in the way that Kelleher supports them.

Finally, Kelleher understands that it is difficult to treat employees and customers with dignity and respect when he doesn't deal with them directly. Therefore, another dominant value that he works hard to establish within the company is that of a lean bureaucracy. One of the ways in which he promotes this value is by minimizing the levels of management between an entry level position in the corporation and himself. Kelleher, who maintains an open door policy, frequently wanders around the organization (Peters and Waterman, 1982) so as to stay in tune with the needs of his people. He allows very few standing committees to exist in the company and forbids his managers and supervisors to have assistants. In addition to his own example, 
this is one way in which he encourages his senior people to deal directly with their employee groups. The other reason that maintaining a lean bureaucracy has become a dominant value at Southwest Airlines is because Kelleher knows how important it is for the company to be able to respond with alacrity to the rapid changes that are so characteristic of the airline industry. He knows that when decisions do not need to go through several layers of management for approval, the company is able to act responsively to industry and market shifts in a much shorter period of time.

Herb Kelleher's success as a transformational leader is due, in part, to his' ability to define these enduring values in a context that is meaningful to the people in his company. He has a special knack for showing the people of Southwest how these values relate to their long-term potential. He understands that by establishing a strong value system that is shared by southwest employees, he can create within them what selznick (1957) labeled as a sense of institutional purpose. Therefore, like an evangelist preaching to a congregation, Herb Kelleher moves through the company's offices, hallways, machine shops, cockpits and galley ways with a preoccupation for instilling these end values. By instilling a value system that provides the people of Southwest with a sense of direction, meaning and purpose in their work, he continues to establish southwest 
Airlines as an extremely difficult force to contend with in the American airline industry.

As an individual who is stimulated by competition and dislikes losing, Herb Kelleher is a master at using power to mobilize resources. He is also very comfortable in political situations and recognizes that politics is an inevitable part of operating a profitable corporation in the airline industry. Consistent with the positions held by McClelland (1975) and Kanter (1983), Kelleher is a powerful individual simply because he works very hard at empowering others. He does not rely on his position of authority at southwest to exercise power. Rather, his influence stems from his ability to empower others. Perhaps the most significant thing that could be said about Herb Kelleher is that he does not desire to be a powerful individual. He is much more interested in uplifting the people in his organization by providing them with the power resources and autonomy to make significant decisions. In this sense, whatever power resources kelleher gains, he uses them to further the common good of the organization and serve its people rather than for self-aggrandizement. In concert with Collins' (1983) perspective, Relleher willingly shares his power resources with the people of Southwest Airlines because his relationship with them is both the motive and the means by which they collectively accomplish their ends. 
Kelleher recognizes that the American airline industry is a highly-charged political environment where corporations struggle to obtain a larger share of the market. With this in mind, he is continually in the process of cultivating an ever-broadening circle of contacts and connections. winether it is a member of the Dallas City Council, a United States Supreme Court Justice, the Mayor of San Antonio, or an influential business leader in the City of Chicago, Herb Kelleher understands that political actors can provide southwest Airlines with the information and support needed to provide entree with certain individuals, enhance the company's credibility, avoid costly decisions, and circumvent the threatening activities of adversaries.

Kelleher's political sophistication can be seen in his ability to accurately assess the positions of various stakeholding audiences and rally key figures around new ideas and future directions. His political savvy broadens the range of alternatives for southwest in terms of the company's ability to move strategically in a rapidly changing environment. For example, with a combination of timing, foresight, and political acumen, Kelleher wooed the politicos of the City of Chicago in order to establish a foothold at Midway Airport. Additionally, he continues to cultivate his relationships with city officials in Houston and San Antonio so as to create two alternatives for the 
company's home base. If the Dallas authorities should fail to fulfill its obligations to southwest, the company could quickly reestablish itself in either Houston or San Antonio.

As a political strategist, Relleher is a very effective negotiator. Although he loves to win, when it comes to bargaining with employee groups within the company, he makes every effort to negotiate contracts that are beneficial to all the parties involved. When dealing with the people of Southwest Airlines, he likes to create win-win situations so that the mutual goals of both employees and shareholders are advanced. In order to do this, Kelleher goes to the bargaining table having studied a situation thoroughly. As his employees will confirm, he is extremely well-prepared, and he knows exactly how far he can go with a particular deal. More importantly, he will give as much as he can in a contract with Southwest employees until he feels that giving any more would be detrimental to another employee group. Thus, whether he is dealing with southwest dispatchers, mechanics, flight attendants, or pilots, Herb Kelleher is respected by his people as an extremely competent and fair negotiator.

As with competition and conflict, Kelleher views politics as a creative endeavor, as a tool to be used in the process of leading the people of Southwest Airlines. There is little doubt that the company's ability to survive 
the potentially devastating attacks from major carriers and the City of Dallas is a result of Kelleher's knowledge and sophistication in the political arena. He is an excellent example of transformational leadership because he uses these attacks as a way of involving his people in a new kind of political participation. In Burns' (1978) terms, he has created a political connection with his employees by presenting them with a cause worth fighting for. That cause has obviously been to stand up against the oppressive forces of the larger carriers as well as the Dallas City Council. By turning things into a cause, Kelleher has shaped the motivation of southwest people and transformed them into passionate, active followers who pool their talents to fight the company's political battles. In this sense, Kelleher has been able to facilitate the actualization of human potential among his people by realizing the full opportunity of politics.

one of the most distinguishing characteristics of transformational leaders is that they move their followers to higher levels of motivation and morality. One of the ways in which they accomplish this is through the process of generativity. Herb Kelleher shows his commitment to the development of future generations in several ways. First, he does a magnificent job of showing the people of Southwest Airlines how their work contributes to the overall mission of the enterprise. He makes them feel 
responsible for the company's success because he firmly believes that they are responsible for its success. As he loads bags into the planes, turns wrenches with the mechanics, and works fiights with the pilots and flight attendants, Kelleher is essentially showing his employees how much he appreciates them as individuals who are making significant contributions to the mission and purpose of the company. Additionally, whether in his speeches to various groups, interviews with the media, or printed materials (e.g. annual reports, newsletters, brochures, memos, etc.) put out by the company, Kelleher never misses an opportunity to encourage his people by praising them publicly. He is also very conscious of resognizing them for their achievements and contributions to the company through formal awards ceremonies.

Second, by promoting projects like the Ronald McDonald Houses, Kelleher has drawn his people into a social vision. Through their involvement in the Ronald McDonald House program, the employees of southwest Airlines know that they are accomplishing a purpose that adds meaning and direction to their work, a purpose that transcends their narrow personal concerns and reinforces their connectedness to a larger whole (Maknight, 1984). By drawing the people of Southwest into a social purpose, Kelleher not only helps them to integrate life and work, he also contributes to shaping social structures throughout the southwest system 
that are more humane for future generations. From the perspectives held by Burns (1978) and Rost (1984), Relleher is committed to the moral development of those around him through his treatment of employees, intensive customer service orientation, and passion for the children at the Ronald McDonald Houses. Daily he engages in developmental relationships with his people that raise them to higher levels of moral aspiration. His relationships with those people who are connected with Southwest Airlines reflect progressively higher standards of human and moral development.

Third, Herb Kelleher is a generative leader in that he recognizes his employees as heroic beings who strive to maintain their positions as members of the Southwest team without giving up their individuality. Thus, while promoting team spirit within the company, Relleher also works diligently to establish a framework wherein his employees can satisfy their needs for significance, He understands that the people in his company aspire toward greatness and therefore, seek to create an environment in which people such as Gigi Perry, Tommy Perryman, and Dale Morrow can accomplish heroic deeds.

Finally, Herb Kelleher is, in Naisbitt and Aburdene's (1985) words, a "developer and cultivator of human potential." He has developed working relationships with a number of employees over the last 15 years in which he 
helps them to maximize their potential and achieve higher levels of maturity. He invests in these people emotionally and supports them in the process of developing their own leadership abilities. A number of these individuals le.g. Colleen Barrett, Gary Barron, Paul Quinn, Jim Amos, and Jim Parker) have matured as a result of their relationships with Kelleher and are now outstanding leaders themselves.

Kelleher's relationships with the people of southwest Airlines are characteristic of what Buber (1937/1970) called "I-thou" relationships. There is an emotional oneness between Kelleher and his people that exists as a result of their reverence for one another. Kelleher does not get caught in the trap of depersonalizing his people by relating to them according to the organizational roles they play. Conversely, he deals with the people of Southwest Airlines as individuals, as "sacred thous" who desire to be treated with dignity and respect. They, in turn, reciprocate by giving him the same kind of respect. Consequently, Kelleher and his people develop the type of relationships where each is elevated to higher levels of humanness.

As a consequence of being highly visible and very accessible in the corporation, Herb Kelleher is a mentor who educates his people primarily through vivid, living, personal example. $\mathrm{He}$ is a generative leader in that he successfully establishes what Gilligan (1982) called 
relationships of interdependence among the people in his company. That is, kelleher is the catalytic agent who creates a fusion of identify, intimacy, nurturance, responsibility, and care among southwest employees. Thus, Kelleher and the people of southwest Airlines are united in an integrated whole that is creating a social and organizational structure which transcends the one in which they now live, a structure that facilitates the moral development of future generations.

From a perspective o: organizational symbolism, Herb Kelleher can be seen as a leader who recognizes that his daily actions are symbolic of a particular value system. He understands that his followers make interpretations and attach meaning to the way in which he establishes his priorities. Moreover, he is aware of the fact that his priorities communicate what he values most--his employees. Kelleher understands that his followers are much more influenced by what he does rather than by what he says (Schein, 1985). Thus, he views his daily actions as symbolic opportunities to instill values and to guide and direct the people of Southwest Airlines. The thing that makes him such an effective leader in this respect is that he is absolutely consistent. The people of southwest know by observing Kelleher daily that they are his number one priority. They know this because they watch him spend 18 hours a day, seven days a week working on things that are 
of concern to Southwest Airlines. Hence, symbolically he shows them what he values, and, in turn, what they should value by the very way in which he spends his time.

Southwest Airlines is a company that is rich with organizational symbolism. The love theme and its heartshaped trademark, the family metaphor, and the language surrounding that special Southwest spirit shape the way Southwest people think and talk about their organization. These symbols are representative of how they make sense out of their relationships with each other and their relationships with customers. This is consistent with Smith's (1982) position that how organizational members think and talk about relations among parts and relations among relations will be determined by the characteristics of the language and metaphors that they use. In this sense, the family metaphor and the symbolic elements incorporated in the love theme at Southwest Airlines affect the employee's view of organizational reality. In congress with the perspectives held by Dandridge, Mitroff, and Joyce (1980), and Smith (1982), these symbolic expressions make comprehendible the unconscious feelings, images, and values to which the people of Southwest Airlines adhere.

It is very apparent that the people of Southwest agree on the subjective meanings and interpretations that are attached to the love theme, the family metaphor, the stories that are told, and the rituals and ceremonies that 
are performed within their organization. That is, Kelleher and his people share a common consciousness at southwest Airiines that appears to be very rare in the American airline industry. They function as an integrated whole in which their common experiences lead to a shared understanding about the nature of organizational realty. ConsequentIy, Southwest employees are able to establish what Borman (1983) called symbolic convergence. Through symbolic convergence then, Kelleher and his employees engage in the process of mutual identification (Burke 1969, Cheney, 1983) as their interpretations about the objects, events, and behaviors that constitute the organization overlap. As a transformational leader, Herb Kelleher encourages his people to identify with southwest Airlines and its mission through the process of promoting symbolic convergence. Using only southwest people in the company's ad campaign, appearing in the ads himself, and promoting the heroic deeds of his people in the articles of Luv lines and the company's awards ceremonies are additional ways in which Kelleher draws his people into a deeper commitment to the airline. Symbolically, the ad campaigns, award ceremonies, and articles in Luv Lines are instruments through which he shows them how valuable they are to the company. Moreover, these things serve as vehicles through which kelleher symbolically communicates his values, attitudes, beliefs and assumptions to southwest employees about the way he 
wants them to deal with each other and the customers they serve.

Discussion and Implications for Future Research

The final section of this chapter is devoted to a discussion of the strengths and weaknesses of this case study, followed by some ideas for future research.

\section{Strengths}

Since James MacGregor Burns introduced the concept of transformational leadership in 1978, scholars in the field of leadership have been skepticai about the application of his model. As a prescriptive tool, Burns' model has been lauded by both practitioners and academicians as an ideal toward which every corporate execuivive should strive. Scholars and practitioners such as Peters and Waterman (1982), Bennis and Nanus (1985), Levinson and Rosenthal (1984), Tichy and Devanna (1986), Schein (1985) and a host of others have provided the field of leadership studies with some research results that have substantiated the legitimacy of Burns' concept as a prescriptive tool. While the literature is rife with works that point to transformational leadership as a prescriptive model, it is also replete with studies that illustrate the application of the model descriptively. Peters and Waterman (1982) and Peters and Austin (1985) have done a remarkable job of providing us with numerous examples that describe how various facets 
of Burns' model have been operationalized. However, even these scholars have not shown the legitimacy of transformational leadership in its entirety with one particular individual. Burns himself used a wide array of leaders to exemplify the particular dimensions of the model. Nowhere in his volume does he illustrate how the model fits together holistically in the life of one leader. Thus, while scholars endorsing transformational leadership applaud the individual elements of the model as they apply to specific leaders respectively, these individuals have been reluctant to suggest that the model in its entirety can be operationalized by one leader. This is primarily because transformational leadership as a holistic model has not been applied to any one individual in the literature on leadership.

The strength of this investigation lies in the fact that it puts the various elements of Burns' (1978) model of transformational leadership to the test in the life of one leader. It answers the question: "Can this model be applied in the life of one individual, and if so, how is it being operationalized?" This study builds upon the work of other researchers by describing how one leader exemplifies each of the major components in the model offered by Burns. That is, the model is legitimated by the fact that it is being operationalized in an organization by one individual. 
This investigation also contributes to our understanding of leadership by offering a more in-depth description of how transformational leadership is exercised by one leader. The study enables researchers and practitioners to examine the attitudes and behaviors of an individual who is facilitating significant institutional change in one of the airline industry's most successful organizations. In providing a thorough, descriptive analysis of Herb Kelleher's leadership practices, this study moves both scholars and practitioners to an increased understanding of the nature of leadership and organizational transformation. The essential strength of this investigation, then, is that it provides researchers with an operational model of a theoretical construct. This is valuable because it shows that while the concept of transformational leadership is lofty and ideal--a leadership of the rarest kind--it is attainable. Thus, for scholars interested in expanding the field of leadership as an academic discipline, the model presented in this study serves as a starting point for conducting future investigations that examine other potential transformational leaders. For practitioners, this study is rich with examples that can be used as tools in the process of leadership development. If, as the concept suggests, educating by example is one of the ways in which we transform followers into leaders, then it is crucial that we present future leaders with a variety of 
in-depth examples that show how leadership is being operationalized.

\section{Weaknesses}

Perhaps the most significant weakness in this study is that the researcher was unable to observe the leader under investigation for long periods of time. Obviously, in the spirit of true participant observation, it would have been optimal to follow Herb Kelleher around for several months and document his behavior. However, as mentioned in the methodology section of this study, leaders at kelleher's level do a tremendous amount of traveling. Assuming that first-hand observation could be done unobtrusively while traveling with an individual like kelleher, the time and expense involved in such a method was beyond the scope of the resources available to the investigator.

Another weakness in the study stems from the fact that the responses gained in the interviews made the researcher vulnerable to certain elements of distortion. With the exception of first-hand observation through long-term residence in the organization, there is no simple way to account for the inherent constraint some interviewees may have when talking about their chief executive officer. It is probable that some individuals may have been cautious in their direct or implied criticism of Herb Kelleher. Conversely, there was a tremendous amount of internal consistency in the information that was gained in 
interviews with different members of Southwest Airlines. The overlapping perceptions and the repetition of experiences shared by these individuals helps to confirm the accuracy of the information.

Finally, the researcher's own selection of material to be presented in this study is another basis for some distortion. First, as the research progressed it became increasingly difficult for the investigator to remain objective. As is their natural tendency, the people of Southwest were extremely warm and quickly adopted the researcher as one of the family. This is obviously reflected in the study in its present state. Unfortunately, it is difficult to avoid this kind of human limitation.

second, distortion emerges in this study as a result of the researcher's biases about transformational leadership. It may be argued that a researcher seeking to uncover a given specified concept such as transformational leadership could create a self-fulfilling prophecy in which he or she constructs a distorted image of the subject that is consistent with the concept under investigation. However, this argument is weakened in regard to the present study by several factors. First, the researcher set out to develop a line of research that sought to examine several leaders that appeared to demonstrate elements of transformational leadership. Through an initial examination of these 
individuals, it became apparent that one emerged as not only the best example of transformational leadership, but indeed as a potentially true example of transformational leadership in every respect. Thus, rather than entering this investigation with an a priori assumption that Herb Kelleher is a transformational leader, the researcher critically compared Kelleher's attitudes and behaviors to those that represent the concept of transforming leadership. Suisequent to the process of observing Kelleher in a particular context and after analyzing the data obtained in the study, the researcher concluded that Herb kelleher is a transformational leader. However, given the fact that the investigator was unable to observe kelleher in every context in which the chief executive operated, it is probable that there are particular contexts in which he does not personify the concept. While first-hand observation in all of the contexts in which Kelleher operates may show that he does not exercise transformational leadership, the accounts outlined in this investigation are the most accurate perceptions the researcher has at present.

\section{Future Research}

With the strengths and weaknesses of this study in mind, there are several areas in which future research is warranted. While this study presents a starting point for conducting qualitative investigations that examine the practice of transformational leadership, the model offered 
by Burns (1978) should be applied in its entirety to other leaders. This will enable future researchers to describe in more detail if and how the model as developed by Burns (1978) is personified by these individuals. Obviously, a concept as broad-based as transformational leadership will not be operationalized in the same manner by different leaders. Therefore, future studies that focus on how the concept is being operationalized by other leaders would also serve to confirm or disconfirm the utility of the model as a description of the nature of leadership.

Methodologically, future researchers could build upon this work through participant observation for an extended period in an organization where transformational leadership is being demonstrated. Moreover, these researchers should attempt to examine potential leaders in as many different contexts as possible. By investigating their subjects in a variety of contexts over time, these researchers would be able to determine the consistency with which these individuals demonstrate transformational leadership and whether or not such consistency is essential to being a transforming leader.

An argument could be made for investigating particular aspects (e.g. symbolic leadership, power and politics, generativity) of transformational leadership more thoroughly. However, this approach may be premature given that the concept has yet to receive widespread validation. 
If researchers and practitioners are going to conduct studies that truly further our understanding of leadership, they must engage in broad-based studies that transcend the trait (Stogaill, 1974) and situational (Hersey \& Blanchard, 1977) theories of leadership. Thus, future studies that incorporate all of the elements of transformational leadership and examine the concept holistically will contribute to a new and growing paradigm that will enhance our understanding of leadership.

\section{Concluding Remarks}

One of the recurring themes in the preceding chapters of this study is that significant institutional change and organizational transformation is expressed in the satisfaction of human wants and needs. This case study presents Herb Relleher as the catalytic agent largely responsible for the transformation that has occurred at southwest Airlines. As the study shows, Kelleher satisfies the wants and needs of his people by drawing them into a valued vision of the future in which their inherent capacities are used to restore and respect the dignity of those around them. In Herb Kelleher we see a personally secure and mature individual who is guided by values that give organizational life at southwest meaning, purpose, and direction. His strength, courage, and conviction is balanced with a nurturing receptivity that emerges out of his humility and faith in people. He creates a spirit of 
trust and cooperation at Southwest that facilitates the growth and development of its members. Consequently, his people share a great deal of freedom and liberty to explore their own humanity in the process of making valuable contributions to the company.

The battle for effective leadership in America is the battle for the human spirit, for the individual goals that our nation values so highly. If this is a battle that we are going to win, and if we have any intentions of truly creating a world in which human and moral development becomes our passion, then we must intensify the search for transformational leaders such as Herb Kelleher. We must raise them up as examples of a type of leadership that responds to our fundamental human needs by embracing a unique combination of intellect, integrity, commitment, and moral purpose. It is my hope that the story of Herb Kelleher and his passion for the people of Southwest Airlines will inspire readers to examine the potential of transformational leadership for themselves and their organizations and encourage them to realize intended, real change in these organizations by exercising transforming leadership. If we do this in many different organizations and throughout the United States and, indeed, the world, we will have made significant progress in creating a nation and a world that transcends the one in which we now live. 


\section{REFEREINCES}

Ackerman, I. S. (1984). The flow state: A new view of organizations and managing in J. D. Adams (Ed.), Transforming work (pp. 114-138). Alexandria, Va: Miles River Press.

Ackoff, R. (1981). Creating the corporate future. New York: Wiley.

Adams, J. D. (Ed.). (1984). Transforming work. Alexandria, VA: Miles River Press.

Adams, J. D. (Ed.) . (1986). Transforming leadership. Alexandria, VA: Miles River Press.

Allison, G. T. (1971). Essence of decision: Explaining the Cuban missile crisis. Boston: Little, Brown, and Co.

Allison, G. T. (1984). Public and private administrative leadership: Are they fundamentally alike in all unimporant respects? In T. J. Sergiovanni \& J. E. Corbally (Eds.), Leadership and organizational culture (pp. 214-239). Chicago: University of Chicago Press.

Argyris, C. (1976). Increasing leadership effectiveness. New York: Wiley-Interscience.

Baldridge, J. V. (1983a) . Organizational characteristics of colleges and universities. In J. V. Baldridge and T. Deal (Eds.), The dynamics of organizational change in education (pp. 38-59). Berkeley: McCutchan.

Baldridge, J. V. (1983b). Rules for a Machiavellian change agent: Transforming the entrenched professional organization. In J. V. Baldridge and T. Deal (Eds.), The dynamics of organizational change in education (pp. 209-219). Berkeley: McCutchan.

Baldridge, J. V., \& Deal, T. (1983). The basics of change in educational organizations. In J. V. Baldridge \& $T$. Deal (Eds.), The dynamics of organizational change in education (pp. 1-11). Berkeley, CA: McCutchan. 
Bancroft, B. (1986). Southwest Airlines celebrates 15 years of luv. (Available from Southwest Airlines Corporation, P.O. Box 37611, Love Field, Dallas, Texas 75235-1625).

Bantz, C. R. (1983). Naturalistic research traditions. In I. I. Putnam \& M. E. Pacanowsky (Eds.), Communication and organizations: An interpretive approach (pp. 5566). Beverly Hills, CA: Sage.

Barthes, R. (1964). Elements of seminology. London: Jonathan Cape.

Bartholome, F. (1983). Executives as human beings. In G. C. Collins (Ed.), Executive success: Making it in management (pp. 53-64). New York: Wiley and Sons, Inc.

Barnard, C. (1938). The function of the executive. Cambridge, MA: Harvard University Press.

Bass, B. M. (1985, Winter) . Leadership: Good, better, best. Organizational Dynamics, pp. 26-40.

Bates, R. J. (1984) . Toward a critical practice of educational administration. In T. J. Sergiovanni \& J. E. Corbally (Eds.), Leadership and organizational culture (pp. 260-274). chicago: University of Illinois Press.

Becker, E. (1973). The denial of death. New York: Free Press.

Becker, E. (1975). Escape from evil. New York: Free Press.

Bednar, D. A.., \& Hineline, J. (1982, August). The management of meaning through metaphors. $\overline{\text { Paper }}$ presented at the annual meeting of the Academy of Management. New York, New York.

Bennis, W. (1983). The artform of leadership. In S. Srivastva and Associates (Eds.), The executive mind: New insights on managerial thought and action (pp. 2739). San Francisco, CA: Jossey-Bass.

Bennis, W. (1984). Transformative power and leadership. In T. J. Sergiovanni \& J. E. Corbally (Eds.), Leadership and organizational culture (pp. 64-71). Chicago: University of Chicago Press. 
Bennis, W., \& Nanus, B. (1985). Leaders: The strategies for taking charge. New York: Harper \& Row.

Berg, P. (1985). Organizational change as symbolic transformation process. In P. Frost, L. Moore, M. Louis, C. Lundberg, J. Martin (Eds.), Organizational culture (pp. 281-300). Beverly Hills, CA: Sage Publications.

Berlew, D. (1981) February. Changing the way we think of change. Boston Globe.

Beyer, J. M. (1981). Ideologies, values and decision making in organizations. In P. C. Nystrom \& W. H. Starbuck (Eds.), Handbook of organizational design (vol. 2, pp. 166-202). London: Oxford University Press.

Blumer, H. (1969). Symbolic interactionism: Perspective and method. Englewood Cliffs, NJ: Prentice-Hall.

Bolman, L. G., \& Deal, T. (1984). Modern approaches to understanding and managing organizations. San Francisco, CA: Jossey-Bass.

Borg, W. R., \& Gall, M. (1983) . Educational research: An introduction. New York: Longman.

Bormann, E. G. (1983). Symbolic convergence: Organizational communication and culture. In $I$. $I$. Putnam \& M. E. Pacanowsky (Eds.), Communication and organizations: An interpretive approach (pp. 99-122). Beverly Hills, CA: Sage.

Brown, M. H., McMillan, J. J., \& Blackman, B. (1981). Investigation into the implications of organizational myth-making in a nursing care facility. Paper presented at the SCA/ICA Conference on Interpretive Approaches to the study of organizational Communications, Alta, Utah.

Brown, M. H. (1984, November). Metaphors, stories, and myths: An examination of narrative forms in organizations. Paper presented at the 70 th annual meeting of the speech Comunication Association, Chicago, Illinois.

Brown, R. H. (1976). Social theory as metaphor: on the logic of discovery for the science of conduct. Theory and Society, $\underline{3}(2), 169-197$. 
Brown, R. H. (1978). Bureaucracy as praxis: Toward a political phenomenology of formal organizations. Administrative Science Quarterly, 3, 365-382.

Buber, M. (1970). I and thou, (W. Kaufmann, trans.). New York: Charles Scribner's Sons. (Original work published in 1937).

Buckley, K. W., \& Perkins, D. (1984). Managing the complexity of organizational transformation. In J. D. Adams (Ed.), Transforming work (pp. 56-67). Alexanaria, VA: Miles River Press.

Burke, K. (1969). A rhetoric of motives. Berkeley: University of California Press.

Burke, K. (1972). Dramatism and development. Barre, MA: Clark University Press.

Burns, J. M. (1978). Leadership. New York: Harper \& Row.

Burns, J. M. (1984). The power to lead: The crisis of the American presidency. New York: Simon and Schuster.

Campolo, A. (1983). A reasonable faith: Responding to secularisin. Waco, TX: World, Inc.

Carbaugh, D. (1985). Cultural communication and organizing in W. B. Gudykunst, L. P. Stewart \& S. Ting-Toomey (Eds.), Communication, culture, and organizational processes (pp. 30-47). Beverly Hills: Sage.

Clark, B. (1970). The distinctive college: Antioch, Reed, and Swarthmore. Chicago: Aldine.

Cohen, A. (1976). Two-dimensional man. Berkeley: University of California Press.

Cohen, M. D., \& March, J. G. (1974). Leadership in ambiguity. New York: McGraw-Hill.

Collier, A. T. (1983). Business leadership and creative society. In G. C. Collins (Ed.), Executive success: Making it in management (pp. 169-185). New York: Wiley.

Collins, E. G. C. (Ed.). (1983). Executive success: Making it in management. New York: Wiley. 
Conrad, c. (1981). Toward a symbology of organizational power. Paper presented at the SCA/ICA Conference on Interpretive Approaches to the Study of Organizational Communicaion, Alta, UT.

Conrad, C. (1983). Organizational power: Faces and symbolic forms. In I. I. Putnam \& M. E. Pacanowsky (Eds.), Communication and organizations: An interpretive approach (pp. 173-194). Beverly Hills, CA: Sage.

Dandridge, T. C., Mitroff, I., \& Joyce, W. F. (1980). Organizational symbolism: A topic to expand organizational analysis. Academy of Management Review $\underline{5}, 77-82$.

Davis. S. M. (1984). Managirg corporate culture. Cambridge, MA: Ballinger.

Deal, T. E., \& Kennedy, A. A. (1982). Corporate cultures: The rite and rituals of corporate life. Reading, MA: Addison-Wesley.

deBivort, L. H. (1984). Fast-talking the transformation of organizations. In J. D. Adams (Ed.), Transforming work (pp. 244-252). Alexandria, VA: Miles River Press.

Deetz, S. A., \& Kersten, A. (1983). Critical models of interpretive research. In L. I. Putnam \& M. E. Pacanowsky (Eds.), Communication and organizations: An interpretive approach (pp. 147-171). Beverly Hills, CA: Sage.

Deetz, S. A., \& Mumby, D. (1984). Metaphors, information and power. Information and Power, 1 , 369-386.

Dewine, S., \& wagner, R. (1981). An alternative way of understanding organizational communication: The study of myths. Proceedings of the SCA/ICA Conference on Interpretive Approaches to the Study of organizational Communication, Alta, UT.

Donaldson, G., \& Lorsch, J. W. (1983). Decision makaing at the top: The shaping of strategic directions. New York: Basic Books.

Drucker, P. F. (1971). Men, ideas, and politics. New York: Harper and Row.

Duncan, H. (1953). Language and literature in society. Chicago: University of Chicago Press. 
Durkheim, E. (1915). The elementary forms of the religious life. (J. W. Swain, Translator). London: Allen \& Unwin.

Dyer, W. G. (1983). Organizational evolution. Unpublished manuscript, sloan School of Management, Massachusetts Institute of Technology, Cambridge, MA.

Edelman, M. (1967). The symbolic uses of politics. Urbana, IL: University of Illinois Press.

Edinger, L. J. (1975, January). The comparative analysis of political leadership. Comparative Politics 17 .

Eisenberg, E. M. (1984). Ambiguity as strategy in organizational communication. Communication Monographs, 51, 227-242.

Eoyang, C. K. (1983). Symbolic transformation of belief systems. In L. R. Pondy, P. J. Frost, G. Morgan, \& T. Dandridge (Eds.), Organizational symbols (pp. 109121). Greenwich, CT: JAI Press.

Erikson, E. H. (1963). Childhood and society. New York: Norton.

Farrar, E., DeSantis, J., \& Cohen, D. (1983). The lawn party: The evolution of federal programs in local settings. In J.V. Baldridge \& T. Deal (Eds.), The dynamics of organizational change in education. Berkeley, CA: McCutchan.

Eaules, D. (1982). The use of multi-methods in the organizational setting. Western Journal of Speech Communication, 46, 150-161.

Follett, M. P. (1941). Dynamic administration. New York: Harper \& Row.

Foster, W. P. (1985, November). Organizational culture and the process of schooling. Paper presented at the California Principals' Conference, Anaheim, CA.

Frost, J., Moore, I. F., Louis, M. R., Lundberg, C. C., \& Martin, J. (1985). Organizational culture. Beverly Hills, CA: Sage.

Gardner, J. W. (1965). The antileadership vaccine. Annual Report of the Carnegie Corporation. New York: Carnegie Corporation. 
Garfield, C. (1986). Peak performers: The new heros of American Business. New York: William Morrow.

Geertz, C. (1973). The interpretation of cultures. New York: Basic Books.

Georges, R. A. (1969). Toward an understanding of storytelling events. Journal of American Folklore, 82, 313-328.

Gilligan, C. (1982). In a different voice: Psychological theory and women's development. Cambridge: Harvard University Press.

Ginzberg, E., \& Reilley, E. W. (1957). Effecting change in large organizations. New York: Columbia University Press.

Goffman, E. (1959). The presentation of self in everyday life. New York: Anchor Doubleday.

Greenfield, T. B. (1984). Leaders and schools: Willfulness and nonnatural order in organizations. In T. J. Sergiovanni \& J. E. Corbally (Eds.), Leadership and organizational culture (pp. 142-169). Chicago: University of Illinois Press.

Harrison, R. (1984). Leadership and strategy for a new age. In J. D. Adams (Ed.), Transforming work (pp. 97112). Alexandria, VA: Miles River Press.

Henderson, B. D. (1979) Henderson on corporate strategy. New York: Mentor.

Hersey, P., \& Blanchard, K. H. (1977). Management of organizational behavior. Englewood Cliffs, NJ: Prentice-Hall.

Hickman, C. R., \& Silva, M. A. (1984). Creating excellence: Managing a corporate culture, strategy, and change in the new age. New York: NAI Books.

Hofstadter, D. R. (1979). Godel, Escher, Bach: An eternal golden braid. New York: Basic Books.

Husserl, E. (1964). The idea of phenomenology. Netherlands: The Hague.

James, W. (1958). Varieties of religious experience: A study in human nature. New York: Mentor Edition. 
Jung, C. G. (1964). Man and his symbols. London: Aldus Books.

Kanter, R. 'M. (1983). The change masters. New York: Simon and Schuster.

Kanter, R. M. (1983). Power failure in management circuits. In Eliza G. C. Collins (Ed.), Executive success: Making it in management (pp. 249-266). New York: Wiley.

Kelleher, H. D. (1985). Deregulation and the troglodytes how the airlines met Adam Smith. Journal of Law and Commerce. 50, 299-318.

Kellerman, B. (1984). Leadership as a political act. In B. Kellerman (Ed), Leadership: Multidisciplinary perspectives (pp. 63-89). Englewood Cliffs, New Jersey: Prentice-Hall.

Kiefer, C. F., \& Senge, P. M. (1984). Metanoic organizations in J. D. Adams (Ed.), Transforming work (pp. 69-84). Alexandria, VA: Miles River Press.

Kiefer, C. F., \& Stroh (1984). A new paradigm for developing organizations in J. D. Adams (Ed.), Transforming work (pp. 171-184). Alexandria, VA: Miles River Press.

Koch, S., \& Deetz, S. (1981). Metaphor analysis of social reality in organizations. Journal of Applied Communication Research, $9,1-15$.

Kohlberg, L., \& Kramer, R. (1969). Continuities and discontinuities in childhood and moral development. Human Development, 12, 94 .

Kotter, J. P. (1983). Power, dependence, and effective management. In G. C. Collins (Ed.), Executive success: Making it in management (p. 306-323). New York: Wiley

Kotter, J. P., \& Lawrence, P. R. (1974). Mayors in action. New York: Wiley.

Krefting, I. A., \& Frost, P. J. (1985). Untangling webs, surfing waves, and wildcatting: A multiple-metaphor perspective on managing organizational culture. In P. J. Frost, L. F. Moore, M. R. Louis, C. C. Lundberg \& J. Martin (Eds.), Organizational Culture (pp. 155168). Beverly Hills: Sage. 
Kuhn, T. S. (1970). The structure of scientific revolutions, 2nd Edition. Chicago: University of Chicago Press.

Iakoff, G., \& Johnson, M. (1980) . Metaphors we live by. Chicago: University of Chicago Press.

Langer, S. K. (1957). Philosophy in a new key. Cambridge: Harvard University Press.

Levinson, D. (1978). The seasons of a man's life. New York: Alfred A. Knopf.

Levinson, H. (1981). Executive. Cambridge, MA: Harvard University Press.

Levinson, H., \& Rosenthal, S. (1984). CEO: Corporate leadership in action. New York: Basic Books.

Inindblom, C. E. (1968). The policy-making process. Englewood Cliffs, NJ: Prentice-Hall.

Long, N. E. (1963). The political act as an act of will. Sociology, 69, 126-138.

Lortie, D. (1975) . School teacher: A sociological study. Chicago: University of Chicago Press.

Maccoby, M. (1981). The leader: A new face for American management. New York: Simon \& Schuster.

Manning, F. V. (1981). Managerial dilemmas and executive growth. Reston, $\mathrm{vA}$ : Reston Publishing Co.

March, J. G. (1984). How we talk and how we act: Administrative theory and administrative life. In T. J. Sergiovanni \& J. E. Corbally (Eds.) Leadership and organizational culture (pp. 18-35). Chicago: University of Illinois Press.

Martin, J. (1982). Stories and scripts in organizational settings. In $\mathrm{H}$. Hastorf \& A. Isen (Eds.), Cognitive social psychology (pp. 255-256). New York: Elsevier North Holland, Inc.

Maslow, A. (1965). Eupsychian management. Homewood, IL: Dorsey Press.

Mcclelland, D. C. (1975). Power: The inner experience. New York: Irvington Publishers. 
McClelland, D. C., \& Burnham, D. H. (1983). Power is the great mocivator. In G. C. Collins (Ed.). Executive success: Making it in management (pp. 289-305). New York: Wiley.

McCoy, C. S. (1985) Management of values: The ethical difference in corporate policy and performance. Boston: Pitman.

McKnight, R. (1984). Spirituality in the workplace. In J. D. Adams (Ed.), Transforming work (pp. 139-153). Alexandria, VA: Miles River Press.

Mead, M. (1959). Apprenticehip under Boas. In W. Goldschmidt (Ed.), The anthropology of Frans Boas, memoir 89 (pp. 29-45). Washington, DC: American Anthropological Association.

Meltzer, B. M., Petras, J., \& Reynolds, L. (1975). Symbolic interactionism: Genesis, varieties, and criticism. London: Routledge \& Kegan Paul.

Meyer, J. W. (1984). Organizations as ideological systems. In T. J. Sergiovanni \& J. E. Corbally (Eds.)

Leadership and organizational culture (pp. 186-206). Chicago: University of Illinois Press.

viller, L. M. (1984). American spirit: Visions of a new corporate culture. New York: Morrow.

Mintzberg, H. (1983). An emerging strategby of "direct" research. In J. Van Maanan (Ed.), Qualitative methodology (pp. 105-116). Beverly Hills, CA: Sage.

Mitroff, I. I., \& Kilmann, R. (1975). The stories managers tell: A new tool for organizational problem solving. Management Review 64, 18-28.

Morgan, G. (1986). Images of organization. Beverly Hills, CA: Sage.

Morgan, G., Frost, P. J., \& Pondy, L. R. (Eds.). (1983). Organizational symbolism. Greenwich, CT: JAI Press.

Naisbitt, J. (1982). Megatrends: Ten new directions transforming our lives. New York: Warner Books.

Naisbitt, J., \& Aburdene, P. (1985). Reinventing the corporation. New York: Warner Books. 
Nelson, I., \& Burns, F. I. (1984). High performance programming: A framework for transforming organizations. In J. D. Adams (Ed.), Transforming work (pp. 226-242). Alexandria, VA: Miles River Press.

Ohmann, O. A. (1975). Retrospective commentary. In Harvard Business Review on management. (pp. 698-713). New York: Harper \& Row.

Ohmann, O. A. (1983). Skyhooks: With special implications for Monday through Friday. G. C. Collins (Ed.), Executive success: Making it in management (pp. 186201). New York: Wiley.

Ortony, A. (1979). Metaphor and thought. Cambridge: Cambridge University Press.

O'Toole, J. (1981). Making America work: Productivity and responsibility. New York: Continuum.

Owen, H. (1984). Facilitating organizational transformation: The uses of myth and ritual. In $J$. D. Adams (Ed.), Transforming work (pp. 209-224). Alexandria, VA: Miles River Press.

Pacanowsky, M. E. (1983). A small town cop: Communication in, out, and about a crisis. In I. L. Putnam \& M. E. Pacanowsky (Eds.), Communication and organizations: An interpretive approach (pp. 261-282). Beverly Hills, CA: Sage.

Pacanowsky, M. E., \& O'Donnell-Trujillo, N. (1982). Communication and organizational cultures. Western Jounal of Speech Communication, 46, 115-131.

Pacanowsky, M. E., \& O'Donnell-Trujillo, N. (1983). Organizational communication as cultural performance. Speech Monographs, 50, 126-147.

Paige, G. D. (1977). The scientific study of political leadership. New York: The Free Press.

Pelto, P. J. (1970). Anthropological research, the structure of inguiry. New York: Harper \& Row.

Perrow, C. (1979). Complex organizations: A critical essay. Glenview, IL: Scott, Foresman \& Co.

Peters, T. J. (1978, Autumn). Symbols, patterns, and settings. Organizational Dynamics, (pp. 3-23). 
Peters, T. J. (1983). Leadership: Sad facts and silver linings. In G. C. Collins (Ed.), Executive success: Making it in management (pp. 202-213). New York: Wiley.

Peters, T. J., \& Austin, N. (1985). A passion for excellence: The leadership difference. New York: Random House.

Peters, T. J., \& Waterman, R. H. (1982). In search of excellence. New York: Harper \& Row.

Pettigrew, A. M. (1979). On studying organizational cultures. Administrative Science quarterly, 24, 570581.

Pondy, R. I. (1983). The role of metaphors and myths in organization and in the facilitation of change. In I. R. Pondy, P. Frost, G. Morgan \& T. Dandridge (Eds), Organizational Symbolism (pp. 157-166). Greenwich, CT: JAI Press.

Pondy, L. R. (1978) . Leadership is a language game. In M. W. McCall \& M. M. Lombardo (Eds), Leadership: Where else can we go (pp. 147-159). Durham, NC: Duke University Press.

Prentice, W. C. H. (1983). Understanding leadership. In G. C C. Collins (Ed.), Executive success: Making it in management (pp. 140-150). New York: Wiley.

Putnam, I. (1982). Paradigms for organizational communication research: An overview and synthesis. Western Journal of Speech Communication, 46, 192-206.

Redding, W. C. (1979). Organizational communication theory and ideology: An overview. In D. Ninmo (Ed.), Communication yearbook 3 (pp. 309-341). New Brunswick, NJ: Transaction.

Reischel, D. (1985, April 7). Herb Kelleher. The Dallas Morning News, p. 1 .

Rodkin, D. (1985, September). Southwest Airlines lands at ont. Inland Business, pp. 11-14.

Rost, J. C. (1982). The politics of leadership. Paper presented at the Annual Meeting of the American Education Research Association, New York, NY. 
Rost, J. C. (1984). Generative leadership. Unpublished manuscript, Graduate School of Education, University of San Diego, San Diego, CA.

Rost, J. C. (1985, November). Shaping the school culture for educational excellence: The nature of transforming leadership. Paper presented at the California Principals' Conference, Anaheim, CA.

Ruch, R. S., \& Goodman, R. (1983). Image at the top: Crisis and renaissance in corporate leadership. New York: Free Press.

Sandy, P. R. (1983). The ethnographic paradigms. In J. Van Maanan (Ed.), Qualitative methodology (pp. 19-36). Beverly Hills, CA: Sage.

Schein, E. H. (1983, summer). The role of the founder in creating organizational culture. Organizational Dynamics, pp. 13-28.

Schein, E. H. (1985). Organizational culture and leadership. San Francisco, CA: Jossey-Bass.

Schorer, M. (1960). The necessity of myth. In H. Murray (Ed.), Myth and mythmaking. New York: George Braziller.

Selznick, P. (1957). Leadership in administration: A sociological interpretation. New York: Harper \& Row.

Serber, D. (1975). Rethinking symbolism. Cambridge: Cambridge University Press.

Sergiovanni, T. J. (1984). Leadership as cultural expression. In T. J. Sergiovanni \& J. E. Corbaliy (Eds.), Ieadership and organizational culture (pp. 105-114). Chicago: University of Chicago Press.

Sergiovanni, T. J. (1984). Cultural and competing perspectives in administrative theory and practice. In T. J. Sergiovanni \& J. E. Corbally (Eds.)... Ieadership and organizational culture (pp. 1-11). Chicago: University of Chicago Press.

Sheey, G. (1981). Pathfinders. New York: Bantam Books.

Simpson, E. L. (1971). Democracy's stepchildren. San Francisco, CA: Jossey-Bass.

Siv, R. G. H. (1980) - The master manager- Chichester, U.R.: Wiley 
Smircich, I. (1981). The concept of culture and organizational analysis. Paper presented at the SCA/ICA Conference of Interpretive Approaches to Organizational Communication: Alta, UT.

Smircich, I., \& Morgan, G. (1982). Leadership: The management of meaning. Journal of Applied Behavior Science 18, 257-273.

Smircich, I. (1983a). Concepts of culture and organizational analysis. Administrative Science Quarterly, 29, 339-358.

Smircich, I. (1983b). Organizations as shared meanings. In I. R. Pondy, P. J. Frost, G. Morgan \& T. Dandridge (Eds.), Organizational symbolism (pp. 55-65). Greenwich, CT: JAI Press.

Smircich, I. (1985). Is the concept of culture a paradigm for understanding organizations or ourselves? In P. J. Frost, L. F. Moore, M. R. Louis, C. C. Lundberg, \& J. Martin (Eds.), Organizational Culture (pp. 55-72). Beverly Hills, CA: Saga.

Smith, K. K. (1982). Philosophical problems in thinking about organizational change. In P. S. Grossman (Ed.), Change in organizations. San Francisco, CA: JosseyBass Publishers.

Smith, K. K., \& Simmons, V. M. (1983). A Rumpelstiltskin organization: Metaphors on metaphors in field research. Administrative Science Quarterly, 28, 377392 .

Smith, R. C. (1985). Mixing metaphors: The changing organizational philosophy of Disneyland. A paper presented at the 56 th annual meeting of the western Speech Communication Association, Fresno, CA.

Smith, R. C., \& Eisenberg, E. M. (1985, November). Conflict and the co-optation of root-metaphors at Disneyland. Paper presented at the annual meeting of the Speech Communication Association, Denver, Colorado.

Stogaill, R. M. (1974). Handbook of leadership: A survey of theory and research. New York: Free Press. 
Tesch, R. (1984, April). Phenomenological studies: A critical analysis of their nature and procedures. Paper presented at the annual meeting of the American Educational Research Association, New Orleans, LA.

Tichy, N. M., \& Devanna, M. (1986). The transformational leader. New York: Wiley.

Toffler, A. (1985). The adaptive corporation. New York: McGraw-Hill.

Tompkins, P. K., \& Cheney, G. (1983). Account analysis of organizations: Decision making and identification. In L. I. Putnam \& M. E. Pacanowsky (Eds.), Communication and organizations: An interpretive approach (pp. 99-122). Beverly Hills, CA: Sage.

Tompkins, P. K., \& Cheney, G. (1985). Communication and unobtrusive control in contemporary organizations. In R. D. McPhee \& P. K. Tompkins (Eds.), organizational communication: Traditional themes and new directions. (pp. 179-210). Beverly Hills, CA: Sage.

Trice, H. M. (1984). Rites and ceremonials in organizational culture. In S. B. Bacharach \& S. M. Mitchell (Eds.), Perspectives on organizational sociology: Theory and research (Vol 4). Greenwich, CT: JAI Press.

Trice, H. M., \& Beyer, J. M. (1984). Employee assistance programs: Blending performance-oriented and humanitarian ideologies to assist emotionally disturbed employees. In Research in community and mental health, Vol. 4. Greenwich, CT: JAI Press.

Trujillo, N. (1983). "Performing" Mintzberg's roles: The nature of managerial communication. In L. L. Putnam \& M. E. Pacanowsky (Eds.), Communication and organizations: An interpretive approach (pp. 73-97). Beverly Hills, CA: Sage.

Turner, v. (1980). Social dramas and stories about them. Critical Inquiry, 1,160 .

Vaill, P. B. (1984). The purposing of high-performing systems. In T. J. Sergiovanni \& J. E. Corbally (Eds.), Leadership and organizational culture (pp. 85105). Chicago: University of Illinois Press.

Vaillant, G. E. (1977). Adaptation to life. Boston: Little, Brown. 
Van Maanan, J. (1983). The facts of fiction in organizational ethnography. In J. Van Maanan (Ed.), Qualitative methodology (pp. 37-55). Beverly Hills, CA: Sage.

Wagner, H. R. (1983). Phenomenology of consciousness and sociology of the life-world. Alberta: University of Alberta Press.

Weick, K. E. (1979). The social psycholoogy of organizing, 2nd edition. Reading, MA: Addison-Wesley.

Weick, K. E. (1976). Educational organizations as loosely coupled systems. Administrative Science Quarterly, 21, $1-19$.

Wilkins, A. L. (1983). Orga Lzational stories as symbols which control the organization. In I. R. Pondy, P. J. Frost, G. Morgan, \& T. C. Dandridge (Eds.), Organizational Symbolism (pp. 81-92). Greenwich, Connecticut: JAI Press, Inc.

Wilkins, A. I. (1978). Organizational stories as an expression of management philosophy: Implications for social control in organizations. Unpublished doctoral dissertation, Stanford University.

WiIson, S. (1983). The use of ethnographic techniques in educational research. Perspectives on Case Study: Ethnography, $\underline{5}, 23-56$. Victoria, Australia: Deakin University Press.

Wolcott, H. (1983). Criteria for an ethnographic approach to research in schools. Perspectives on Case study: Ethnography, 5, 23-56. victoria, Australia: Jeakin University Press.

Wolf, W. B. (1974). The basic Barnard: An introduction to Chester I. Barnard and his theories of organization and management. New York, NY: state school of Industrial and Labor Relations, Cornell University.

Zaleznik, A. (1983). Managers and leaders: Are they different? In G. C. Collins (Ed.), Executive success: Making it in management (pp. 123-139). New York: Wiley. 
APPENDIX A. LETTERS FROM SOUTHWEST CUSTOMERS

July 15,1986

Nir. Herb Kelleher

President

Southwest Airlines

P.O. Box 37611

Dallas, Texas 75235

Dear Mr. Kelleher:

I would like to commend Alex Thrailkill of the Baggage Department in San Antonio for coming to my rescue during my recent trip.

I had inadvertently left my ticket on the counter in Dallas and, since my plane was about to take off. I was unaible to return to pick it up. The ticket was put on the next flight bound for San Antonio where Ms. Thrailkill personally met the plane, picked up the ticket and made sure it got to me.

I very much appreciate Mr. Thrailkill's personal involvement. She is a credit to Southwest Airlines.

sincerelv,

Larry Sinclair

President

IS : mo

cc: Alex Thrailkill 
Albuquerque

\section{Westerice suts contentr}

If Paso

A DIASSION OF SALES FORCE COMPANIES. INE.

the facilitatars*

July 17,1986

Mg. Colleen Bartert

Executive Assistant to the President

Southwest Alrlines co

PO Box 37611

Love Field

Dallas, IX 75235

Dear colleen,

On Friday, July 18, I was unfortunate enough to be Involved rith your Flight 682 from Kansas City to Albuquerque with a comection to 21 Paso on Flight 969 .

Once again, the friendly folks of Southrest came thru. When it became apparent that we probably would not mice our consection in Albuquerque, your gate attendant, Kimberaly (Employee 4836), not oaly advised us of the sicuntion but checked other alrlines for possible flighes. The thing kimberely did that was really impressive to we was to check 1nto room rates in Albuquerque and to fatroduce two young women who had both fadicated they had very little woney to each other in order that they could share the cost if need be.

As you are aware, the ground crew and dispatch came thru and arranged for Untted to hold thei: Elight. Therefore, Kumberely's help was not needed, but the "Spirtt of Southrest" was greatly appreciated.

Stncerely,

DOYCE WIIEITE

Vice President 


\section{AAR COTP}

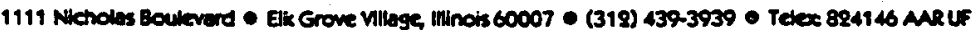

$$
\text { September 4, } 1986
$$

Ms. Colleen Barrett

Vice President of Adainistration

Southwest Airlines. Executive offices

P.0. Box 37611

Dalias, TX 75235

Dear Ms. Barrett:

I had the opportunity this past Labor Day weekend to fly with Southwest Afrlines frcm chicago to Houston (round trip). I had heard good things about your airline but, to be honest, I did not know what to expect. This letter is to let you know that I was both pleased and tupressed.

From the manent we began boarding on wy flight to Houston, I noticed sowething different about your airline - the boarding systea! At last, a fair systen that rewards on-time passengers with first choice in seating but wich still protects those with reservations. That's a nice touch that reflects a real interest in the passenger. Once on board, I noticed the other things that make Southwest a littie unfque. On wy fight (\$453S). they included salles. less formal attire for flight attendents, complimentary drinks and nice treatment.

It is not for this that I an writing this letter. The real reason for this letter is Tamara kirkpatrick, one of the fight attendents on by return flight (\$418) from Houston on Labor Day. She ts truly a spectal employee and an ambassador for custcmer relations. She was both professional and friendly and truly seemed to enjoy what she was doing. She made fiying fun for me and for the other passengers as well. I will let her explain some of the things she does to brtghten trips for her passengers, but in my opinion, she makes a perfect flight attendent.

I'm not in the habit of writing nice letters when I get good service; this is an exception. It calis attention to a fine empioyee and to an enjoyable trip made possible by fine flight crews.

Yours truly,

Philip W. Stern

Director of Human Resources

PWS:wsb 


\title{
Rifley, Srec.

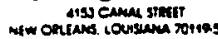 \\ vinom
}

August 4, 1986

\author{
3r. Herb Kelleher \\ President \\ Southwest Alrlines \\ P.O.box 37611 \\ Love Field \\ Dallas, Texas 75235 \\ Dear Mr. Kelleher,
}

On Sunday, July $27 \mathrm{th}$, I boarded your 1:00PM 1light leaving New Orleans wth a Iinal destination of Dallas, Texas. A change of planes in Houston, Texas was scheduled.

During the change, I left ay racquetball bag and equipaent plus my wallet containing approximately $\$ 2500.00$ in cash at Gate $\$ 10$. I did not notice the bag was missing until my arrival in Dallas, Texas.

I was referred to your baggage claim department and met with Mr. B1II White lmmediately. Before I could even get the entire story conveyed to Mr. White, he informed me the bag had been found by an agent and would be placed on the next flight to Dallas. The bag arrived with all the contents about 4:00PM.

IMPRESSED!!!!!!You can bet your 11fe on $1 t$. I only wish our customer service employees would extend continous interest and helpful-efflcient service to all our custowers as was granted to me by your employees.

Today, I am sending a copy of this letter to all of our salesmen and well over 150 dealers handling our products asking then if at all possible to travel with Southwest when their schedule w111 permit and particularly when they can choose Southwest over another available airline.

I also want to mention the service employees on the plane. Just before arriving in Dallas and noticing the bag was missing, I informed the stewardess about the missing bag. She went out of her way to begin a chain of command.... to the captain as well as your gate director.

Permlt me to verbally Tip Ny hat.....to........ SOUTHWEST AIRLINES.

CJM:jk 


\section{APPENDIX B. HERB KELLEHER'S SENIOR MANAGEMENT TEAM}

\section{MEET OUR VICE PRESIDENTS}

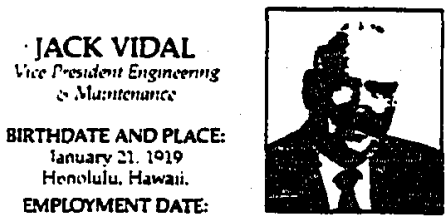
MPLOYMENT DATE

$$
\text { lane is } 10 \% \text {. }
$$

TRAITS I LOOK FOR IN AN EMPLOTEE: Honessy: willing to pertion on therr own rood ourluok on lite: hapoy.

MOST VALUABLE LESSON EVER LEARNED: Treat people the way you wivild like them to ireas you.

THE PERSON I MOST RESPECT (MY HERO): lohn Kennedy and Sick Bez. President ut liest Coust Auttines.

FAVORITE PASTIME: Coll. reading. and listening to good quiet music FAVORITE FOOD: Orieneal - Chinese. Iapunese. Talwas. FAVORTE MOTTO QUOTE: Tou only go around once, make the best of

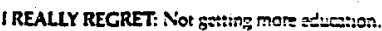

LEAST FAVORTE JOB I HAD: One year at Braniff in 10;0.

FAVORITE SONC: You and Mie Ayanst the World.

THE PERSON WHO MOST INFLUENCED MY LFE: My mother and $\mathrm{my}$ wite.

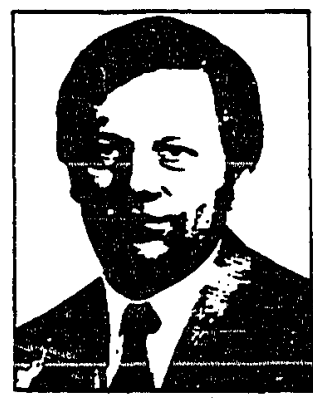

\section{JM BRUNJES}

Vice President - Systoms

BIRTHDATE AND PLACE.

December 31. 1046 Waco. Texas.

TRATS I LOOK FOR IN AN

EMPLOVE: Prospective employees confidence in his/ her ability to

THE LAST BOOK I READ: Wings of Eagles:

MY MOTHERS BEST ADVICE WAS TO: Solve the problem at the time it "reurred. My mother did not wast for my dad to come home to handle" the stustion.

FAVORITE FOOD: Chicken fned steak.

I REALLY RECRET: Not knowing my grandparents better

FAVORTE PASTTME: ANy :Ime with my daughivet.

LEAST FAVORIE JOB I HAO: A parking lot attendant at Astroworld.

THE PERSON I MOST RESPECT IMY HEROI: My grandfather-

FAvORITE MOVIE: Casablana.

THE PERSON WHO MOST INFLUENCED MIY UFE: MY stepmothet.

FAVORITE SONC: The Aggie War Hymn."

MY BEST ASSET: My ability to be a good listener.

MY WORST HABTT: Cuzaling too much coffee.

FAVORITE MOTTO QUOTE: "Cream always nses to the top." If guess.

unless it s homogenuzed milk!)

IF I HAD TO CHOOSE ANOTHER PROFESSION, ID BE: AN Engineer.

FAVORITE VACATION SPOT: SAn Antonio.

THE CITY I WOLID LIKE TO VISTT NEXT: San Francisco.

MOST VALUABLE LESSON EVER LEARNED: Haxd work and loyalty are Jlways rewarded (although not always ismediately).

FAVORIE ALL-TIME TELEVISION SHOW: "Rockeord Files"

DESCRIBE SOUTHWEST AIRLINES IN TEN WORDS OR LESS: PRde cint and enthisiasm. $\$$

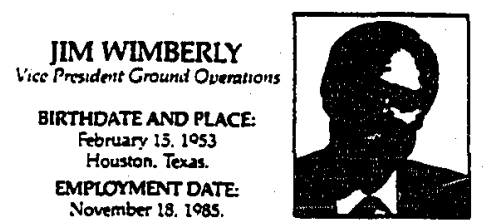

TRAITS I LOOK FOR IN AN EMPLOKE: Honesy. dediation. a sense of thumo: loyalty. and smiles.

MOST VALABLE LESSON EVER LEARNED: That there are ulways two sicies to every story.

THE PERSON I MOST RESPECT (MY HERO): Archie Damon.

FAVORITE PASTTME: There are two. One is unmentionable and the other is making mussic with frimds.

FAVORITE FOOO; Barbecue thomemadel hamburgers and raw unoons.

EAVORITE MOTTO QUOTE: 'Be what you are."

I REALIY RECRET: Nothing.

LEAST FAVORITE JOB I HAD: Hauling and stacking hay bales in the couniry outside of Houston in August.

FAVORITE SONG: Amazing Cnce:"

THE PERSON WHO MOST INFUENCED MY LIFE: UAargle Wimberly. my wite.

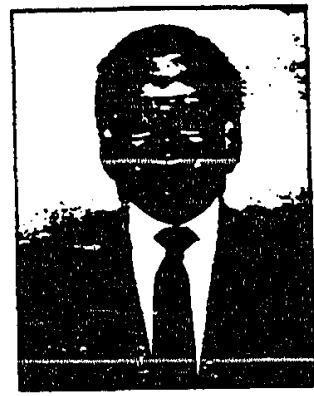
Vice President - Finence
JOHIN G. DENISON

BIRTHDATE AND PLACE: INULA. :5. luis - Highland Tark, Hickiga Not quite line the Teras versions. WIFES NAME: Kathy. CYILDREN AND THEIR AGES Stacy . 15: lusten - :2. Kan . O TRAITS I LOOK FOR IN AN EMPLOY EE: integnty inietlest. approprate experience. abialy to work with others. and the desire to piense.

MOST VALUABLE LESSON EVER LEARNED: Life is a lot more pleasant with some money in vour pocket. THE LAST BOOK I READ: "Poland" MY MOTHERS BEST ADVICE WAS TO: Treat all the garis like your sister.

FAVORTtE FOOD: Sirloin steak with baked potato.

I REALIY RECRET: Treating all the giris like my siant. FAVORTE PASTIME: COIf.

LEAST FAVORTE IOB I HAD: Worked in a foundry doing tume and motion studies on some pretty surly chaneres.

THE PERSON I MOST RESPECT (MY HERO): lohn Wayne.

FAVORITE MOVIE: True Grit. THE PERSON WHO MOST INFUUENCED MY LIFE: My iather. EAVORTTE SONC: "Yestenday" MY BEST ASSET: MY wife. Kathy. MY WORST HABrT: Eating too much late at night. GAVORITE MOTTO,QUOTE: Never started. never finished. IE I HAD TO CHOOSE ANOTHER PROFESSION. ID BE: in a finanCal position to "manage my own atfats"

FAVORTE VACATION SPOT: London. THE CTY I WOULO LIKE TO VISTT NEXT: Washington. D.C. FAVORIT ALLTTME TELEVISION SHOV: "Saturday Night Live". DESCRIBE SOUTHWEST ARRUNES IN TEN WORDS OR LESS: The company with a heart as big as What Texas. 


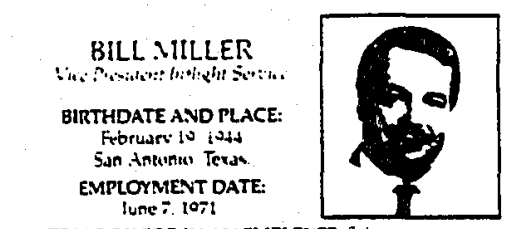

TRAITS I LOOK FOR IN AN EMPLOYEE: Setl-mutitatina Ferwon who is hunest and trakght-tumiard.

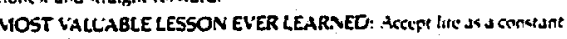
tate ot chanic

THE PERSONS I MOST RESPECT . MY HEROES: Herb Kelleher und RAv Kimman

FALORITE PASTIME: Spendinx : :the with mv chatdren.

FAVORITE FOOD: Wlexican tood.

FAVORITE MOTTO QLOTE: Trust in the Word with sil thine hesre dnd kesn not unto thine imn inderctanding. in all thinks uchnow ledke him and he -hall diret: the pashe

LEAST FAVORITE IOB I HAD: LJWator: Service.

FAVORITE SONG: Memor:S

THE PERSON WHO MOST INFLLENCED MY UIFE: MV IAWVT

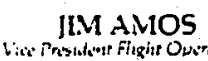

$$
\begin{aligned}
& \text { BIRTHDATE AND PLACE: } \\
& \text { Uctibeet: 1045 } \\
& \text { Sullisin: Okiahoma. } \\
& \text { lune } 1 \text { : } 0 T
\end{aligned}
$$

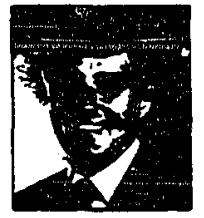

TRAITS I LOOK FOR IN AN EMPLOYEE: Honesty, Sependzbility dedied:inn to the Compans: proressionalism and trustworthiness. MOST VALCABLE LESSON EVER LEARNED: In lite, the erturt everted in MOST VALCABLE LESSON EVER LEARNED: In lite. the eftort THE PERSON IMOST RESPECT IMY HERO: Captain DonaidC Okden.

FAVORITE PASTIME: Aerobatic tlying I compettition!.

FAVORITE FOOD: Rach of tamb with mins ielly

FAVORITE MOTTO QUCTE: He who dies with the musk loys wirns:

I REALLY RECRET: Verv little.

LEAST FAVORITE JOB I HAD: Wiestern Eleetne Company: while I was in :hyght schwol. working in a non-ilyung related perition.

THE PERSON WHO MOST INFUENCED MY LIFE: Captasn Donald C.

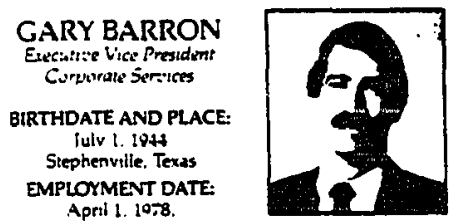

TRAITS I LOOK FOR IN AN EMPLOVEE: Competence. desire is exrel. willungness to decept responsibulity sense of humor.

MOST VALUABLE LESSON EVER LEARNED; That I am not as smart as thousht ! was when ! was sixieen veans old

THE PERSON I MOST RESPECT IMY HEROI: Herb Kelleher.

FAVORTE PASTIME: Colf.

FAVORITE FOOD: Chicken ined steak.

FAVORITE MOTTO QUOTE: "If you an t stand the heat. get out of the kitshen:

I REALLY RECRET: Too many things ro list. none of which 1 can do

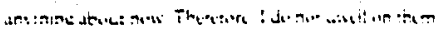

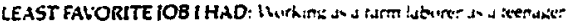
FAVORITE SONG: LA burman if um a prinduet ot the ou, a what can

THE PERSON WHO MOST INFLLENCED MY LIFE: MI isther

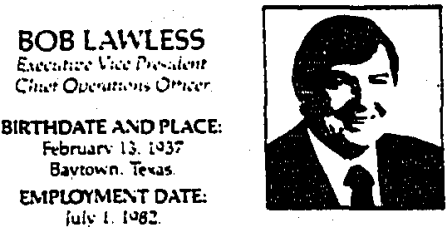

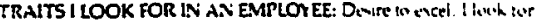

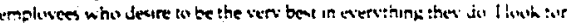

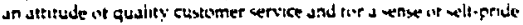
MOST VALUABLE LESSON EVER LEARNED: Ser:se tc te :he test in

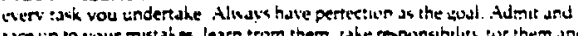
race up to your mistakes lesen trem them. rake mounnsbelias sur them und princtert.

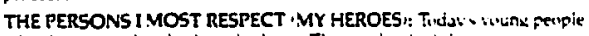

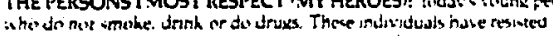
: the do nat tmike. drank or da druxs. These inditidusts hate tes ell-itermination.

EAVORITE PASTIME: Spendink time with the tami

FAVORITE FOOD: LIExICAN

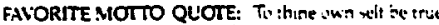

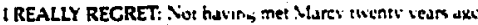

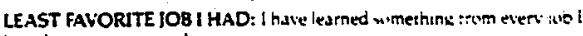
have ineen furtunate to have

EAVORITE SONC: How Great Thus Art.

THE PERSON WHO MOST INFLLENCED MY LIFE: .HV muthe

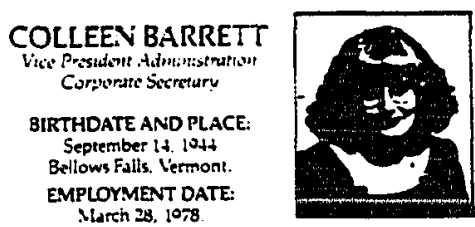

TRAITS I LOOK FOR IN AN EMPLOYEE: Whenever I am hirng. i lowk

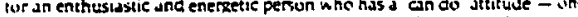
who truly wants to work and one who is dezressive but not pushy. creative, upen to suggestion: alwaws willing co learn articulate both verbally and on papers: other onented is upposed to relf" I ledm plaver. in my opinton it is critical that an empoloyee nut take himseis herset too seriousiy and that he she possesses a good sense ot humor

MOST VALUABLE LESSON EVER LEARNED: To slwavs base TV opIn!c un a person and his her personslity and or work pertormance sha a tixthand knowledge basis and not on a word or mouth reputation. THE PERSON I MOST RESPECT MY HEROI: Roy Spence trom our udverrising agency CSDE.S1.

FAVORITE PASTIME: Listentnx to Willie Nieison with a gooct buttle ot Burgundy.

FAVORITE FOOD: Thick. :are steak.

FAYORITE MOTTO QUOTE: The univ award worth recewing is that received tron those who work at the sume bench.

I REALLY RECRET: That I no longer know dll or the Southwest Arrlines employees on a personal tirst name basts.

LEAST FAVORTE IOB I HAD: Workung tor a Real Estate Lowvet.

FAVORITE SONC: Thy the Impossible

THE PERSON WHO MOST INFUENCED MY LIFE: Hert Keileter 


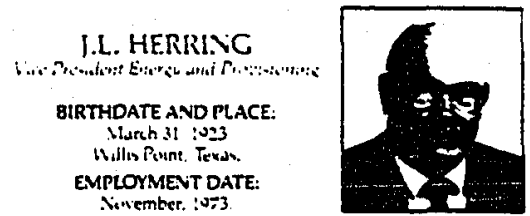

TRAITS I LOOK FOR IN AN EMPLLOYE: Sirit-contidenct and I enwi " humure.

MOST VALLABLE LESSON EVER LEARNED: That Evervine sin cinc in

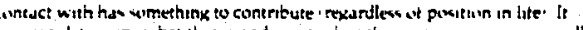

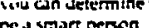

THE PERSON IMOST RESPECT IMY HERO I: Mf yrandtsthe FAYORITE PASTIME: "JuntinR water chilur!

FAVORITE FOOD: Blue Bell ice cresm

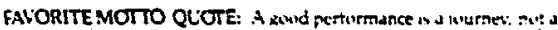
Jeatinatiun

I REALLY RECRET: I didnt buy more SWiA soch : 1073

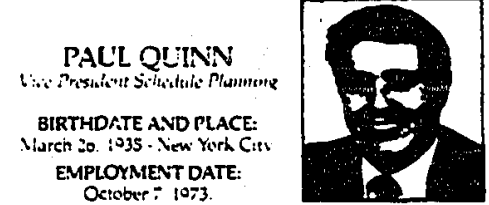

TRAITS I LOOK FOR IN AN EMPLOYEE: Loyaley and dedication to Southisise

MOST VALLABLE LESSON EVER LEARNED: Be nice to them in vour wav up ywu will meet them alt on you wav bach Jown.

THE PERSON I MOST RESPECT IMY HEROI: Chuch Yearer.

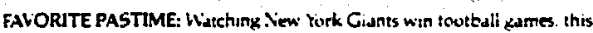
then : happen too citten.

EAVORITE FOOD: Anvthing Italian

EAVORITE MOTTO QLOTE: The kids will do the dishes.

I REALLY RECPET: .iut lesining to plas' a musical instrument.

CEAST FAVORITE JOB I HAD: I liked all of thern.

FAVORITE SONG: Heurtuches

THE PERSON WHO MOST INRLLENCED MY LIFE: MV wite. SUSan

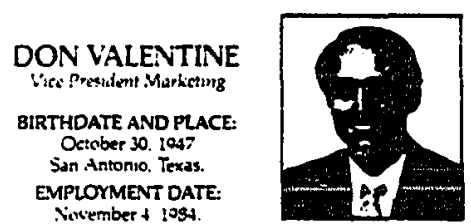

TRAITS I LOOK FOR IN AN EMPLOYEE: TOSItive CAN-DO attitude zeal hiv MOST VALUABLE LESSON EVER LEARNED: Balance in unes life. THE PERSON I MOST RESPECT IMY HERO I: MY parents. FAVORITE PASTMME: Quiet. comantic evenings. I Im a lalentrne - what mure con l ay:"

FAVORITE FOOD: Lo-al Mexion tood.

FAVORITE MOTTO QUOTE: Cant never did anything

I REALLY RECRET: I have no regress itha: I an thunk of!

LEAST FAVORITE JOB I HAD: it summer spent unlouding bux cars bn the xtaveyard shite tor H.E.B. zrocery stors in Sin Antonio.

FAVORITE SONC: Theme trom A Summer Mace:

THE PERSON WHO MOST INFUENCEO MY LIFE: M1: tather.

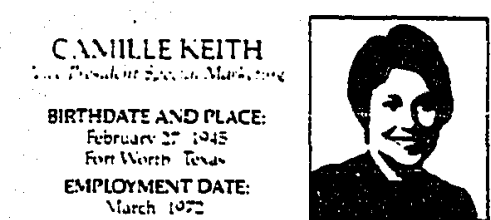

TRAITSILO TIN AN ENPLOTEE:

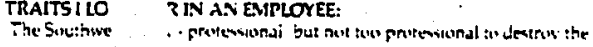
iun imske

MOST VALLAB E LESSON EVER LEARNED: Be Jhuse w what perpte

3. not what the wy thes do.

THE PERSON I MOST RESPECT . MY HERO: Dr EC. RHAMANS I

windertul tescher und issener.

FALORITE PASTIME: Decoralinx und yardeniny

FAVORITE FOOD: Chuculdie pIe.

EAVORITE MOTTO QLOTE: Treat uther as :wu wivh tw be :rested

I REALLY RECRET: That i didne : $r$ the neewnoh :elewsisn :ob

LEAST FAVORITE JOB I HAD: Retal sales while wirhing my was throush

G.)liex:

FALORITE SONC: ImpMnibie Dresm

THE PERSON WHO MOST INFLUENCED MY LIFE: Lif mutter Und mv" in
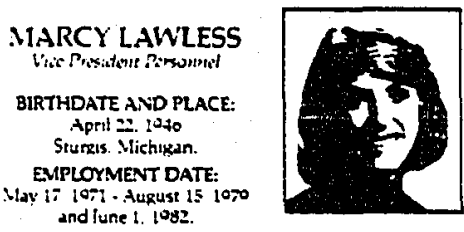

TRAITS I LOOK FOR IN AN EMPLOKEE: SIncerity: enthuslasm rense on humure. and a desire tor sitd dediestion to exceilence

MOST VALLABLE LESSON EVER LEARNED: That with dedication Jevire and a beliet in unesett. a persun on literally do wityriners

THE PERSON I MOST RESPECT IMY HEROI: Bob Ldwless for the exumple ne stes in his personal intexrity. credibility and an uncompromising isumple ne

FAVORITE PASTIME: Mlakinx our house a home - I really enjoy decorating and chanxing things artund and then l enjoy relaving in the surreundings

EAVORITE HOOD: I liwe it ali - it could never be sald that $4 \mathrm{~m}$ a lixht of picky eater: Mevion is probably my tavonte tollowed by french. FAVORITE MOTTO QLOTE: Happiness is not a Jestination - it s a method er eravei.

I REALLY RECRET: Verv tew things in my lite. tive lesmed valuable lessons in even thang I ve ever done. I do wish. however. lid completed my

education beture my arser took utt:

LEAST FAVORITE IOB IHAD: Regional Sales. Manager tor Fox Pho: which involved traveling 3-4 days a week

FAVORITE SONG: Cutrentiy 'Wve Theme trem St. Elmos Fire All Time Rhapsody in Biue

THE PERSON WHO MOST INFLUENCED MY LIFE: Prier to $100 \bar{t} \cdot \mathrm{my}$

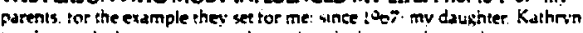

tur the toy she has given me Jnd tor what she has faught me about itlatisnships 


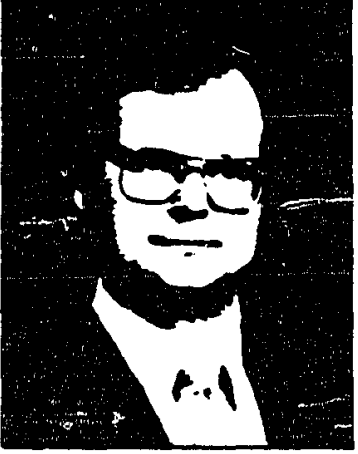

JMM PARKER

vice Presidert - Cemerai Lutunse

WIFES VAME: Patteia

CHILDREV AND THEIR ACES: lamie - II lennuter - 5

TRAITS I LOOK FOR IN AN EMPLOTEE: Ind:viduality cornonn sense

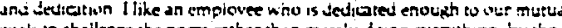
sivis WYY MOTHERS BEST ADVICE: Yus ean attract more lies with honey than

THE PERSON WHO MOST INFLUENCED MY LIFE: MIY PATERtS

MY BEST ASSET: MY tamiY.

MY WORST HABT is: Wautng to the last minute. l usually meet deadines. but only with the help oi very tolerant people around me. EAVORITE PASTIME: I send teward particifatory sports sueh as pluying puner und Watkhing taseball cames

LEAST FAVORTTE IOB I HAD: A summer : 6 b trVIng to interpret computer Frtn'-ult:s describing spare parts. I lound it amazing how many people it tovk to ervice the computer. It might t.ave been a lot simpler iust to ge look un the shell when vod wanced to know how man parts were thete. IF I HAD TO CHOOSE ANOTHER PROFESSTON. ID BE: A wrter etthet a ioumdalist or a novelist. Sumetrmes the :wo are hatd to tell apart. FAVORITE SONG: Tomotrow trom the Broadway musial dinnie. MOST VALLABLLE LESSON IVER LEARNED: TAke your work seTtously. but tar yourselif. When you luse your sense ot humor. you lose your

TREALIY RECRET: Not betng invted to marth in the 1985 Chiago 5 Ratricks Say Parde.

FAVORITE FOOD: Mexian iood.

THE PERSON I MOST RESPECT IMY HEROI: I guess in order to be 2 hero" you have to be dead - probably for a century or so at least. One of mer you have and instghe ro intluenes the wartd round him without eve losing his common sense or serse ot humor.

EAVORTE VACATION SPOT: Maine

THE CITY I WOULD UKE TO VIST NEXT: ANW place in Switzerland. FAVORTE ALL-TIME TELEVISION SHOW: Leave it to Beaver. FAVORITE MOTTO. QLOTE: If I had the ability to reduce global concepts to the fiw words required tor a motto or quote. I would probably be urpelled trom the bar assocustion.

IESCRIBE SOUTHWEST AIRLINES NN TEN WORDS OR LESS: The most danng experiment in tree enterprise of this half -rentury. II know that

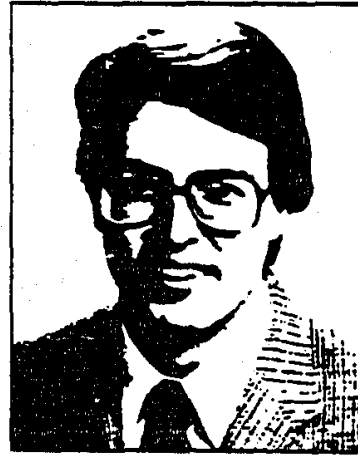

RON RICKS

thee Presidert - Govemmertal Affats

WIFES NAME: Eilsen

CHILDREN AND THEIR ACES: Alan - 3

TRATS I LOK FOR IN AN EMPLOYEE: Enthusiastic self-motiwited Trarmsino

MY MOTHERS BEST ADVICE: Take this 10b: 'SWA 10b,

THE PERSON WHO MOST INFUENCED MY LIFE: My iather who :auscht me thas it is's worth doing. you should go ahead and have iun while you re at it.

MY BEST ASSET: Ability to tind a common ground with other people.

MY WORST HASIT IS: Thinking outloud.

FAVORTE PASTIME: Colk.

LEAST FAVORTE IOB I HAD: Worktng on a rooting erew durng the summer in Del Rio.

IFI IHAD TO CHOOSE ANOTHER PROFESSION ID BE. PoliteOl

Grtoonist is I could draw!: an artine pilot it $i$ could see:

FAvORITE 5ONG: 'You Cani Always Get What tou Wiant" - Roilung

Stones

MOST VALUABLE LESSON EVER LEARNED: To always look it up muself. That is. you have to pay attention to the details and not rely on

I REALLY RECRET: Never leaming to play a musual ins:rument. FAVORTE FOOD: The ltalian dish my wife is prepanng at the tume. THE PERSONI MOST RESPECT (MY HERO): Anyone who an motivate othess to achieve thest rull porent:si.

BAVORTE VACATTON SPOT: Canbbean lsiands.

THE CITY I WOUTD LIKE TO VISTT NEXT: Vancouver. Bntish Columbia FAVORITE ALL-TMME TELEVISION SHOW: Rockford Files:

FAVORTE MOTTO QUOTE: 1 would never belong to a club that would have me as a member. Groucho Mar

DESCRIBE SOUTHWEST AIRLITES IN TEN WORDS OR LESS: On-the go - less dough - more show! 


\title{
APPENDIX C. RESUME FOR HERB RELLEHER
}

\author{
HERBERT D. KELLEHER \\ Chaiman of the Board, President, \\ and Chief Executive Officer \\ of Southwest Airlines Co. \\ Chaiman of the Board of \\ Transtar Airlines Corp. \\ (214) $353-6110$
}

\section{BUSINESS AWARDS AND FONORS}
.Best Chief Executive Officer, Airline Industry - Financial World; - Best Financial Management, Airline Industry - Air Transport Worla; - Best Chief Executive Officer, Regional Airline, Wall Street Transcript; . One of three "Best Managed Companies," Airline Industry - "Quality of Management Report," Investment Decisions; . Herbert D. Kelleher/MCorp Professorship - University of Texas at Austin; Business School; -Certificate of Distinction, CEO Honor Roll, Airline Industry - Einancial World.

\section{EDUCATION}

Graduate

New York University, IL.B. - 1956 (with honors)

(New York University Law Review 1955-1956, Root-Tilden Scholar)

Clerk, Supreme Court of New Jersey 1957-1959

\section{Undergraduate}

Wesleyan University, Middletown, Conn., B.A. (with honors); (Olin Scholar; President of student body; literary editor of Yearbook; Outstanding Undergraduate and Athlete Awards)

\section{PERSONAL BACRGROUND}

Born March 12, 1931; married to Joan Negley; four children: Julie, Michael, Ruth, and David. 
HERBERT D. KEILLEHER (continued)

\section{MEMBERSHIPS; BUSINESS AND CIVIC AFEILIATIONS}

-Founder, Director, and General Counsel, Southwest Airlines Co. fram inception (1967) to 1978;

. Secretary, Southwest Airlines Co. - from inception to March 1978;

- Interim President and Chief Executive Officer, Southwest Airlines Co. - March 1978 to August 1978;

. Chaiman of the Board, Southwest Airlines Co. - August 1978 to present;

-President and Chief Executive Officer, Southwest Airlines Co. September 1981 to present

-Founder, Director, Shareholder, Oppenheimer, Rosenberg, Kelleher \& Wheatley, Inc., 1971 to 1982 (leave of absence taken in February 1982) ;

- Menber, The University of Texas College of Business Adninistration

- Vice-Chaiman of The University of Texas College of Business

Administration Advisory Council 1980-1981;

- Chaiman of The University of Texas College of Business Administration Advisory Council 1981-1982;

-Director, May Petroleum, Inc. - February, 1980 to 1985;

-Director, MCorp - from November 1981 to present;

- Member, Advisory Comittee, Texas Transportation Institute, Texas

A\&M University System, 1983-present;

-Member, NYSE Listed Company Advisory Committee, 1985-present;

-Member, Cormunities in Schools Advisory Council, 1985-present;

- Merber, Dallas Citizens Council; currently on Board;

-Director, Better Business Bureau of Metropolitan Dallas, Inc., 1985-present;

- Member, McDonald Observatory and Department of Astronomy Board of Visitors, MoDonald Observatory at Mount Locke, The University of Texas at Austin, 1985-present;

.Director,..Past President and Member, Board of Trustees of St. Mary's Hall;

-Past Director, Greater San Antonio Chamber of Commerce;

- Past President, Travelers Aid Society of San Antonio;

- Texas Cavaliers;

- Order of the Alamo;

- American Bar Association;

- State Bar of Texas;

-San Antonio Bar Association;

- Dallas Bar Association;

- Merber, Texas Bar Foundation;

. Who's Who in World; America; Southwest; Law; etc.

- Menber, San Antonio Bar Foundation 


\section{Good fences make good neighbors}

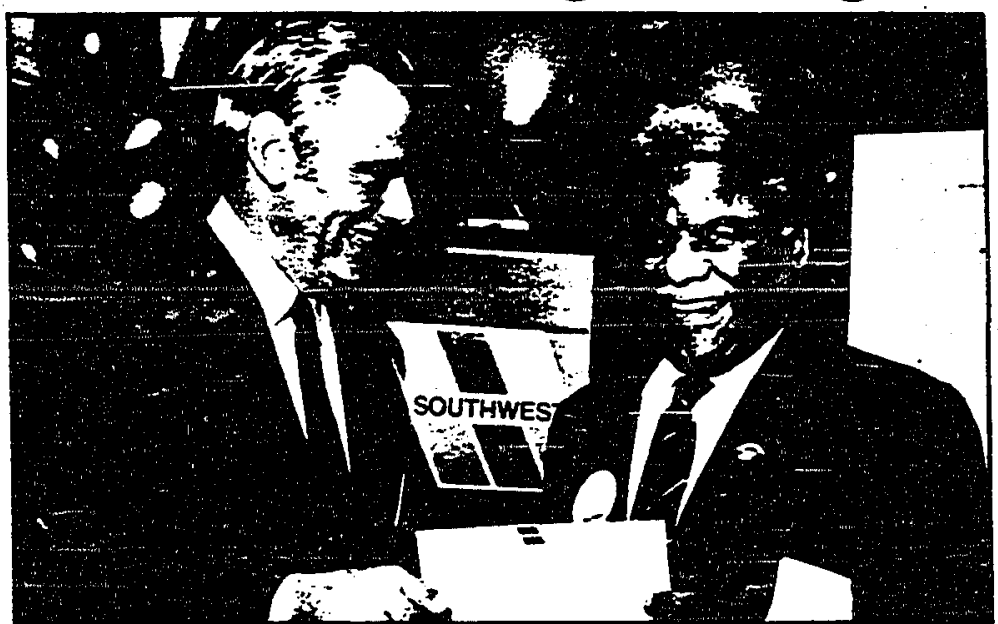

Herb Kelleher presents Chicago Mayor Harold Washington with a $\$ 50.000$ check for the installation of new accoustical fencing at Midway Airport.

$\mathrm{U}$ nderscoring our commitment to the revitalization of Midway Airport, Herb Kelleher recently presented Chicago Maÿor Harold Washington with a $\$ 50,000$ check for the installation of new accoustical fencing along Midway Airport's southeast border. The fence will help reduce noise in the areas surrounding the airport. The capital development donation was presented during a "Midway" luncheon celebration on October 21.

The contribution will enable the City of Chicago to step up plans for new fencing, originally slated for installation in mid-1986, as part of the Chicago Department of Aviation's \$200 million Midway modernization program.

The "Midday at Midway" luncheon offered approximately 250 local government, business and civic leaders a firsthand look at Southwest's Midway operation. The luncheon, a Mexicanstyle buffet, was staged in Southwest's gate area at the airport. The program included an overview of the revitalization of Houston's Hobby Airport and Dallas' Love Field.

To better serve Midway customers in the upcoming months, Southwest will install four jetways valued at $\$ 700,000$. Southwest's current investment in Midway marketing, facilities and operations totals over $\$ 5,000,000$ and the investment for service and airport improvements over the next five years is expected to cost an additional $\$ 5,000,000$.

"Response from the Chicago community during Southwest's first sèven months of service has been remarkable. commented Herb. More than 200,000 travelers have benefitted from Southwest's low fares and convenient, frequent service. 
APPENDIX E. SOUTHWEST'S IOVE THEME.

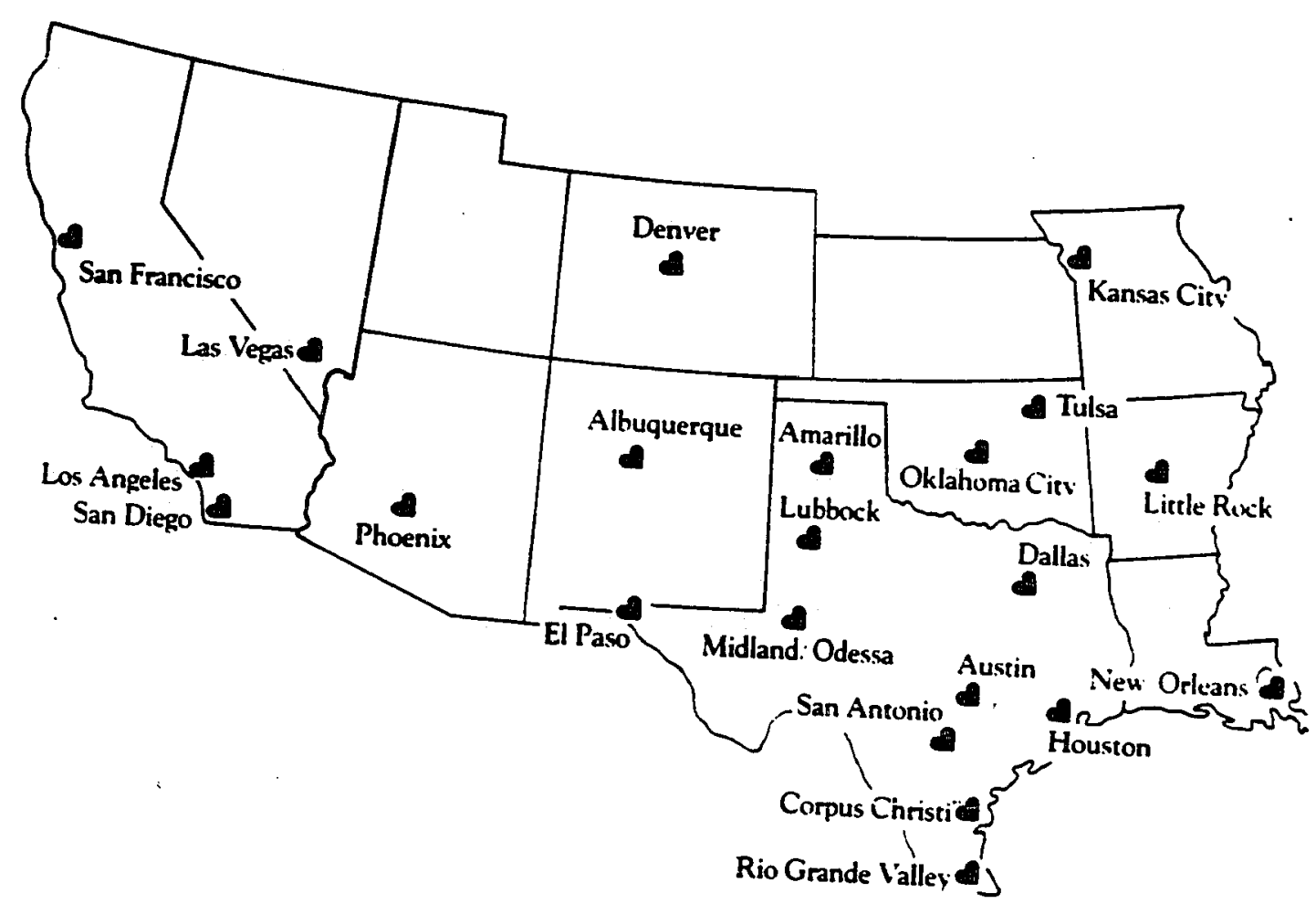

Southwest Airlines 


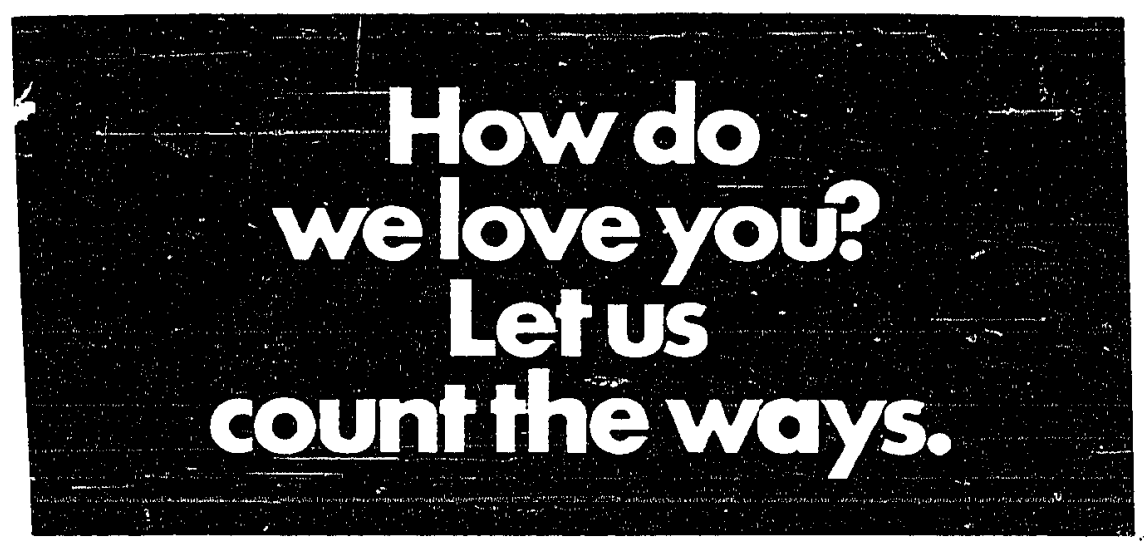

Dellas/Et. Worth to Houston

$\begin{array}{lr}\text { 70por } & \text { Arrive } \\ 7: 30 q^{*} & 8: 18 \mathrm{q} \\ 8: 45 \mathrm{q}^{*} & 9: 33 \mathrm{q} \\ 10: 00 \mathrm{q} & 10: 48 \mathrm{q} \\ 11: 15 \mathrm{q}^{*} & 12: 03 \mathrm{p} \\ 12: 30 \mathrm{p} & 1: 18 \mathrm{p} \\ 1: 45 \mathrm{p}^{* *} & 2: 33 \mathrm{p} \\ 3: 00 \mathrm{p} & 3: 48 \mathrm{p} \\ \text { 4:15 } & 5: 03 \mathrm{p} \\ 5: 30 \mathrm{p} & 6: 18 \mathrm{p} \\ 6: 45 \mathrm{p}^{* * *} & 7: 33 \mathrm{p} \\ 8: 00 \mathrm{p} & 8: 48 \mathrm{p} \\ 9: 15 \mathrm{p}^{* * *} & 10: 03 \mathrm{p}\end{array}$

Dallas/Ft. Worth to San Antonio

Dopert Airivo

- 7:00 a $\quad 7: 500$

9:30a 10:20a

12:00 n 12:50 p

2:30 $\mathrm{p} \quad 3: 20 \mathrm{p}$

5:00p 5:50p

7:30p=" 8:20p
Houston to Daltas/Ft. Worth

\begin{tabular}{|c|c|}
\hline Doperp & Arrive \\
\hline 7:30 a* & $8: 18 a$ \\
\hline $8: 45$ a & $9: 330$ \\
\hline $10: 00 \alpha^{*}$ & $10: 48$ a \\
\hline $11: 15 \mathrm{a}$ & $12: 03 \mathrm{P}$ \\
\hline 12:30 p* & $1: 18 p$ \\
\hline $1: 45 p$ & $2: 33 p$ \\
\hline $3: 00$ p" & 3:48 p \\
\hline 4:15 p & 5:03p \\
\hline 5:30 P" & 6:18 p \\
\hline $6: 45 \mathrm{P}$ & 7:33 p \\
\hline 8:00 p" & $8: 48 p$ \\
\hline 9:15 $p^{\circ+1}$ & $10: 03 p$ \\
\hline
\end{tabular}

San Antonio to Dallas/Ft. Worth

Depent

Arrive

$8: 150^{*}$

10:45 a

$1: 15 \mathrm{p}$

3:45 p

6:15 p

8:45 p"*
9:050

$11: 350$

2:05p

4:35p

7:05 p

$9: 35 \mathrm{p}$ 


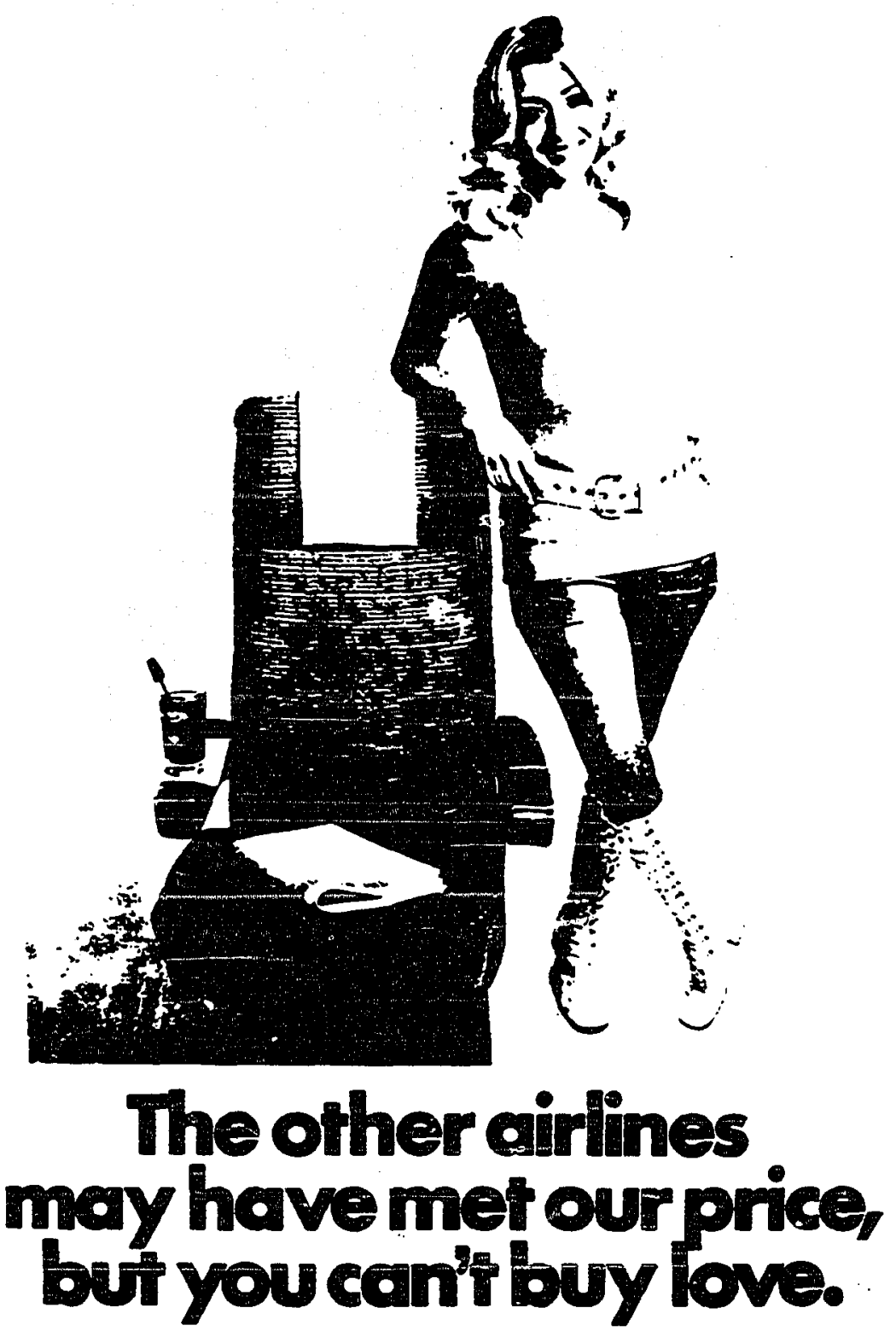




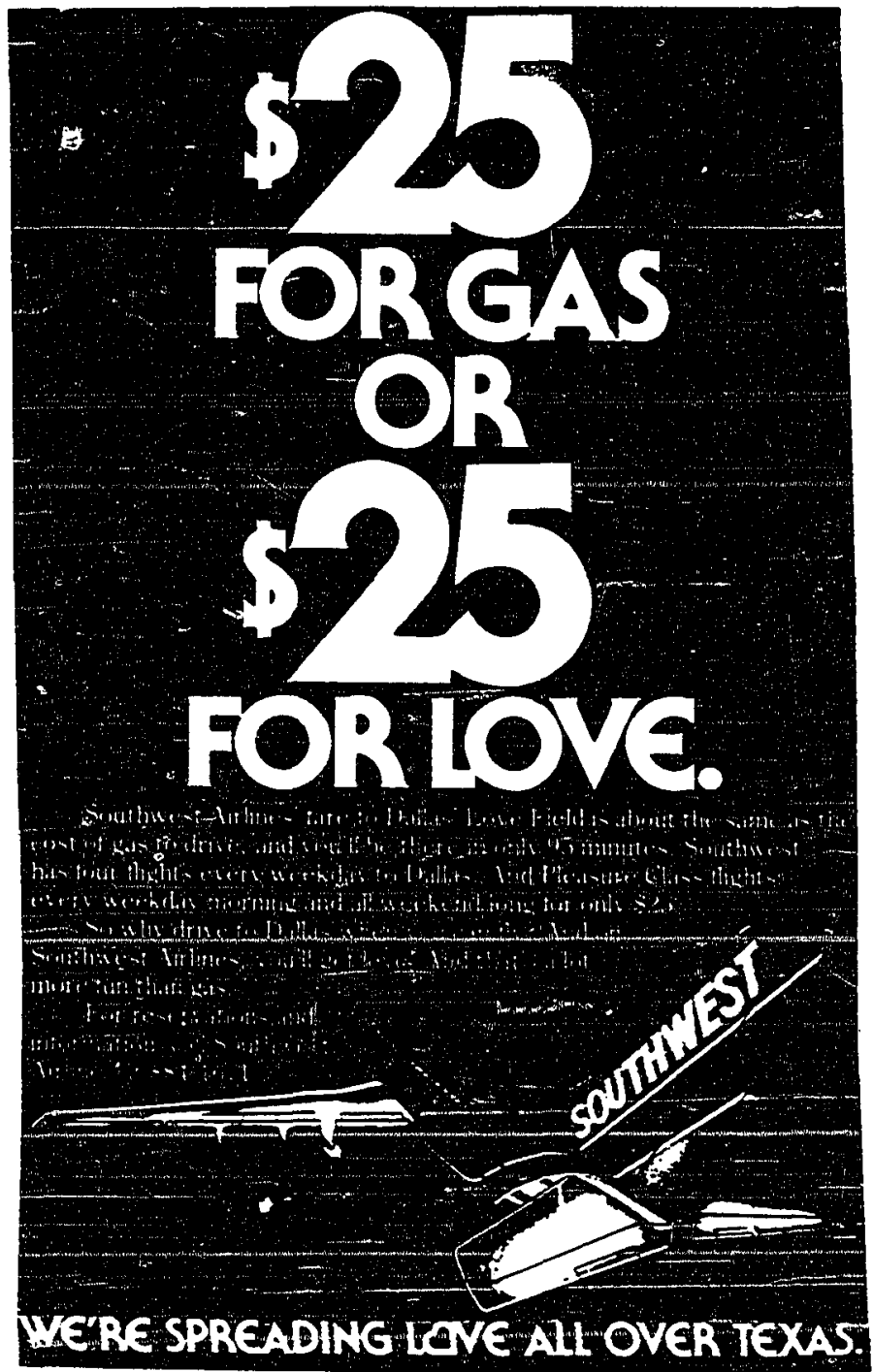




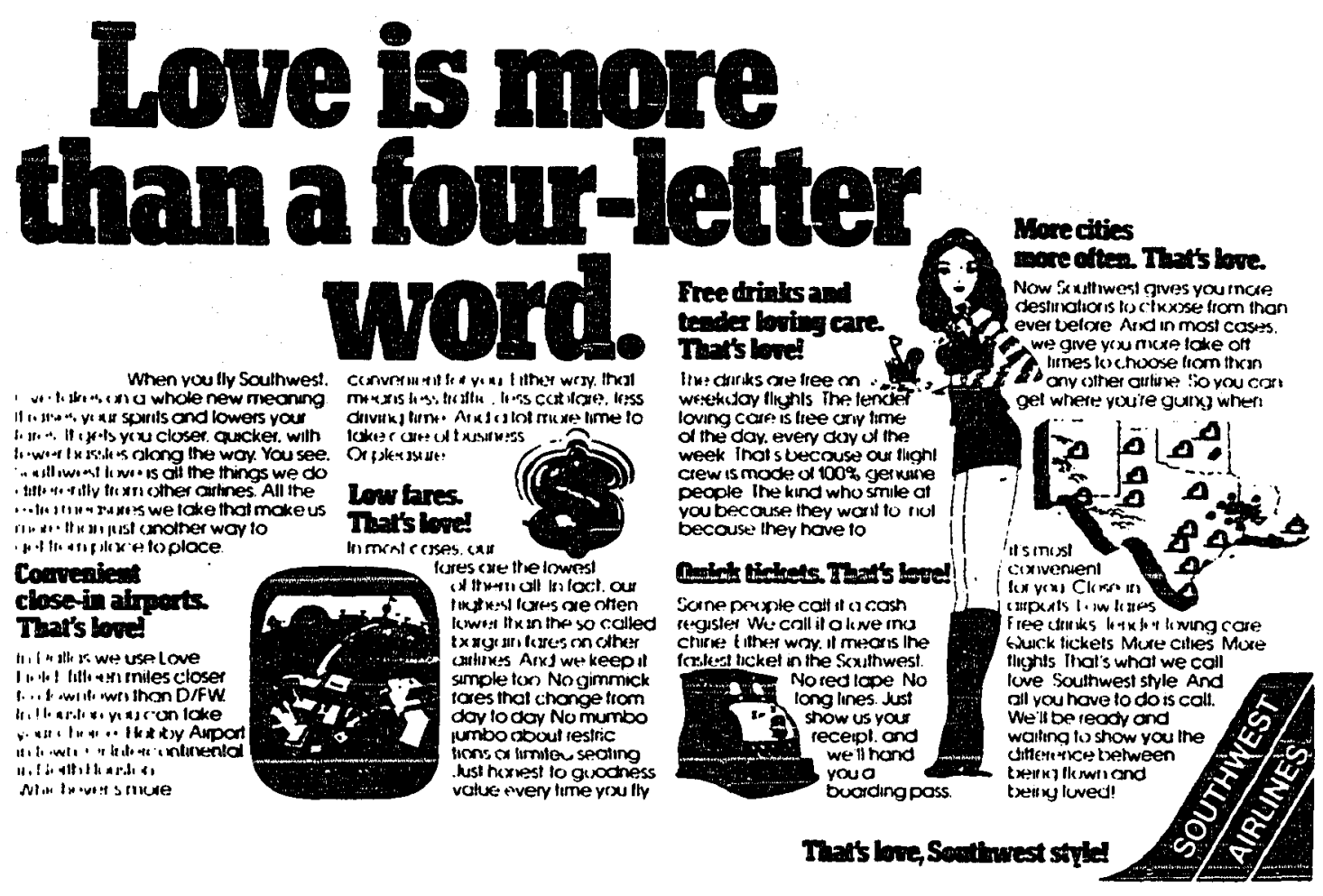




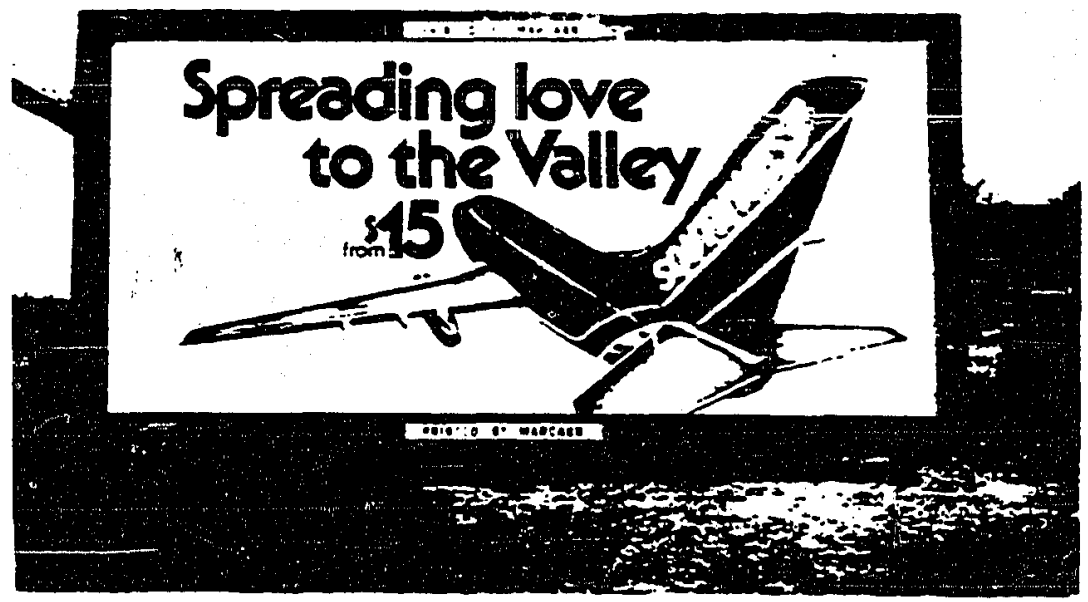

You pay for the fare, but not for the drinks.

They're free on all Southwest flights this week to celebrate a full year of having Somebody else up there who loves you. SOUTHWEST AIRLINES

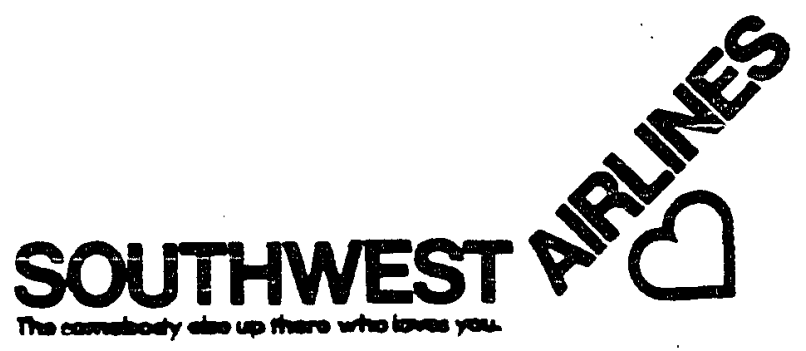




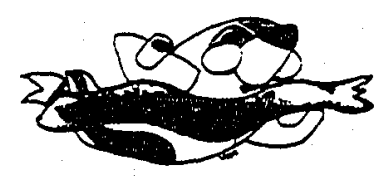

A recond number of 15 employees A received a 'Winning Spirit' award on Thursday. August 14. The presentations were made by Hert in the Executive Board Room where each employee received an awards pin. certifiate and two positive space passes for their extraordinary efforts.

\section{DAVID SHOEMAKER - Midland} Customer Servic: Agent Supervisor

It is said that "a little good ole. down home Southern hospitality goes a leng way." and Middland Custome: Service Agent Supervisor David Shoemaker ce:tainly epitomized that old adage when he accommodated a farnily whose luggage did not artive in Midland when they did.

Upon discovering that they had locked their keys in their missing luggage. David also took notice of their sick. tired baby, and their low spirits. and offered to drive them home. When they got there to find that their neighbors were not home either. David took the family to his home. where they spent the afternoon. The baby was aliowed to sleep. and the family was able to rest until their luggage artived. They were very appreciative for the "above and beyond" efforts of David Shoemaker, and wrote a glowing commendation telling us such.

Such a caring selfless act is indiative of David's aring Southwest Spirit. and one that is greatly appreciated.

KEVIN SMITH - LBB Remp Agent

Lubbock Ramp Agent Kevin Smith was on the headset during an engine start for a flight from Lubbock to Dallas. As the " 2 engine was winding up. Kevin noted something unusual about the 44 main tire. Kevin saw to it that both engines were shut down, and the tire's pressure was checked at 70 PSI, and the tire was changed.

Thanks to the alert action of Ramp Asent Kevin Smith, a flat tire and potential accident was avoided. It goes unsaid that the detection of a flat tire is not an easy one, especially from head

\section{"WINNING SPIRIT"}

on. in the position of starter. Our hats. and those of the crew onboard light *303. are ott to Kevinis perceptive detection of this irregularity.

\section{ROBERT BURROUS - SFO RamP} Agent

A unique incident in San Francisco was the subject of the jollowing outstanding nomination recognizing the true sense of the Winning Spirit Award.

On July 17 Robert Burrous. SFO Ramp Agent was working a scheduled overtime shift on his day olf. Prior to clocking out. Robert checked the bookings. and realizing that they could use the extra help. elected to stay an additional two and a haif hours on his own time. This is typical ot Bob. but not the specific reason he has been selected a recipient of the Winning Spirit Award.

When Robert finally exited the ramp area and boarded the TWA bus to the stait parking lot at 1730. as he had a pnor engagement commencing at 1830 . he saw a man lying face down in an adjacent parking lot, with a few casual observers surrounding him.

Robert hurriedly drove over to the soene and assumed immediate control of the situation. Hie instructed a TWA fueler to call the fire dept. and police dept.. and returned to his nearty ar to retrieve a blanket and his first aid kit.

The onlookers at the scene informed Bob that the victim was dead, but Bob discovered a faint pulse in the man's neck. Al this time Bob initiated CPR and continued to do so for the next 25 minutes prior to the arrival of the firemen. Upor their armval. a fireman and Bob shared the responsibiitity of administering CPR.

administering CPR.
Throughout the ordeal Bob felt tronger pulses intermittently and additional color in the victim's face Throughout the CPR exercise. the victim expelled body fluids into Bob, all of which did not deter him from his pursuit of attempting to save a life.

An ambulance finally arrived and took the victim to the nearest hospital. The following day, it was leamed that the victim had died enroute to the hospital. The cause of the death was a heart attack.

Needless to say. Bob had a restless sleep that evening while refiecting back on the day's events. Regardless. Bob reported to work the next day two hours prior to his scheduled shift, and as usual, lent a helping hand on his own time.

Bob is SFO's Sarety Coordinator. and for good reason, as the preceding account proves. Bob's shining Southwest Spirit. and basic humanitarian attitude serves as an example to us.

\section{PEGGY HUEFFNER - Dallas}

Provisioning Luventory Clerk

A Winning Spint nomination was recently sent to the Executive Oftice signed by several of the nominee's coworkers. The letter read as follows:

"She exemplifies the Southwest Spirit in her job responsibilities and toward her co-workers. She goes out of her way to help others without concern tor personal benefit.

All station employees recognize her as the "World Traveler" and she has been known to arrange complete vacations tor others. She organized and coordinated the fantastic enchilada dinner for the Dallas Ronald MeDonald house in May.

With the exception of a three month leave in 1981, she has maintained a pertect attendance record since her hire date on May 20. 1978. and has maintained excellent standards in her job responsibilities."

Such a description given by her coworkens is cerrainly an honor and weildeserved privilege for none other than Dallas Provisioning Inventory Clerk Pegzy Hueffner.

TERRY WESTERHOF - SFO Operations Supervisor

Since his stare at Southwest back in July of ' 84 , this outstanding employee has gone from airplane cleaner to Operations Agent: and after only seven 
months as an Operations Agent. Terry Westerhot was promoted to that of Operations Supervisor.

This employee averages 10 hour days, of which little is charged to overtime. He takes responsibility with enthusiasm and follows through with all projects. In SFO. where there has not been an assistant manager since Sept. of 84 . he has taken over the administrative duty of payroll and done a superb job. When SFC obtained its own ramp. he volunteered to overset it until they could fill the position of

Ramp Supervisor, once again doing a formidable iob. and never once complaining $c$ the heary workload. On one specific ocasion. an aircraft in SFO had a cracked window in the rear service door. No window could be located at SFO. but one was available from Air Cal in Oakland.

Unfortunabely, neither our contractor nor Air Cal could get the part w SFO in time to make a scheduled departure. so Terry rushed out to Air Cal in Oakland at 2 a.m. picked up the part and delivered it to the aircrait at $4 \mathrm{a.m}$. in time to make an ontime departure. For his dedication and exemplary SOUTHWEST SPIRIT, we salute Terry Westerhof, SFO's Operations Supervisor.

\section{IIM HENNINCSEN - SAN RUmp Agen}

In the same light of alert attention $\infty$ detail. while on the Ramp at LAX. before being transferred to SAN. Ramp Agent Jim Henningsen observed abnormal leakage from one of the aircraft systems. Immediately pointing it out to the crew, Maintenance was alled to check the airufaft, and it was discovered that a hydraulic leak had developed, aused by 2 wom $O$ ring. Repair was completed and the flight continued on safely.

The "extra efforts" and special attention to duty saved flight $" 703$ from porential detriment.

\section{MORGAN WILSON - Fight \\ Athendant}

Whenever an aircaft has a delay. there's often a bitter complaint or a glowing commendation close behind. simply because the employees' inflight endurance and "people skills" are truly tested. Flight Altendant Morgan
Wilson's skills were so tested on a flight from Dallas to Tulsa. A Customer wrote to teil us of the "exceptional service" provided by Fight Attendant Morgan Wilson. Tarit speak for everyone," he said, "but Morgan waited on me hand and foot without my having to ask for anything."

When the pilot informed us that it would be 2 p.m. before we arrived in Tulsa (after an 11:50 departure) Morgan remained unruffled by everyone's impatience and exhibited a wonderful sense of humor to put all of us - me - at ease."

We salute Morgan's consistently outstanding, undaunted service to our valued Customers.

\section{STEVE HOZDULICK - Fight} Dispatcher

Flight Dispatcher Steve Hozdulick is a fine example of one of those dedicated "above and beyond." "stay until it's finished" type employes. He propagates the Dispateh philosophy that "Our job is to solve problems, not to create them."

He works many hours at home. using his personal home computer to make sure that the Dispatchers rotate the right shifts and desks. He also coordinates the vacation bidding and the training days which helps give the Dispatchers and Southwest Airlines an outstanding product.

Steve is always willing to take on special projects, assignments, and duties to improve Southwest's Operations, including serving on the seheduling committee. While doing his regular work as a Dispatcher. he exhibits an outstanding unselfish attitude and an untiring sense of SOUTTWEST SPIRIT!

\section{GARY KLAGMANN - E P2so} Customer Service Agent

Gary Klagmann. El Paso Customer Service Agent is another one of those Southwest Airlines employes who is always willing to take on our valued Customers "mishaps" as a personal challenge. Two Customers recently wrote in to tell us of the extraordinary measures Gary went to in order 10 retrieve their luggage.

The first Customer who was in E Paso for a convention and had never before visited E. Paso, wrote to tell us of
Gary's ability to remember a Customer's first name and his high standard of professional service in seeking to comfort them.

When the Customer and his date arrived in El Paso to find that their luggage was still in Dallas, they were directed to Gary, who promised to personally tind their luggage and deliver it to their hotel. Gary kept his promise and alled the hotel to inform the Customers of the arrival of their luggage.

The other Customer, whose claim checies showed that he had mistakenly checked his luggage to Chicago instead of through to El Paso, also found Gary. who said that as a courtesy of Southwest, he would do his best to loate the lusgage and have it sent to $E$ Paso, which, in fact. he did.

It is the "above and beyond" attitude that instills the positive SWA image in our reguiar and first-time Customers and keeps them coming back.

\section{ROBERT HAYNES - Fisst Officer}

First Oificar Rob Haynes has contributed numerous articles to the safety committee's newsletter. He spent three months writing $2:$ i isicle on Downdrafts" which was published in the lanuary 1986 issue or

"CROSSFEED:" The 17-page article was compiled from over 10 books. periodicals, and reports, and is the most comprehensive pilot-oriented compilation of windshear and downdraft information available in one single document. Not only was this issue distributed within our company to pilots and operations personnel, but also to the saftey committees at Delta. American. Eastem. Pan Am

Continental, Embry Riddle University. let East, and numerous governmenta agencies. Recently, at a week-long. industry-wide seminar in San Diego. Dr. Ted Fujita of the University of Chicago and author of one of Robs sources, Downdrafts," read January's CROSSFEED and complimented Southwest Airlines on the thoroughness and correctress of Rob's article.

Rob has made a significant contribution towards tlight safecy within our company, as well as throughout the aviation industry. We salute you. Rob. for your untiring efforts and dediation. 
STAN CIELAK - LASR Rmp Agent Stan Cielak was certainly in the right place at the nght time when he noticed a fellow ramp agent ehoking on some food. He quickly jumped up and administered the Heimlich maneuver. and dislodged the food from his fellow and disloded the food from his tellow saved his co-worker irom a potentially life-threatening situation.

According to several sources. the quick action demonstrated in this incident is chanacteristic of Stan's approach to his job responsibilities in general. We thank you. Stan. for your quick action in this instance, as well as in your daily duties.

\section{GENE IOLIY - AMA Operation} Agent

A passenger confined to a wheelchair and having limiond use of his arms and hands arrived in Amasillo with no one to meet him. After working the flight. Operations Agent Cene Jolly checked on the Customer only to discover that no one had yet come to pick him up.

Unable to help himself to the

restroom until it was too late. Cene assisted him in the bathroom, helping him to change clothes and clean up.

This exemolarv act is consistent with. and certainly not atypial of Cene's daily display of dedication to Southwest and its valued Customers.

MIKE MERCER - Manager Dallws Reservations Center

One of the greatest attitudes for caring that I have ever seen, and more patience than is required of any human being. His cooperation and support have meant a great deal to Customer Relations, and to the entire Company. said one Southwest employee describing Manager of Dailas

Reservations Mike Mercer.

During the recent Senior Citizen promotions. Fun Fares, and all the phone problems in between for reservations. Mike was always exceptionally helpful. When Customers could not get through the reservation lines and would all Customer Reiations Mike had Customer Relations all him personally, at which time he would handle the reservation on the spot. This enabled our Customers to have their reservations confirmed. His "Winning Spirit" and willingness to go that "extra mile" serve as an example and we thank you. Mike Meroer, tor your dedicated "spirit."
BILL KROSLEY - AUS Ramp Agent A Southwest aptain recentiy wrote in to tll us about the fine job Austin Ramp Agent Bill Krosley is doirg. Upon pushback. Bill spotted a large chunk of metai embedded in the $\$ 3$ tire. He promptly brought it to the attention of the crew, who. in turn. immediately headed back to the gate. Bill's fine attention to detail and overall awareness while on duty could have prevented a pountially serious situation trom developing.

SIEVE PENDERGRASS - DAL Lixe Mainterance

There were approximately 90 school children whose flight was made just a bit more special and memorable due to the efforts of Line Mainterance

Mechanic Steve Pendergrass. Onboard a flight that had 30 minutes ground time. Steve took the excited. restless children in groups up to the cockpit. The 30 minutes that could have seemed like an eternity to tive flight attendants and Customers onboard turned into a mini "field trip," thanks to Steve's patience and humor.

It's that caring. patient, "individual touch" that is so appreciated by. Southwest and its Customers. 
APPENDIX G. LUV LINES ANNIVERSARY ISSUE

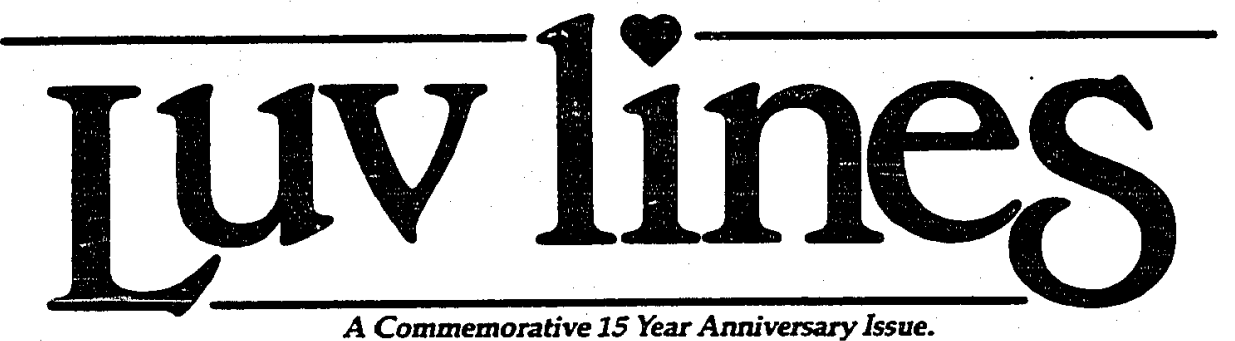

A Commemorative 15 Year Anniversary Issue.

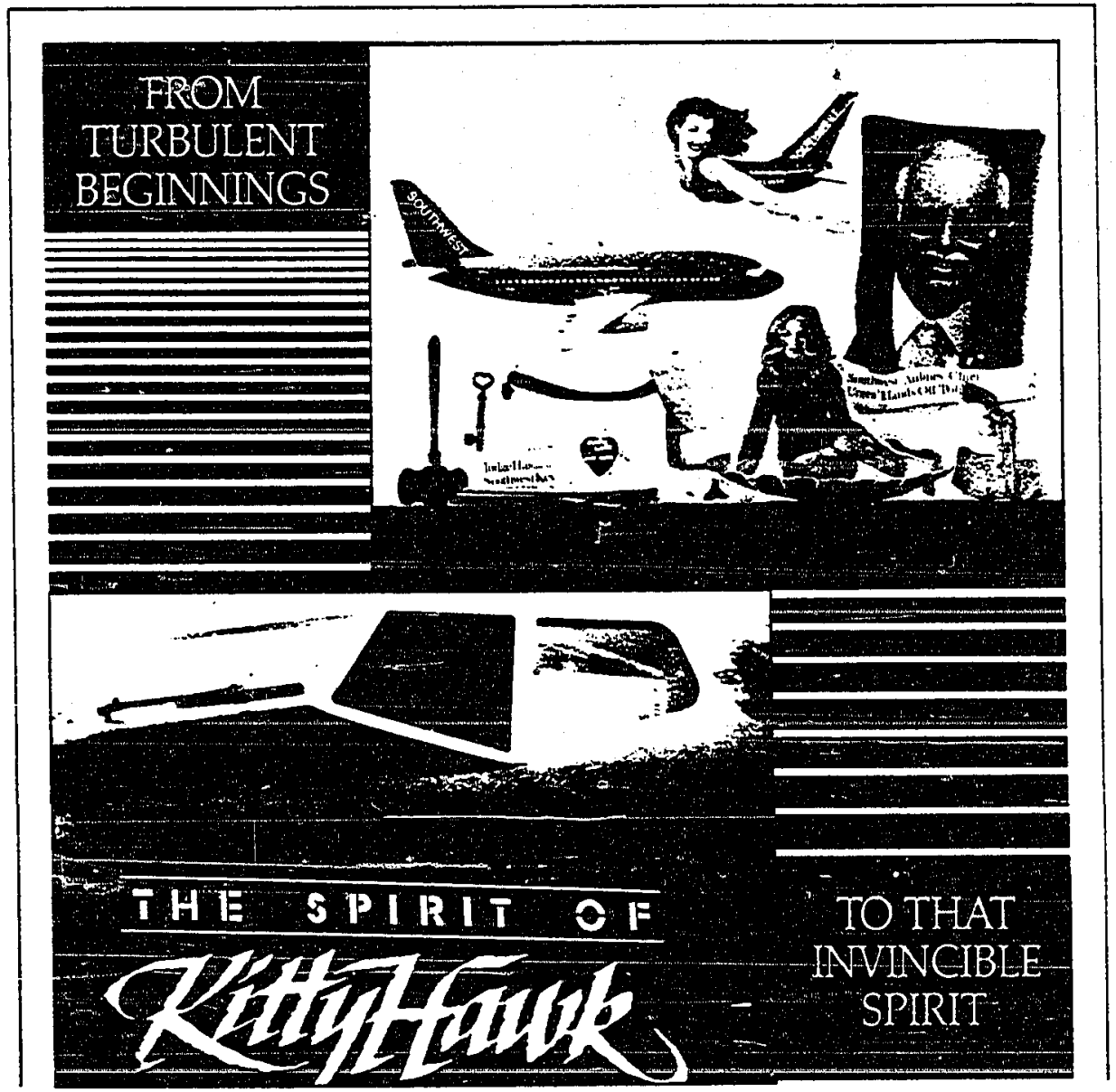




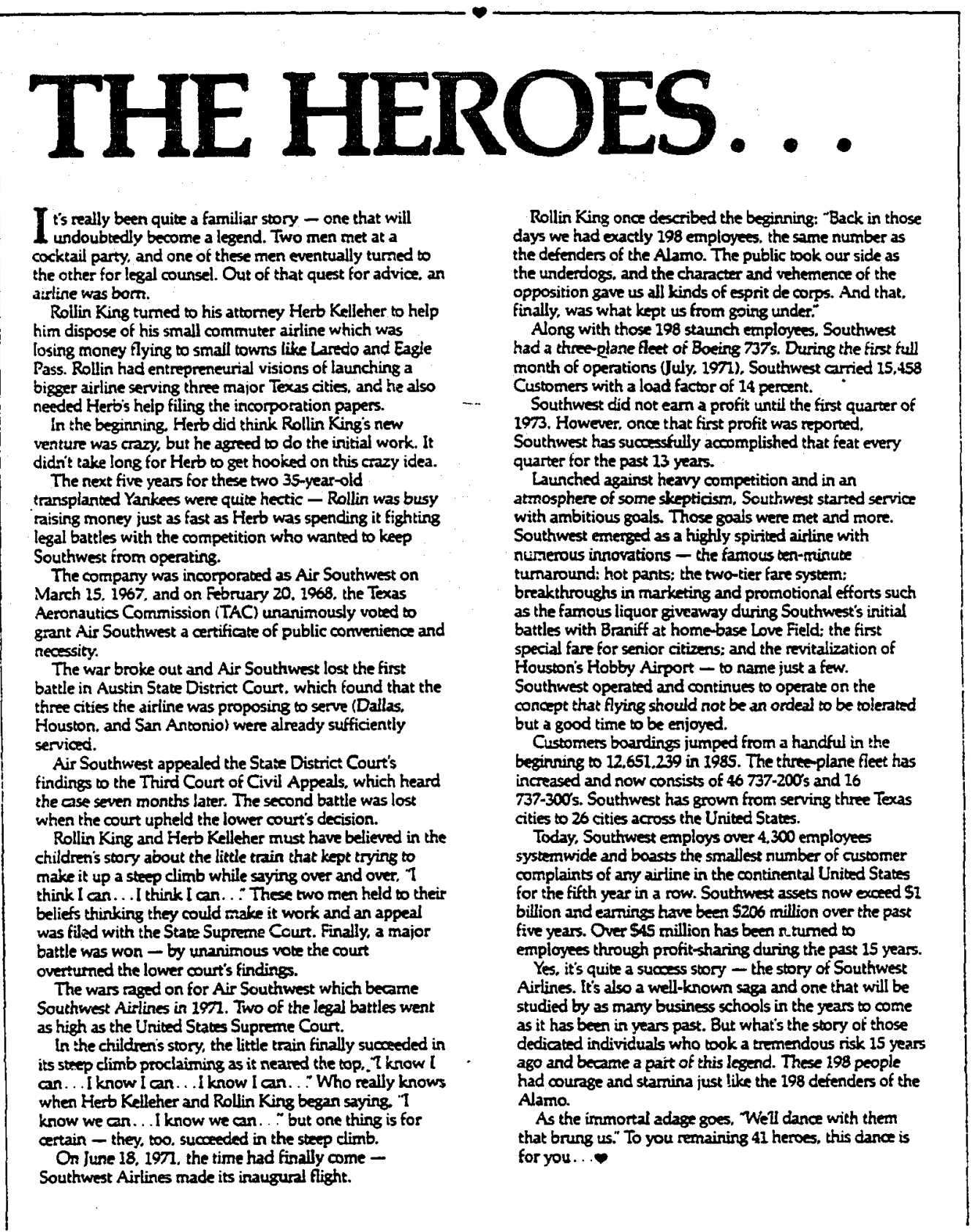




\section{TO THE ORICINAL TEALI}

In the beginning, there was an idea.

They transformed that idea into a legend.

The toois they used were

indornitable spirit, boundless energy, immense good will.

and a buming desire to succeed.

They created something out of nothing.

That is called "creation."

And they are the creators.

To the original employees of Southwest Airlines - my thanks. And my love.

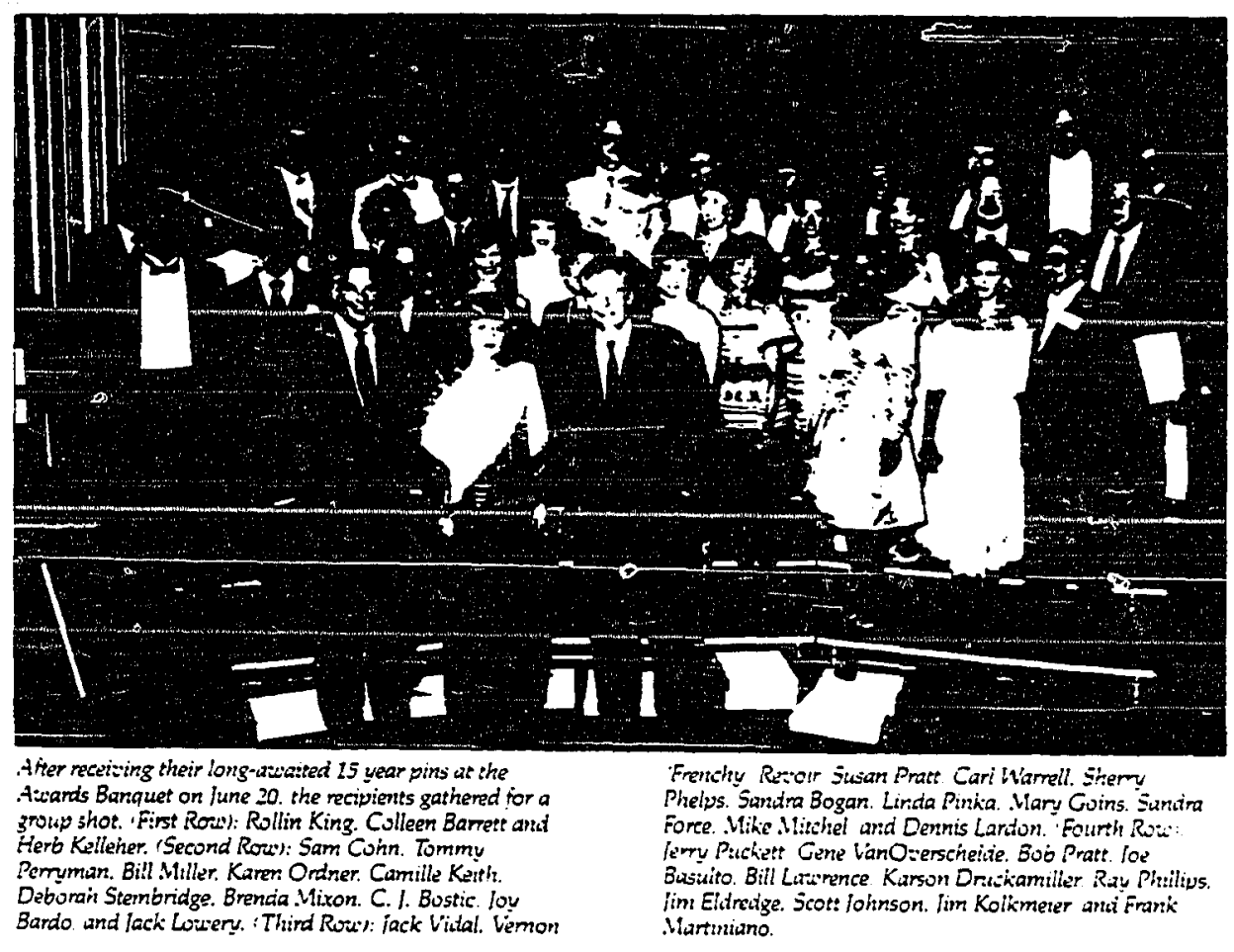




\section{“GROUND FLOOR"APPREHENSIONS...}

(What It Was Like Beginning Work For A Newly Formed Airline)

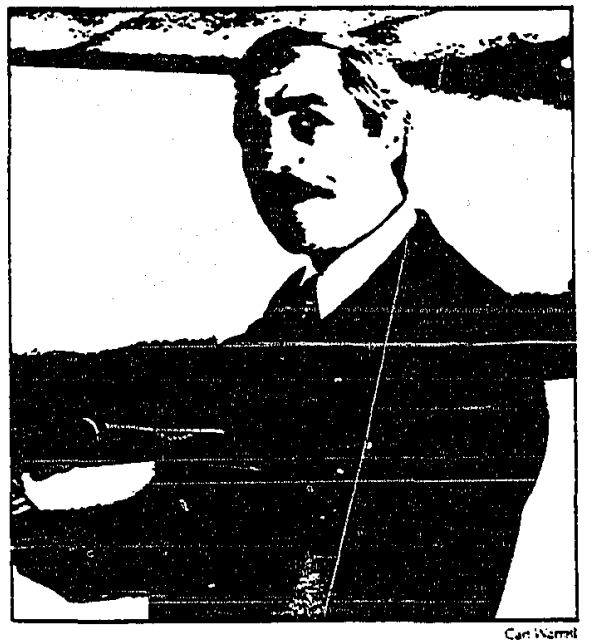

Starting to work at Southwest was the most unique

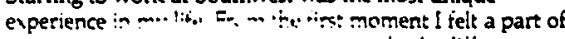

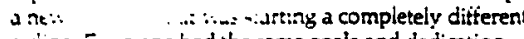
aurine. Everyone had the same goals and dedication. Those who didnt were not around lo-g

- Sandra Bogan

Actually, it was 20 years ago. and I was feartul that we might not survive the barrage of legal. political. and economic "brickbats" that would be hurled at us by the incumbent carriers. They threw then, but we either ducked or hurled them back. and thus Southwest was bom.

\section{- Herb Kelleher}

Not a very secure job prospect. In fact. I waited two vears before I felt comfortable enough to buy a home. As I worked my last fow days at my former empls ment. my fellow workers were continually asking whi. this new airline was. It was difficult to give them a knowiedgeable answer. A lot of uncertainty!

- Ray Phillips

I remember seeing that one little cash register at the end of the Frontier ticket counter. and I really wondered if wed make it.

- Jack Lowery

I'm too old to remember anything 15 years ago!

- Denris Lardon
After teaching school tor tive years and deciding to change professions. I heard of a newily formed airline called Southwest trom a neighbor who was home for lunch. I was sunning on a raft in the middle of my apartment pool and enjoying my summer vacation. After listening to my neighbor's description of an airline that never leaves the State of Texas, has no layovers. doesrit fly at all on Sundays, and wears hot pants as a uniform. I decided that my tife as a "school marm" sounded pretty dull. I immediately got off my raft, dried off, and made an appointment for an interview that very afternoon. I interviewed and was hired all in the same day. I an't say that in the early days Southwest gave us much security. We really didn't know if we would have a job from paycheck to paycheck. It was touch and go for the first few years.

- Sandra force

Sared. but excited! Everyone created an atmosphere of closeness within the company and were cheerleaders for one another. Both the company and passengers showered us with respect. praise, and best of all - gifts. Our frequent flyer passengers would load us down with goodies on holidays.

- Deborah Franklin

A dream come true! I had interviewed with every airline in the world and nobody was hiring. The :wo airtines that did hire me - United and National - cancelled all classes for 197 shortiy after they notified me that I had been hired! It meant staying in the South: wearing hot pants. which were hot irom the streets of Pars; and no meal service!

- Inn Mabry

I had just been laid off from an airline that was closing down. my wife was five months pregnant, and I had two other daughters who needed the basic essentials. I guess you could say I was a little down when I arrived, but I was bound and cetermined that if I had anything to do with this new airline making it. I would give it all my energy and positive attitude.

- Jerry Puckekt

Relief - that I had found a job. I had quit my previous job and didnit have another one lined up. I was glad to be working in the airrraft industry as I had previousiy worked for Boeinz Aircraft in Wichita. Kansas before joining the Army.

- Bill Lawrena

I felt that I was taking a chance, but it turned out to be the best gamble I ever took. I believed in the concept. and I believed the time had come.

- Carl Warrell 
Sared to death! It was my tirst job. We had to wear those horible hot pants and memorize our drink orders. It has been fun watching the many changes Southwest has had.

\section{- Brenda Mixon}

The way I got my job at Southwest helped form my opinion about the company. I was walking down the halls at Love Field and stopped to ask directions to Eastem trom a black girl dressed in orange coveralls, who appeared to work at the airport by the "outfit" she wore. I had recently divorced and desperately needed a job. We talked briefly, and I explained my situation to her. She said that not many airlines were hiring. She asked. You really need a job bad. huh?" I rold her. Yes. I really do." Then she replied. I work for Southwest Airlines which is a brand new airline - I clean the planes. but they said that I could have the next ticket agent job. which is open right now. But. you take that job and I'l take the next one"! Imagine my shock when she took me into the Station Managers office introduced me, anc told him that she wanted me to have the trcket agent job that was open. She said that she would take the next one. because I really needed a job! I was hired that day. and I will never forget Cherry Stephens. who has since moved. nor will I forget the special feeling of "luv", sharing, and aring!

- Joy Bardo

I was excited, scared, and not too certain that I had made the correct decision to 80 with a brand new company. At the time. I needed a job. I also liked the idea of starting and growing up with a new company. I waneed to help make it grow.

- Karson Drackamiller

1 had never heard of Southwest Airlines or, for that matter, a 737 aircraft when I moved from my home in Wichita Falls to the bis city - fresh out of college. newiywed. and eager to conquer the world. I knew I could make more money in a more conventional job, but there was something intriguing about getting in on the ground floor of a tough little company of about 150 employees who defied every convention ever dictated. I had to take the challenge and decided I could always get another job if little SWA didrit fly.

- Sherry Phelps

Have I lost my mind to leave a television areer for a company that may not make it. . . but, boy, if it does. I1 be at the beginning of a great career.

- Camille Keith

I did not believe that Southwest had a chance to make it. All other airlines were laying off personsel.

- fim Kolkmeier

When I came to Dallas I was looking for a job with an airline. I was in Dallas about 14 months before I heard about Southwest. When I got hired. I was so pleased that I sook a $\$ 150.00$ a month cut in pay to come to work for Southwest.

- fim Eldredge

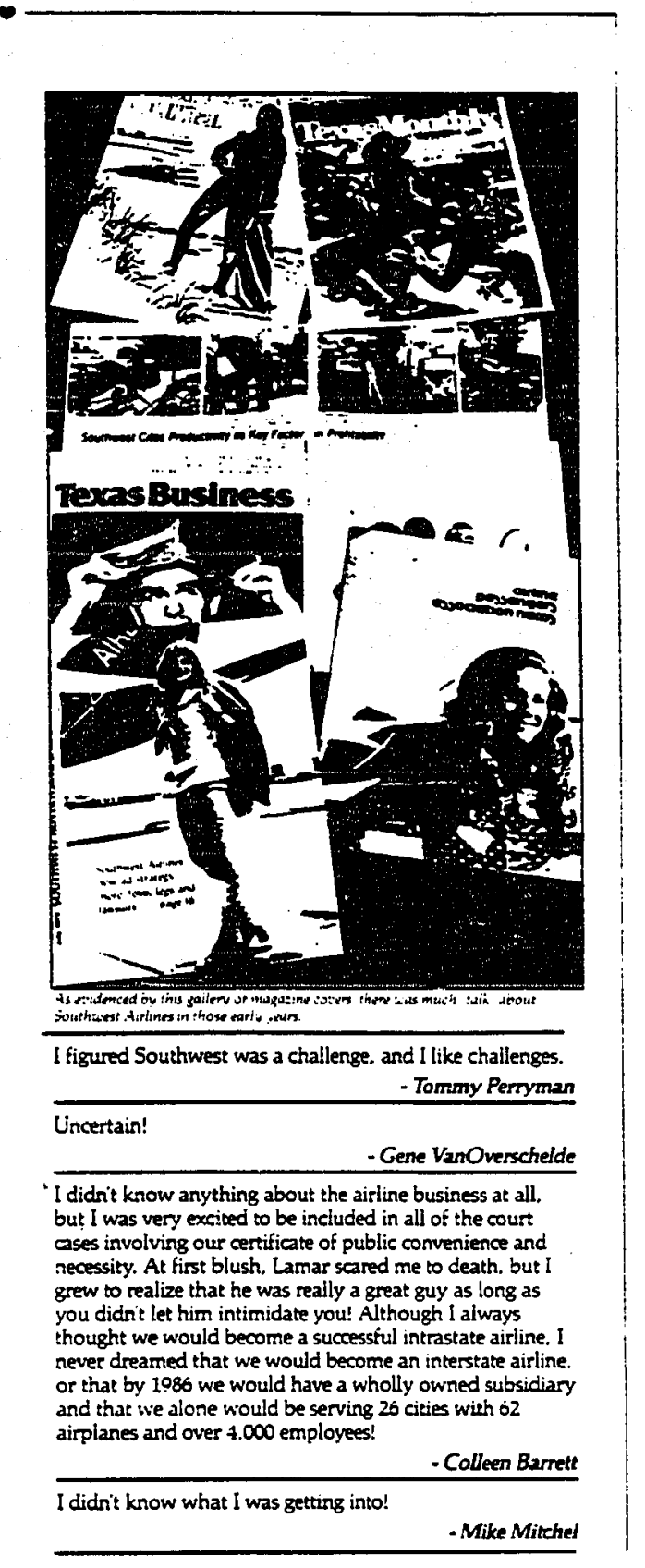


Working tor an airline was romething I aiwavs wanted to do ever since I was a youngster. When I started. I was hyperactive and made errors of enthusiasm. To have a job with a new airline working $6^{1 / 2}$ hours a day, 6 days a week. and being paid $\$ 450.00$ a month. was the greatest thing in the world. After two weeks. I was almost turloughed.

\section{- Frank Martiniano}

One of elation. A once in a lifetime chance to set up and establish your own work init. Watch it grow and watch it work and to be an integral part of the whole.

-Jack Vidal was just a stopover point for me. I was too young to be apprehensive.

- Suser Pratt

I was very excited about my new career. Although I was very young and inexperienced, I was ready to strike out and start adventuring with Southwest Airlines.

-C. /. Bostic
It cidn't bother me. I was on my way to California - this

In 1971 I had a choice of being laid off or furloughed by Frontier. A Frontier supervisor told me about Southwest Airines. a new upstart airline which was currently interviewing. I got reaily excited and applied. I did get hirec by Southwest in Revenue Accounting: however. Southwest wanted me to begin work on lune 1 and Frontier wasnit releasing me until July. Therefore. for one month I worked for boch companies. I was the breadwinner of my family, and I didn't want to lose my seniority with Fronties. I knew I was gambling. - Karen Ordner

Apprehension alter leaving a large airline for one that was unknown and with an unknown future. - Bill Miller

My parents thought that I was crazy to leave a good job paying 5375.00 a month to 80 to work for an airiine with no airpianes.

- Deborah Stembridge

I was just proud to be here! - Sam Coinn

\section{FIRST DAY REFLECTIONS. . .}

My first day at Southwest began at 0600 with me making coffee and serving it to our passengers. Then. I went into the station manager's office and hanciled all the correspondence. did the Daily Manager's Sales Report for the previous day, and made the deposits for sales. Next. I went into the "very small reservations office". and put on my fourth hat for the day by taking reservations. I got off around 8:00 p.m. that night. We worked long hours in those days for comp time, mandatory time. etc The second day was the same. only l added another hat ticket agent. In the "old days" you were a ticket agent one day, and a reservations agent the next day, rotating jobs. In addition to that. many times we were alled out on the ramp to assist in loading bags. It was definitely intenesting and "varied" - you were surely never bored!

- Joy Bardo

I remember in the beginning we used to send the ticket agents through the terminal to recruit servicemen that were traveling standby on other carriess.

- Carl Warrell

I was IAid my first day and my dad was on the plane. Most people know my dad and what a joker he is. To this day, he's still the worst passenger l've ever had to serve!

-Mary Goin:

My first day at Southwest was spent getting familiar with the stockroom layout and using the Boeing IPC manuals in order to find part numbers for the mecharics.

- Bill Lawrence

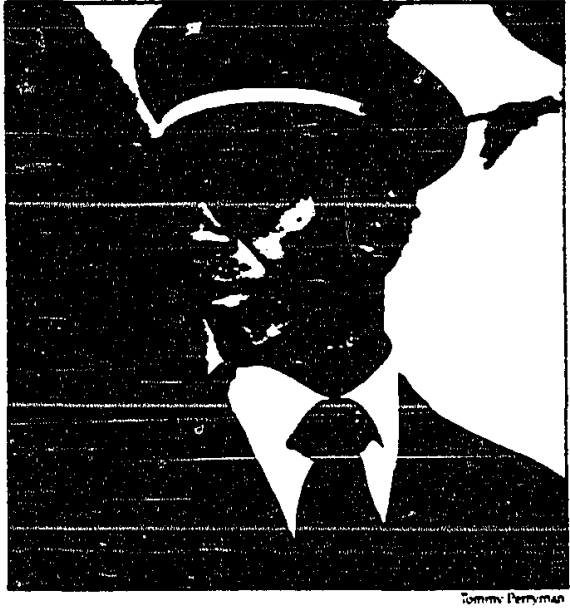

Very hectic from the standpoint that there was so much to do with so fev. Ho with omper organization. we survived the first day and many after that. It was a thrill to see the enthusiasm of those onboard that had come from a cross section of the United States.

- Jack Vidal 
The first day at Southwest was hard. Wie were recelving the desks. cabinets, etc for the General Office which was located at Love Field Drive on the second floor. We had to carry all the desks up those winding stairs!

- Jim Eldredge

I spent my first day in the ait galley crying. Believe it or not. I was overwhelmed with having a check ride by my supervisor and the stress of taking are of three passengers. Is that ridiculousi I have great compassion and respect for the new flight atsendants that are faced with 122

passengers their first day. You would have had to carry me off the airplane on a stretcher if I had been taced with that.

\section{- Deborah Frankli.}

EXCITED. lost , trying to learn how to spel

"737". wondering who the hell this Bill Franklin person was.

- Dennis Lardon

I an hardiy remember my first day at Southwest. My first day turned into 15 years. it seems.

- Sandra Force

Quite frankly, I donit even remember my first "otficial work day" at Southwest because I was involved with the court ases dating back to 1067. and by the time lune 18 . 10."? came uround. I was already "hooked" as a "lifer" with cur LW' airline.

- Colleen Barrett

My first day with Southwest Airlines was one spent as a ramp and operations agent. I was assigned the ramp the tirst day and wore our new red ramp overalls. We were filmed by ABC National News as we worked the first Alight out of San Antonio. We were all nervous and had stage fright the whole first day.

- Bill Miller

Enthusiastic!

- Gene VanOverschelde

Can you imagine just returning from Viet Nam wearing narrow ties, having short lair and then standing at the loot of a 737 aistair looking up the stairs and seeing a beautiful flight atcendant with legs that seemed to reach to the heavens. wearing boots and orange hot pants. Can you inagine what was going through my mind when I started up the stairs for my first flight. Reaching the top. I stopped iust long enough to make sure I was not dreaming on what I had eyed from the bottom of the stairs. It was real . . . no dream. I then put my hand out to introduce myseif and said. "I'm Sam Cohn" She said Weicome aboand Im Pinks." Without batting an eye, she ignored my extended hand. and with a smile and laughter that I will never forget. she !@ 15\%ock"! I stopped dead in my tracks. looked her straight in the eye, could not say a word. but thought to myself. "T have just entered heaven:"

$-\operatorname{San}$ Cohn

EDITOR'S NOTE: You will have to call Sam if you wan further clarification on this one.
My very tirst day was spent pondering how we could raise the opital and develop the political suppor necessary to succeed in obtaining a certificase of Public Convenience and Neressity and in beating off the forays against us in the Texas Legislature and the courts.

- Herb Kelleher

Pure chaos! Bloom Advertising account executives were in trying to get approval of a major advertising plan; we were trying to hire some new flight attendants (who at that time were part of the Marketing Department): we were interviewing for a second Houston sales rep to make a sales force of five systemwide: Read-Poland. our public relations firm. had a hot new publicity idea to present, and I had a hard time distinguishing Bill Franklin from Lamar Muse.

- Sherry Phelps

Very excited and eager to jump at each job that had to be done. There were a lot of questions to ask all of your coworkers: "Who did you work for prior to this company"? What type of work did you do there"? "Have you found an apartment or house yet"?

- Ray Phillips

I had no office. no chais. no desk and an airline that was one of the state's greak unknowns. My job - to make it known and I didn't even have a telephone!

- Camille Keith

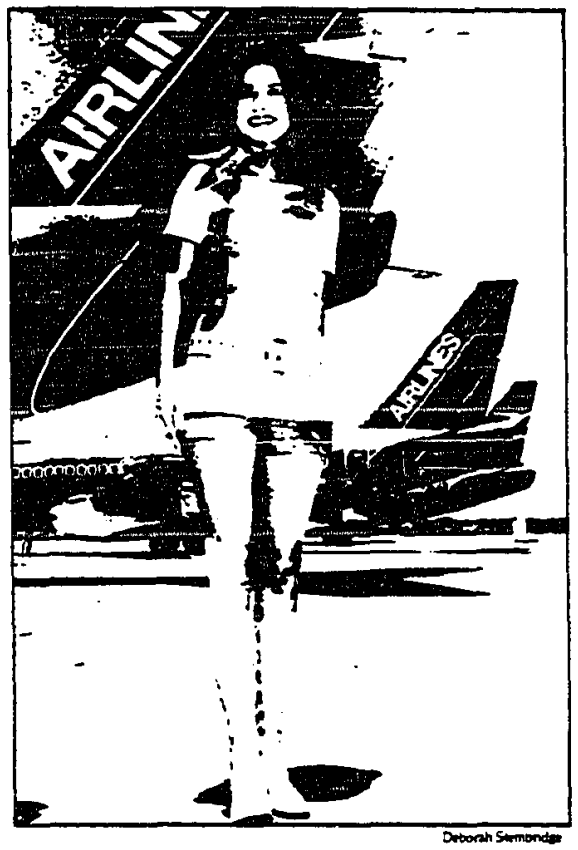


First of all. the mechanics met at the most run down. dirty. and smallest hangar I had ever seen. A short time later. we had a group meeting with Mr. King and Mr. Vidal. Mr. King gave a pep talk about our new airline, telling us we would start by flying three airplanes between Dallas. Houston, and $\operatorname{San}$ Antonio. and eventually we would have seven aircraft. enough to property serve Texas. Next on the day's agenda was a midday meal at the Royal Coach Inn where we all got to meet each other and swap stories about ourselves. All in all, it was a great day!

- Jerry Puckett

Actually. i began work 18 days before we started flying. I spent my first day in Revenue Accounting taking inventory of ticksts which were being sent to the travel agents. I remernber in the "early days" we wore many hats out of necessity, and we lived by the "KISS" approach.

- Karen Ordner

Everyone wanted to do something to make the airline run. and no one knew what to do. It was a learning process from the first day.

- $\lim$ Kolkmeier

We carried a total of 18 passengers on six lights my first day. I kept thinking that things better pick up. The

passengers seemed a little apprehensive - they couldrit believe our hot pants.

- Susan Prat

I was walking around in a daze - awed - looking at a 737 and wondering what to do.

- Frank Martiniano

It was so long ago I anit remember except that I was so scared!

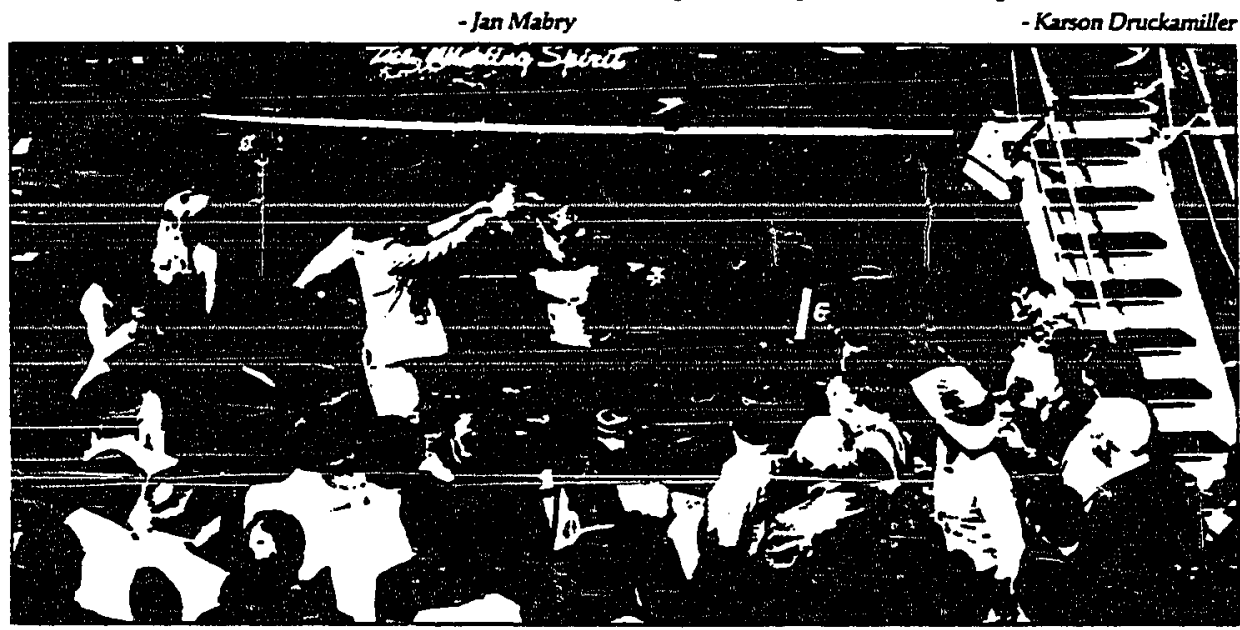

10
In the beginning we did everything from seiling tickets and checking bags to loading bags and taking reservations. We took reservations by merely making a stroke on a sheet of paper. Often, we had to leave the phones unattended to go and work a fight.

- Mike Mitchel

That first cay is lost in a memory fog. I must not have paid attention one day in class because when I got on the plane I didr't know where to sit that first week - I just sat anywhere I wanted to.

- Deborah Stembridge

I remember there wasnit much business. One Saturday Lamar Muse was the oniy passenger. When he returned to Dallas, Lamar called Bill Franklin and told him to cill Carl Warrell, the station manager, and rell him that San Antonio was overstaffed.

- Tommy Perryman

Nervous. but excited! i have never been so thrilled about getting on an aircraft and experiencing the travel and serving of those few passengers we had. 1 don't remember much about the passengers except it was a long day and my teet were killing me.

\section{-C. J. Bostic}

My crew tew one of our Lovebirds" to Austin and Houston to pick up the VIP's for an introductory party at the Faimont. Sid Adger was my tirst passenger in Houston. We landed at Love Fieid and all of us went on buses to the hotel. It was quite a blowout!

- Sandra Bogan

I spent my first day moving my tool box into our hangar. meeting with the people I would work with and trying to -Krson Druckamiller 


\section{THE "FUNNIES"}

Manv funny things have happened to me at Southwest. and one of the qualities I value most about the Company is its very special ;ense ot humor and comaradere. Right after Lamar left in 1978. I was thying to SAT from DAL and attempted to place my hanging bag in the little tlight attendant eloset at the rear of the airplane. One of our new flight attendants said. 'Who do you thisk you are?" 1 replied. "Im the president of Southwest Airlines." She responded. 'Teah. and I'm the King of Siam." I promptly put my hanging bag in an overhead bin.

\section{- Herb Kelleher}

At the time, it wasnit that funny, but I planned to start a amily with precision timing so that maternity leave would be between major projects. My timing was perfect, but tour months into my pregnancy. Lamar Muse resigned. and I had oniy six weeles 10 go when Howard Putnam was hired. I expected to be summarily dismissed. but it's now been 15 years, and I'm still hanging around!

- Sherry Phelps

On a crip out of SAT. a prest was trying to deliver a package. The ticket counter employees rushed him along to the gate. explaining that the gate was the place to take care of his business. but he should hurry since the plane was gerting ready to take off. When he got to the gate (it was back in the days when the flight attendants took up the ticketsi. he was so hurriedly pushed onboard without being able to speak. or even say why he was really there. When the tlight attendant came to take his ticket, he explained that he was never even supposed to have gotten on the plane at all. He was just trying to send a packaze and no one would listen to him. By that time. the plane was airbome. It wasn't like we could send him on the next light back because it was in the days when flights were three to four hours apart.

- Mary Goirs

I was flying with a new tlight attendant. Brian Mitciell for the tirst time. I was asking him why he chose Southwest. since his dad works for Amerian Airlines. He told me that he had only ridden Southwest once. He was 8 vears oid. and he flew down with his dad to set the Alamo and flew back as an unaccompanied minor. He thought a few seconds and said. "And. Jan. I think you were my flight attendant:" Yiz even had a picture that his parents took as we were walking off. How depressing! Of cousse. everyone knows I quit high school to start flying!

- Jan Mabry

Having a lav cart named after me. - Dernis Lundor

Trying to catch a mouse in the check-out soom in Houston.

-Frank Martiniano

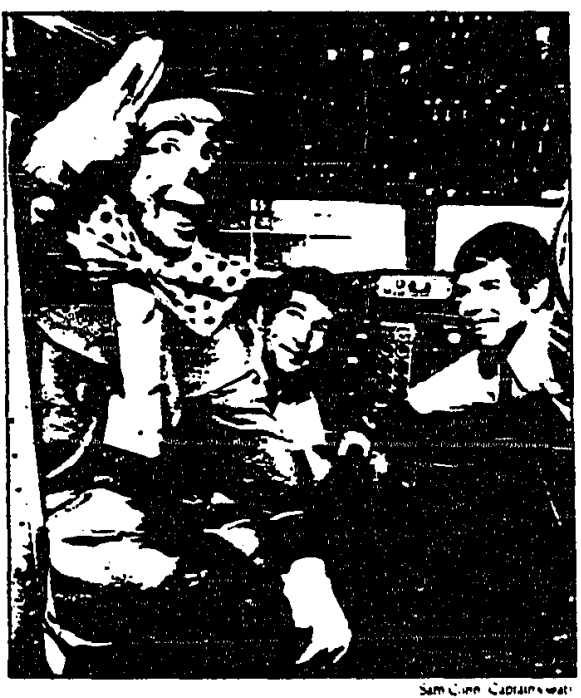

The funniest thing that ever happened to me at Southwest is how I finally obtained a typewriter that would work. The one I had didn't work about half of the time. so I wrote (in long hand) a merno to W. W. Franklin requesting a new one. He sent me a memo back (see below).

TO: MEMORANDUM

Joy Bardo

FROM: W. W. Franklin

DATE: March 29, 1979

SUBIECT: Typewriter

Dear Oldest and Devotedest Employee:

This is being written by the most wonderful and kind supervisor to one of his oldest and devotedest employees conceming both an old used typewriter and a new unused typewriter and the repair of whichever of the above requires it.

You may not have a new typewritet. You may continue to type great volumes on your existing typewriter after it is reained - or if you prefer betore it is repained. Debbie may write her memos by hand since she appears to be neither devoked nor old.

Please note that my secretary types this on her new IBM Selectric Il, which we purchased tor $\$ 730.00$ and. you are risht, she just loves it:

I did eventually get a new typewriter.

- Joy Bardo

Working a flight as an Operations Agent with the back of my pants split after a liquor change in $\boxminus$ Paso. Yes. you an kesp one side to the jetway wall at all times.

- Bill Miller 
My funniest memones took place with Mary Goins and Brenda Mixon. They were too numerous, but listed below are a few:

(1) A How Many People Can We Get into the Aft Lav" contest. Nine was the highest number.

(2) A "Find Your True Love" bootin. On the oid planes, we had aft lounge areas. We would send passengers to the back of the piane. behind a hanging blanket, and have their palms read.

(3) A Who Has the Cutest Knees" contest. Male

passengers would roll up their part legs and parade up and down the aisle with a napkin held on their back by a band-aid. The remaining passengers would vote on the cutest knees. One of the flight attendants would sing. "A Pretty Man Is Like a Memory. . . while the men paraded. (4) Food Auction - One of our liights was delayed on the runway for a couple of hours with a tull airplane. The three of us were deadheading to Houston. It was around dinner time, and the plane was out of everything. Wie had lettover food from our lunch that day. so we auctioned of the remaining apples. cheese and crackers. etc to the surrounding passengers.

(5) "Who Has the Ugliest Driver's License Picture" contest. (6) The Easter $=\infty 8$ hunts on the airplane.

- Deborah Franklin

My funniest experiences have been talking to customers on the plane (while lve been non-reving), and listening to them explain to me how you can beat Southwest Airlines reservation system. At the end of the Aight. I simply hand them my business ard.

\section{- Karen Ordner}

The reactions you gat after you answer a new employees questions. "And what is your employee number"?

- Jerry Puckett

After working many seven day weeks. I decided to take a Sunday oft. We had a fellow mechanie named Hugh Kirwin working for us at the time. I asked the lead mechanic Marvin Amason. who was working the Sunday shift. He replied. "Hugh and me." And I said. Like hell I am." I thought he said. You and me."

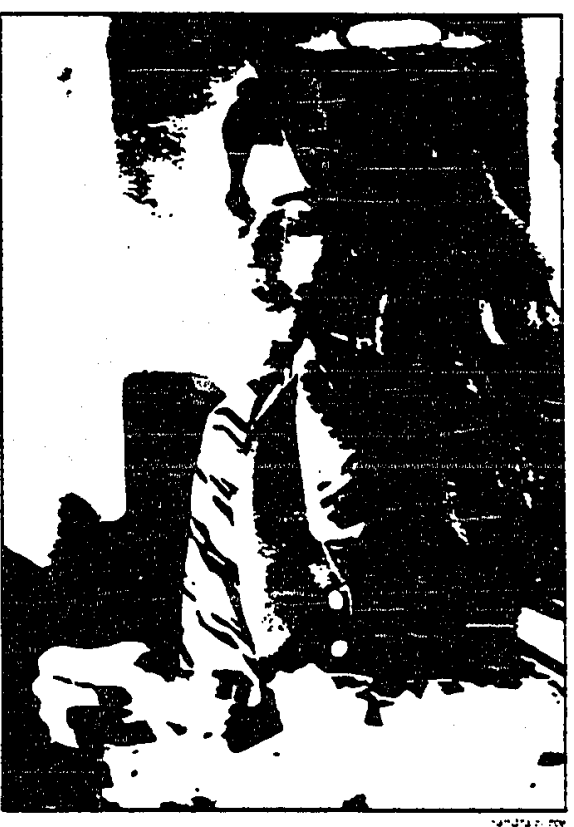

I had previously worked for Branift. and the Braniff employees were always walking by, telling the that Branift was going to put us out of business.

- Tommy Perryman

Flying with Ernie Gabona

- Gene VanOverschelde

This ont is easy for me. It was when I arrived very late at a wedding reception for one of our original flight attendants. The door was opened by an extremely handsome man (the groom, as a matter of fact). who was dressed in a tie only!

- Colleen Barrett

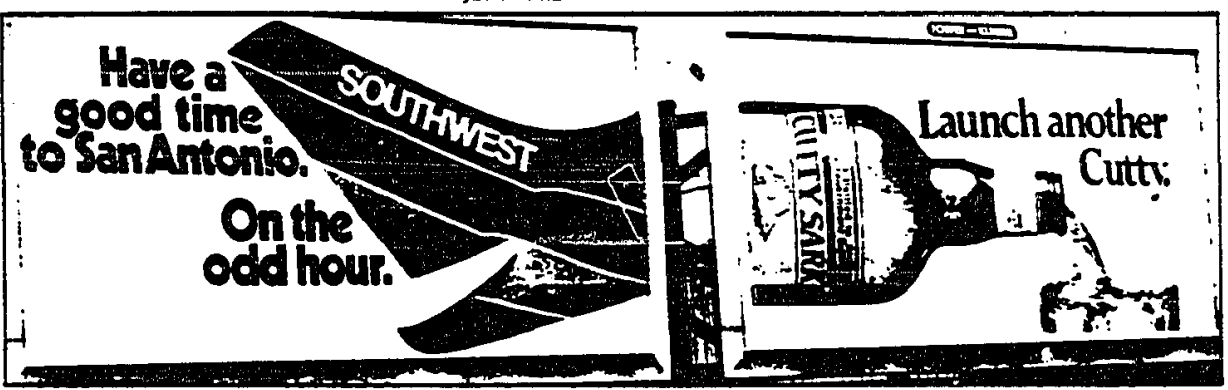


Being questioned about what I was doing with a female plight attendant on Company time. in a stockroom van. on Walnut Hill Lane.

- Bill Lawrence

Riding in the company pickup crossing Runway 18-36 to uur "old" hangar with "Frenchy" driving. The tower told us to expedite. so Frenchy followed through and the sudden movement jerked my tool box out of the back of the truck onto the runway, spilling my wools in all directions. Luckily, the control tower was very tolerant of our problem and didnit schedule a landing until we got all the tools picked up. A. J. Foyt would have bees? proud of our fast take off.

\section{-Ray Phillips}

On the tirst leg of an eight leg tnp. I broke my heel off my high heels. I didn't have a spare pair of shoes. nor did the girls I was flying with. My tall, six-foot captain pulled out his tennis shoes from the llight bag and offered them to me. I wasn't embarassed about wearing them; actually. they felt great. The embarrassing part was that they fit perfectly! UGH!

- Sandra forer

Wearing our hats on order from Mr. Herring. - Sandra Bogan

The day it snowed in Houston. We didn't have any deicins equipment. and we tried to mop off the wings with glycol. Four hours later. we gave up. No one got out of Houston that day. :

- Mike Mitched

Southwest had been in business about two weeks when Jules Bergman and the ABC camera team came to film Southwest in operation. Of course. we wanted the plane to be full. We found some "decoys" in San Antonio to help fill the plane. and unbeknown to us. Dallas sent down some "decoys." Needless to say, we ended up with twice as many people as we had seats. Jules Bergman asked me if he and his crew should deplane.

- Carl Warrell

Mary Coins, Jill Cohn ard myself had a couple of hours on the ground in Dallas. Mary and I had forgotten to bring clothes for the layover. We took a provisioning truck across the field and went to Mary's apartment to get some clothes. We rode the provisioning trick back to the airport and got back in time for the flight. Bill Catlin was watting under the wings for us, but Captain Cabeza took up lor us. We had our clothes and we went out and had a great time!

- Brenda Mixon

On a Alight between Dallas and New Orleans a guy went into the bathroom and stayed and stayed. I kept knockins on the door asking if he was olay. Finaily, out of the bathroom emerged one of the best looking women I'd ever seen. Quite a transtormation in the SWA lav!

- Susan Prate
A passenger on one of my flights got extremely drunk and went into the aft lav. He got so ill that he passed out! His head ended up in the toilet, and ! panicked thinking to myself that he might drown. I grabbed him by the hair on his head. and as I yanked it back. I took off his toupee that now looked tinted blue!

- Pinka

Kirk Douglas (yes, the star) and I were ietting to Dailas on a promotion. He was given champagne as a welcome aboard." Deciding that he did not want the bubbley. I suggested that we have a contest among the Customers who would guess the combined ages of the flight attendants. After committing his guess to the napkin. he turned to his role as judge. Soon it appeared almost certain that he would win his champagne back until the final guess edged him out by a year.

- Camille Keith

It happened on a shortback. The whole crew was exhausted. and we were griping in advance because this hotel was always late picking us up. We were all so surprised when the station wagon pulled up just as we were walking out. The driver jumped out. opened the back. then hursied inside. We threw our luggage in the back and climbed in and waited. Then, the hotel station wagon pulled up - we were in someone eise's car!

- Deborah Stembridge

My first day!

- Sam Cohn

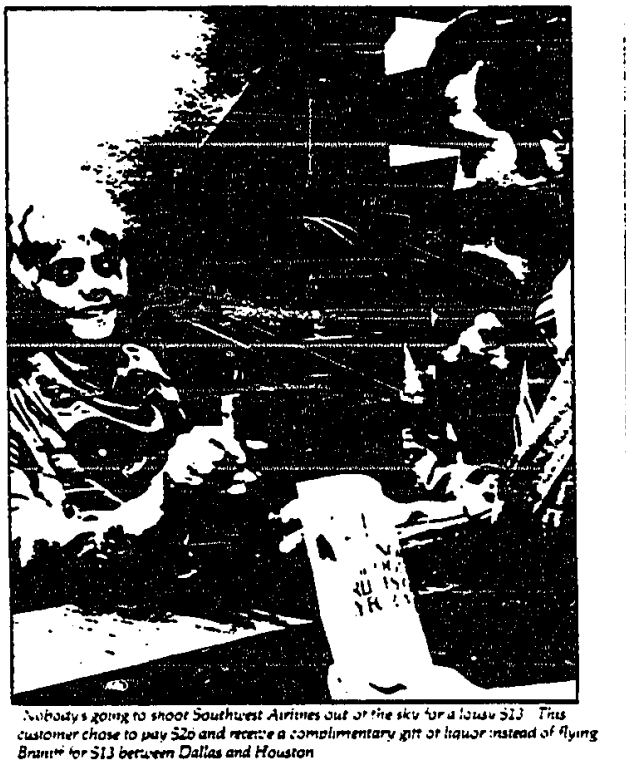




\section{MOST MEMORABLE EXPERIENCE...}

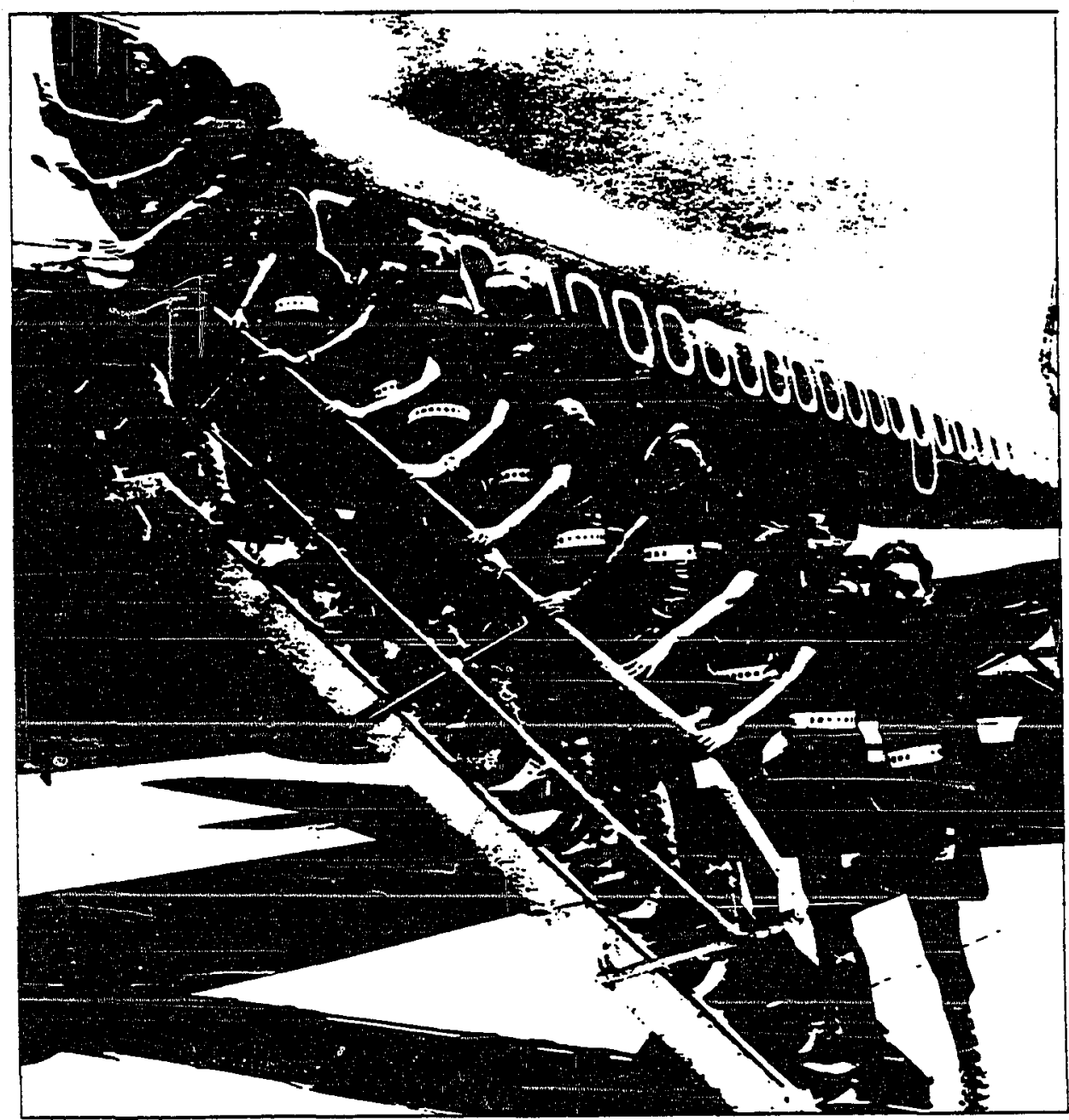

Ive had several - working my tirst bomb threat: working a Friday night in Houston when we had our first 1.000

customer day; making strokes in a book for reservations:

trying to find a cat that had iumped out of the bin and ran into the building: beating Herb Kelleher in the plane toss at the ten-year original employee party.

Over the last 15 years lve had some wondertul times. Miy most rewarding teelings are of the super people and friends l've met.

Today - 15 years later!

- Pinka fim Kolkmeier

it 
Test flights on Southwest aireraft out of Everett. Washington. after mini-overhauls.

- Karson Druckamilles

Wow - there have been so many! One big memory was taking the check to. New York and signing on behalf of Southwest all the necessary documents so that we could accept deliver: of a new aireraft in Seattle. Another "biggie" was teeling my heart sweil with pnde when we rolled out the Kitty Hauk. and flying with Chuck Yeager.

- Sherry Phelps

Being a part of the 7:00 a.m. special emergency meeting Being a part of he 700 am special eme Braniff lowered the fare on Southwest's most profitable route.

- Camille Keith

Celebrating our ten year anniversary and success.

- Sandra Bogar

I have had a myriad of memorable experiences at Soutiwest. but certainily one of the most moving was when our birst aircraft arrived at the American Airlines hangar for an evacuation test. It was visible, tangible. beautiful evidence that after $31 / 2$ years of struggle we were really going to have an airline. I kissed the nose: developed leaky eves: and put my head into the back of an engine. A mechanic snatched me away, explaining that the thrust reverser could decapitate me if activated. I said "even that would feel good"!

- Herb Keileher

Wv most memorable experience was being the tirst person in the maintenance department to be selected for the Presidents Award.

- Jerry Puckett

Fying co-pilot with Jerry Stecle and Jerry saying look at that beautiful girt - that beautiful girl beome my wife and the mother of two of the greatest children that any man could have.

$-\operatorname{San}$ Cohn

The tirst day of the company's operation. . opening the $E$ Paso station. . . opening of the Amarillo station. . the first SWA 737 I saw. . . being made Director of Provisioning. . winning the President's and Founder's Award . . being made Vice President of Inflight Services.

- Bill Miller

The ten-year orginal employees party! - Gene VunOverschelde

I was honored and surprised to receive the founders Award in 1981. Although there were other flight attendants that probably deserved it. I was very happy and most appreciative. This awand meant a great deal to me because I feit someone really ared.

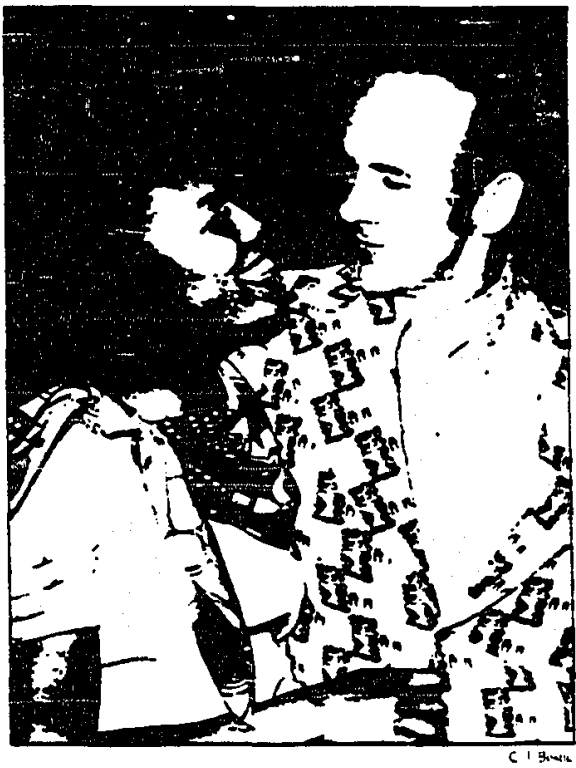

Black Wednesday (the day before Thanksgiving) when al! the ATC computers went down - airplanes were everywhere. . the ten-year employze party. . the dediation of the -300 aireraft.

- Mike Mitchel

This is an almost impossible question tor me since so many events have taken place over the years that it is impossible to pick out one event as being the most memorable, and I hope that there are still many ruture memosable events/experiences to take place. Some of the highlights of my SWA career have included: our inaugural flight: winning our first Love Field lawsuit: our first profitable quarter: attending our annual awards banquet: getting our first interstate route: each and every new city opening: our airplane dedications; our ten-year parties and our original emplovee party: the -300 inaugural events: watching several original employees receive the Founder's Award: etc

- Colleen Barret

Cetting the first computer system in Reservations... the ten-year original employee party where I knew what Cindereila felt like. .. the ecquisition of Transtar. - Karen Ordner

My most memorable expenence was winning the President's Award in 1980, which was one of the first given. It was definitely an honor. and words cannot express how COOD it made me teel. 


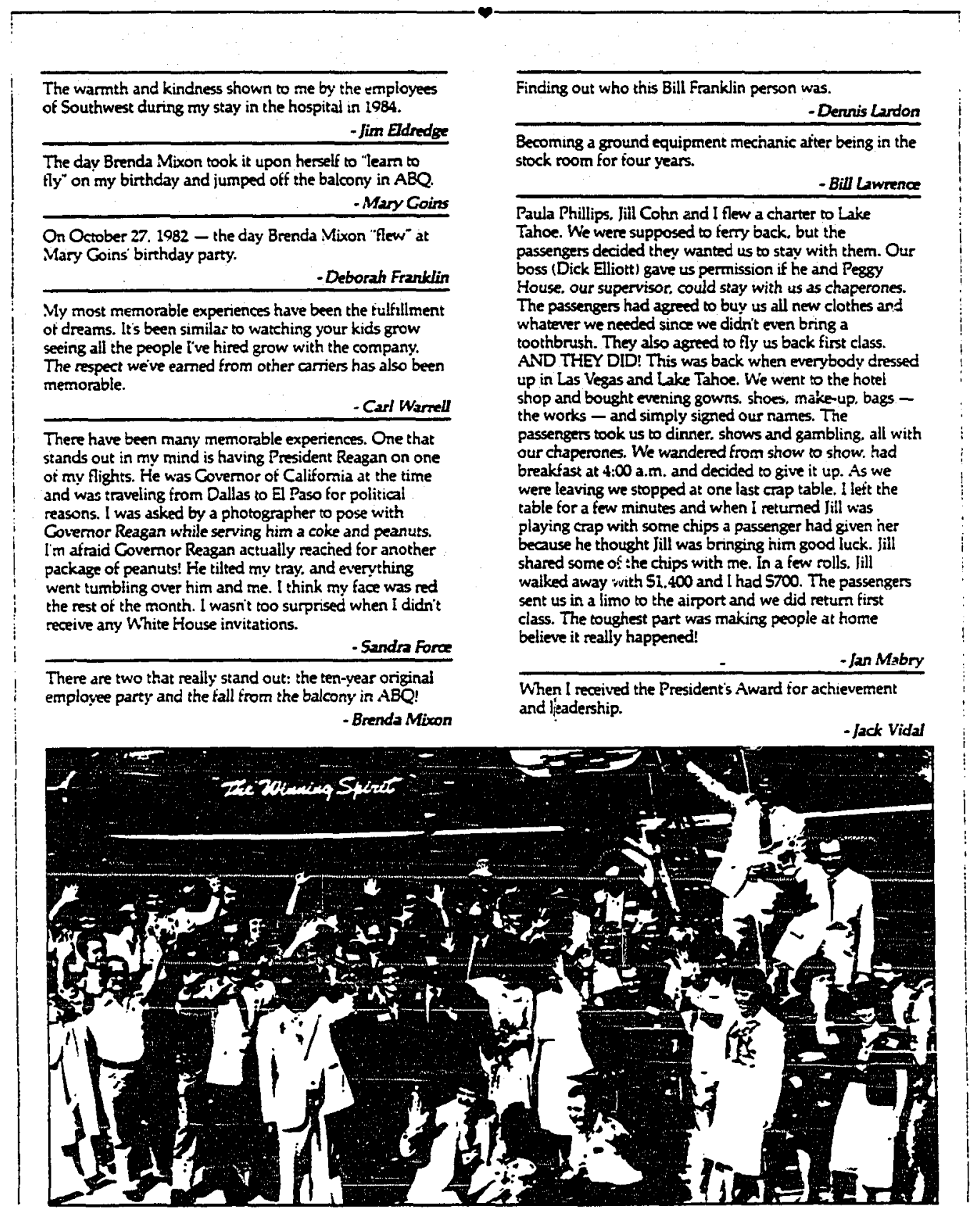

16 


\section{SOUTHWEST AIRLINES IS. . .}

(In Ten Words or Less)

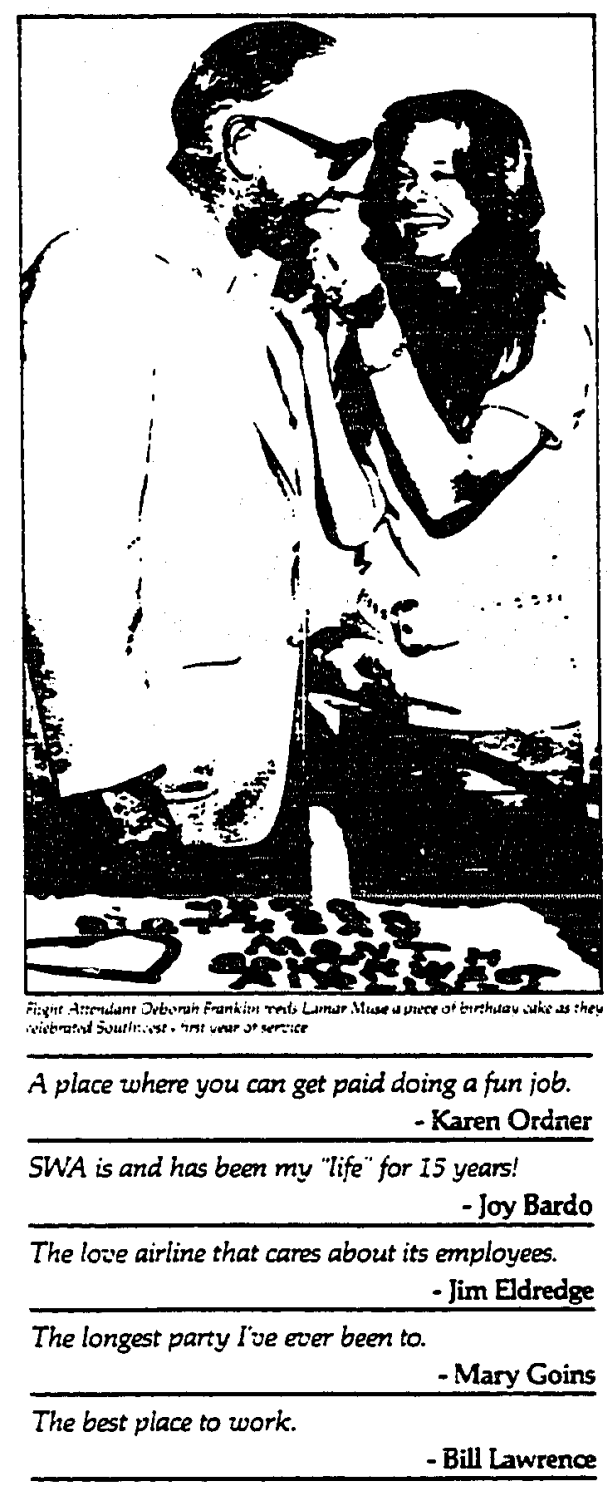

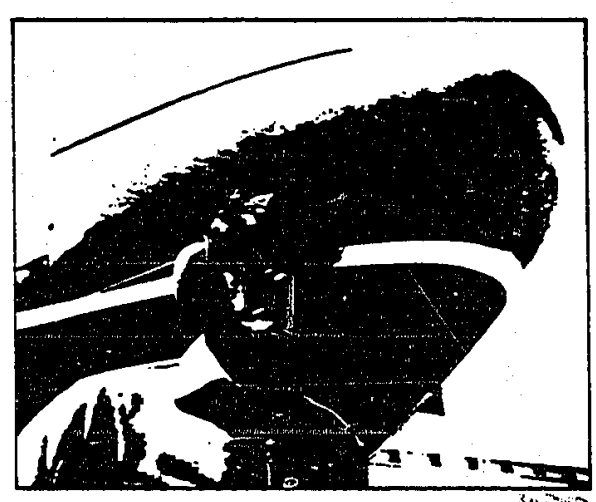

The airline to pattern other airlines by.

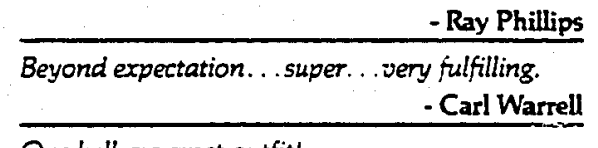

One helluva great outfit!

- Karson Druckamiller

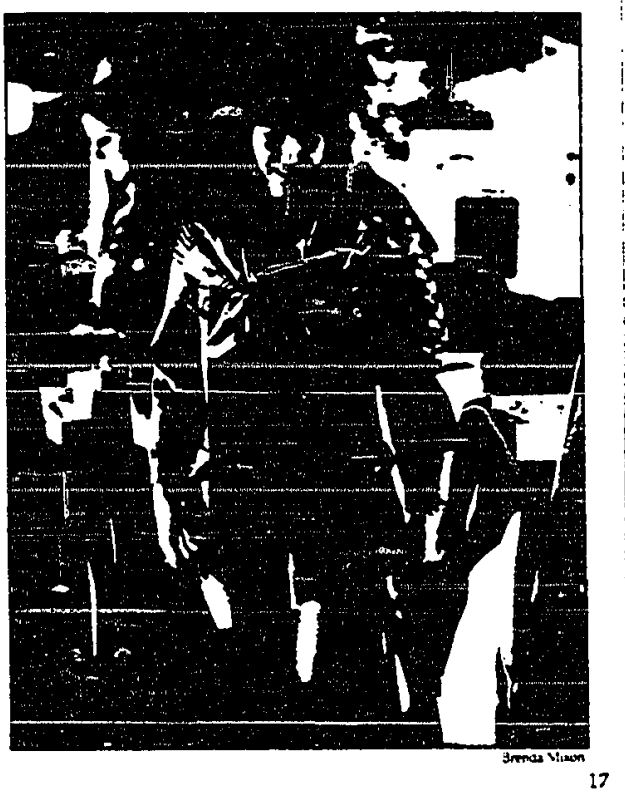


Great people. . quality service. . unity of purpose. . industry leadership. . excellence.

- Herb Kelleher

Unique!

- Gene VarOverschelde

My family - an extremely important part of my life.

An airline whose heart, sole. and spirit is its people.

- Jerry Puckett

Fun. . free-spirited. . hectic . . rewarding. . . sometimes a bitch.

- Dennis Lardon

Once a new kid on the block and now "he" runs the whole neighborhood!

- Sandra Force

My second family!

- Deborah Stembridge

The best company l ever worked for.

- Tommy Perryman

Looking to the future.

- Gene VanOverschelde

An experience - something new every day.

- Mike Mitchel

A warm, caring, loving, and fun family - my life!

- Colleen Barrett

Fun-filled!

- Frank Martiniano

The best!

- Jack Lowery

Friendly. . successful . . honest, not arrogant. . . loyal. . . inspiring. . . dedicated.

- Jack Vidal

Very spirited. creative and dedicated. Friendly people make this a great airline!

- Brenda Mixon

Utterly titillating!!

- Sherry Phelps

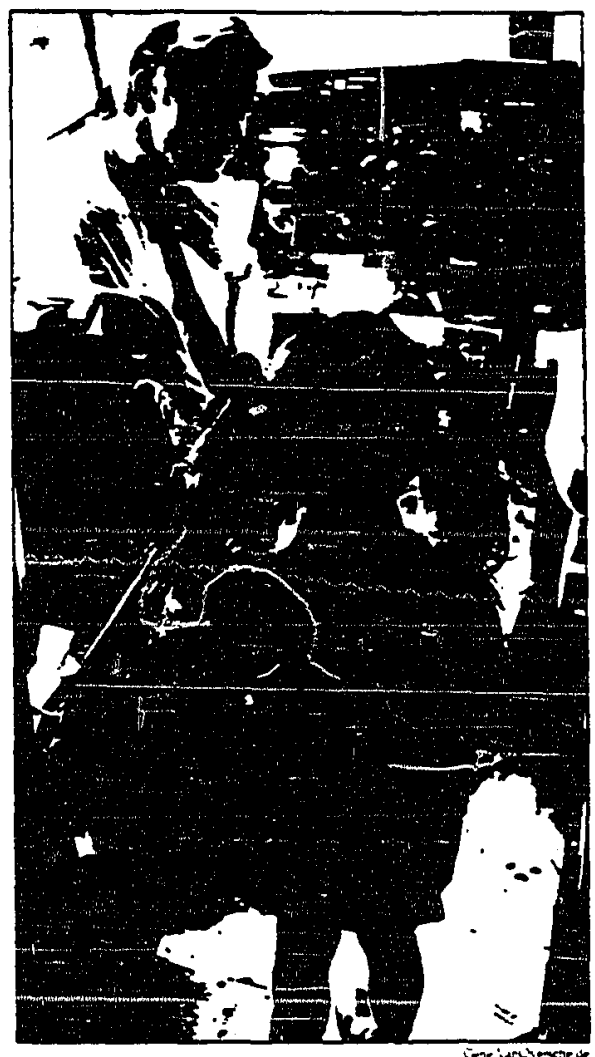

At Southwest - the difference is people!

- Camille Keith

The most employee oriented. entrepreneurial. free enterprising company started in the last fifteen years.

-Sam Cohn

Change is the best word I know for Southisest Airlines.

- Bill Miller

The best thing about Southwest is the people I work with.

- Susan Pratt

Our airline is the greatest surline in the world! -C. J. Bostic

18 


\section{“TD LIKE TO ADD". .}

I couldn't work for a better company - they aiways stick by me.

- Jack Lowery

Southwest is the second best thing to come into my life.

- Jack Vidal

Southwest is one of a few companies that lets its employees use their imagination to erchance their abilities: thus. in tum. Southwest is one - if not the most productive company per empioyez in this country.

- Sam Cohn

Being a part of this dynamic company has been the most rewarding and exciting part of my life. I tiuly appreciate all those who have lent me a helping hand to leam and grow and those who continue to do so.

- Bill Miller

I feel fortunate to be a part of Southwest Airlines. - Gene VanOverschelde

I have always believed that when the job was no longer fun. I would retire.

- Frank Martiniano

Although I have had my own personal ups and downs over the years. I cannot think of anything I would rather be doing, and since I have to work. I consider myself dam lucky to be working in a position and for a company which $I$ thoroughly enjoy as much today as I did on my first day!

- Colleen Barrett

If I had it all to do over, I'd do exactly the same thing. . except l'd buy a lot more of that "high risk" $\$ 3.25$ stock!

- Sherry Pheips

When I joined Southwest. I was so shy. Because we had to entertain the passengers in the beginning, it helped to bring me out. I quit thinking about myself and tried to remember the other person. Now. I'm a "loud mouth lime." thanks to Southwest.

- Deborah Franklin
There have been very few days that I did not look forwand to coming to work; although, there were many days I wished I were sailing or playing golf.

- Dennis Lardon

I'm so glad we have established ourselves at Southwest as a successful airline without the help of "hot pants." After all. we are still the same sexy girls, just in skirts now!

- Sandra Foroe

This is only the first 15 years - we ve only iust begun!

- Carl Warrell

I remember when Braniff called me back from furlough. I went to Carl Warrell and asked him what he thought of the ally. He told me that he was putting everything on Southwest Airlines. I took his advice and remained with Southwest! - Tommy Perryman

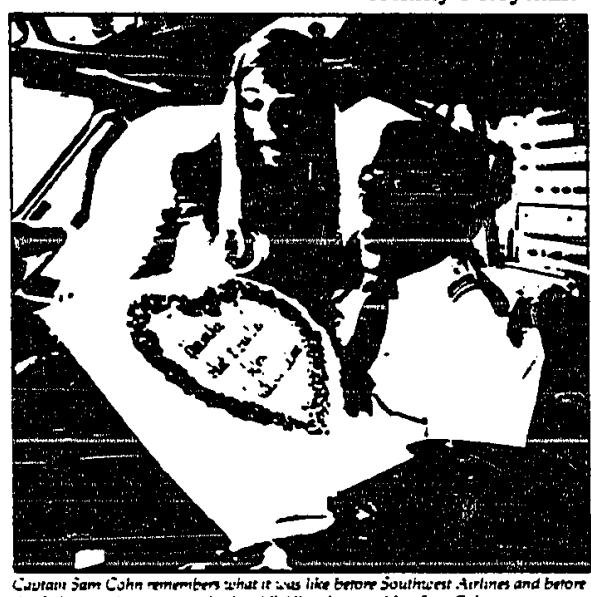

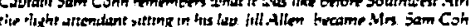

I am very glad to be an "original" with the company. It makes me feel so close and family oriented. i hope Southwest will continue to strive for perfection and keep the winning spirit flowing forever!

-C. J. Bostic 


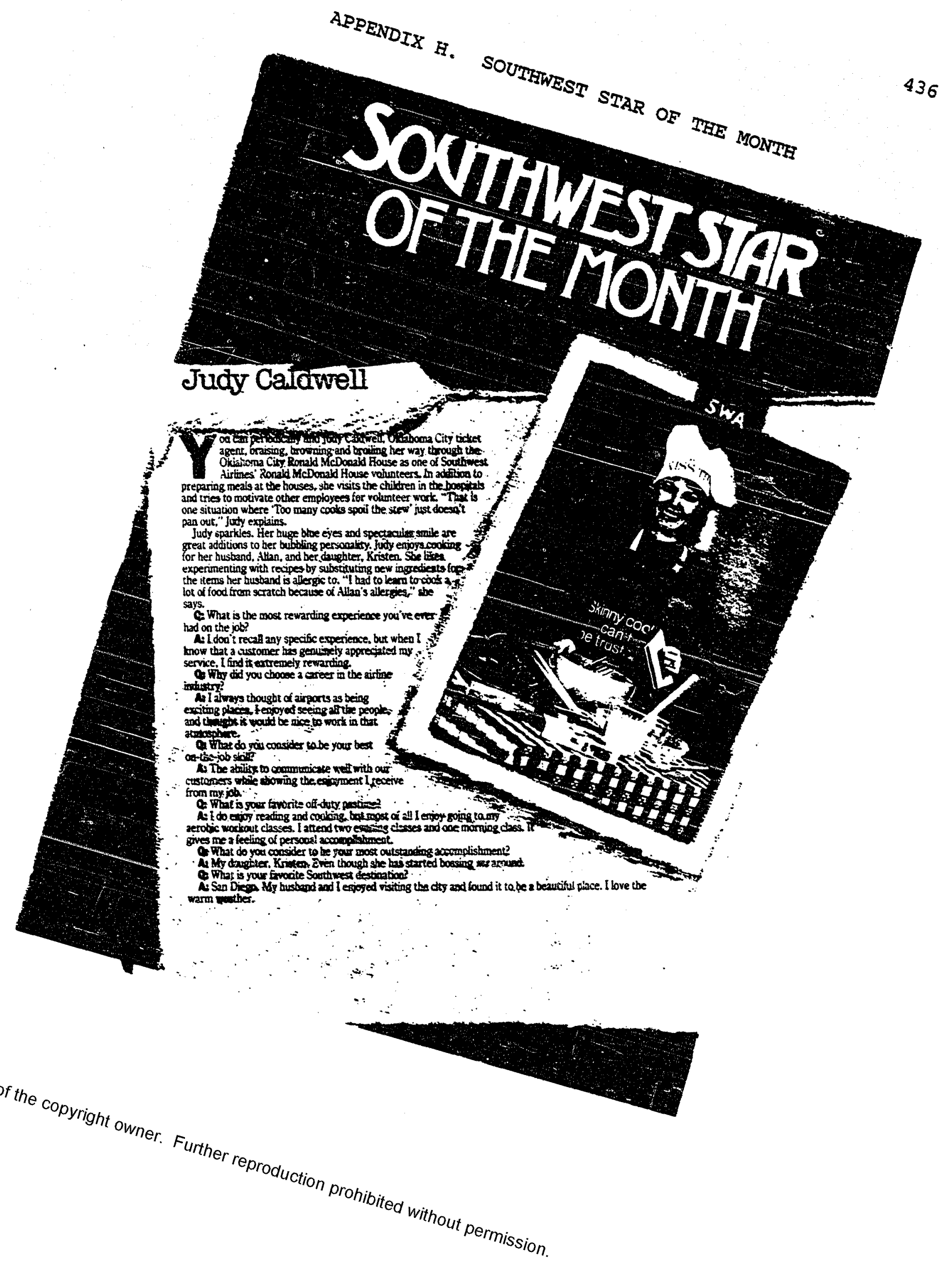



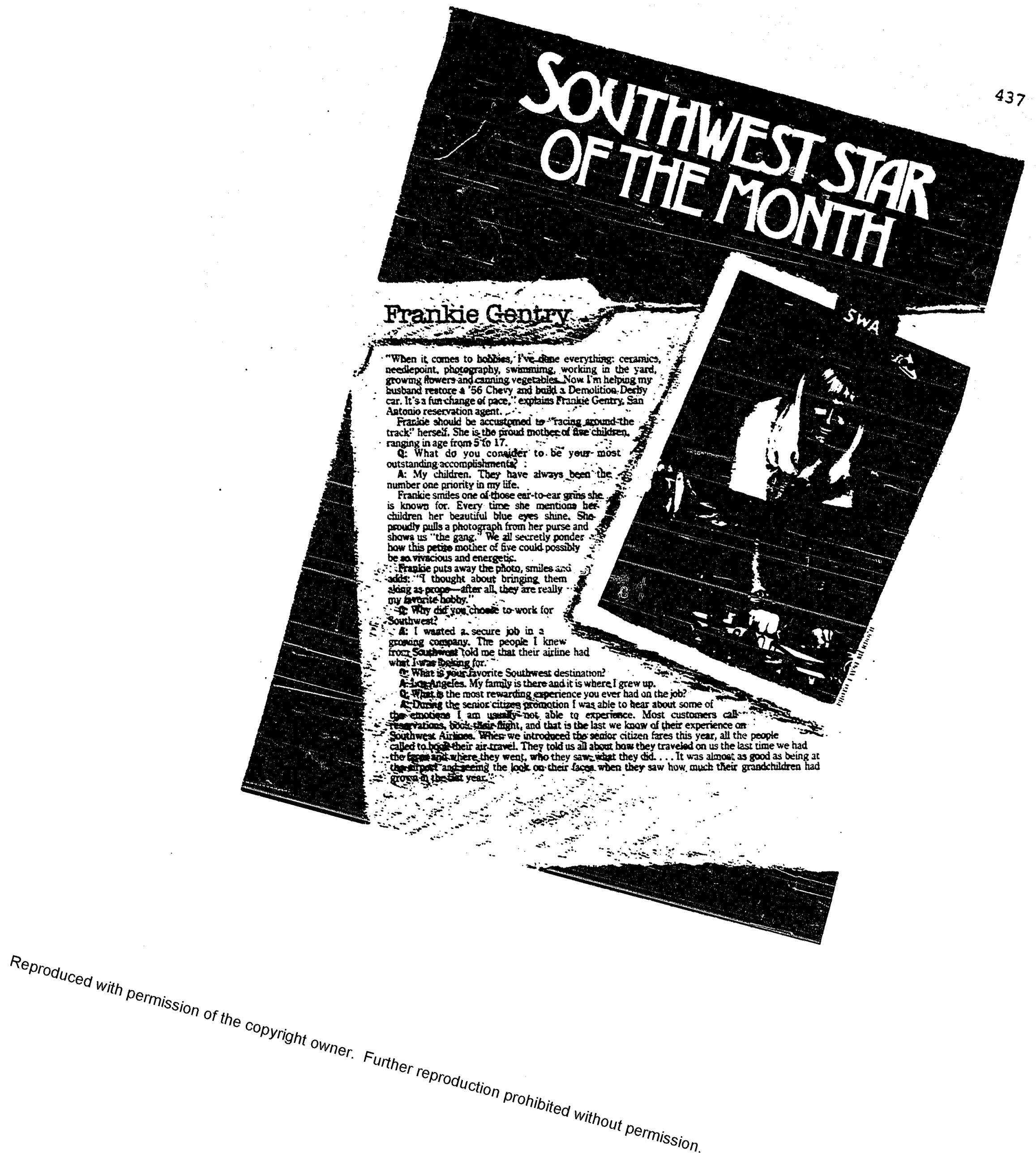


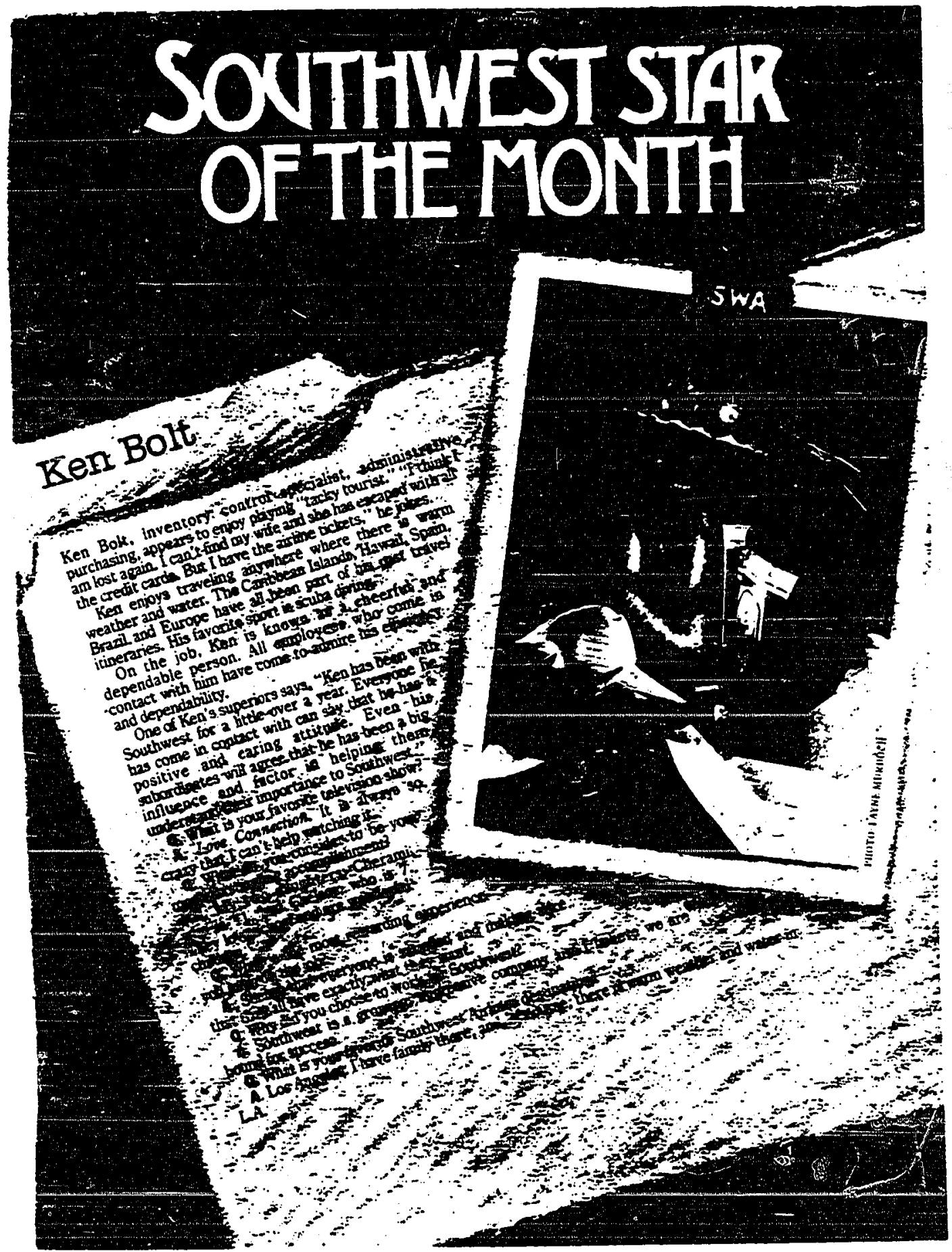




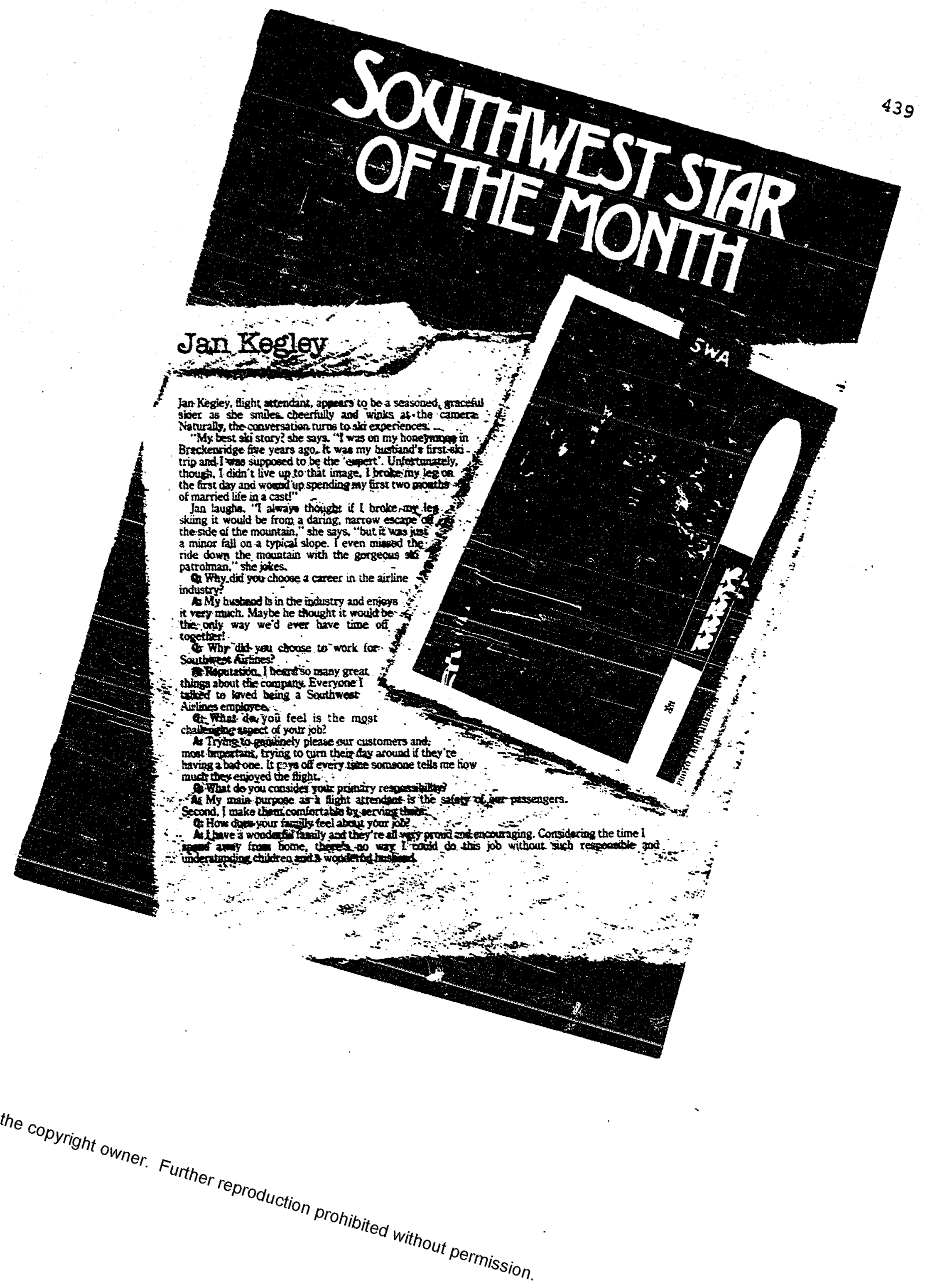

